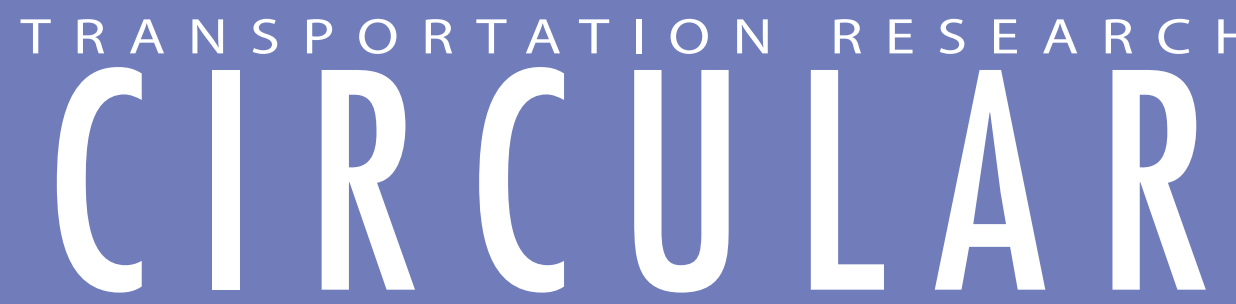

Number E-C078

Roadway Pavement Preservation 2005

Papers from the

First National Conference on Pavement Preservation

October 31-November 1, 2005

Kansas City, Missouri 


\section{TRANSPORTATION RESEARCH BOARD 2005 EXECUTIVE COMMITTEE OFFICERS}

Chair: John R. Njord, Executive Director, Utah Department of Transportation, Salt Lake City

Vice Chair: Michael D. Meyer, Professor, School of Civil and Environmental Engineering, Georgia Institute of Technology, Atlanta

Division Chair for NRC Oversight: C. Michael Walton, Ernest H. Cockrell Centennial Chair in Engineering, University of Texas, Austin

Executive Director: Robert E. Skinner, Jr., Transportation Research Board

\section{TRANSPORTATION RESEARCH BOARD}

2005 TECHNICAL ACTIVITIES COUNCIL

Chair: Neil J. Pedersen, State Highway Administrator, Maryland State Highway Administration, Baltimore

Technical Activities Director: Mark R. Norman, Transportation Research Board

Christopher P. L. Barkan, Associate Professor and Director, Railroad Engineering, University of Illinois at Urbana-Champaign, Rail Group Chair

Christina S. Casgar, Office of the Secretary of Transportation, Office of Intermodalism, Washington, D.C., Freight Systems Group Chair

Larry L. Daggett, Vice President/Engineer, Waterway Simulation Technology, Inc., Vicksburg, Mississippi, Marine Group Chair

Brelend C. Gowan, Deputy Chief Counsel, California Department of Transportation, Sacramento, Legal Resources Group Chair

Robert C. Johns, Director, Center for Transportation Studies, University of Minnesota, Minneapolis, Policy and Organization Group Chair

Patricia V. McLaughlin, Principal, Moore Iacofano Golstman, Inc., Pasadena, California, Public Transportation Group Chair

Marcy S. Schwartz, Senior Vice President, CH2M HILL, Portland, Oregon, Planning and Environment Group Chair

Agam N. Sinha, Vice President, MITRE Corporation, McLean, Virginia, Aviation Group Chair

Leland D. Smithson, AASHTO SICOP Coordinator, Iowa Department of Transportation, Ames, Operations and Maintenance Group Chair

L. David Suits, Albany, New York, Design and Construction Group Chair

Barry M. Sweedler, Partner, Safety \& Policy Analysis International, Lafayette, California, System Users Group Chair 


\title{
Roadway Pavement Preservation 2005
}

\author{
Papers from the \\ First National Conference on \\ Roadway Pavement Preservation
}

October 31-November 1, 2005

Kansas City, Missouri

\author{
Organized by the \\ Transportation Research Board \\ Task Force on Roadway Pavement Preservation
}

October 2005

Transportation Research Board 500 Fifth Street, NW

Washington, DC 20001

www.TRB.org 


\title{
TRANSPORTATION RESEARCH CIRCULAR E-C078 ISSN 0097-8515
}

The Transportation Research Board is a division of the National Research Council, which serves as an independent advisor to the federal government on scientific and technical questions of national importance. The National Research Council, jointly administered by the National Academy of Sciences, the National Academy of Engineering, and the Institute of Medicine, brings the resources of the entire scientific and technical communities to bear on national problems through its volunteer advisory committees.

The Transportation Research Board is distributing this Circular to make the information contained herein available for use by individual practitioners in state and local transportation agencies, researchers in academic institutions, and other members of the transportation research community. The information in this Circular was taken directly from the submission of the authors. This document is not a report of the National Research Council or of the National Academy of Sciences.

\section{Task Force on Roadway Pavement Preservation}

Larry Galehouse and James S. Moulthrop, Cochairs

\author{
Fred Altizer, Jr. \\ Timothy B. Aschenbrener \\ W.R. Bill Ballou \\ Doyt Younger Bolling \\ Steven C. Bower \\ Samuel H. Carpenter \\ Billy G. Connor \\ Colin A. Franco \\ Anthony R. Giancola \\ Wouter Gulden \\ Affan Habib
}

Kent R. Hansen

Keith D. Herbold

R. Gary Hicks

David L. Huft

Thomas J. Kazmierowski

Edward J. Kearney

Ken F. Kobetsky

Susan Massey

Emily O'Quinn McGraw

Roger C. Olson

Harold R. Paul
David G. Peshkin

Tony Miller Porter

Charles A. Pryor, Jr.

Larry A. Scofield

Shakir R. Shatnawi

Roger E. Smith

James B. Sorenson

Marshall L. Stivers

Dean M. Testa

John J. Weigel, Jr.

Frank N. Lisle and Frederick D. Hejl, Transportation Research Board Staff

\author{
Transportation Research Board \\ 500 Fifth Street, NW \\ Washington, DC 20001 \\ www.TRB.org
}

Javy Awan, Production Editor; Jennifer Correro, Proofreader and Layout 


\section{Preface}

This publication contains papers written for the Transportation Research Board First National 1 Conference on Roadway Preservation held in Kansas City, Missouri, October 31-November 1,2005 . The conference addressed all aspects of successfully implemented roadway pavement preservation activities, including management, engineering, economics, the establishment of strategic performance goals, and the implementation of routine maintenance, preventive maintenance, and minor rehabilitation activities. The objective of the conference was to provide a forum for the exchange of information on the state-of-the-art and state-of-the-practice in roadway pavement preservation. The conference included papers and presentations on surfaced and unsurfaced roadway pavement program network and project treatment characteristics.

The views expressed in the papers contained in this publication are those of the authors and do not necessarily reflect the views of the Transportation Research Board or the National Research Council. The papers have not been subjected to the formal TRB peer review process. 



\section{Contents}

\section{PART 1: PROJECT}

Analysis of New Zealand Chip Seal Design and Construction Practices

Douglas D. Gransberg, Bryan Pidwerbesky, and David M. B. James

Constructability of Longitudinal Construction Joints in

Hot-Mix Asphalt Pavements with Sealers to Retard Future Deterioration ...................... 16

Edward J. Denehy

Seal Coat Options: Taking Out the Mystery

Peter W. Bolander

Chip Sealing over Fabric in Borrego Springs, California

Lita Davis

Quality Control and Quality Assurance on Chip Seal Projects.

Lita Davis

Lessons Learned from the Long-Term Pavement Performance Program and

Several Recycled Sections in Texas

Dar-Hao Chen and Jerome Daleiden

\section{PART 2: NETWORK}

Integration of Preventive Maintenance in the Pavement

Preservation Program: Ontario Experience

Wael Bekheet, Khaled Helali, Tom Kazmierowski, and Li Ningyuan

Condition-Based Determination of Preservation Needs of a Road Network

Raja A. Shekharan and Douglas C. Gilman

Warranty Administration in the Michigan Department of

Transportation's Capital Preventive Maintenance Program

Kevin Kennedy

Preventive Surface Treatments Versus Traditional Corrective

Maintenance Measures

N. Mike Jackson, Deepak Dave, Peter E. Sebaaly, and Gail L. Porritt

Development of the Caltrans Maintenance Technical Advisory Guide

Shakir Shatnawi, Christopher Antonucci, and R. Gary Hicks

Changing Our Way of Thinking: Have We Succeeded?

Judith Corley-Lay, J. Neil Mastin, and Emily O. McGraw

Improving Safety as Part of a Pavement Preservation Program

Kathryn A. Zimmerman and Roger Larson

The Role of Pavement Preservation in Privatized Maintenance

Dennis A. Morian, James W. Mack, and Tanveer Chowdhury 
Pavement Preservation Training in Texas

Yetkin Yildirim

Sustaining Toll Road Operation Through

Performance-Based Management

George Tanner and Yung-Ching Shen

Performance Evaluation of Novachip Surface Treatment in Louisiana

Samuel B. Cooper, Jr. and Louay N. Mohammad

Gravel Roads Asset Management.

George Huntington and Khaled Ksaibati

Appendix: Author Contact Information................................................................... 231 


\section{PART 1}

\section{Project}





\title{
Analysis of New Zealand Chip Seal Design and Construction Practices
}

\author{
DOUGLAS D. GRANSBERG \\ University of Oklahoma \\ BRYAN PIDWERBESKY \\ FIPENZ, Fulton-Hogan Limited \\ DAVID M. B. JAMES \\ ICC, Alberta Highway Services Limited
}

\begin{abstract}
Chip seal is the most frequently used preventive maintenance treatment on flexible pavements. Many public highway agencies use chip seals with limited knowledge of effective practices employed abroad. Information is available on good practice for materials, design, construction techniques, and effectiveness of chip seals both in the literature and through survey. This paper reports on a comparison of practices for the design of maintenance chip seals that springs from a survey of 40 U.S. states with those used in New Zealand. The study was confined to maintenance chip seals that were placed on top of an existing surface. The paper compares and contrasts the design methods used in North America and New Zealand and offers information regarding best practices in chip seal design including material selection criteria (physical, chemical, and gradation); design methodology for application rates; specifications; warranties and performancebased specifications. Additionally, it finds that area that seems to have the greatest potential for enhancement of North American chip seal practice is in the area of chip seal design. The major issue in chip seal design lies in accurately characterizing the surface on which the chip seal will be applied using engineering measurements of macrotexture and hardness. This knowledge allows engineers to select both binder types and aggregate gradations that are compatible with the surface on which they will be applied. Additionally, New Zealand pavement preservation practices such as the use of the ultra high pressure (UHP) watercutter machine to retexturize bleeding surfaces are also detailed and their potential for use in the United States is discussed. The paper finds that U.S. public agencies can benefit from an exchange of technical information between public and private organizations in each country. Additionally, it found that practices in the United States are quite similar across the nation but significantly less technical when compared to those used in New Zealand. The paper's major finding points to the need to evaluate chip seal construction practices from New Zealand for potential implementation in the United States.
\end{abstract}

P oor road conditions cost U.S. motorists $\$ 54$ billion a year in repairs and operating costs$\$ 275$ per motorist. Americans spend 3.5 billion hours a year stuck in traffic at a cost of $\$ 63.2$ billion a year to the economy... the nation continues to shortchange funding for needed transportation improvements" (1). With these kinds of economic impacts, the need for vibrant pavement preservation programs in the nation's departments of transportation (DOTs) is greater than ever. Chip seals are a key component to any pavement preservation program which seeks to "put the right treatment on the right road at the right time" (2). Unfortunately, a recent NCHRP Synthesis Report concluded that research into chip design in the United States essentially stopped in 1969 when the Asphalt Institute adopted the McLeod method as its chip seal design methodology (3). That study also found that there is an attitude found in many U.S. public road 
agencies that treats chip seal as a commodity to be purchased in bulk rather than an important pavement preservation tool that requires a rational design approach based on sound engineering principles and a strong construction quality management effort to insure that it is properly installed and this effectively exacerbates the problem of developing a strong chip seal program (3). Therefore, the study concluded that American public road agencies will need to look abroad for the latest technical tools in the chip seal area, and New Zealand is one of those countries who have continuously invested in advancing the state-of-the-art in chip seal design and construction.

New Zealand chip seal design and construction practices have evolved over a number of years through research and monitoring performance in the field. The seal design procedure is a rational system, based on the volumetric characteristics of the sealing aggregate, for calculating the amount of aggregate to spread and the quantity of binder required to hold it in place. There are a number of factors, such as the condition of surface on which the seal is to be placed, terrain, pavement geometry, etc., that influence the volume of voids in the seal and the rate at which these reduce under trafficking. Allowances are used in the seal design formula which increases or decrease the binder application rate as required to cater for these variations. The binder application rate depends upon the size, shape, and orientation of the aggregate particles, embedment of aggregate into the underlying pavement, texture of surface onto which the seal is being applied, and absorption of binder into either the pavement or aggregates. The aim of the design process is for the residual binder to be $1 / 2$ to $2 / 3$ the height of the aggregate layer. New Zealand road controlling authorities must all use the same economic analysis procedure (which includes road agency and road user benefits and costs to assess and prioritize construction and maintenance activities). A key factor in this economic analysis procedure is that a discount rate of $10 \%$ must be applied to discount all future benefits and costs to their present value; this effectively limits the use of structural asphalt pavements to those roads carrying over 25,000 annual average daily traffic, and precludes the use of rigid (concrete) pavements. Thus, $95 \%$ of New Zealand's road network is surfaced with chip seals, due to their lower initial cost. Field trials of high-quality chip seals on private forestry roads have shown that high-quality chip seals over granular pavements can carry extremely heavy loads (up to 16 tons per single axle) and high numbers of load repetitions ( $>15$ million equivalent single-axle load) $(4,5,6)$.

A chip seal (also called a seal coat) consists of a single layer of asphalt binder that is covered by embedded aggregate (one-stone thick) with its primary purpose being to seal the fine cracks in the underlying pavement's surface and prevent water intrusion into the base and subgrade (7). The aggregate's purpose is to protect the asphalt layer from damage and to develop a macrotexture that results in a skid resistant surface for vehicles. Chip seals and similar surface treatment use originated in the 1920s and 1930s (8). These early uses were predominantly as wearing courses in the construction of low-volume gravel roads. In the past 70 years, chip seals have evolved into maintenance treatments that can be successful on both low- and high-traffic volume pavements. The popularity of chip seals is a direct result of their low initial costs in comparison with thin asphalt overlays and other factors influencing treatment selection where the structural capacity of the existing pavement is sufficient to sustain its existing loads.

\section{ENGINEERING A CHIP SEAL PROJECT}

New Zealand's chip seal programs are based on a more specific set of engineering principles than those used by highway agencies the United States. For example, New Zealand seal 
designers actually measure surface characteristics of the existing pavement and use that information in their design process (9). The use of these sound engineering principles reduces the uncertainty and variability associated with chip sealing to the point where field adjustments of binder and aggregate application rates are minimized. Not only do these sound engineering principles seek to optimize material application rates, they have furnished a platform upon which to develop and enforce specifications to an extent where performance driven contracts transfer the risk of the project to the contractor (3). As such, New Zealand has moved the chip seal project out of the maintenance world and into the construction contract arena.

\section{CHIP SEAL DESIGN PRACTICES}

The very early practitioners of chip seals appear to have used a purely empirical approach to their design. Sealing a pavement was considered then, as it is now in many circles, an art. The design of a chip seal involves the calculation of correct quantities of a bituminous binder and a cover aggregate to be applied over a unit area of the pavement. New Zealand was the country of origin for chip seal design in the 1930s (8). New Zealand was also the country where Norman McLeod visited to develop his design method in the 1960s (10). The literature review and survey results revealed the use of two generally accepted chip seal design methods in use in North America: the Kearby method (dating to 1953) (11) and the McLeod method (dating to1969) (10). While a few North American agencies have also developed their own formal design procedures that are not based on either Kearby or McLeod, most utilize either an empirical design method or no formal method at all. The reader can see from the dates listed in the previous sentences that the "current" U.S. chip seal design methodology has not been updated for several decades.

\section{Hanson Method}

The first recorded effort at developing a design procedure for seal coats appears to be made by a New Zealander named Hanson (8). His design method was developed primarily for liquid asphalt, particularly cutback asphalt, and was based on the average least dimension (ALD) of the cover aggregate spread on the pavement. Hanson calculated ALD by manually calipering a representative aggregate sample to obtain the smallest value for ALD that represents the rolled cover aggregate layer. He observed that when cover aggregate is dropped from a chip spreader on to a bituminous binder, the voids between aggregate particles is approximately $50 \%$. He theorized that when it is rolled, this value is reduced to $30 \%$ and it further reduces to $20 \%$ when the cover aggregate is compacted by traffic. Hanson's design method involved the calculation of bituminous binder and aggregate spread rates to be applied to fill a certain percentage of the voids between aggregate particles. Hanson specified the percentage of the void space to be filled by residual binder to be between $60 \%$ and $75 \%$ depending on the type of aggregate and traffic level.

\section{New Zealand's Performance Based Design Procedure}

Chip seal contracts overseas are increasingly moving towards performance-driven contracts (12). These contracts no longer have the agency specifying "where, when, or how," that network decision is now the responsibility of the contractor (12). All design and construction liabilities 
are assumed by the contractor, with the agency's only responsibility being to specify outcome. A performance specification is defined as a measurement of "how the finished product should perform over time" (13). Specification of design life expectations is an effective means of determining long-term chip seal performance.

The most prominent example of a chip seal design performance specification is New Zealand's P17: Notes for the Specification of Bituminous Reseals (9). The New Zealand design procedure is similar to the Austroads procedure depicted in the appendix, with the designer/contractor making regional adjustments to the base output (12). This performance-based design method utilizes an extensive list of input parameters for determining aggregate and binder application rates. Aggregate angularity, traffic volume, road geometry, ALD of aggregate, aggregate absorption, pavement absorption, and texture depth are the input variables for this method. The main assumption of this design model is that the aggregate in a seal is orientated approximately one layer thick and contains a percentage of air voids. As such, filling a percentage of the voids with binder determines the binder application rate. The minimum binder application rate is determined by the percentage of voids to be filled, the total available voids, and the thickness of the seal.

Adjustments for aggregate characteristics and anticipated traffic levels are added to derive a design voids factor. The resulting design voids factor is then multiplied by the average least dimension of the aggregate to determine the basic binder application rate. This base binder application rate is then modified with allowances to cater for the texture and absorption of the pavement surface and the aggregate. Some aggregates are susceptible to absorbing binder, resulting in the decrease of effective binder and a possible loss of aggregate from the seal under traffic. Adding allowances to the basic binder application rate compensates for this characteristic. The amount of binder required will depend on the size, shape, and orientation of the aggregate particles, embedment of aggregate into the base, texture of surface onto which the seal is being applied, and absorption of binder into either the pavement or aggregate. The geometry of the road can affect the design of a seal and it is necessary to make adjustments to the binder application rate. Geometric factors include narrow lanes, climbing lanes, and turning locations. Where traffic is channeled into confined wheel paths such as on single lane bridges, tight radius curves or pavements with confined lane widths, a traffic adjustment factor is necessary. The design binder application rate is calculated by adding all the allowances to the basic binder application rate. It should be noted that some of the allowances may be negative and thus the design binder application rate may be lower than the base binder application rate.

For multiple course chip seals, the New Zealand design methodology distinguishes between whether the additional courses are applied immediately or at a subsequent time. When it is planned that all courses of the chip seal will be placed on the same day, the design is essentially the same as for a single course treatment, with a reduction in the design voids factor. Adjustments are made for designing as a reseal, but adjustments for surface texture and embedment are not performed. When it is planned to stage a delay in the application of the courses, the binder application rates for the additional courses are generally set at a minimum, and aggregate application rates are commonly reduced to $70 \%$ of conventional design.

The philosophy behind the P17 design specification is that the texture depth after a 12month inspection is the most accurate indication of the performance of the chip seal for its remaining life. The New Zealand specification contends that "the design life of a chip seal is reached when the texture depth drops below 0.035 in. $(0.9 \mathrm{~mm})$ on road surface areas supporting speeds greater than $43 \mathrm{mph}(70 \mathrm{~km} / \mathrm{h})$ "'(9). The deterioration models developed in New Zealand 
have directed the P17 Specification to require the following minimum texture depth 1 year after the chip seal is completed using Equation 1.

$\mathrm{Td}_{1}=0.07 \mathrm{ALD} \log \mathrm{Y}_{\mathrm{d}}+0.9$

where

$\mathrm{Td}_{1}=$ texture depth in 1 year $(\mathrm{mm})$;

$\mathrm{Y}_{\mathrm{d}}=$ design life in years; and

ALD $=$ average least dimension of the aggregate.

The entire specification is based on this deterioration model and is founded on the assumption that chip seal service life is ultimately determined by the consequence of bleedingtexture loss (6). In New Zealand, the surface texture of the chip seal projects are measured using the sand patch test after the end of 1 year, and the payment is adjusted according to the whether the project's macrotexture has performed as designed (3).

Research in New Zealand has shown that there has not been any significant increase in bid prices to reflect the shift in risk caused by their performance-driven contracts (14). New Zealand's experience illustrates that when warranties are used in association with performance and end product specifications, the contractor is provided with the incentive to pursue more innovative technologies and methods for highway projects, leading to economic benefits for all parties involved in the highway construction process (14). It should be noted that Michigan had a similar experience when it experimented with chip seal warranties. Research on the Michigan experience stated: "The final results gave contractors greater flexibility [emphasis added by author] in selecting the materials and application methods used for warranted surface treatments" (15).

\section{CHIP SEAL CONSTRUCTION PRACTICES}

Chip seal is treated like a construction project rather than a maintenance project in New Zealand (3). Significant investment is made in preparing the road's surface prior to chip sealing. This work is originally defined in the design process and in response to measurements made of surface texture and hardness made to determine the appropriate binder and aggregate combination. This process effectively identifies those areas of pavement that are flushed or bleeding. These areas can then be addressed through the use of water retexturizing using either a full lane width waterblasting machine or if the flushing is localized, the watercutting machine. The important fact to remember about this process is that the New Zealanders are removing excess bitumen in areas of the road that are flushed before the new seal. This is opposed to the North American practice of sealing over these areas and trying to reduce the binder application rate on the fly in the field during construction.

There are two primary advantages of water retexturizing. First, it leaves the road's surface in a reasonably uniform condition and thus greatly reduces the need to adjust binder application rates during chip seal installation. Research in the United States has shown that it takes highly experienced personnel to properly adjust binder application rates in the field (16). So by adjusting the surface texture prior to applying the new seal, construction can proceed in accordance with the application rates shown on the plans for the project. 
The second advantage is that the use of water retexturizing to restore skid resistance to localized areas of flushed surface may, in fact, obviate the need to do a reseal entirely. This process can be used to effectively extend the service life of a chip seal by restoring skid resistance to the pavement's surface through water retexturizing alone

This process has been so successful in New Zealand that they have developed a construction specification for water retexturizing as a separate process. This specification calls for the end result to restore a texture of at least $1.1 \mathrm{~mm}$ of average texture depth (17). This idea makes a lot of sense when one considers the fact that loss of surface texture generally only occurs in the wheelpaths. Thus, investing in water retexturizing to remove excess binder only in the areas where it is present is extremely efficient and it also has a positive effect on the road's life-cycle cost by minimizing the total amount of bitumen and aggregate are used over the life of the road.

\section{Watercutting Machines}

A significant piece of unique equipment identified in this study is the UHP watercutting machine. The restoration of texture to a road surface that is slick with excess binder can be performed by the use of the watercutting machine. The results of water retexturizing are shown in Figure 1. These truck-mounted machines can eliminate the effects of bleeding by using carefully directing high-pressure water to remove the any binder that is submerging the aggregate on the existing surface. An AASHTO scanning tour report recommended that this and other overseas chip seal equipment be investigated for use in the United States (19). Figure 2 is a photograph of a New Zealand "watercutter" in use.

Figure 3 displays the results of research conducted on the impact of wattercutting on skid resistance. Looking at the Roxburgh Grade 3 Chip Seal portion of the graph, one can see that the skid resistance as measure by the GripNumber of the watercut section was improved dramatically after the retexturizing process was completed. Figure 4 shows the improvement gained by watercutting in texture depth and its corresponding skid resistance improvement as measured by the British Pendulum Number. One can see that before retexturizing the surface depth was about roughly $0.5 \mathrm{~mm}$ and it was improved to around $2.0 \mathrm{~mm}$. This depth is better than the P26 specification of $1.1 \mathrm{~mm}$ cited in the previous section. The graph goes on to show that the test section retained a texture depth greater than the specification for the 1 year period of analysis.

\section{Rolling Specifications}

A recent paper in a U.S. journal proposed a formula to calculate the required number of pneumatic-tired rollers that would allow the production rate of the asphalt distributor to be maximized (20). The hypothesis of the paper was that chip seal aggregate retention was a function of the rolling and that previous research had identified that U.S. public highway agencies were not paying adequate attention to the rolling process (16). Chip seal contractor profitability is largely a function of being able to attain the maximum possible production out of the chip seal equipment train, and as a result, attention during construction is focused on the front end of the equipment train leaving little attention being paid to the quality of the rolling that comes at the rear end of the process. Many U.S. highway agencies have weak or no specifications with regard to ship seal roller operations (3). Thus, this is one area (i.e., the 
development of detailed specifications for roller operations) in the chip seal construction process that can easily be improved.

New Zealand utilizes a formula that is very similar to the one found in the U.S. literature cited above. It is found in Transit New Zealand Specification P4 (21). The formula calculates the required rolling time for a given number of rollers rather than the U.S. approach of calculating the required number of rollers to achieve a given amount of rolling time. The $\mathrm{P} 4$ specification formula is shown in Equation 2.

$$
\mathrm{T}=\frac{\mathrm{V}_{\mathrm{t}}}{450(\mathrm{~S})(\mathrm{n})}
$$

where

$\mathrm{T}=$ Total roller requirement (hours);

$\mathrm{V}_{\mathrm{t}}=$ Total volume of binder sprayed (liters);

$\mathrm{S}=$ Average rolling speed (kilometers per hour); and

$\mathrm{n}=$ Number of rollers employed in uninterrupted rolling.

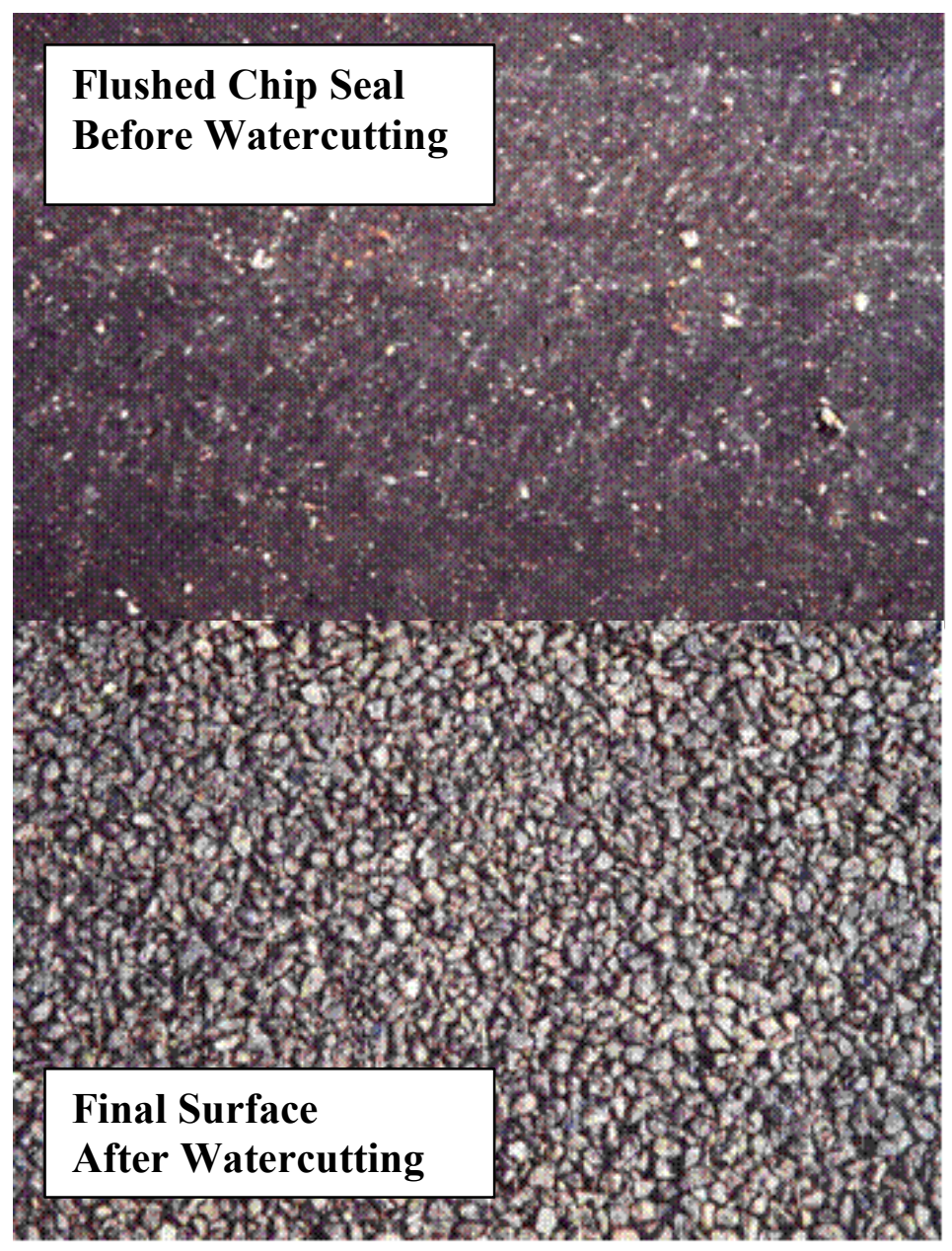

FIGURE 1 Before and after image of water-retexturizing (15). 


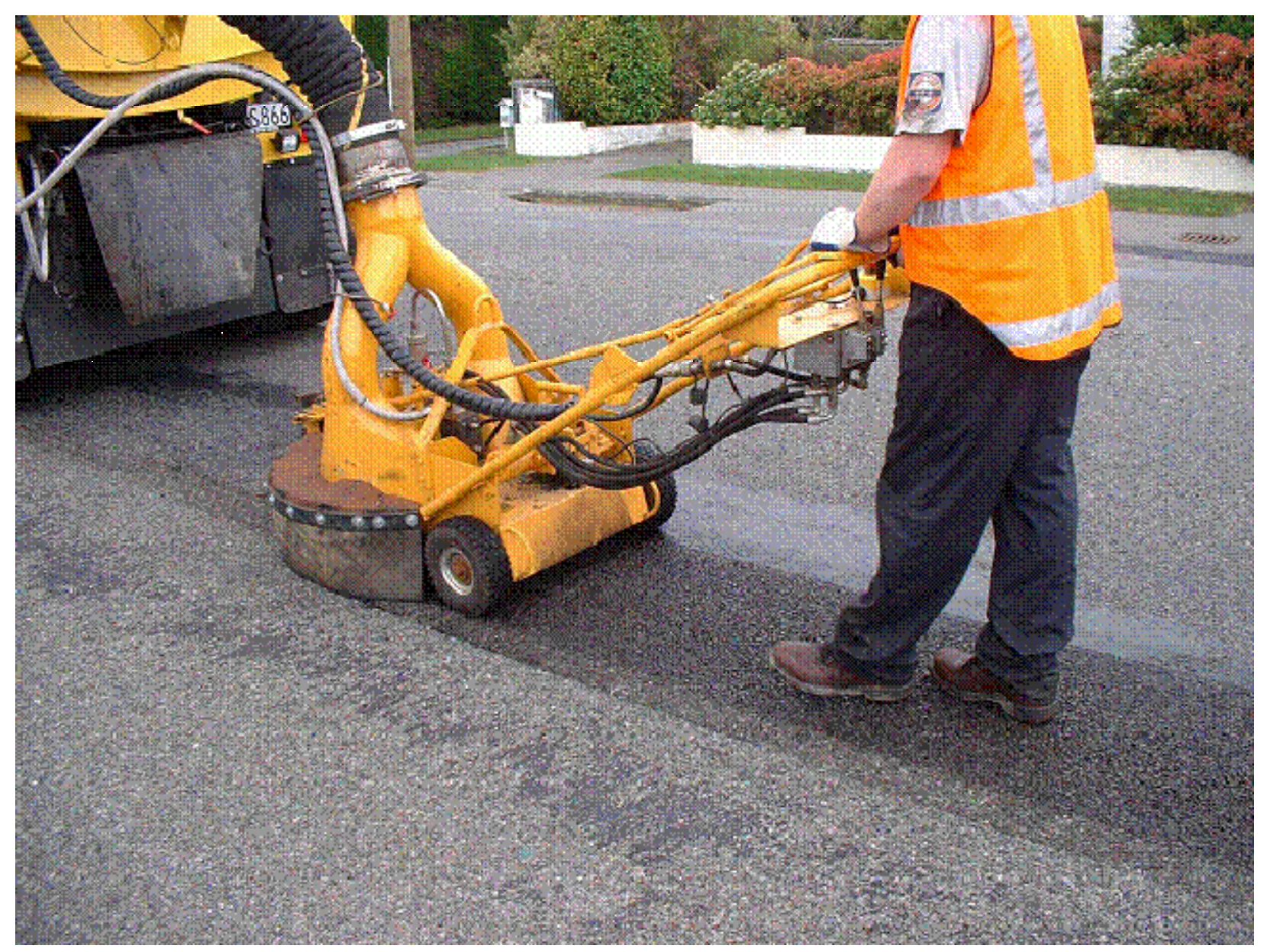

FIGURE 2 Retexturizing using the UHPO watercutter in New Zealand (15).

This time calculated in Equation 2 is then split in half with the first half being designated as "initial rolling" and the second half designated "finish rolling." The specification goes on to define the maximum volume of binder that can be applied before pausing to allow the rollers to finish the initial rolling and catch up with the distributor and chip spreader using Equation 3:

$\mathrm{V}_{\mathrm{m}}=450(\mathrm{~S})(\mathrm{n})$

where $\mathrm{V}_{\mathrm{m}}$ is maximum binder volume (liters).

Thus, these requirements transfer a large degree of specificity to the field which can in turn be enforced by quality assurance personnel. They also serve to ensure that the rolling is conducted when the binder is as tender as possible thus enhancing the retention of chip seal aggregate. This level of attention to roller operation detail confirms that the problems identified in U.S. chip sealing operations in the literature can be effectively alleviated through the application of rational methodologies based on engineering principles. 


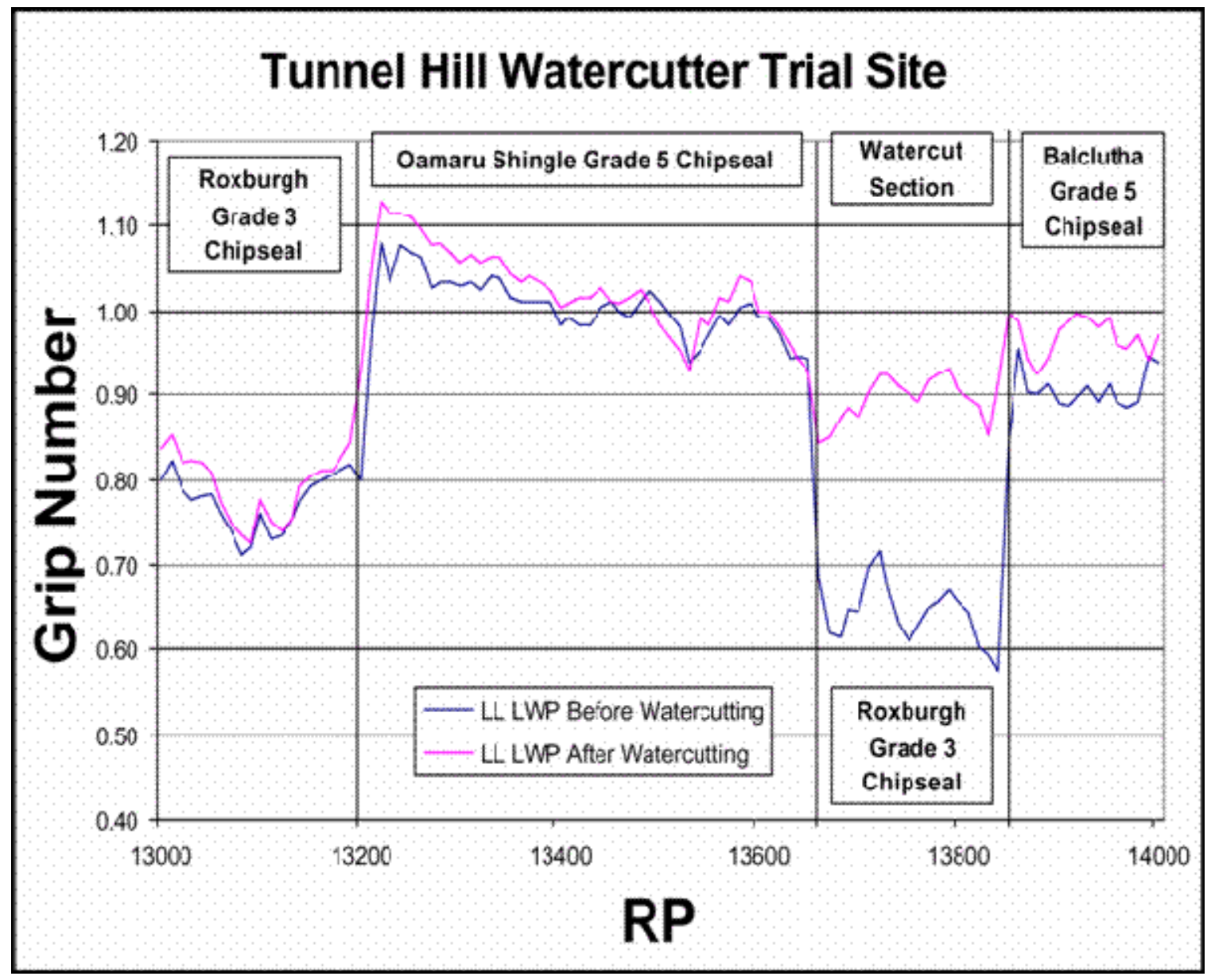

FIGURE 3 Skid resistance as measured by the grip number change due to wattercutting (15).

\section{CHIP SEAL PERFORMANCE}

All of the above discussion leads one to ask whether the increased attention to engineering detail and greater technical rigor applied to the design process in New Zealand really pays off in terms of a higher quality chip seal. The NCHRP Chip Seal Best Practices Synthesis Report (3) queried its respondents as to the expected service life of their typical chip seals. Figure 5 displays the result of that survey and one can see that New Zealanders expect to get approximately 2 years longer service life than their counterparts in America.

Additionally, survey respondents were asked to rated the quality of ride on their chip seals. This question sought to quantify the perception that chip sealed roads were both rougher riding and noisier than hot-mix asphalt pavements (3). Figure 6 shows the ride quality is perceived to be significantly better in New Zealand than in North America. Some of this enhanced level of ride quality can be attributed to the fact that New Zealand uses multiple chip sizes in many of its seals. The smaller chips fill in the voids between the larger chips reducing road noise and enhancing smoothness. Thus, it can be seen that the increased technical rigor applied to the New Zealand chip seal program appears to render the benefits of increased service life and enhanced ride quality. 
Fulton Hogan Ultra High Pressure Watercutter for Texture Restoration

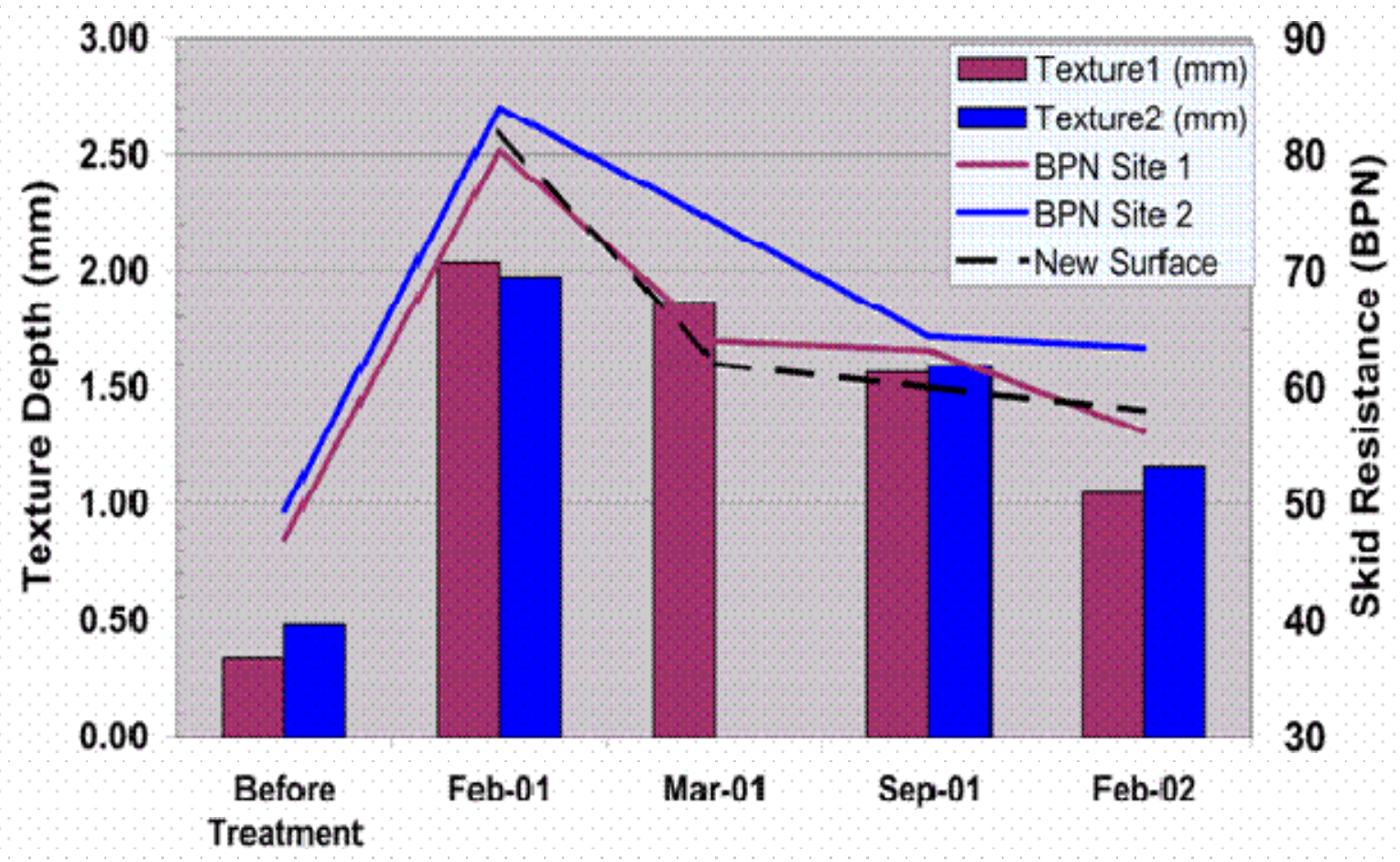

FIGURE 4 Texture depth and skid resistance as measured by the British pendulum number change due to wattercutting (15).

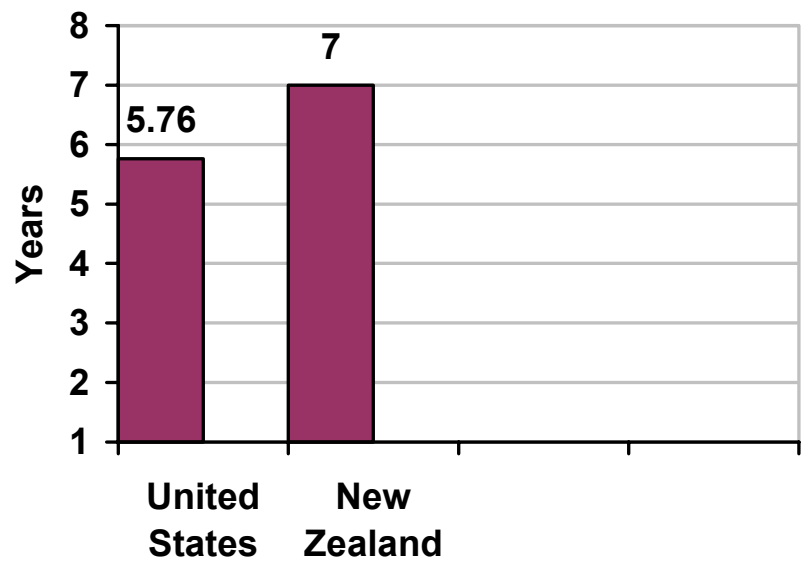

FIGURE 5 Comparative expected service lives of chip seals in the United States and New Zealand (3). 


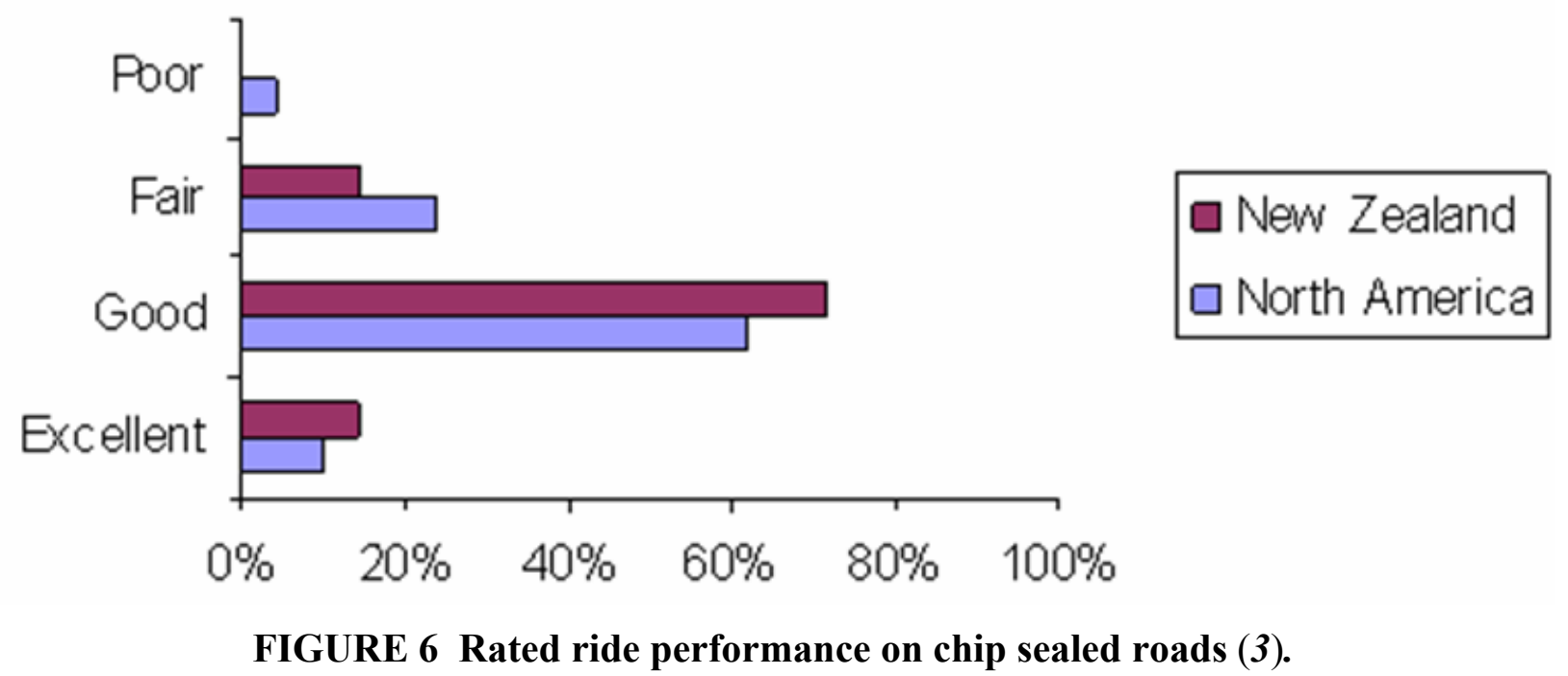

\section{CONCLUSIONS}

The fact that New Zealand literally depends on chip seals to furnish large percentages of its national transportation system speaks to the fact that chip seal pavement preservation technology can indeed be reliably and predictably engineered. The authors believe that the chip seal design and construction methods used in New Zealand are superior to the practices found in the United States. The New Zealand chip seal design method is the result of over 30 years of continuous improvement, whereas North American design methodology has not been advanced since McLeod's research in the 1960s (10). As previously stated, the state-of-the-art in U.S. chip seal design essentially ended in the 1960s in North America when Norman McLeod proposed his design method based on New Zealand design practices, and it was accepted by the Asphalt Institute and most North American departments of transportation as the theoretical basis on which chip seals would be delivered to the traveling public. The development further stalled as public agencies evolved to a system where no design is performed and only empirical rates are used to develop estimated quantities for unit price chip seal contracts.

Luckily, our fellow engineers in the New Zealand did not allow their search for a technically engineered chip seal to cease in 1969. U.S. public highway agencies need to evaluate the transfer of technology from nations such as New Zealand and continued research on the use of their specialized equipment and scientific design is essential. Therefore the following conclusions can be drawn from this analysis:

- Emphasis on characterizing the road's existing surface and using that data as input to the chip seal design process has had a positive impact on the quality and service lives of New Zealand chip seals.

- The use of preconstruction surface preparation methods such as water retexturizing reduces the inherent variability of chip seal process and therefore has a positive impact on construction quality.

- The use of the watercutter to remove excess bitumen from flushed chip seals eliminates the need for resealing due to loss of skid resistance. This also enhances the life-cycle 
economics of chip seals by reducing the number of reseals required in a fixed period of time which in turn increases the service life.

- The New Zealand chip seal specification furnishes an excellent method to rationally compute the required rolling time for chip seals. This is important in that the major short-term distress seen in chip seals is loss of aggregate due to inadequate embedment $(3,20)$ and the only piece of equipment in the chip sealing train that is devoted to achieving proper embedment is the roller. Thus, the use of this formula or the one proposed in the U.S. literature $(3,20)$ allows both the public agency and the contractor to quantify roller requirements in direct relation to the production estimates used in the bidding process. These requirements can then be use in the chip seal quality management process.

These conclusions lead to several recommendations for utilizing the information gained in this study to enhance U.S. pavement preservation programs. First, research should be undertaken to import as much of the New Zealand chip seal program methodology to the United States as possible. The initial step would be to evaluate its design procedures and develop U.S.equivalent standard testing procedures that permit the characterization of existing road surfaces based on precise engineering measurements. Once the design procedure is adapted for use in the United States, various design outputs such as the use of multiple size chip seals should then be tested to determine their applicability to North American climate and traffic conditions. The use of road surface preparation methods such as watercutting would next be assessed to identify not only the technical benefits but also the life-cycle cost associated with importing this technology to the United States. Finally, the process for transferring a high degree of technical specificity to the construction process used in New Zealand as exemplified by its formulaic specifications for rolling requirements should be adopted by U.S. agencies to shift the paradigm from seeing chip seals as maintenance activities in which quantities of a commodity are purchased to seeing it as a construction project which directly supports the agencies' pavement preservation program.

\section{REFERENCES}

1. Report Card for America's Infrastructure. American Society of Civil Engineers. Available at www.asce.org/reportcard/2005/page.cfm?id=103. Accessed March 30, 2005.

2. Galehouse, L., J. S. Moulthrop, and R. G. Hicks. Principles for Pavement Preservation: Definitions, Benefits, Issues and Barriers. TR News, September/October 2003, pp. 4-9.

3. Gransberg, D. D., and D. M. B. James. NCHRP Synthesis of Highway Practice 342: Chip Seal Best Practices. Transportation Research Board of the National Academies, Washington, D.C, 2005.

4. Pidwerbesky, B. D., and J. S. Pollard. Design and Performance of Sprayed Seal Coats for Unbound Granular Pavements Carrying Heavy Logging Trucks. Transportation Research Record 1291, TRB, National Research Council, Washington, D.C., 1991, pp. 66-71.

5. Pidwerbesky, B. D. and G. Arnold. Seal Coat Design for Unbound Granular Pavements Carrying Heavy Axle Loads. Journal of Forestry Engineering, Vol. 7, No. 1, 1995, pp. 18-27.

6. Arnold, G., and B. D. Pidwerbesky. Polymer-Modified Bitumens in Chip Seals for High Stress Conditions. Proc., Joint 18th ARRB Transport Research Conference and Transit NZ Land Transport Symposium, Part 2, Christchurch, New Zealand, 1996, pp. 197-209.

7. Asphalt Surface Treatments-Construction Techniques. Educational Series No. 12 (ES-12). Asphalt Institute, Lexington, Ky., undated.

8. Hanson F. M. Bituminous Surface Treatment of Rural Highways. Proc., New Zealand Society of Civil Engineers, Vol. 21, No. 1934, p. 35.

9. Notes for the Specification for Bituminous Reseals. TNZ P17. Transit New Zealand, Wellington, 2002. 
10. McLeod, N. W. A General Method of Design for Seal Coats and Surface Treatments. Proc., Association of Asphalt Paving Technologists, Vol. 38, St. Paul, Minn., 1969.

11. Kearby, J. P. Tests and Theories on Penetration Surfaces. Highway Research Board Proceedings, Vol. 32 , 1953, pp 232-237.

12. Austroads Provisional Sprayed Seal Design Method. Austroads, Sydney, Australia, 2004.

13. Chamberlain, W. P. NCHRP Synthesis of Highway Practice 212: Performance-Related Specifications for Highway Construction and Rehabilitation. TRB, National Research Council, Washington, D.C., 1995.

14. Owen, M. Managing the Risk in a New Performance Based Environment. Presented at Conference on Asphalt Pavements for Southern Africa, September 1999, Zimbabwe.

15. Galehouse, L. Innovative Concepts for Preventive Maintenance. Transportation Research Record 1627, TRB, National Research Council, Washington, D.C., 1998, pp. 1-6.

16. Gransberg, D. D., S. Senadheera, and I. Karaca. Analysis of Statewide Seal Coat Constructability Review. Report TX-98/0-1787-1R. Texas Tech University, Lubbock, 1998.

17. Specification for Improvement of Pavement Macrotexture. TNZ P26. Transit New Zealand, Wellington, 2003.

18. Waters, J. Retexturing Polished Surfaces Using the Watercutting Process. Fulton Hogan Ultra-High Pressure Watercutter (CD ROM). Fulton Hogan, Ltd., Christchurch, New Zealand, 2004.

19. Beatty, T. L., D. C. Jackson, D. A. Dawood, R. A. Ford, J. S. Moulthrop, G. D. Taylor, F. L. Danchetz, D. A. Blank, J. M. Fay, D. S. Keough, L. M. Rodqiquez, M. D. Voth, and Z. L. Webb. Pavement Preservation and Technology in France, South Africa, and Australia. American Trade Initiatives, Alexandria, Va., 2002.

20. Gransberg, D. D., S. Senadheera, and I. Karaca. Calculating Roller Requirements for Chip Seal Projects. Journal of Construction Engineering and Management, Vol. 130, No. 3, 2004, pp. 1-7.

21. Specification for Resealing. TNZ P4. Transit New Zealand. Wellington, 1995. 


\title{
Constructability of Longitudinal Construction Joints in Hot-Mix Asphalt Pavements with Sealers to Retard Future Deterioration
}

\author{
EDWARD J. DENEHY \\ New York State Department of Transportation
}

\begin{abstract}
The failure of hot-mix asphalt (HMA) pavements at the longitudinal construction joint is well documented. Several studies have been undertaken to determine the best way to construct these joints to prevent premature deterioration. As the results of several studies became clear, the New York State Department of Transportation (NYSDOT) first changed the procedures for constructing longitudinal joints from rolling the joint from the cold side to rolling the joint from the hot side. Subsequently, the NYSDOT approved the use of a notched wedge joint for HMA longitudinal joint construction. The studies on longitudinal joint construction also included the use of longitudinal joint sealers. In the Pennsylvania study, the joints constructed with the longitudinal joint sealer performed the best. The NYSDOT was interested in this technique, but it was not convinced that the installation of the sealer could be accomplished without disrupting the HMA placement. In the summer of 2004, the NYSDOT constructed three HMA pilot projects using three different joint sealers to determine their constructability. One project on Interstate 81 (I-81) in Cortland County used the XJB eXtruded Joint Bond product from Asphalt Materials, Inc. A second project used the Crafco Pavement Joint Adhesive product on New York State Route 417 (NY-417) in Steuben County. The third project used the Deery Cold Joint Adhesive product on I-87 in Saratoga County. This paper will document the installations and problems, or lack thereof, experienced during the pilot projects.
\end{abstract}

Tn Highway Research Record 51, published in July 1964, a paper entitled Constructing Longitudinal Joints in Hot-Mix Asphalt Pavements by C. R. Foster, S. B. Hudson, and R. S. Nelson made the following statement: "Joints are often the weakest portion of a bituminous concrete surfacing and under unfavorable conditions of exposure and/or construction, visible defects may occur first at the joints. These defects may allow the ingress of water into the pavement leading to further disintegration..." (1) The authors went on to say that their literature search found no other pertinent information on the subject. This author's literature search also found that this paper appeared to be the first published work on this subject. Foster, Hudson, and Nelson postulated that their unanticipated finding of a "low-density zone" at the joint in the first pass "may well be the basic problem in constructing durable longitudinal joints in asphalt pavements" (1).

J. R. Croteau, R. F. Baker, J. J. Quinn, and E. J. Hellriegel, in a paper presented at the 69th Annual Meeting of the Transportation Research Board, presented "the results of a 5-year study undertaken to develop a technique for producing more durable longitudinal construction joints in bituminous pavements" (2). The authors were either employed by the New Jersey Department of Transportation (NJDOT) or retired from NJDOT. NJDOT began experimenting in 1982 with ways to improve the durability of longitudinal joints. They studied a wedge joint as a method of improving the density gradient across the longitudinal joint. In their literature search, Baker et al. credited Arizona Department of Transportation with being one of first agencies to implement the longitudinal wedge joint. The New Jersey study placed a steeper wedge than 
Arizona (3:1 versus 6:1) to reduce potential raveling. New Jersey also introduced infrared heating of the cold joint into the process (2).

Croteau et al. found that the wedge joint eliminated the density gradient across the longitudinal joint and they recommended that their agency adopt the wedge joint with infrared heating for all courses of HMA. Their control sections, conventionally placed butt joints, displayed the expected density gradient. On one test section, the infrared heating was left out, but no reason was given, so we are left to ponder whether they wanted to do it or if the heater malfunctioned. In this section, the density gradient across the wedge joint was nonexistent. Regardless of the reason, this section may show that the infrared heater was not necessary. This would be left for subsequent researchers to investigate (2).

While Croteau et al. showed that their wedge joint eliminated the density gradient that is inherent with the traditional butt joint, they did not follow up on the performance of the joints over time (or at least they did not document it). In this author's view, the postulated fundamental cause of longitudinal joint failures, namely the density gradient across the longitudinal joint, has not been proven by this study. While they found a way to eliminate it, they did not prove that it causes the performance problems.

In what appears to be the definitive studies in this area, the National Center for Asphalt Technology (NCAT) led three separate experiments where several different longitudinal construction joint techniques were installed and monitored in four states (Michigan, Wisconsin, Colorado, and Pennsylvania) over 4 years (1992-1995) (3-6). One of their major first conclusions was that "the performance ranking of the different joint construction techniques appears to have been influenced by the overall density at the joint obtained by the technique. The joints with high densities generally show better performance than those with relatively low densities" (5).

NCAT went on to conclude that the notched wedge joint (Michigan wedge) performed best in Michigan and second best in Wisconsin. The best performer in Wisconsin was the edge restraining device $(3,5)$. A modified Michigan notched wedge joint performed best in Colorado. Also performing well in Colorado was the cutting wheel and the rubberized tack coat $(4,5)$. In Pennsylvania, the cutting wheel, the rubberized tack coat, and rolling from the hot side were the top performers, but the observations were only after one year of service. In all four states, rolling from the hot side was the best performing rolling technique (3-5).

In a paper presented at the 79th Annual Meeting of the Transportation Research Board in January 2000 the results of another NCAT study were presented. Five projects were constructed in five states (Colorado, Indiana, Alabama, Wisconsin, and Maryland) using both the conventional butt joint and the notched wedge joint. "The results of the study indicated that the notched wedge joint can be used successfully to increase the in-place density at the longitudinal joint" (7). Evaluations of joint performance were planned for subsequent years, but they could not be located by this author.

In a follow-up study of the Pennsylvania work, Kandhal et al. reported on longitudinal joint performance 6 years after construction. Their first conclusion was "longitudinal joint constructed using rubberized joint material gave the best performance with no significant cracking, closely followed by the joint made with the cutting wheel." They went on to say that constructing the joint with the cutting wheel was difficult. To obtain consistent performance of longitudinal joints, they recommended using the rubberized joint material or the notched wedge joint. Additional recommendations were to roll the joint from the hot side (preferably $150 \mathrm{~mm}$ away from the joint) and to specify a minimum compaction level at the joint ( 6 ). 
The state of Maine undertook a longitudinal joint study in 1996 and issued a final report in September 2001. The joint maker system, edge trim (cutting wheel), and several different rolling procedures were utilized in the study. Conventional butt joints were used; no wedge joints were included. In results differing from previously reported studies, static rolling of the joint with the first pass on the cold mat with a $150 \mathrm{~mm}$ overlap on the hot mat, then from the low to the high side produced the best results. Although the edge trim had the second lowest amount of cracking, the cracking was the most severe. Construction problems were suspected. The control section, which rolled the second mat from low to high side to within $150 \mathrm{~mm}$ of the joint, then pinched it with $610 \mathrm{~mm}$ over the cold mat produced the next best results, followed closely by the technique that made the first pass on the hot mat $150 \mathrm{~mm}$ from the joint, the second pass pinching the joint, then rolling from the low to high side. Rolling from the hot side with $150 \mathrm{~mm}$ on the cold mat then rolling from high to low side and the joint maker were the worst performing joints in the is study $(8)$.

The state of Maine is also conducting a study on the use of joint sealers to retard the cracking of longitudinal joints in HMA pavement. The study, which began in 2000, used three different products to seal the joints: a rubberized joint sealer, a joint adhesive, and a HFMS-1 emulsion. A visual evaluation in late 2003 found all joints performing well except for small areas at the beginning of two sections where construction problems were suspected rather than product failures. The study has not concluded yet (9).

A March 2005 article in Better Roads entitled "Oscillation Compaction Solves Longitudinal Joint Woes" chronicled a Colorado contractor's experience in meeting a longitudinal joint density requirement in Colorado. The contractor reported that they used a oscillating roller to meet Colorado's 2003 specification requirement of 94\% (plus or minus 4\%) density on the joint itself (10). Although the article was courtesy of the roller manufacturer, to this author the technique merits further study.

\section{NEW YORK STATE DEPARTMENT OF TRANSPORTATION CHANGES TO LONGITUDINAL JOINT REQUIREMENTS}

In 1995, NYSDOT organized several working groups including NYSDOT engineers, representatives of contractor organizations, and contractors' engineers to address several areas of hot mix asphalt construction. One of the working groups was responsible for joint construction. The working group held several meetings over the next 4 years after reviewing the available research on the subject. Informal studies of joint densities were performed by coring sample projects at and near the longitudinal joints. The task force (as it became to be known) recommended that NYSDOT allow use of the notched wedge joint as an alternative to the butt joint. Additionally, the task force recommended that rolling from the hot mat with $150 \mathrm{~mm}$ overlap on the cold mat for one pass towards the paver and one pass away from the paver and then rolling from the low side to the high side be the approved method of compacting the longitudinal joint. After management approval, the task force developed changes to the NYSDOT standard specifications to allowing the notched wedge joint option and rolling from the hot side.

The task force also developed a pilot joint density specification for use on a few demonstration projects. The specification included joint density requirements and an incentive, but no disincentive for not meeting the requirements. The specification has been used several 
times with mixed success due to the lack of a disincentive. Further development of the specification has been put on hold due to personnel changes and reassignments.

During the same time period, NYSDOT undertook an in-house study to compare the joint-maker manufactured by TransTech Systems, Inc., with the conventional butt joint. Two 305-m sections were selected on three projects to compare the joint-maker with the conventional butt joint. Joint-rolling patterns were varied on the three projects. On all three projects the average densities were higher at the joint for the conventional butt joint than the joint-maker. No significant differences were found between the three projects for both the cold mat and hot mat densities. As a result of this study, NYSDOT decided not to pursue obtaining joint-makers for its fleet of NYSDOT-owned pavers.

\section{FURTHER WORK BY NYSDOT REGARDING LONGITUDINAL JOINTS IN HOT MIX ASPHALT PAVEMENT}

As the results of further studies became available, especially the follow up Pennsylvania study, it became apparent to NYSDOT that the use of the longitudinal joint sealant offered an increased chance for improved longitudinal joint performance for a disproportionately small increase in cost. During early 2003, NYSDOT began the process of locating projects where the installation of the joint sealant could be piloted. It was postulated that the placement of the sealant might hold up the paving contractor, create a mess, and lead to higher prices for HMA. Small pilot projects where all parties were in agreement to halt the sealant installation if problems occurred needed to be located. During 2003, NYSDOT located two projects, but the engineer in charge of the projects decided against using the sealant.

Project selection began again in 2004 and three projects were selected. The project information is as follows:

- Route 417, Town of Jasper, Steuben County

- Location: Reference Marker 1172 to 1173 with sealant; 1171 to 1172 without sealant

- Sealant Manufacturer: Crafco, Inc.

- Product: Pavement Joint Adhesive

- Sealant placed by Crafco, Inc.

- Paving Contractor: A.L. Blades and Sons, Inc.

- Notched wedge joint

- Date sealant placed: 6/21/04

- Route I-87, Exits 15 to 16, Saratoga County

- Location: Northbound, between second and third lane joint

- Mile Marker 34.1 = Reference Marker 87I 1509/1258

- $100 \mathrm{ft}$ north of MM 34.0 to $34.1-50 \mathrm{~mm}$-band

- MM 34.1 to 34.2 -64-mm band

- Without sealant: joint between first and second lanes

- Sealant Manufacturer: Deery Corp.

- Product: Joint adhesive

- Sealant placed by Artco Equipment Sales, Inc.

- Paving Contractor: Kubricky Construction Corp. 
- Notched wedge joint

- Date sealant placed: 9/14/04

- Route I-81, near Exit 13, Town of Preble, Cortland County

- Location: Northbound, Reference Marker 3102 to 3103 with sealant; 3103 to 3104 without sealant

- Sealant Manufacturer: Asphalt Materials, Inc.

- Product: eXtruded Joint Bond

- Sealant placed by Suit-Kote, Inc.

- Paving Contractor: Suit-Kote, Inc.

- Notched wedge joint

- Date sealant placed: 9/29/04

\section{Project-Specific Information}

$N Y-417$

In the area of the project, NY-417 is a rural two-lane two way highway with 3.6-m lanes and $3.0-\mathrm{m}$ shoulders. The average annual daily traffic (AADT) is 2,140 . The affected section of pavement is on a relatively level tangent section. The treatment included a $25-\mathrm{mm}$ thick (average) truing and leveling course and a 40-mm top course. Both courses used a 9.5-mm Superpave HMA with a performance grade (PG) 64-28 binder. The first mat, placed on June 20, 2004, included placing the eastbound travel lane and shoulder simultaneously. The notched wedge joint, which consisted of $12.5-\mathrm{mm}$ vertical step-down and 1 on 8 taper, was used. Compaction of the first mat proceeded from the low side to the high side and rolling of the joint was accomplished by rolling up to but not past the step-down. The sealant was placed on June 21, 2004, out ahead of the paver, which was proceeding westbound placing the westbound lane and shoulder simultaneously.

The sealant, placed by Crafco, Inc., was placed using conventional crack sealing equipment. A 100-mm diameter sealing disk was used producing a 3-mm thick, $100-\mathrm{mm}$ wide swath of sealant that covered the notch and extended part way down the taper. The sealant became tacky within a few minutes and the lack of pickup was demonstrated by driving a pickup truck over the sealant with no damage to the sealant whatsoever. Sealant installation was accomplished at a pace of 15 to $18 \mathrm{~m}$ per minute.

The second mat was placed with the paver overlapping the cold mat by 25 to $40 \mathrm{~mm}$. The overlap thickness was $10 \mathrm{~mm}$. The excess material was luted onto the hot mat so that the roller operator could crowd the excess material into the hot side of the joint. Rolling of the joint was accomplished immediately after paving with a vibratory roller operating on the hot mat with 150 to $200 \mathrm{~mm}$ on the cold mat rolling towards the paver and a second pass away from the paver. After compacting the joint, the roller proceeded to roll the rest of the mat from the low side to the high side.

Paving was not adversely affected at all. None of the sealant was picked up by the rollers. After the joint was compacted, only a small thin line of sealant was visible at the joint in some small areas. On this project, the contractor was not affected negatively by the sealant placement. Some extra coordination was necessary to get the sealant installers on the project when necessary. 


\section{I-87}

In the area of the project, I-87 is a six-lane divided expressway with three 3.6-m lanes in each direction. There is a $3.0-\mathrm{m}$ right shoulder and a $1.8-\mathrm{m}$ left shoulder in each direction. The AADT is 44,610 . The affected section of pavement is on a relatively level tangent section. The project required night work. The treatment included milling off $40 \mathrm{~mm}$ of pavement on all three lanes and both shoulders and replacing it with a 40-mm course of 12.5-mm Superpave with a PG 6428 binder.

The contractor milled all three lanes and both shoulders during the week of September 5, 2004. The overlay began on September 14, 2004, with the first lane paved being the left or passing lane with the lane and left shoulder placed simultaneously. The same notched wedge joint as described for NY-417 was used on this project. Compaction of the first mat was accomplished using the same procedure as for NY-417. Placement of the Deery sealant was done by Artco Equipment, Inc. using conventional crack sealant equipment. A $50 \mathrm{~mm}$ sealing shoe was used first producing a $50 \mathrm{~mm}$ wide band of sealant. A $100 \mathrm{~mm}$ shoe was used after the first $152 \mathrm{~m}$ and the resulting band only increased to $64 \mathrm{~mm}$. The band of sealant was placed in the middle third of the taper of the wedge joint.

This manufacturer's sealant also became tacky within a few minutes, even at night, and the speed of installation was the same as for Route 417 . The second mat was placed as described for Route 417 and the rolling procedure was also the same.

Again, paving was not adversely affected at all. None of the sealant was picked up by the rollers. Due to the location of the sealant in the middle of the wedge, sealant was not visible in the finished joint. Also, on this project, the contractor was not affected negatively by the sealant placement. As on Route 417, some extra coordination was necessary to get the sealant installers on the project when necessary.

\section{I-81}

In the area of the project, I-81 is a four-lane divided expressway with two 3.6-m lanes in each direction. There is a 3.0-m right shoulder and a $1.8-\mathrm{m}$ left shoulder in each direction. The AADT is 23,730 . The affected section of pavement is on a relatively level tangent section. The treatment included milling off $40 \mathrm{~mm}$ of pavement in both lanes and replacing it with a $40 \mathrm{~mm}$ course of 12.5-mm Superpave HMA with a PG 64-28 binder. On this project, traffic was allowed to ride on milled surfaces, so both lanes were milled prior to paving.

The passing lane was placed first and a conventional butt joint was formed. Placement of the Asphalt Materials Inc., sealant was done by Suit-Kote using conventional joint sealing equipment. This material was thicker than the Crafco and Deery sealant and there was difficulty in placing the material at the right thickness using a 50-mm sealing shoe on the butt joint. SuitKote switched to a conical wand head with an ellipsoid shaped nozzle and installation proceeded smoothly after that. Due to the small amount of sealant needed for this demonstration project, there was some concern that the large kettle used was not heating the sealant to the proper installation temperature. Switching the nozzle also took some time which allowed the sealant to be heated to a higher temperature. The sealant completely covered the sloped portion of the butt joint. 
The Asphalt Materials, Inc., sealant also became tacky within a few minutes and the speed of installation was the same as for NY-417 and I-87. The second mat was placed as described for NY-417 and I-87 and the rolling procedure was also the same.

Here also, paving was not adversely affected at all. None of the sealant was picked up by the rollers. After the joint was compacted, only a small thin line of sealant was visible at the joint in some small areas. On this project also, the contractor was not affected negatively by the sealant placement. Some extra coordination was necessary to get the sealant installers on the project when necessary.

\section{CONCLUSIONS AND RECOMMENDATIONS}

There were no problems with the installation of three different brands of longitudinal joint sealant materials for HMA pavements by three different contractors on three different geographically separated projects across New York State.

The use of longitudinal joint sealant materials for HMA pavements did not negatively affect HMA paving and compaction on these three projects.

It is recommended that NYSDOT continue with larger installations of these sealants. A long term research project should be undertaken to install sealants on several projects in different areas of the state with experimental and control sections to see if their use positively affects performance of longitudinal joints in HMA pavements.

\section{FOLLOW-UP}

In 2005, NYSDOT will be constructing experimental projects using longitudinal joint sealants for HMA pavements. The projects will include experimental and control sections on five projects: two in Schenectady County, two in Oswego County, and one in Otsego County. These projects will include 30 centerline kilometers of longitudinal joints. Each project will include a short control section and the rest of each project will include sealants. Allowable sealants will include those demonstrated in 2004 and approved equals.

\section{AKNOWLEDGMENTS}

This work could not have been accomplished without the cooperation and participation of the following contractors and companies: A. L. Blades and Sons, Inc.; Kubricky Construction Corp.; Suit-Kote Corp.; Crafco Inc.; Asphalt Materials Inc.; Deery American Corp.; Artco Equipment Sales Inc; The following individuals deserve special thanks for their participation: Tom Pfuelb of Crafco Inc.; Chris Blades of A. L. Blades and Sons, Inc.; Gary Foux of Suit-Kote Corp.; Rick Stone of Artco Equipment Sales Inc.; and Zoeb Zavery, Steve Palko, and Chris Euler of the NYSDOT Materials Bureau. 


\section{REFERENCES}

1. Foster, C. R., S. B. Hudson, and R. S. Nelson. Constructing Longitudinal Joints in Hot-Mix Asphalt Pavements. In Highway Research Record 51, TRB, National Research Council, Washington, D.C., 1964.

2. Croteau, J. R., J. J. Quinn, R. R. Baker, and E. J. Hellriegel. Longitudinal Wedge Joint Study. Transportation Research Record 1282, TRB, National Research Council, Washington, D.C., 1990, pp. 18-26.

3. Kandhal, P. S., and S. S. Rao. Evaluation of Longitudinal Joint Construction Techniques for Asphalt Pavements. In Transportation Research Record 1469, TRB, National Research Council, Washington, D.C., 1994, pp. 18-25.

4. Kandhal, P. S., and R. B. Mallick. Study of Longitudinal Joint Construction Techniques in Hot-Mix Asphalt Pavements. In Transportation Research Record 1543, TRB, National Research Council, Washington, D.C., 1996, pp. 106-112.

5. Kandhal, P. S., and S. Rao. Longitudinal Joint Construction Techniques for Asphalt Pavements. In Proceedings, Eighth International Conference on Asphalt Pavements, Vol. 1, University of Washington, Seattle, August 1997.

6. Kandhal, P. S., T. L. Ramirez, and P. M. Ingram. Evaluation of Eight Longitudinal Joint Construction Techniques for Asphalt Pavements in Pennsylvania. Report 02-03, National Center for Asphalt Technology, Auburn, Ala.. 2002.

7. Buchanan, M. S. Evaluation of Notched-Wedge Longitudinal Joint Construction. Presented at 79th Annual Meeting of the Transportation Research Board, Washington, D.C., 2000.

8. Marquis, B. Longitudinal Joint Study: Final Report. Maine Department of Transportation, Bangor, September 2001.

9. Marquis, B. Longitudinal Joint Treatment: Interim Report, Third Year. Maine Department of Transportation, Bangor, March 2004.

10. Kuennen, T. Oscillation Compaction Solves Longitudinal Joint Woes. In Better Roads, March 2005. 


\title{
Seal Coat Options \\ Taking Out the Mystery
}

\author{
Peter W. Bolander \\ U.S. Department of Agriculture Forest Service
}

\begin{abstract}
Many seal coat treatments and products are available for today's parking lot or road facility manager to provide an aesthetic surface or use for preventative maintenance. In order to understand what treatment to use it is imperative to understand how these treatments differ. This ranges from understanding their basic bitumen components to the typical additives used to the sand or aggregate sizes unique to each seal coat treatment. The Pacific Northwest Region of the U.S. Department of Agriculture Forest Service (USDA-FS) has applied many seal coat treatments and has found that successful seal coats can be applied if the components are understood, if the components are compatible, if they are applied to the appropriate surface, and if proper construction methods are followed. To assist facility managers in their seal coat treatment decision making process the basic components are addressed for each seal coat treatment as well as recommended locations of use, application rates, and construction tips based on the past experiences of the Pacific Northwest Region of the USDA-FS.
\end{abstract}

The Pacific Northwest Region (Region 6) of the U.S. Department of Agriculture Forest Service (USDA-FS) manages approximately 4,100 mi of paved roads (hot and cold mix and bituminous surface treatments), approximately 200 paved parking areas, and approximately 250 mi of paved trails in the states of Oregon and Washington. Many of these paved facilities have been seal coated for preventative maintenance (PM) or for aesthetic purposes. The most common seal coat treatment used by Region 6 is a chip seal on roadways and some form of driveway or parking lot seal coat on parking facilities; however, Region 6 has used many other types of seal coat treatments. This paper represents the knowledge Region 6 has gained in understanding, selecting, and constructing seal coat treatments.

What is a seal coat treatment? A seal coat treatment is defined as a layer of bituminous material with or without aggregate, typically less than 1 in. thick, applied to an existing bituminous surface.

A seal coat treatment can perform many functions including the following:

- Seal the surface to prevent water intrusion.

- Seal fine cracks $(<1 / 4$ in.) in the pavement surface.

- Protect the surface from degradation caused by petroleum or chemical spills.

- Minimize surface oxidation (hardening) thus preventing the raveling of the fine aggregate in the pavement.

- Replace the fine aggregate materials in worn asphalt surfaces.

- Rejuvenate the underlying bituminous pavement.

- Provide an aesthetic, smooth, and uniform-colored surface.

- Improve the surface's skid resistance.

- Provide better resistance to studded tire wear depending on the type of seal coat and size of aggregate used in the seal coat. 
Seal coat aggregate can be pre-mixed with a bituminous material prior to application or applied as a cover for the bituminous material. Bituminous materials include asphalt cement, asphalt emulsions, cutback asphalt, coal tar emulsions, asphalt rejuvenating agents, or a combination of above.

Common seal coat treatments include fog seals, rejuvenation seals, sand seals, restoration seals, scrub seals, chip seals, driveway and parking lot seals, slurry seals, cape seals, microsurfacing, and thin-lift hot asphalt concrete (AC) overlays. Because these seal coat treatments are maintenance activities that do not add structural strength to the underlying pavement they should be used only on sound pavements. Any pavement with visible indications of defects, such as alligator cracking or longitudinal cracking within the wheel paths, indicate a structural defect and should be evaluated prior to placing a seal coat treatment. Some seal coats may "repair" a limited number of pavement mix deficiencies and they are noted within this report.

Seal coat treatments are commonly applied to low traffic, low speed areas such as trails, parking lots, visitor centers, campground roads, snow parks, or loading areas. However, some seal coats, such as chip seals, slurry seals, microsurfacing, and thin-lift hot AC overlay can be applied to higher traffic and higher speed roads such as residential streets, local, or collector road systems, and even higher traffic speed roads depending on the additives used with the seal coat.

Various references are available to determine whether a seal coat is the appropriate PM treatment. These include:

- Hicks, Seeds, and Peshkin. Selecting A Preventative Maintenance Treatment for Flexible Pavements. June 2000. 1991.

- Hunt, E. Asphalt Pavement Maintenance and Rehabilitation Selection Guide, June

- Asphalt Seal Coat Treatments. USDA-FS, April 1999.

- Asphalt Seal Coats. Washington Department of Transportation, March 2003.

Initial purchase and application costs and the need for future seal coat applications should always be a consideration when selecting a seal coat treatment for use on a particular project. A life-cycle cost analysis should be used when looking at seal coat alternatives over a 10- to 20year time span. This would help evaluate whether more frequent applications of one seal coat would be more cost effective than a single application of another seal coat treatment. Hicks, Seeds, and Peshkin's Selecting A Preventative Maintenance Treatment for Flexible Pavements, Hunt's Asphalt Pavement Maintenance and Rehabilitation Selection Guide provide guidance on performing a life-cycle cost analysis.

\section{SEAL COAT TREATMENT COMPONENTS}

Table 1 lists the various types of seal coat treatments and their primary and secondary functions. The material used in seal coat treatments can consist of asphalt cement (paving grade both unmodified and modified), asphalt emulsion, cutback asphalt, coal tar emulsion, or some combination or modified version of one or more of the above; aggregate; mineral filler; and various additives. Additives can include polymers, ground rubber, rejuvenators, or the mineral 
Gilsonite. An understanding of these materials is important to understanding how seal coats work. Table 2 lists the major components of various seal coat treatments.

\section{Asphalt Cement}

Asphalt cement is refined and distilled from naturally occurring crude oil to meet the requirements of ASTM D 946 and D 3381. It exhibits visco-elastic characteristics, thereby requiring heating for it to be sprayed or mixed with aggregate. Once applied to the road surface the heated asphalt cement cools rapidly.

\section{Cutback Asphalt}

Cutback asphalt is asphalt cement "cut" with lower viscosity petroleum products to provide lower viscosity asphalt cement allowing the end product to be mixed or sprayed at lower temperatures compared to asphalt cement. Cutback asphalt, also known as liquid asphalt, meets the requirements of ASTM D 2026, D 2027, or D 2028. The base asphalt cement is typically equivalent to an AC 2.5 or AC 5. Cutbacks are designated as rapid curing (RC), medium curing (MC), or slow curing (SC) based on how quickly the cutback evaporates back to its original asphalt cement properties. The cutter typically used for RC curing is naphtha, for MC kerosene, and No. 2 diesel for SC. In Region 6 cutbacks are commonly used for chip seals and prime coats. ASTM D 2399 provides guidance on selecting the proper cutback.

\section{Asphalt Emulsions}

Asphalt emulsions were developed to lower application temperatures and mitigate cutback asphalt volatiles from evaporating into the atmosphere. Asphalt emulsions are the most common bituminous material used by Region 6 in the construction of seal coat treatments. They are produced by milling hot asphalt cement and creating minute asphalt cement droplets, which are coated with an emulsifying agent and suspended in water. These droplets are either anionic (negatively charged) or cationic (positively charged) based on the emulsifying agent used to coat the asphalt droplets. The asphalt cement droplets stay suspended until they come in contact with a foreign substance, such as aggregate or a pavement surface, at which such time the droplets flocculate and coalesce. As the droplets start to flocculate and coalesce the asphalt emulsion "breaks." In the field this can be observed as the asphalt emulsion turns from chocolate brown to black. As the asphalt cement continues to coalesce, it produces a continuous film of asphalt cement on the aggregate or the pavement (1). Complete coalescence and curing occurs when all the water is evaporated from the emulsion. The emulsifying agent and other chemicals can be used to control the asphalt emulsions break time. The designation used to differentiate between the time for the asphalt emulsion to break are as follows: RS for rapid setting emulsions, MS for medium setting emulsions, SS for slow setting emulsions, and QS for quick setting emulsions. Typical emulsifying agents used are fatty acids (tall oils, rosins, lignins), fatty amines (animal or vegetable), or fatty quaternary ammonium salts. Emulsifying agentss are also referred to as surfactants. 
TABLE 1 Types of Seal Coats

\begin{tabular}{|c|c|c|c|c|c|c|c|c|c|c|c|}
\hline 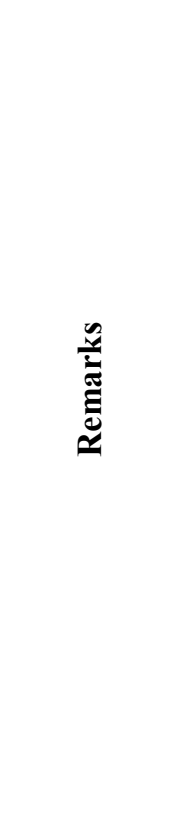 & 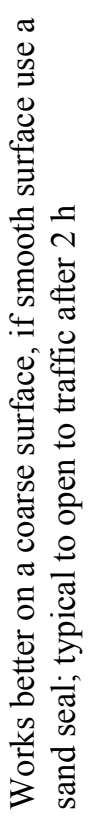 & 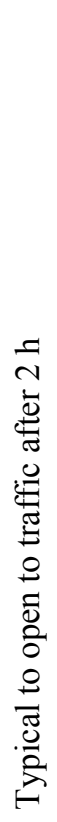 & 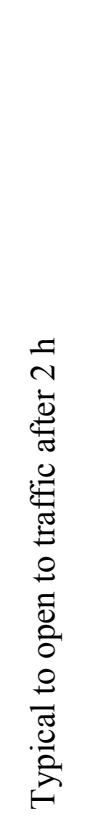 & 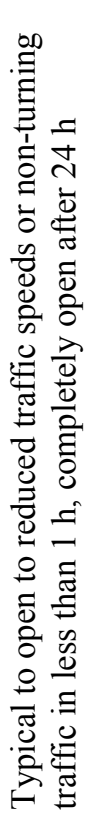 & 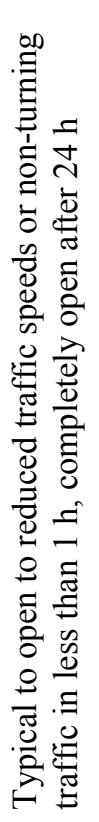 & 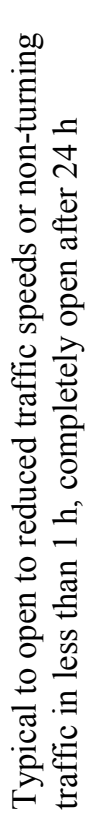 & 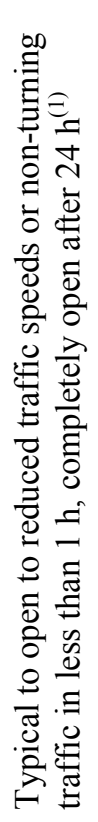 & 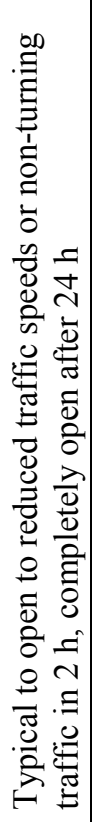 & 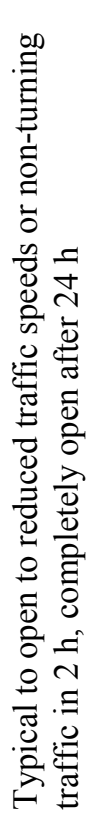 & 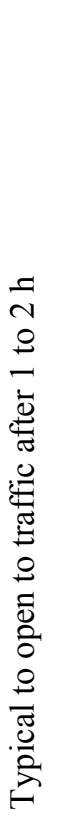 & 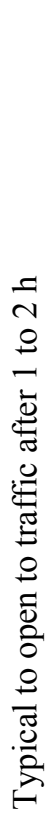 \\
\hline $\begin{array}{l}\text { Improve } \\
\text { Traction }\end{array}$ & $\mid$ & | & | & $x$ & $x$ & $x$ & $x$ & $x$ & $x$ & $x$ & $x$ \\
\hline $\begin{array}{l}\text { Improve } \\
\text { Aesthetics }\end{array}$ & $x$ & | & $x$ & | & $x$ & $\mid$ & $x$ & $x$ & $x$ & $x$ & $x$ \\
\hline Rejuvenate & $\mid$ & $x$ & $x$ & | & | & | & | & | & | & | & | \\
\hline $\begin{array}{l}\text { Replace } \\
\text { Fines }\end{array}$ & | & | & $\mid$ & $\ddot{x}$ & $\ddot{x}$ & $x$ & $x$ & 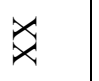 & $x$ & $x$ & $x$ \\
\hline $\begin{array}{l}\text { Prevent } \\
\text { Raveling }\end{array}$ & $x$ & $\ddot{x}$ & $x$ & $x$ & $x$ & $x$ & x & $x$ & $x$ & $x$ & $x$ \\
\hline $\begin{array}{c}\text { Protect } \\
\text { from Spills }\end{array}$ & $\mid$ & | & $\mid$ & $\mid$ & | & | & | & $\ddot{x}$ & $\underset{x}{x} \widetilde{I}$ & | & | \\
\hline $\begin{array}{c}\text { Seal Crack } \\
<1 / 4 \text { in. }\end{array}$ & $x$ & | & $x$ & $x$ & $x$ & $x$ & $x$ & $x$ & | & | & $x$ \\
\hline $\begin{array}{c}\text { Seal } \\
\text { Surface }\end{array}$ & x & | & $x$ & $x$ & $x$ & $\ddot{x}$ & $x$ & $x$ & $x$ & $\ddot{x}$ & $\ddot{x}$ \\
\hline 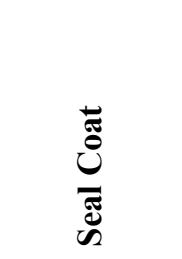 & $\begin{array}{l}0 \\
0 \\
00 \\
0 \\
\end{array}$ & 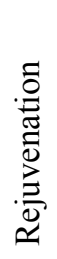 & 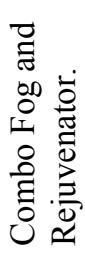 & 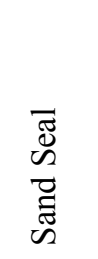 & 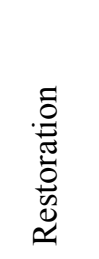 & $\begin{array}{l}\tilde{D} \\
\tilde{0} \\
\vec{Z} \\
\tilde{n}\end{array}$ & 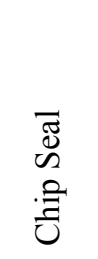 & 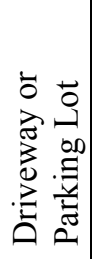 & 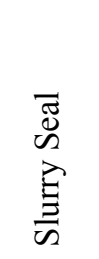 & 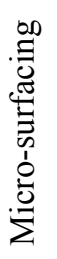 & 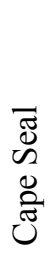 \\
\hline
\end{tabular}


TABLE 2 Seal Coat Details

\begin{tabular}{|c|c|c|c|c|}
\hline \multirow{2}{*}{ Seal Coat } & \multirow{2}{*}{ Major Components } & \multirow{2}{*}{$\begin{array}{c}\text { Typical Seal Coat } \\
\text { Application Rate, } \\
\text { gal/sy (1) }\end{array}$} & \multicolumn{2}{|c|}{ Typical Residual } \\
\hline & & & $\begin{array}{c}\text { Bituminous Material, } \\
\# / \text { sy } \\
\end{array}$ & $\begin{array}{l}\text { Aggregate \& Mineral } \\
\text { Filler, \#/sy }\end{array}$ \\
\hline Fog Seal & One to one mix of slow setting asphalt emulsion and water & $\begin{array}{l}0.08 \text { to } 0.15 \text { of diluted } \\
\text { product }\end{array}$ & 0.20 to 0.37 & NA \\
\hline Rejuvenation Seal & $\begin{array}{l}\text { Two parts modified asphalt emulsion, and wetting agents to one part } \\
\text { water }\end{array}$ & $\begin{array}{l}0.10 \text { to } 0.15 \text { of diluted } \\
\text { product }\end{array}$ & 0.27 to 0.41 & NA \\
\hline $\begin{array}{l}\text { Combination fog } \\
\text { and rejuvenation } \\
\text { Seal }\end{array}$ & $\begin{array}{l}\text { One to one mix of asphalt emulsion (may be modified) and wetting } \\
\text { agents, and water }\end{array}$ & $\begin{array}{l}0.10 \text { to } 0.20 \text { of diluted } \\
\text { product }\end{array}$ & 0.28 to 0.57 & NA \\
\hline Sand Seal & $\begin{array}{l}\text { Rapid or medium setting asphalt emulsion or resin (thermoplastic and } \\
\text { epoxy) and } 1 / 4 \text { in. minus clean sand }\end{array}$ & 0.10 to 0.20 & 0.57 to 1.14 & 10 to 15 of aggregate \\
\hline Restoration Seal & $\begin{array}{l}\text { Asphalt emulsion (may be modified), wetting agents, and water and } \\
1 / 4 \text { in. minus sand }\end{array}$ & 0.15 to 0.30 & 0.41 to 0.81 & 10 to 15 of aggregate \\
\hline Scrub Seal & $\begin{array}{c}\text { Asphalt emulsion, which may include polymer and/or rejuvenator and } \\
\text { one-size sand or aggregate }\end{array}$ & 0.15 to 0.40 & 0.86 to 2.30 & 15 to 25 of aggregate \\
\hline Single Chip Seal & $\begin{array}{l}\text { Rapid or medium setting asphalt emulsion, hot asphalt cement, both } \\
\text { w/ or w/o polymers or cutback and one-size aggregate chips }\end{array}$ & 0.15 to 0.44 & 0.80 to 2.01 & 12 to 35 of aggregate \\
\hline $\begin{array}{l}\text { Multiple Chip } \\
\text { Seal }\end{array}$ & $\begin{array}{l}\text { Single either } 1 / 4 \text {-or } 1 / 2 \text {-in. chips } \\
\text { Double } 1 / 2 " \text { chips followed by } 1 / 4 \text {-in. chips }\end{array}$ & 0.71 to 0.91 & 2.36 to 3.16 & 37 to 53 of aggregate \\
\hline $\begin{array}{l}\text { Driveway and } \\
\text { Parking Lot Seals }\end{array}$ & $\begin{array}{l}\text { Asphalt emulsion (may be modified), wetting agents, and water and } \\
1 / 4 \text { in. minus sand }\end{array}$ & 2 coats each at 0.10 to 0.18 & 0.33 to 0.66 & 1.0 to 2.0 \\
\hline $\begin{array}{l}\text { Type I, II, and III } \\
\text { Slurry Seal }\end{array}$ & $\begin{array}{l}\text { Slow setting asphalt emulsion or coal tar (water or solvent based), } \\
\text { Fine Clean Sand, and fillers, (mineral and/or Carbon Black }\end{array}$ & $\begin{array}{l}\text { I @0 } 0.14 \text { to } 0.33, \text { II @ } 0.16 \text { to } \\
0.47 \text {, and III @ } 0.20 \text { to } 0.63\end{array}$ & $\begin{array}{l}\text { I @ } 0.80 \text { to } 1.9, \text { II @ } 0.90 \text { to } \\
2.7, \text { III @ } 1.17 \text { to } 3.60\end{array}$ & 6 to 20 of aggregate \\
\hline Micro-surfacing & $\begin{array}{l}\text { Quick setting asphalt emulsion, } 1 / 8-\frac{1 / 4}{4} \text {,- or } 3 / 8 \text {-in. well-graded } \\
\text { aggregate, and }\end{array}$ & $\begin{array}{l}\text { Type II @ } 10 \text { to } 20 \# / \text { sy } \\
\text { Type III @ } 15 \text { to } 30 \# / \text { sy }\end{array}$ & $\begin{array}{l}\text { Type I@ } 0.35 \text { to } 1.35 \\
\text { Type III @ } 0.69 \text { to } 2.00\end{array}$ & $\begin{array}{l}\text { Type II @ } 10 \text { to } 20 \\
\text { Type III @ } 15 \text { to } 30\end{array}$ \\
\hline Cape Seal & $\begin{array}{l}\text { Modified quick setting asphalt emulsion, graded aggregate, and filler, } \\
\text { min. of } 3 \% \text { polymer by weight of bitumen }\end{array}$ & NA & 2.51 to 4.71 & 37 to 55 of aggregate \\
\hline
\end{tabular}

(1) Application rates are based on using asphalt emulsions with a residual asphalt cement content between 65 to 70 percent. Use the higher application rates for porous or coarse textured surfaces and the lower application rate for flush or tight textured surfaces. 
Asphalt emulsions are also designated by the particle charge that coats the droplets of asphalt cement. A cationic emulsion, noted by the letter " $\mathrm{C}$ " in front of its designation, holds a positive electrical charge and an anionic emulsion holds a negative charge. The electrical charge of the aggregate should have the opposite charge of the asphalt emulsion; this ensures a strong bond between the aggregate and asphalt emulsion.

Asphalt emulsions meet the requirements of ASTM D 977 and D 2397 with the base bituminous product for most asphalt emulsions an AC-5 or AC-10. If the letter " $h$ " is at the end of the designation then the base asphalt cement is typically an $\mathrm{AC}-10$ or $\mathrm{AC}-20$ which provides a more viscous (stiffer/harder) seal coat.

Another asphalt emulsion used by the USDA-FS is the "high float" emulsion. High floats are anionic and are more applicable to use on dusty aggregate (2). These emulsions produce a gel structure in the residual asphalt cement making the emulsion less susceptible to flowing at high temperature conditions. This allows the emulsion to be used successfully on grades and to reduce bleeding at high temperatures.

Another type of asphalt emulsion used by the USDA-FS is a low-temperature asphalt emulsion. These emulsions are anionic polymer modified, which are formulated to quickly adhere to the aggregate prior to evaporation of the water in the emulsion by means of a chemical reaction rather than evaporation. They can be applied in temperatures as low as $40^{\circ} \mathrm{F}$, but should not be applied once temperatures rise above $80^{\circ} \mathrm{F}$. For the emulsion to completely coalesce, the water needs to evaporate. Therefore, it is important to ensure that at some point, soon after application, that climatic conditions are conducive for the water to evaporate.

It is important to select the proper type and grade of asphalt emulsion to use for the particular seal (1). ASTM D 3628 and the Asphalt Institute publication A Basic Asphalt Emulsion Manual, 3rd Edition can provide guidance in selecting the appropriate asphalt emulsion.

\section{Coal Tar Emulsions}

Coal tar emulsions are also used for seal coats, but commonly used only when the purpose is to protect the surface from occasional spillage of car or airplane fuel. The fuel can penetrate and degrade the underlying asphalt surface. Coal tar is a by-product of the high temperature treatment of coal to make metallurgical coke or natural gas (3). The coal tar is then emulsified to meet the requirements of ASTM D 5727. Coal tar pitch is produced from coal tar by distillation. USDA-FS use of coal tar emulsions has been limited to air tanker loading areas.

\section{Polymers}

The addition of polymers in asphalt cement, asphalt emulsion, and coal tar emulsion typically increases the early stiffness of the seal coat which leads to improved retention of the aggregate used to cover the bituminous material (4). In addition, a polymer increases the flexibility/elasticity of the seal coat in cold climates and reduces bleeding and flushing during periods of high pavement temperature.

What are polymers? Polymers are long chains of the same molecule (monomers) strung together much like a set of pearls on a necklace. If different molecules are strung together in a chain, like an alternating diamond and pearl necklace, the combination is termed a copolymer. If one chemically links the polymer chains side-by-side create a cross-linked polymer. 
Polymers can be grouped into three broad categories, fibers, elastomers, and plastomers (5). Not all fibers are polymers and fibers are not typically used in seal coat treatments but can be found in asphalt concrete or portland cement concrete (PCC). Examples of natural polymer fibers include cotton, wool, cellulose, silk, and starch and synthetic polymer fibers include nylon, polyester, rayon, and acrylic. Elastomers and plastomers are commonly used as seal coat polymer additives.

Elastomers provide resiliency and flexibility characteristics and are able to return to their original shape after being stretched or compressed. Typical elastomers include natural rubber, natural latex (latex is a term used for any natural or synthetic rubber that is emulsified), crumb rubber, styrene butadiene rubber, and styrene butadiene styrene. Plastomers provide stiffness characteristics and soften with increasing temperature but as the material temperature cool they regain their stiffness. Typical plastomers include ethylene acetate, polyethylene, various compounds of polypropylene, polyethylene vinyl acetate, and ethylene-methyl acrylate.

Polymers oxidize (age thus degrade) at various different rates, but most polymers used in bituminous materials oxidize at a slower rate than asphalt cement.

The AASHTO specification M-316 lists requirements for polymer modified asphalt emulsions. Their CRS-2P requires that a minimum of $2.5 \%$ of the residue be a styrene butadiene or a SBS polymer and their CRS-2L emulsion include in the residue a minimum of $2.5 \% \mathrm{SBR}$ or polychloroprene latex polymer.

\section{Rejuvenators}

Asphalt cement consists of two main fractions, asphaltenes and maltenes ( 6 ). The asphaltenes are the components that provide the hardness found in asphalt cement. Maltenes are the components that contribute to the adhesion and ductility of asphalt cement and include oils and resins. As the asphalt cement oxidizes, the maltene compounds "evaporate," which results in a reduction of the asphalt cements ability to adhere to the aggregate and flex with traffic and temperature. Asphalt rejuvenators restore the maltenes compounds back to the asphalt cement as they penetrate into the underlying surface.

Typical rejuvenation products are coal tar oil, tall oil, lignin, and maltene rich asphalt emulsions or oils that are close in composition to the asphalt maltenes (7). For a product to claim that it can rejuvenate the surface, the product has to have one of the above mentioned rejuvenation components and the ability to penetrate or migrate into the underlying surface.

\section{Aggregate}

Aggregate used in all seal coat application should be angular, polish resistant, clean, hard, durable, and free of clay and other objectionable material to develop a skid-resistant surface (1). Sand is aggregate typically smaller than $1 / 4$ in. If the sand is one sized it may be referred to as a "choke." Chips refer to one-sized aggregate, typically larger than $1 / 4 \mathrm{in}$. Chip seal aggregate should not include flat or elongated particles.

\section{Mineral Filler}

Mineral filler includes, but is not limited to, limestone dust, hydrated lime, PCC, carbon black, and fly ash. Expansive clays are sometimes used as fillers and they help in reducing the tackiness of the 
bituminous emulsion and provide a uniform distribution of the seal coat but they may cause drying and shrinkage cracks if the mixture incorporates too much clay.

\section{Gilsonite}

Gilsonite is a natural black resinous hydrocarbon substance similar to the mineral obsidian $(8)$ and is high in asphaltenes. It can be blended with asphalt cement, which increases the viscosity of the resulting binder. It can also be blended with a rejuvenating agent to provide a multipurpose seal coat.

\section{TYPES OF SEAL COAT TREATMENTS}

Seal coats can be grouped into four basic treatments; bituminous sprays, bituminous sprays followed by an application of cover aggregate, cold bituminous mixtures, and hot bituminous mixtures.

\section{Bituminous Sprays}

\section{Fog Seal}

A fog seal is an application of asphalt emulsion diluted to the proper consistency in order to get complete coverage on the roadway and applied by an asphalt emulsion distributor truck (9). The typical dilution ratio is one part asphalt emulsion to one part water. The most common asphalt emulsions used are SS-1, SS-1h, CSS-1, and CSS-1h. Polymers are not commonly used with fog seals since the addition of polymers would not help improve or extend the life of the fog seal.

\section{Rejuvenation}

A rejuvenation seal is an application of modified asphalt emulsion diluted to the proper consistency in order to get complete coverage on the roadway and applied by an asphalt emulsion distributor truck (9). The typical dilution ratio is one to two parts modified asphalt emulsion to one part water. A wetting agent or surfactant is also added to allow penetration of the rejuvenator into the pavement and the fine ( $<1 / 4$ in wide) cracks prior to the break of the asphalt emulsion. The asphalt emulsion is modified for use as a rejuvenator to reduce the amount of asphaltenes and increase the maltenes fraction, providing a maltene rich emulsion. An asphalt emulsion can also be blended with any of the previously mentioned rejuvenation products to create a rejuvenation seal.

Polymers are not commonly used with rejuvenators since the addition of polymers would not help improve or extend the life of the rejuvenator, in fact, the use of polymers may impede the penetration of the product into the pavement surface.

\section{Combination Fog and Rejuvenation Seal}

Some products combine an asphalt emulsion and a rejuvenation agent to create a combination seal. These seal coats are diluted to the proper consistency in order to get complete coverage on the roadway and applied by an asphalt emulsion distributor truck.

Polymers are not commonly used with combination seals since the addition of polymers would not help improve or extend the life of the seal. 


\section{Bituminous Sprays Followed by Application of Aggregate}

\section{Sand Seal}

A sand seal is an application of asphalt emulsion applied by an asphalt emulsion distributor truck followed by a uniform cover application of clean sand. A pneumatic tired roller is often used after applying the sand. Excess sand is removed from the road after rolling. The asphalt emulsion may be modified with a polymer.

\section{Restoration Seal}

A restoration seal combines an asphalt emulsion with a rejuvenating agent and applied by an asphalt emulsion distributor truck. The emulsion is immediately covered with clean sand using a sanding truck. The bituminous material may be modified with a polymer and the emulsion may be scrubbed as noted below for a scrub seal.

\section{Scrub Seal}

A scrub seal is a sprayed application of polymer modified asphalt emulsion, applied by an asphalt emulsion distributor truck, followed by brooming (scrubbing). An application of clean sand is then applied which also may be broomed prior to rolling. Aggregate larger than sand can also be used but then it wouldn't be broomed. A pneumatic tired roller is then used to embed the sand into the bituminous material and the cracks. The brooming process helps to force the emulsion into some of the cracks. The broom is typically a $12-\mathrm{ft}$ wide by 8 - $\mathrm{ft}$ long frame with diagonal bracing that has stiff brooms attached to the bottom of the cross members of the frame. The scrubbing can also be accomplished with a squeegee drawn behind the asphalt distributor. A scrub seal commonly only fills cracks larger than $1 / 8$ in. width. Rejuvenation products can be added to the asphalt emulsion to help rejuvenate the underlying pavement.

Polymers can also be added to the asphalt emulsion to improve chip retention and help seal the cracks in the underlying pavement.

\section{Chip Seal}

A chip seal is an application of bituminous material applied by an asphalt emulsion distributor truck immediately followed by a uniform cover of aggregate (chips). Typical bituminous materials are hot asphalt cement, cutback asphalt (MC-250 or MC-800), emulsified asphalt cement (RS-2 or CRS-2), or modified asphalt emulsions. Polymers and melted crumb rubber are sometimes added to the bituminous material to improve aggregate retention, reducing windshield damage, or improving retention in areas shaded by trees or buildings. A pneumatic tired roller is used immediately after applying the aggregate to embed the aggregate into the bituminous material. Excess aggregate is removed from the road after rolling.

Multiple layers of chip seal can be applied with each successive layers using smaller aggregate, typically half the size of the preceding layer. The total thickness ends up about the same size as the maximum aggregate of the first course. Using successive smaller aggregate allows the chips to interlock thus minimizing chip loss and providing a smoother surface. A twolayer chip seal is called a double chip seal and a three-layer chip seal is called a triple chip seal. 
Excellent guidance in the design and construction of chip seals can be found in the following publications:

- ASTM D-1369 and D-5360.

- A Recommended Performance Guideline for Single and Multiple Chip Seals Using Asphalt Emulsion. Asphalt Emulsion Manufacturers Association, unknown date.

- A Basic Asphalt Emulsion Manual, 1st and 3rd edition. Asphalt Institute.

- Surface Treatment Manual. Chevron, 1985

- Minnesota Seal Coat Handbook. Minnesota State Department of Transportation, 1998.

- Asphalt Seal Coats. Washington State Department of Transportation, March 2003.

Region 6 has adopted the McLeod chip seal design method found in Asphalt Institute's $A$ Basic Asphalt Emulsion Manual 1st Edition and found that it calculates the aggregate application rates fairly accurately, but the calculated asphalt emulsion application rate needs to be increased by $5 \%$ to $8 \%$ to adequately embed the chips.

Various modifications from the standard chip seal have recently developed. The scrub seal is one modification and is addressed above. Another is a sandwich seal where the aggregate goes down first followed by the bituminous emulsion, and then followed by another layer of aggregate $1 / 2$ to $1 / 3$ the maximum size of the first aggregate. The surface is then rolled with a pneumatic tired roller. An inverted seal is the same as a double chip seal but the smaller aggregate is placed underneath the larger aggregate (10).

The placement of geotextiles saturated with asphalt emulsion prior to placing the chip seal is another chip seal modification and used more as a corrective measure than a PM seal (11). The geotextile is placed to help seal and prevent the migration of pavement cracks up through the chip seal. Rubber modified emulsions have also been used successfully to seal and prevent cracks migrating through the chip seal (12). The rubber modified emulsion may consist of up to $20 \%$ crumb rubber.

\section{Cold Bituminous Mixtures}

\section{Driveway and Parking Lot Seals}

These seals are commonly a mixture of asphalt emulsion, sand, mineral fillers and water. The sand is one-size, with the maximum size between the No. 20 Sieve (1/30 in.) and No 70 Sieve (1/120 in.). Many propriety products are available that meet this seal coat description. The product come concentrated thus requiring dilution prior to application at either one or two parts concentrate to one part water. The product can also come "ready mixed" requiring $15 \%$ to $30 \%$ water added prior to application. Some products are applied in one coat and others in two coats. Not all products are the same so follow the manufacturers mixing and application recommendations.

For most of these seal coats the amount of sand on the finished grade is typical of the sand observed on sandpaper of the equivalent size sand, i.e., a seal coat using No. 20 Sieve material would have the same concentration of sand as No. 20 grit sandpaper.

The Asphalt Sealcoat Manufacturers Association has recommended specifications for these asphalt emulsion based seal coats. 
For coal tar emulsions there are three ASTM standard specifications for coal tar emulsion mixtures:

- ASTM D 6945 addresses two "ready to use mixtures" for commercial lots and other low-speed pavement sealers; Type I (mixture of coat tar emulsion, aggregate and water) or Type II (a mixture of coal tar emulsion aggregate, water, and additives; the aggregate is either a coarse-graded sand (a clean No. 20 Sieve minus sand), a medium-graded sand (a clean No. 30 minus sand), or a fine-graded sand (a clean No. 40 minus sand).

- ASTM D 6946 addresses two "ready to use mixtures" for homeowner driveway sealers; Type I (mixture of coal tar emulsion, water, and additives) or Type II (a mixture of coal tar emulsion, water, clean medium-graded sand, and additives).

- ASTM D 3423 addresses coal tar pitch emulsions and is a mixture of coal tar pitch emulsion, clean medium-graded sand, and mineral filler.

Coal tar pitch emulsions are not diluted with water prior to application. ASTM D 4866 outlines the desired properties of a coal tar emulsion mixture when polymer additives are included in the mixture.

\section{Slurry Seal}

A slurry seal is a uniform application of slow setting or modified slow setting (quick setting) asphalt emulsion, fine graded aggregate, mineral filler, additives, and water. The fine-graded aggregate is smaller than $1 / 8,1 / 4$, or $3 / 8$ in. representing a Type I, II, or III slurry seal respectively. The ingredients are mixed on site in a self-contained truck and typically spread using a specially designed spreader drag box with a rubber strike-off blade for a uniform application. The product can also be applied using a squeegee. Typical thickness of the slurry is approximately 1 to $1 \frac{1 / 2}{2}$ times the maximum sized aggregate. If the area is exposed to a high number of vehicle turning forces or if traffic is not soon released to the sealed surface on a Type II or Type III slurry seal then a pneumatic tired roller is suggested to help embed the aggregate. Rolling should occur after the slurry cures enough to prevent pick-up of the slurry on the roller's tires.

Perform a mix design according to ASTM D-3910 of the asphalt emulsion, aggregate, additives, and water to ensure proper consistency, set time (initial set time), cure time (time to obtain cohesion between the emulsion and the aggregate), resistance to stripping, and resistance to abrasion. Typical additives used with slurry seal emulsions include PCC or aluminum sulfate, which are used to retard asphalt emulsion break during mixing with the aggregate.

\section{Microsurfacing}

Microsurfacing is similar to a slurry seal but allows a thicker layer to be placed and cures faster than a slurry seal. Polymer modified slow setting asphalt emulsions are commonly used. Specialized mixing techniques and an application truck are required to apply microsurfacing. Microsurfacing can also be used to correct minor surface deformities and has also been used to fill and level ruts up to $1.5 \mathrm{in}$. in depth if a specialty spreader box is used during placement.

Typical mineral fillers in micro-surfacing include PCC or hydrated lime. Perform a mix design of the asphalt emulsion, aggregate, additives, and water to ensure proper consistency, set time, cure time, resistance to stripping, and the resistance to abrasion. 


\section{Cape Seal}

A cape seal is a single-layer chip seal followed by a slurry seal after the chip seal cures. This seal combination provides a longer life compared to each individual seal and stops chip loss due to traffic.

\section{Hot Bituminous Mixtures}

\section{Ultra Thin-Lift Overlays}

Ultra-thin overlays can be a dense-graded hot mix, open-graded friction course hot mix, a sand hot mix using a polymer-modified asphalt cement, or a stone-matrix hot mix (13). Some propriety mixes are placed with a specially built machine that place an asphalt emulsion membrane and then a $1 / 2$ - to $3 / 4$-in. thick gap-graded hot mix filled with asphalt mastic of sand, filler, and asphalt binder.

\section{RECOMMENDATION ON USE AND CONSTRUCTION OF SEAL COAT TREATMENTS}

Table 3 provides a general guide on the cost, limitations, and expected life of the most common seal coat treatments based on various references and Region 6 projects. Residual bitumen refers to the bitumen left after the evaporation of water in the emulsion. Table 3 can be used in conjunction with Table 1 to help determine the desired seal coat based on the purpose and economic analysis of the present and future costs expected with a seal coat preventative maintenance treatment plan.

\section{General Seal Coat Use and Construction Tips}

- The expected life of a seal coat treatment is a function of the type and quality of seal coat, the structural condition of the underlying pavement, and the type of traffic. More bitumen and aggregate used in the seal and the use of polymers equate to a longer lasting seal coat. Pavements with structural defects or increasing traffic, especially trucks, equate to a shorter seal life.

- Ensure that any future striping and pavement markings are compatible with the selected seal coat treatment.

- Provide clean surfaces prior to seal coat operations. Remove any debris, grass, sod, and dust prior to applying the seal coat treatment.

- If the product or seal coat treatment does not have a local track record, determine the success rate of the product or seal coat in similar climatic and traffic conditions. In addition, obtain a seal coat job mix formula.

- Consider using polymer modified emulsions when seal coating facilities handling more than 500 average daily traffic. Successful seal coat treatments in high traffic facilities require quality aggregate, good construction practices, and designed seal coat mixtures and application rates. 
TABLE 3 Seal Coat Costs, Limitations, and Longevity

\begin{tabular}{|c|c|c|c|c|}
\hline \multirow{2}{*}{ Seal Coat } & \multirow{2}{*}{ Cost, $\$ / \mathbf{s y}{ }^{(1)}$} & \multirow{2}{*}{ Limitations } & \multicolumn{2}{|c|}{ Expected Longevity ${ }^{(2)}$, years } \\
\hline & & & $<100 \mathrm{ADT}$ & 100 to $500 \mathrm{ADT}$ \\
\hline Fog Seal & 0.15 to 0.45 & $\begin{array}{l}\text { May cause temporary reduction in traction until asphalt } \\
\text { wears from the top of the aggregate }\end{array}$ & 2 to 4 & 1 to 3 \\
\hline Rejuvenation Seal & 0.45 to 0.65 & Does not seal the surface & 1 to 4 & 1 to 2 \\
\hline Combination fog and Rejuvenation & 0.50 to 0.65 & $\begin{array}{l}\text { May cause temporary reduction in traction until asphalt } \\
\text { wears from the top of the aggregate }\end{array}$ & 1 to 4 & 1 to 2 \\
\hline Sand Seal & 0.75 to 0.95 & & 2 to 4 & 1 to 5 \\
\hline Restoration Seal & 0.60 to 0.75 & & 2 to 4 & 1 to 3 \\
\hline Scrub Seal & 0.60 to 1.30 & Need uniform surface texture & 2 to 8 & 2 to 6 \\
\hline Single Chip Seal & 1.20 to 1.50 & Need uniform surface texture & 4 to 12 & 3 to 6 \\
\hline Multiple Chip Seal & 1.85 to 2.50 & Need uniform surface texture & 5 to 15 & 5 to 7 \\
\hline Driveway and parking lot Seals & 0.75 to 1.50 & & 4 to 6 & 2 to 3 \\
\hline Slurry Seal & 0.75 to 1.50 & $\begin{array}{l}\text { Depending on the additives used it may not effectively } \\
\text { seal cracks, portland cement tends to stiffen the mixture }\end{array}$ & 5 to 10 & 5 to 8 \\
\hline Micro-surfacing & 0.95 to 1.85 & & 8 to 15 & 6 to 8 \\
\hline Cape Seal & 1.75 to 2.50 & & 8 to 15 & 6 to 8 \\
\hline
\end{tabular}

(1) See Yamada (9) and Hansen (13). Note that cost vary considerably based on availability of materials, project locality, size of project, and availability of local contractors. Also the use of polymer modified emulsions will increase the cost if not included as part of the normal seal coat materials, typically about 30\% more than non-modified emulsions (16).

(2) Areas with a large amount of wheel twisting and turning will have a lower life expectancy; the use of polymers or a thicker seal coat will negate this reduction of life. 


\section{Rejuvenators}

Application rates for rejuvenation products are a function of the surface profile, the amount of pavement deterioration, and porosity of the surface. It is recommended to perform small test patches and determine the application rate based on the amount of rejuvenator that penetrates into the surface in $45 \mathrm{~min}$.

\section{Chip Seals}

The key ingredients in a successful chip seal are:

- Adherence of the seal coat to underlying layer.

- Use a one-size chip placed one-chip thick.

- Apply sufficient asphalt to hold and embed the chips.

- Test for compatibility between the asphalt and chips.

- Use damp chips when using asphalt emulsions.

- Use equipment that will apply a uniform application of asphalt and chips.

- Place during favorable climatic conditions.

- Promptly roll the chips into the asphalt.

- Limit vehicle speed immediately after construction.

- Remove excess chips soon after construction.

To properly hold the aggregate, at least $60 \%$ to $70 \%$ of the chip must be embedded in residual asphalt after the traffic has compacted and aligned the aggregate into its densest most compacted state. Proper embedment is based on either the average chip size or the average least dimension (ALD) of the chips. For instance, if an asphalt emuslion is used, the embedment before any water is evaporated, is $70 \%$ to about $100 \%$ of the average chip size or the ALD. Note that the surface texture plays a role in the amount of asphalt cement needed to hold the chip. If the pavement has a coarse texture, the asphalt cement will need to fill the pavement voids before any of it is available to hold the chips. Likewise a flush pavement will allow all of the asphalt cement to be available to embed the chip. The emulsion application rate should be adjusted for pavement texture as noted in all of the chip seal design guides. Traffic plays a role in the amount of embedment as well, the lower embedment recommendations are typically used for higher traffic volumes (1).

Conditions are never ideal for chip sealing due to road geometery, traffic, weather, variation in surface texture, or some other factor so adjustments need to be made to ensure a good chip seal. Table 4 lists some typical road or construction scenarios and potential resolutions to these scenarios that the USDA-FS has found successful in the past.

More cover aggregate is not better, even if one believes it is needed to act as a blotter. Excess aggregate will prevent the chips from seating into the emulsion during rolling and dislodge any properly embedded aggregate once exposed to traffic prior to brooming.

In the addition to using polymers, three techniques have been used successfully to mitigate early chip loss due to traffic. They include placing a fog seal, pre-coating the aggregate, or placing a clean choke just after the first roller. The fog seal also provides an aesthetic looking surface. Pre-coating the aggregate typically involves mixing $0.5 \%$ to $1.0 \%$ residual asphalt 
cement with the aggregate in a hot-mix plant. The use of a choke (typically a No. 4 or No. 8 maximum size) is also known as a racked-in seal.

Design aids for the construction of chip seals in high traffic areas in addition to the information found in the design guides previously mentioned include:

- The Sweep Test (ASTM D-7000).

- The Vialit Test (California State Department of Transportation. Vialit Test for Aggregate Retention in Chip Seals).

- The Texas State Department of Transportation new testing protocol for seal coats

- The Sand Patch Method (ASTM E 965) used for determining the macrotexture of the existing surface.

- NCHRP Synthesis of Highway Practice 342: Chip Seal Best Practices

recommendations for contract administration and construction.

\section{Driveway and Parking Lot Seals}

When using these seals it is important to:

- Properly select and design the seal coat materials, if not a "ready mixed" product.

- Use quality construction practices for all seal coats to ensure an improved pavement surface (15).

Most manufacturers recommend placing two thin lifts instead of one thick lift. This allows the seal to cure quicker. When placing these types of seal coats follow the manufacturer's recommendations in terms of the amount of water and additional sand per gallon and the spread rate and number of coats. Adding more sand than suggested by the manufacturer is not recommended. Too much aggregate may result in poor adhesion, reduce the spill resistant characteristics of the seal coat, reduce the flexibility of the seal coat (18) and provide poor coverage since the excess sand will not stay in suspension during application. Adding more water than necessary will shorten the life of the seal coat and will not help the seal penetrate any deeper into the underlying pavement cracks.

Some manufacturers provide two or more seal products rating them good, better, or best. Increasing rating or quality generally includes the addition of polymers, more bitumen than clay filler, and larger-sized sand, i.e., 20 Grit versus 70 Grit sand.

If the facility will experience an abnormal amount of tire twisting and turning, especially in warm climates, consider the use of polymers, the use of a harder base asphalt cement (CSS- $1 \mathrm{~h}$ instead of CSS-1), or larger-sized sand. The addition of larger-sized sand makes the seal more durable and adds skid resistance to the surface.

The use of fine-graded sand may not increase traction in areas with high vehicle speeds. This happens since there really isn't any exposed aggregate available to grip the tires for traction and the surface's macrotexture does not allow water to rapidly drain. A drained surface with good aggregate exposure improves the contact between the tire and the pavement. 
TABLE 4 Chip Seal Design Scenarios and Their Resolution

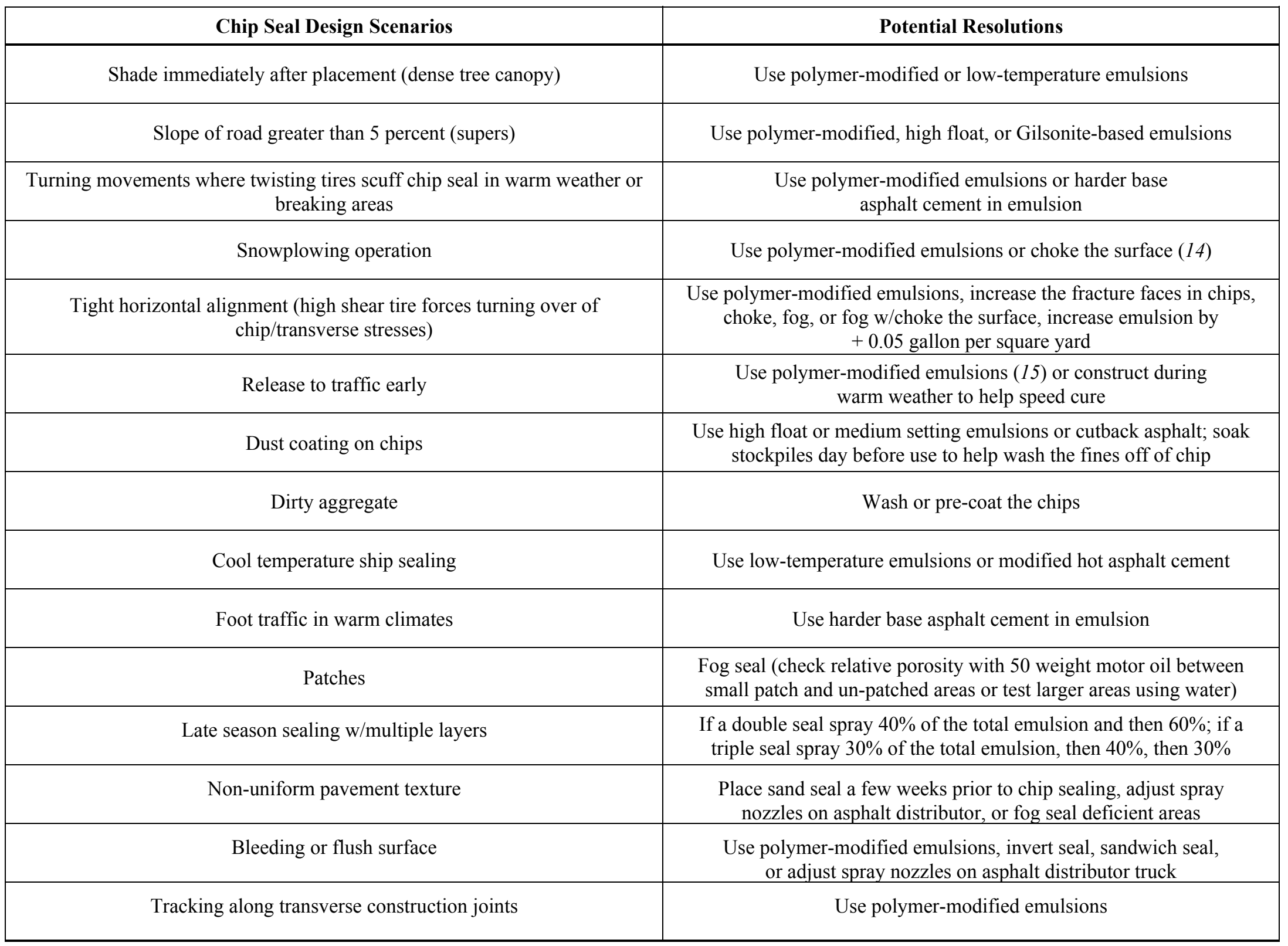


Therefore, fine aggregate cover or a fine aggregate mixture is commonly used only for trails, driveways, or other facilities with low traffic speeds. For higher traction requirements a slurry seal is suggested instead of a driveway or parking lot seal coat.

Some potential problems exist with the use of coal tar-based emulsions. Coal tar seal coats are reported to lower the skid resistance of pavement areas when wet. Therefore, it is generally suggested not using coal tar-based emulsions on streets, taxiways, runways or areas where traction is required.

Other concerns include the potential incompatibility between certain asphalts and the shrinkage and brittleness of the coal tar coating. Coal tars tend to dry, shrink, and crack with time with the resulting surface exhibiting a small chicken wire pattern. Chipping may even develop as the coal tar goes through various wet/dry or freeze/thaw cycles. Placing another coal tar emulsion seal coat the following year or providing a mix of coal tar and asphalt cement in the emulsion tends to mitigate this concern.

In lieu of using a coal tar emulsion based seal coat to protect against spills, another alternative is to apply multiple layers of asphalt emulsion based seal coats or apply more frequent asphalt emulsion based seal coats, which, will act as a sacrificial layer to the spills.

\section{SUMMARY}

The Pacific Northwest Region of the USDA-FS has applied many seal coat treatments and has found that successful seal coats can be applied if the components are understood, treatments are applied to the appropriate surface, and if proper construction methods are followed. To assist facility managers in their seal coat treatment selection process the basic components were addressed for each seal coat treatment as well as their recommended locations of use, application rates, and special construction considerations.

\section{ACKNOWLEDGMENTS}

Thanks to those who reviewed this paper and for their support throughout the years by answering my many questions. They include Jim Brownridge, Dave Goglin, Gary Hicks, Steve Monlux, Mark Truebe, Sandra Wilson Musser, and Dave Zillman.

\section{REFERENCES}

1. A Basic Asphalt Emulsion Manual (3rd Edition). Manual Series (MS) No. 19, Asphalt Institute.

2. Janisch, D. W., and F. S. Gaillard. Minnesota Seal Coat Handbook. Minnesota Department of Transportation, April 1998.

3. Creosote Chemical Backgrounder. National Safety Council. Available at www.nsc.org/library/chemical/ Creosote.htm. Accessed May 15, 2005.

4. Holleran, G. A Good Emulsion Made Better. Valley Slurry Seal, Inc., August 1998. Available at www.slurry.com/articles/articles_goodemul_0898.shtml. Accessed May 13, 2005.

5. Application of Polymers. Case Western Reserve University Polymer and Liquid Crystal Virtual Laboratory. Available at www.plc.cwru.edu/tutorial/enhanced/files/polymers/apps/apps/htm. Accessed May 13, 2005.

6. The Reclamite Manual for Asphalt Rejuvenation. Witco Chemical-Golden Bear Division. Unknown published date but pre 1990. 
7. Holleran, G., and J. Reed. Asphalt Emulsions-Definition, Manufacture and Useage. Valley Slurry Seal Company. Available at www.slurry.com/techpapers/techpapers_emulsion96mexico.shtml. Accessed May 21, 2005.

8. What is Gilsonite? Ziegler Chemical \& Mineral Corporation. Available at www.pioneerasphalt.com/gilsonit.htm. Accessed May 21, 2005.

9. Yamada, A. Asphalt Seal Coat Treatments. United Stated Department of Agriculture, Forest Service, Technology and Development Program, April 1999.

10. Gransberg, D., and D. M. B. James. NCHRP Synthesis of Highway Practice 342: Chip Seal Best Practices. Transportation Research Board of the National Academies, Washington D.C., 2005.

11. Davis, L. Chipsealing Over Fabric. GFR. June/July 2003, pp. 28-31.

12. Van Kirk, J. Maintenance and Rehabilitation Strategies Utilizing Asphalt Rubber Chip Seals. Valley Slurry Seal Company. Available at www.slurry.com/techpapers_astrategy.shtml. Accessed May 21, 2005.

13. Hansen, K. Pavement Preservation with Thin Overlays. In Better Roads, Vol. 73, No. 6, June 2003, pp. 48-50.

14. Hicks, R. G., S. B. Seed, and D. G. Peshkin. Selecting a Preventative Maintenance Treatment for Flexible Pavements. Prepared for the Foundation for Pavement Preservation, Washington, D.C., June 2000.

15. Jahren, C. T., and K. R. Behling. Comparative Study of Thin Maintenance Surface Treatments (CD-ROM). Presented at the 83rd Annual Meeting of the Transportation Research Board, Washington D.C., 2004

16. Kuennen, T. Polymers Add Performance to Asphalt Emulsions. In Better Roads, Vol. 74, No. 11, November 2004, pp. 28-37.

17. Yazgan, B., and S. Senadheera. A New Testing Protocol for Seal Coat (Chip Seal) Material Selection (CDROM). Presented at the 83rd Annual Meeting of the Transportation Research Board, Washington, D.C., 2004

18. Dubey, G. Hazards of Altering Sealer Mix Designs. In Pavement Magazine, January 1998.

19. O'Leary, B. Type of Treatment, Road, and Timing Affect Pavement Maintenance Management. Federal Highway Pavement Preservation Compendium. Available at www.fhwa.dot/preservation/ppc0309.cfm. Accessed May 21, 2005. 


\title{
Chip Sealing over Fabric in Borrego Springs, California
}

\author{
LITA DAVIS \\ County of San Diego, California
}

This paper will discuss the County of San Diego's practice of placing pavement reinforcing fabric, followed by chip sealing and fog sealing, on roads located in the county's desert area of Borrego Springs, California. Due to extreme desert temperature variations and exposure to flash floods, surface cracks on the asphalt road surface are a routine occurrence, and crack sealing is a constant road maintenance issue. The cost to seal the numerous surface cracks reduces the funds needed to apply a surface treatment to the entire road surface. In 1987, the county conducted a study of placing various surface treatments on desert roads to determine which address surface cracks and also seal the entire road surface. It was found that placing pavement reinforcing fabric, immediately prior to placing a chip seal, prevented surface cracks from reflecting through the new road surface treatment, and prevented moisture from penetrating into the pavement and underlying base. It was also discovered that considerable savings were experienced by not having to crack seal before or after the placement of the pavement reinforcing fabric. This paper will address the placement of pavement reinforcing fabric, in conjunction with chip sealing and fog sealing, via contracts awarded to private construction firms on a competitive bid basis. Life-cycle cost analysis will also be addressed.

$\mathrm{T}$

he County of San Diego's Department of Public Works has found chip sealing over pavement reinforcing fabric (fabric) as a cost-effective method of preventive maintenance (PM) for roads in the desert area of San Diego County. This method is done to eliminate the need to crack seal the thermal cracked bituminous surface, prevent premature aging of the roadway, and to extend the life of the roadway.

Chip sealing is a surface treatment, which consists of the application of a polymermodified asphaltic emulsion and crushed aggregate (chips), used to seal the bituminous road surface. The emulsion seals the bituminous road surface and prevents oxidation and moisture penetration into the road surface and underlying base, which are known to cause potholes and accelerate deterioration of the roadway. The crushed aggregate provides an improved surface friction course (skid resistance) and an all-weather wearing surface.

The county is responsible for maintaining approximately 1,900 centerline miles $(3,065$ centerline kilometers) of public roads. To maintain the roads with the limited funds available, the county has taken an active role in developing a PM program, in lieu of allowing roads to deteriorate at a faster rate and require repairs at a higher cost.

The Borrego Springs surface treatment construction contracts are performed by private construction firms, via competitive bidding, and range in value from $\$ 0.5$ to $\$ 1.5$ million dollars. Private contractors are required to provide traffic control, materials testing, and placement of all materials (fabric binder, fabric, sand, chip seal, fog seal, and pavement markers). County forces replace the traffic striping and pavement marking. 


\section{PROJECT INFORMATION}

\section{Where Is the County of San Diego?}

The County of San Diego is located in the southwest corner of the continental United States and the State of California. The county's geographical terrain consists of coastal lands, inland valleys, mountain ranges, and desert regions. Elevations throughout the county, including the desert region of Borrego Springs, range from mean sea level to approximately $6,000 \mathrm{ft}(1,830 \mathrm{~m})$.

\section{Where Is Borrego Springs?}

Borrego Springs is located in the northeast quadrant of San Diego County. This desert community is bordered by mountain ranges to the north, south, and west, and desert valleys in the middle and to the east.

Borrego Springs is exposed to hot temperatures in the summer and freezing temperatures in the winter. Summer temperatures can reach $135^{\circ} \mathrm{F}\left(57^{\circ} \mathrm{C}\right)$, with pavement temperatures of $185^{\circ} \mathrm{F}\left(85^{\circ} \mathrm{C}\right)$. During fall, daytime high and evening low temperatures can vary as much as $50^{\circ} \mathrm{F}$. Cracks on the bituminous road surface are a common sight, as a result of the expansion and contraction of the bituminous road surface that occurs from these temperature extremes. Oxidation of the bituminous road surface is also accelerated as a result of these temperature extremes.

Borrego Springs also experiences flash floods, which are sudden and violent floods that occur after heavy rains. Unsealed road surface cracks allow water to penetrate into the road surface and underlying base, thus accelerating deterioration of the roadway's structural section if left untreated.

\section{NEED FOR PREVENTIVE MAINTENANCE}

Borrego Springs consists of circulation element roads (major roads) and non-circulation element roads (minor roads). There are approximately 151 centerline miles (244 centerline kilometers) of major roads and 60 centerline miles (97 centerline kilometers) of minor roads.

The county's PM program requires roadways be evaluated approximately every 3 years. The county evaluates the structural integrity of roadways with its Road Rating Deflection Survey method. This method evaluates the structural integrity of the roadway, by applying simulated loads, and determines what type of maintenance work is needed to maintain or restore the roadway's structural integrity. A visual inspection is also done to determine if any surface work is necessary.

To qualify for PM, the roadway's structural section should be sound. If isolated repairs are needed, these repairs can be done and still qualify the road for a PM surface treatment; in the Borrego Springs area, a chip seal over fabric.

Roadways that qualify for PM in Borrego Springs are included in one of the county's annual surface treatment contracts (chip seal over fabric, followed by a fog seal). The county limits the size of the Borrego Springs contract to 30 centerline miles (48 centerline kilometers) to insure the work can be done after the peak of summer and before the onset of winter. 


\section{Experimenting with Various Methods of Surface Treatments for Addressing Surface Cracks}

Chip seals are designed to seal the road surface, but typically are not designed to seal wide cracks on the road surface. Crack sealing can be done, but may be cost prohibitive if numerous cracks are present. Because of the numerous surface cracks that are inherent with the Borrego's desert roads, other PM methods had to be considered to extend the life of the bituminous roadways at a reasonable cost (see Figures 1 and 2).

In 1987, the County of San Diego conducted a study to place and evaluate various road surface treatments exposed to the temperature extremes of Borrego Springs. The test sections consisted of:

- Chip seal with 21/2\% latex-modified emulsion;

- Chip seal with 5\% latex-modified emulsion;

- Chip seal with 2-1/2\% latex-modified emulsion over fabric;

- Chip seal with 5\% latex-modified emulsion over fabric;

- Chip seal with ground rubber modified paving asphalt binder;

- $51 \mathrm{~mm}$ (2 in.) of road mix with SC-250 (slow curing) and seal; and

- Double fog seal with 5\% latex-modified emulsion.

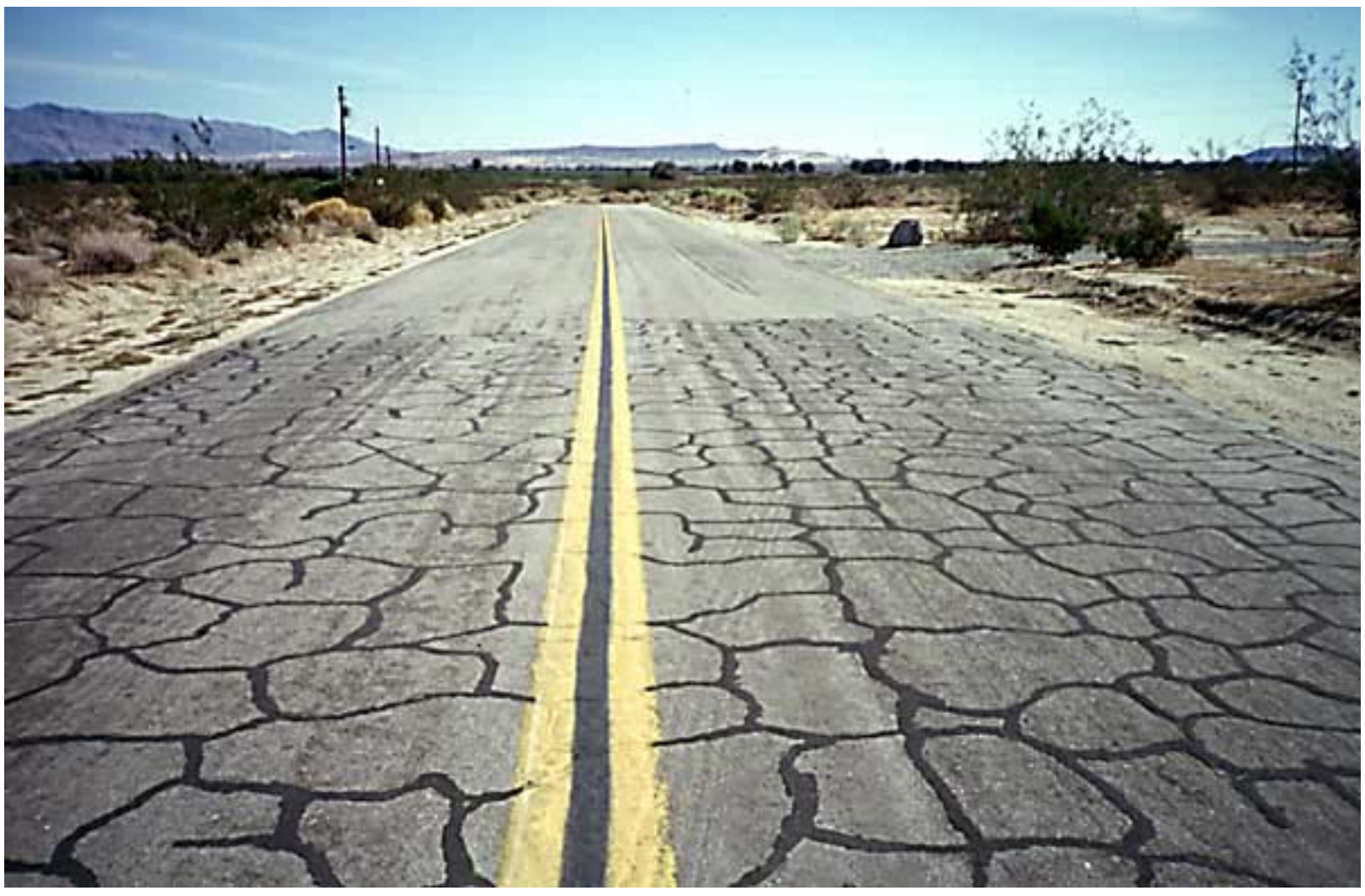

FIGURE 1 Crack sealing normally required on desert roads. 


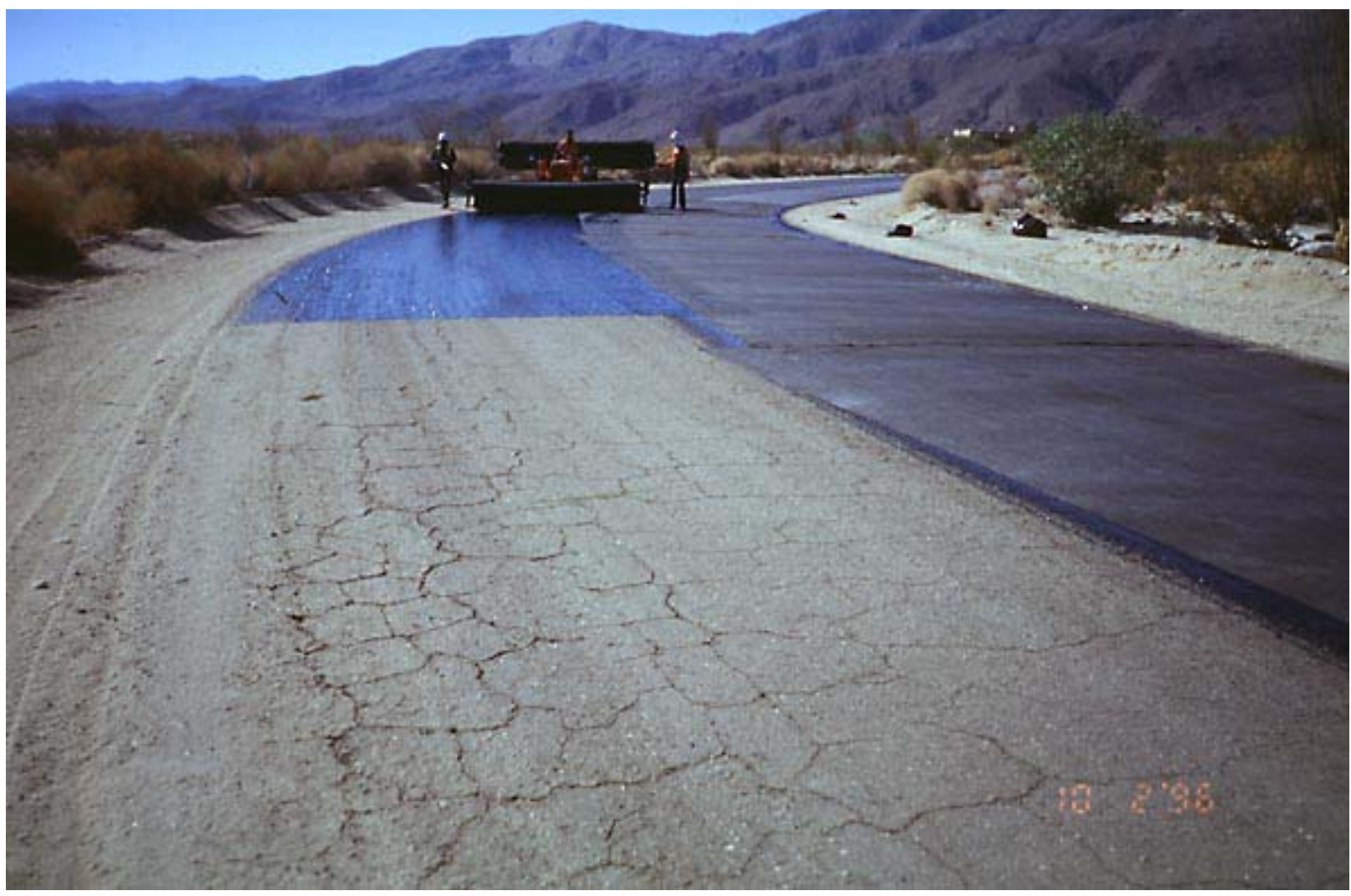

FIGURE 2 Placing fabric has eliminated the need for crack sealing.

Each test section was 0.55 to 0.65 centerline miles ( 0.89 to 1.05 centerline kilometers) in length, and was placed the full road width to evaluate the impact of traffic in both directions. The test sections' terrain consisted of flat to steep grades, and straight and winding sections of bituminous pavement. Because the test sections were placed adjacent to each other on one roadway (Yaqui Pass Road), and under one public works contract, the conditions of all of the test sections were comparable to each other.

There were two experimental surface treatments that performed very well in addressing the reflective surface cracks, and sealing the bituminous road surface, under desert conditions:

- Chip seal with latex modified emulsion over fabric, and

- Chip seal with ground rubber modified paving asphalt binder.

The width of the surface cracks determined which of the two surface treatments performs best. Chip sealing with ground rubber modified paving asphalt binder performed well on roads that did not have wide surface cracks - if wide surface cracks were present, then crack sealing was also be needed. However, chip seal with latex modified emulsion over fabric eliminated the need for crack sealing, regardless of the width of the surface crack.

Normally when bituminous road surfaces have wide cracks, crack sealing is required prior to the placement of a surface treatment. If crack sealing were not done, crack sealing would be required within 5 years after placement of any surface treatment that did not include fabric placement. 
The county found crack sealing, before or after the placement of the chip seal over fabric, was not required for this surface treatment to be successful.

\section{Present Performance of 1987 Test Section}

The test sections placed in 1987 are now 18 years old. The test sections where chip seals were placed over fabric have no reflective cracking as of this date. The fabric is still in tact and the underlying base is in good condition and in no need of crack sealing or repairing the underlying structural section.

Because the structural integrity of the 1987 chip seal over fabric test sections is sound, the next scheduled road maintenance strategy will be a surface treatment (chip seal followed by a fog seal). The next surface treatment can be either a polymer-modified chip seal or a chip seal with ground rubber-modified asphalt cement tack coat [asphalt cement tack coat (paving asphalt)] binder. Regardless of the surface treatment selected in the future, neither crack sealing nor another layer of fabric will be necessary due to the performance of the underlying fabric.

\section{FABRIC SPECIFICATION AND REQUIREMENTS}

On public works projects, the County of San Diego typically uses the State of California Department of Transportation (Caltrans) Standard Specifications. Special provisions are also included in the contracts and provide specific clauses setting forth conditions or requirements peculiar to the work and supplementary to the Caltrans Standard Specifications.

The pavement reinforcing fabric is manufactured from polyester or polypropylene material. The fabric is non-woven, heat treated on at least one side, and conforms to the specifications shown in Table 1 .

\section{QUALITY CONTROL AND QUALITY ASSURANCE}

Because of the numerous road maintenance and capital improvement projects the county materials lab monitors, the county requires the contractor to provide a private testing laboratory, independent of the contractor's work force, for quality control and quality assurance. This insures all parties receive the test results in a timely manner before and during construction operations.

The County of San Diego requires the contractor to demonstrate the products meet the contract requirements before they are allowed to apply them to the road surface. The contractor accomplishes this task by submitting prequalification material samples to the county materials lab. The county materials lab then splits the samples and forwards one set to the approved private testing laboratory. Both the county materials lab and the private testing laboratory test their set of the split samples and compare test results.

Pre-qualification testing is required for the asphalt cement tack coat (paving asphalt), chip seal emulsion, crushed aggregate (chips), and fog seal emulsion (prior to dilution). A certificate of compliance is submitted for the fabric. The independent testing laboratory's test 
TABLE 1 Fabric Specifications

\begin{tabular}{|l|l|}
\hline Specification & Requirement \\
\hline $\begin{array}{l}\text { Weight, ounces per square yard, minimum } \\
\text { ASTM Designation: D-3776 }\end{array}$ & 4.1 \\
\hline $\begin{array}{l}\text { Grab tensile strength (1-in. grip), pounds, minimum, in each direction } \\
\text { ASTM Designation: D-4632 }\end{array}$ & 90 \\
\hline $\begin{array}{l}\text { Elongation at break, percent, minimum } \\
\text { ASTM Designation: D-4632 }\end{array}$ & 40 \\
\hline $\begin{array}{l}\text { Fabric thickness, mils. } \\
\text { ASTM Designation: D-461 }\end{array}$ & 30 to 100 \\
\hline
\end{tabular}

results for the prequalification and field sample testing are used for contract compliance. The County of San Diego runs sporadic tests to confirm the results received from the independent testing laboratory are consistent with the county materials lab's test results.

When all the proposed materials meet the prequalification testing requirements, construction operations are allowed to proceed.

During construction operations, samples of the asphalt cement tack coat (paving asphalt), chip seal emulsion, chips, and fog seal emulsion are taken on a daily basis. Tests are performed daily on the chip seal emulsion and chips for contract compliance. Field samples of paving asphalt and fog seal emulsion are stored for future testing, in the event poor performance is experienced in the field. Certificates of compliance are received for each shipment of fabric to the job site.

Field samples of the chip seal emulsion and chips are delivered to the independent testing laboratory and county materials mab within $24 \mathrm{~h}$ of sampling. The samples are tested, and test results are reported within $24 \mathrm{~h}$ of the independent testing laboratory receiving the samples. This allows the contractor and the county to receive test results within $48 \mathrm{~h}$ of sampling. This provides the contractor an opportunity to review the test results and make modifications in the event the test results show the products do not meet contract requirements. This also allows the county to monitor the test results for contract compliance.

\section{PRODUCT PLACEMENT}

\section{Optimum Weather for Placing Chip Seal over Fabric}

Borrego Springs has ambient temperatures that vary not only in a single day, but also year round. After the peak of summer and before winter, when construction typically occurs for this surface treatment, it is common for evening and daytime temperatures to range from $60^{\circ} \mathrm{F}$ to $110^{\circ} \mathrm{F}$ $\left(16^{\circ} \mathrm{C}\right.$ to $\left.43^{\circ} \mathrm{C}\right)$.

Construction operations are scheduled to occur after the peak of summer to allow the asphalt products [asphalt cement tack coat (paving asphalt)], chip seal emulsion, and fog seal emulsion) to age before they are exposed to the extremely hot temperatures the following summer. As a result, work is typically performed during the months of September, October, and November when optimum daytime temperatures are typically present. 


\section{Methods of Placement}

The construction operation consists of three construction operations (placing fabric, chip seal, and fog seal) on high-speed and low-speed roads. The method of how and when the products are placed is determined by the traveling speed of the motoring public, not the volume of traffic.

\section{Method 1: High-Speed Roads}

Method 1 is used for roads that have high-speed traffic. High-speed traffic, regardless of the traffic volume, require pilot car-assisted traffic control to reduce the speed of the traveling public to from 55 to $25 \mathrm{mph}$ ( 90 to $40 \mathrm{~km} / \mathrm{h}$ ) during construction operations.

It is the county's policy not to have high-speed traffic exposed to asphalt cement tack coat (paving asphalt) or loose gravel (chips) when traffic control is removed from the roadway. Exposed asphalt cement tack coat (paving asphalt) can be a slick surface when exposed to moisture, and can stick to other objects (tires, shoes, etc.) when exposed to heat. Loose gravel (chips) can affect traction or cause windshield damage to the motoring public.

- Phase 1: Clean the roadway surface. Apply asphalt cement tack coat (paving asphalt), fabric, and sand cover, use pneumatic-tired rollers to seat the fabric into the asphalt cement tack coat (paving asphalt). The sand cover serves as a bond breaker to prevent the rollers' tires from coming in contact with, and sticking to, the asphalt cement tack coat (paving asphalt). Remove excess sand. Apply chip seal [latex/polymer-modified asphaltic emulsion and crushed aggregate (chips)], use pneumatic-tired rollers to seat the chips into the emulsion. Remove excess chips.

The road is not closed to traffic during construction operations. One lane is kept open at all times to provide one-way traffic control. Traffic speeds are controlled through the construction site, at a reduced speed of $25 \mathrm{mph}(40 \mathrm{~km} / \mathrm{h})$ with the use of pilot car-assisted traffic control during construction operations. Upon completion of removing the loose chips, the road is opened to public traffic. after Phase 1.

- Phase 2: Clean roadway surface. Apply fog seal. Phase 2 is performed 7 to 14 days

\section{Method 2: Low-Speed Roads}

Method 2 is used for roads that have low-speed traffic. Posted speed limits are $25 \mathrm{mph}$ (40 $\mathrm{km} / \mathrm{h}$ ); therefore, pilot car assisted traffic control is not required to maintain low traffic speeds during construction operations.

- Phase 1: Clean the roadway surface. Apply asphalt cement tack coat (paving asphalt), fabric and sand cover, use pneumatic-tired rollers to seat the fabric into the asphalt cement tack coat (paving asphalt). The sand cover serves as a bond breaker to prevent the rollers' tires from coming in contact with and sticking to the asphalt cement tack coat (paving asphalt).

- Phase 2: Remove excess sand. Apply chip seal (latex/polymer-modified asphaltic emulsion and crushed aggregate), use pneumatic-tired rollers to seat the chips into the emulsion. Open road to public traffic. Remove excess chips the following day. Phase 2 is performed 5 to 10 days after Phase 1. 

after Phase 2.

- Phase 3: Clean roadway surface. Apply fog seal. Phase 3 is performed 7 to 14 days

The preferred method of placement is Method 2 because it allows the asphalt cement tack coat (paving asphalt) to harden overnight and allow traffic to provide additional seating (rolling), of the fabric into the underlying asphalt cement tack coat (paving asphalt) for several days before placing the chip seal.

Methods 1 and 2 are both placed successfully in Borrego Springs; each method has benefits depending on the roadway's environment (traffic speed).

\section{Equipment Requirements}

The fabric binder, chip seal emulsion and fog seal are applied with distributor trucks equipped with computerized rate control. Distributor trucks are calibrated on site to insure materials are being applied at the application rate directed by the engineer.

The chip spreader is required to be a self-propelled chip spreader, with a minimum width of $10 \mathrm{ft}$, but no greater than $16 \mathrm{ft}$. Computerized rate control chip spreaders can be used at the option of the contractor.

A minimum of three pneumatic-tired rollers is required to insure full coverage immediately behind the chip spreader.

Mobile pick-up brooms perform pre-sweeping and post-sweeping operations. Materials are not allowed to be kicked off onto the road shoulder.

\section{KEY ISSUES IN PRODUCT PLACEMENT}

In order to guarantee success, one must respect the number of liquid asphalt materials that are being placed on any given day during construction operations, and how the placement of one material affects the placement of the next material.

During all phases of construction operations it is important to have a clean road surface, dry sand, chip seal emulsion formulated to meet field conditions, surface damp chips, properly diluted fog seal emulsion, required ambient and pavement temperatures, properly calibrated construction equipment, experienced staff, and adequate traffic control.

Materials are hauled directly from the plant to the construction site; stockpiling of chips is not allowed to prevent contamination. Because of the remote location of Borrego Springs to the various materials suppliers, this results in materials being hauled approximately two hours, one way, to the construction site. As a result, the remote location of Borrego Springs affects the unit prices bid for the various materials used on this project, compared to chip seal projects that are closer to the various material suppliers.

This surface treatment is designed to prevent the need for crack sealing surface cracks and to seal the bituminous road surface; however, it is also designed to provide a long lasting surface friction course for improved skid resistance. The surface friction course of the existing bituminous pavement is improved by the size of aggregate applied. Medium-size aggregate is applied on high-speed roads (major roads). Medium-fine aggregate is applied on low-speed roads (minor roads). The sizes of these aggregates are displayed in Table 2. 
It is important to respect the number of liquid asphalt products that are placed in this surface treatment to guarantee a successful end product. If the asphalt cement tack coat (paving asphalt) properly saturates the fabric, the chip seal can be placed at application rates specified for a bituminous road surface. When the proper amount of chip seal emulsion is applied to provide the desired chip embedment, then the fog seal can also be applied at a normal application rate.

Should either the asphalt cement tack coat (paving asphalt) or chip seal emulsion be applied at a lesser amount than needed, an increase in the application rate of the next asphaltic emulsion product will be necessary. A low or excessive application rate of asphalt cement tack coat (paving asphalt) can cause fabric slippage on the road surface. A low application can also cause the fabric to absorb the chip seal emulsion and not leave enough chip seal emulsion on the fabric surface for proper chip embedment, thus chip loss can occur. A low application of chip seal emulsion can also cause chip loss.

Overapplication of the liquid asphalt products can also affect the end product. Over application of asphalt cement tack coat (paving asphalt) can cause fabric slippage during hot weather or under lateral stress of vehicular traffic. Over application of the chip seal can cause bleeding or flushing and a reduced surface friction course. Over application of the fog seal can also cause bleeding or flushing, and a reduced surface friction course.

Fabric placement is not recommended for roads with steep grades (10\% or greater), sharp winding curves, or in the last $100 \mathrm{ft}(30 \mathrm{~m})$ approaching intersections with controlled stops (traffic signals or stop or yield signs).

When designed properly, this construction process is no different than any other construction process. It requires a conscientious construction crew, appropriate construction equipment and personnel, proper inspection, and material sampling and testing during all phases to insure contract compliance and a successful end product.

TABLE 2 Material Application Rates

\begin{tabular}{|c|c|c|c|}
\hline Material & $\begin{array}{l}\text { Chip } \\
\text { Size }\end{array}$ & $\begin{array}{c}\text { Material } \\
\text { Application Rate }\end{array}$ & $\begin{array}{c}\text { Material } \\
\text { Temperature }\end{array}$ \\
\hline $\begin{array}{l}\text { Asphalt cement tack coat } \\
\text { (paving asphalt) } \\
\text { (AR4000 or AR8000) }\end{array}$ & $\mathrm{N} / \mathrm{A}$ & $\begin{array}{l}0.25 \text { to } 0.30 \mathrm{gal} / \mathrm{yd}^{2} \\
\left(1.1 \text { to } 1.4 \mathrm{~L} / \mathrm{m}^{2}\right)\end{array}$ & $\begin{array}{l}290^{\circ} \mathrm{F} \text { to } 350^{\circ} \mathrm{F} \\
\left(143^{\circ} \mathrm{C} \text { to } 177^{\circ} \mathrm{C}\right)\end{array}$ \\
\hline $\begin{array}{l}\text { Latex-modified chip seal } \\
\text { emulsion } \\
\text { (LMCRS2h or LMRS2h) } \\
\text { Polymer-modified chip seal } \\
\text { emulsion } \\
\text { (PMCRS2h or PMRS2h) }\end{array}$ & $\begin{array}{l}\text { Medium } \\
\text { Medium- } \\
\text { Fine }\end{array}$ & $\begin{array}{l}0.25 \text { to } 0.35 \mathrm{gal} / \mathrm{yd}^{2} \\
\left(1.1 \text { to } 1.6 \mathrm{~L} / \mathrm{m}^{2}\right) \\
0.25 \text { to } 0.40 \mathrm{gal} / \mathrm{yd}^{2} \\
\left(1.1 \text { to } 1.8 \mathrm{~L} / \mathrm{m}^{2}\right)\end{array}$ & $\begin{array}{l}130^{\circ} \mathrm{F} \text { to } 180^{\circ} \mathrm{F} \\
\left(55^{\circ} \mathrm{C} \text { to } 82^{\circ} \mathrm{C}\right)\end{array}$ \\
\hline $\begin{array}{l}\text { Crushed Aggregate (Chips): } \\
3 / 8 \text { in. } \times \text { No. } 6 \\
(9.5 \mathrm{~mm} \times 3.35 \mathrm{~mm}) \\
5 / 16 \mathrm{in} . \times \text { No. } 8 \\
(8.0 \mathrm{~mm} \times 2.36 \mathrm{~mm})\end{array}$ & $\begin{array}{l}\text { Medium } \\
\text { Medium- } \\
\text { Fine }\end{array}$ & $\begin{array}{l}20 \text { to } 30 \mathrm{lb} / \mathrm{yd}^{2} \\
\left(10.9 \text { to } 16.3 \mathrm{~kg} / \mathrm{m}^{2}\right) \\
16 \text { to } 25 \mathrm{lbs} / \mathrm{yd}^{2} \\
\left(8.7 \text { to } 13.6 \mathrm{~kg} / \mathrm{m}^{2}\right)\end{array}$ & $\begin{array}{l}\text { N/A } \\
\text { N/A }\end{array}$ \\
\hline $\begin{array}{l}\text { Fog seal } \\
\text { (CQS1h) }\end{array}$ & $\mathrm{N} / \mathrm{A}$ & $\begin{array}{l}0.05 \text { to } 0.10 \mathrm{gal} / \mathrm{yd}^{2} \\
\left(0.2 \text { to } 0.5 \mathrm{~L} / \mathrm{m}^{2}\right)\end{array}$ & $\begin{array}{l}100^{\circ} \mathrm{F} \text { to } 180^{\circ} \mathrm{F} \\
\left(38^{\circ} \mathrm{C} \text { to } 82^{\circ} \mathrm{C}\right)\end{array}$ \\
\hline
\end{tabular}




\section{GUARANTEE}

The contractor guarantees all work against defective workmanship and materials for a period of one year. The 1-year guarantee period begins upon completion of all work required by the contract.

\section{LIFE-CYCLE COST ANALYSIS}

This life-cycle cost analysis uses the year 2000 construction costs that are inherent with this remote desert community. It should be noted that the life cycle cost analysis does not take into account the cost of inflation over a 30-year life cycle.

Due to the width of the surface cracks typically found on the roadway surfaces in Borrego Springs, the County of San Diego has found chip sealing over fabric more cost-effective than chip sealing with ground rubber-modified paving binder, or chip sealing with latex/polymer-modified asphaltic emulsion without fabric.

This analysis was done utilizing the following considerations:

$\$ 1.40 / \mathrm{yd}^{2} \quad$ Crack seal

$\$ 1.00 / \mathrm{yd}^{2} \quad$ Fabric (including asphalt cement tack coat)

$\$ 2.25 / \mathrm{yd}^{2} \quad$ Polymer-modified chip seal

$\$ 3.50 / \mathrm{yd}^{2} \quad$ Chip seal with ground rubber-modified paving asphalt binder

$475,460 \mathrm{yd}^{2} \quad$ Size of project

30 years Life cycle

Table 3 gives a summary of the price comparisons shown below.

\section{Polymer-Modified Chip Seal with Crack Seal}

Year 1: Apply crack seal and polymer-modified chip seal

$$
\left(475,460 \mathrm{yd}^{2}\right)\left(\$ 1.40 / \mathrm{yd}^{2}+\$ 2.25 / \mathrm{yd}^{2}\right) \quad=\$ 1,735,429
$$

Year 11: Apply crack seal and polymer-modified chip seal

$$
\left(475,460 \mathrm{yd}^{2}\right)\left(\$ 1.40 / \mathrm{yd}^{2}+\$ 2.25 / \mathrm{yd}^{2}\right) \quad=\$ 1,735,429
$$

Year 21: Apply crack seal and polymer-modified chip seal

$$
\begin{aligned}
\left(475,460 \mathrm{yd}^{2}\right)\left(\$ 1.40 / \mathrm{yd}^{2}+\$ 2.25 / \mathrm{yd}^{2}\right) & =\underline{\$ 1,735,429} \\
\text { Total } & =\$ 5,206,287 \\
\text { Annual Cost } & =\$ 173,543
\end{aligned}
$$

\section{Chip Seal with Ground Rubber-Modified Paving Asphalt Binder}

Year 1: Apply chip seal with ground rubber-modified paving asphalt binder

$$
\left(475,460 \mathrm{yd}^{2}\right)\left(\$ 3.50 / \mathrm{yd}^{2}\right) \quad=\$ 1,664,110
$$

Year 5: Crack Seal

$$
\left(475,460 \mathrm{yd}^{2}\right)\left(\$ 1.40 / \mathrm{yd}^{2}\right) \quad=\$ 665,644
$$


TABLE 3 Price Comparisons of Surface Treatments

\begin{tabular}{|l|l|l|}
\hline \multicolumn{1}{|c|}{ Surface Treatment } & \multicolumn{1}{|c|}{ 30-Year Cost } & \multicolumn{1}{c|}{ Annual Cost } \\
\hline Polymer-modified chip seal with crack seal & $\$ 5,206,287$ & $\$ 173,543$ \\
\hline Chip seal with ground rubber-modified paving asphalt binder & $\$ 3,993,864$ & $\$ 133,129$ \\
\hline Polymer-modified chip seal over fabric & $\$ 2,615,030$ & $\$ 87,168$ \\
\hline
\end{tabular}

Year 16: Apply chip seal with ground rubber-modified paving asphalt binder

$$
\begin{aligned}
\left(475,460 \mathrm{yd}^{2}\right)\left(\$ 3.50 / \mathrm{yd}^{2}\right) & =\$ 1,664,110 \\
\text { Total } & =\$ 3,993,864 \\
\text { Annual Cost } & =\$ 133,129
\end{aligned}
$$

\section{Polymer-Modified Chip Seal Over Fabric}

Year 1: Place fabric and apply polymer-modified chip seal

$$
\left(475,460 \mathrm{yd}^{2}\right)\left(\$ 1.00 / \mathrm{yd}^{2}+\$ 2.25 / \mathrm{yd}^{2}\right) \quad=\$ 1,545,245
$$

Year 16: Apply polymer-modified chip seal

$$
\left(475,460 \mathrm{yd}^{2}\right)\left(\$ 2.25 / \mathrm{yd}^{2}\right)
$$

$$
\begin{aligned}
& =\$ 1,069,785 \\
\text { Total } & =\$ 2,615,030 \\
\text { Annual Cost } & =\$ 87,168
\end{aligned}
$$

\section{CONCLUSIONS}

The test sections placed in 1987 are now 17 years old. The test sections where chip seals were placed over fabric have no reflective cracking as of this date. The fabric is still in tact and the underlying base is in good condition and in no need of crack seal or repair. The County of San Diego has placed chip seals over fabric on other desert roads and these roads are experiencing the same performance results as the 1987 test sections.

As mentioned earlier, the County of San Diego insures the structural integrity of the road is sound before the chip seal over fabric is placed. As a result, the county is finding the chip seal over fabric has protected the structural integrity of the roads that received a chip seal over fabric, and the next scheduled road maintenance strategy will most likely be another surface treatment; another application of fabric will not be necessary. The next surface treatment such as a polymermodified chip seal, or a chip seal with ground rubber-modified asphalt cement tack coat [asphalt cement tack coat (paving asphalt)] binder. In either case, crack sealing will not be necessary prior to chip sealing due to the performance of the underlying fabric.

Because of county's use of fabric to address surface cracks on desert roads, no subsequent crack sealing has been required or performed to date. This is true for the test sections that received fabric in 1987, and other desert roads that have received a chip seal over fabric since. As a result, the county is experiencing savings of $\$ 87,168$ per year because these areas no longer require crack sealing for the pavement surface.

It should be noted that inflation is not included in the $\$ 87,000$ figure; thus, monetary savings are actually greater than reported. 


\section{SUMMARY}

The County of San Diego is responsible for maintaining public roads with cost-effective methods and minimal repair work with funds provided by the taxpayers. As a result of the test sections completed in 1987 in Borrego Springs, the county has found effective surface treatments that are appropriate for the desert environment.

In the 1987 test sections where a chip seal over fabric was placed, the fabric continues to protect the underlying base and the structural section is in no need of repair. However, the surface friction course needs to be restored because the chips have become polished due to 17 years of vehicular traffic. Because the structural section is sound, the next road maintenance surface treatment will be a chip seal to restore the surface friction course.

The innovation of the 1987 test sections on Yaqui Pass Road were successful because of the cooperative effort between the county, the desert community and private industry to experiment with different surface treatments. Because of this cooperative effort and the success of the test sections, desert roads are now maintained with cost-effective construction methods that are appropriate for this desert environment. 


\title{
Quality Control and Quality Assurance on Chip Seal Projects
}

\author{
LITA DAVIS \\ County of San Diego, California
}

It is everyone's desire to have successful chip seal projects. In the county of San Diego, private contractors compete to win this agency's annual multi-million dollar chip seal contract. Because the contractor knows this winning the contract will guarantee work for the majority of the chip seal season. But it isn't that easy. An experienced contractor also knows the work involved in planning, scheduling and placing chip seals on a variety of roads, everyday, for several months. The county of San Diego wants the chip seal work done in one chip seal season. So the county of San Diego developed and incorporated a quality control and quality assurance $(\mathrm{QC} / \mathrm{QA})$ program into its contract specifications to insure quality materials are used on the project; this also helps prevent construction delays and reduce the number of damaged windshields. The county also recognizes the importance of when to advertise a chip seal project for bidding. They found that advertising in late winter or early spring allows bids to come in at a lower cost, and contractors have the maximum amount of warm weather available to do the work. This paper discusses the cooperative effort between the county of San Diego and private contractors to develop a QC/QA program for the county's chip seal contracts. This paper covers topics such as, road selection, when to advertise a project, material sampling and testing, equipment usage and maintenance, visual inspection of materials, and proper sequence of construction operations.

$\mathrm{T}$ here is a variety of asphalt emulsion surface treatments that a public agency can select from to seal asphalt concrete (AC) roadways; these include various forms of chip seal, slurry seal, cape seal, sandwich seal, or micro-surfacing. Each surface treatment is designed for a specific purpose and varies in surface life and cost.

The county of San Diego takes an active role in finding cost-effective ways to maintain its roadways with the limited funds available and uses more than one form of surface treatment in its toolbox for roadway maintenance. The county has found that chip sealing its major roads is a costeffective way to seal and retard the aging process of the underlying $\mathrm{AC}$ surface, if done early in the life of the AC pavement, and prevents future costly road repairs.

The reason for this is chip seals prevent water from penetrating beneath the AC surface, which is known to cause potholes and further deterioration of the roadway. When a surface treatment is placed on an AC surface, it is the surface treatment that is exposed to oxidation and water - not the underlying and more expensive AC surface. The county also uses chip seals to improve the roadway's surface friction course.

The county of San Diego's annual chip seal contract typically consists of approximately 75 to 125 centerline miles (120 to 200 centerline kilometers). Depending on the location, optimum ambient and pavement temperatures needed for applying a successful chip seal can be limited from a working window of a few weeks to several months.

Advertising a project at the right time and incorporating a quality control and quality assurance (QC/QA) program helps insure the contractor will complete the chip seal portion of the contract in one chip seal season and at a reasonable cost.

For the benefit of the reader, this paper will discuss how incorporating a QC/QA program helped the county of San Diego obtain successful chip seal projects using polymer-modified emulsion. 


\section{PROJECT IDENTIFICATION}

\section{Weather in San Diego}

To better understand why chip seals can be placed successfully in San Diego County, it is important to understand that a road's climate plays a major role. Many think San Diego has plenty of warm and dry climate; not true.

San Diego County consists of a variety of climate and geographical conditions. It has geographic terrains consisting of coastal regions, inland valleys, mountain ranges, and deserts with elevations ranging from mean seal level to $6,500 \mathrm{ft}(1,980 \mathrm{~m})$. Awareness and sensitivity to how each area of San Diego County differs gives the contractor the ability to place a successful chip seal at each location.

San Diego County includes not only the unincorporated area of the county of San Diego, but also incorporated cities, federal military sites, and Indian reservations. The unincorporated area maintained by the county of San Diego consists of approximately 4,200 square miles (10,878 square kilometers) and approximately 1,900 centerline miles (3,060 centerline kilometers) of major and minor roads.

Temperature and annual precipitation also vary. Depending on location, a $15^{\circ} \mathrm{F}$ to $50^{\circ} \mathrm{F}$ change between daytime highs and evening lows is common. Seasonal rainfall is $10 \mathrm{in}$. in the coastal area, and increases as you head east towards the inland valleys and mountain ranges. The average precipitation in the mountain ranges varies from 20 to 40 in., depending on the elevation. The mountain ranges are also exposed to snow each winter.

During the summer months, dry easterly winds (commonly referred to as a "Santa Ana") will last for several days and increase ambient temperatures as high as $90^{\circ} \mathrm{F}\left(32^{\circ} \mathrm{C}\right)$ along the coast, $100^{\circ} \mathrm{F}\left(38^{\circ} \mathrm{C}\right)$ in the inland valleys, and $125^{\circ} \mathrm{F}\left(50^{\circ} \mathrm{C}\right)$ in the desert.

In regards to a working window for placing a chip seal, the coastal temperatures are moderate due to year-round offshore winds. This means the coastal areas have only a few weeks of optimum ambient and pavement temperatures to chip seal. In the mountain ranges, tropical storms are typical during August which requires chip sealing be done during the early summer months before the rains begin.

\section{What Types of Roads Does the County of San Diego Maintain?}

As mentioned earlier, the county of San Diego maintains approximately 1,900 centerline miles (3,060 centerline kilometers) of roads, which are designated as either circulation element roads or non-circulation element roads.

Circulation element roads serve as arterial or major roads and carry traffic between communities. The traffic volume on a circulation element road can reach 30,000 vehicles per day. Non-circulation element roads serve as minor roads and consist of residential collectors, cul-de-sac roads or loop roads.

Depending on the type of roads, speed limits range from 25 to $55 \mathrm{mph}$ (40 to $90 \mathrm{~km} / \mathrm{h}$ ).

\section{How Is Each Roadway's Maintenance Determined?}

In order to maintain the roadways with the limited funds available, the county of San Diego has a preventative maintenance program to determine roadway maintenance. This is done in lieu of 
allowing roads to deteriorate and then resurfacing or rebuilding on a more frequent and costly basis.

The county presently uses two methods for evaluating the roadways: visual assessment and the Materials Testing Lab's Road Rater Deflection Survey. The visual assessment is used to rate the surface condition of the road. The Road Rater Deflection Survey applies a simulated load to measure the structural integrity of the road. Combining the results of both of these rating methods determines the type of maintenance work that is needed such as crack sealing, isolated dig outs, chip seal (with or without pavement reinforcing fabric), or AC resurfacing (with or without pavement reinforcing fabric).

Roadways typically selected for the annual chip seal contract have a sound structural section and may need only isolated repair work. County staff performs the isolated repairs, such as crack sealing, or dig outs, before chip sealing begins.

The chip seal contract (without fabric) is limited in size to approximately 75 to 125 centerline miles (120 to 200 centerline kilometers) to insure the chip seal portion of the contract can be completed when optimum weather is present. This contract is one of the largest chip seal contracts in the state of California and ranges in value from $\$ 1.5$ to $\$ 2.5$ million.

Chip sealing over fabric is confined to the desert portion of San Diego County and is not discussed in detail in this paper.

\section{When to Advertise a Chip Seal Contract for Public Bidding}

Chip seals are applied when warm ambient and pavement temperatures are present, typically in the summer. Private contractors who bid this type of work understand this and also know that once optimum temperatures are gone, chip sealing operations will cease and not resume until warm temperatures return the following year. If a project is not completed, then it will go into weather suspension. To avoid having a project go into weather suspension, it is wise to advertise the project for bids in late winter or early spring.

Once a project is advertised, it takes approximately 3 to 4 months before construction will begin. The first month is the advertising period and receiving bids. The second month consists of evaluating the contractors' bids and determining who will be awarded the contract. The third and fourth months consist of having the pre-construction meeting, testing material submittals, and the contractor building an aggregate (chip) stockpile.

Another benefit to advertising early is contractors will bid on multiple projects to keep their crews busy for the full chip seal season. By not keeping their crews busy, they run a risk of losing employees to companies that can guarantee ongoing work. By advertising your project early, you increase the odds of having multiple contractors bidding your project; thus, you will get more competitive bids. The longer you wait to advertise your project, contractors with full schedules have to determine if they can complete your work with the other contracts they were awarded. If winning your bid will be an added expense to them then this extra cost will be added into your project, which results in a higher bid.

\section{How Large Should a Chip Seal Project Be?}

There are fixed costs a contractor incorporates into their bid, besides the construction cost. These fixed costs consist of mobilization, company overhead, bonding, insurance, and profit. 
Advertising the largest contract you can fund will reduce the percentage of the contractor's fixed cost to the contract's construction cost.

However, you do not want to make a project so large that it cannot be completed in one chip seal season. When this happens, more than likely at the end of the chip seal season the remaining portion of the chip seal work will go into weather suspension. Weather suspension is costly to everyone.

Weather suspension is an increased cost to the agency because they agency has to continue to maintain the remaining roads scheduled for chip sealing. This maintenance continues throughout the weather suspension (fall, winter, and spring) until warm weather returns the following summer. The cost of ongoing maintenance, which likely was not planned for, will likely come from funds that were budgeted for other road maintenance projects.

Weather suspension is an increased cost to the contractor because the agency is withholding some of the contractor's funds, known as contract retention, to insure completion of the project. This also affects the contractor's bonding capacity to bid other work during weather suspension. Another risk to the contractor is performing the remaining work at the unit prices originally bid. If the cost of equipment, labor or materials increases over weather suspension, this increased cost will have to be absorbed by the contractor.

Weather suspension also affects all of the contractor's subcontractors and materials suppliers the same way it affects the contractor.

If a project cannot be completed during the first chip seal season, then the contractor may request the agency to cancel the balance of the contract to avoid going into weather suspension. This is a fiscal decision the contractor has to make to recover its contract retention funds, increase its bonding capacity and protect its cash flow.

\section{PLANNING FOR QUALITY CONTROL AND QUALITY ASSURANCE}

\section{Program Goals and Components}

In order for a contractor to complete a chip seal contract within one chip seal season, regardless the size of the contract, the county of San Diego felt adopting a QC/QA program was necessary. Implementation of a QC/QA program helps:

- Prevent unnecessary construction delays,

- Insure quality materials are used on the project,

- Insure completion of the contract when optimum temperatures are present,

- Prevent minimal windshield claims and chip seal repair work, and

- Insure a successful chip seal.

The county of San Diego requires contractors to implement a Quality Control Plan as part of its chip seal contract. The Quality Control Plan consists of the following components:

- Quality Control Plan Administrator (typically the contractor's superintendent),

- Hiring a qualified independent testing laboratory, and

- Procedures for testing, reporting and storing material samples (pre-qualification and field samples). 


\section{Performance-Based Specification}

Prior to 1998, the county of San Diego construction inspection staff was responsible for determining if a change in emulsion's formulation was necessary, determining each material's application rate, coordinating post sweeping operations, and scheduling traffic striping and pavement legends.

The contractor was responsible for furnishing the labor, materials, tools, equipment, and traffic control to furnish and place the chip seal. Upon completion of the contract, the contractor was then required to guarantee the end product for 1 year.

Private contractors requested to have the responsibility for determining the emulsions' formulation and the materials' application rates if they were expected to guarantee the chip seal. As a result of this request, the county of San Diego worked with California's chip seal industry to develop a performance-based specification that was acceptable to the agency and the private contractors. As a result of the cooperative effort, the county of San Diego began incorporating a performance-based specification into its chip seal contracts.

The county continues to provide the material specifications for the emulsion and aggregate. It is now the contractor's responsibility to determine how the emulsion should be formulated, and what the materials' application rates should be for a successful chip seal.

Incorporating these changes in the contract specifications also gave the contractor a level of comfort knowing their decisions would result in what kind of chip seal they would be guaranteeing for 2 years. This was also beneficial to the agency because it took this burden off the inspection staff.

The performance-based specifications require the contractor to guarantee the chip seal against raveling, flushing (bleeding), delaminating or streaking for a period of 2 years after the chip seal is placed. Should a finished chip seal not meet the performance criteria specified in the contract, the defective work is repaired at the contractor's expense.

\section{QUALITY CONTROL FOR THE MATERIALS}

Materials are the most important factor for a successful chip seal. Poor quality emulsion or aggregate (chips) will prevent the contractor from providing a successful chip seal despite the effort taken to provide quality road preparation, traffic control, equipment, material placement, or finishing (seating) the materials and during ideal weather conditions.

As stated earlier, the county of San Diego's chip seal contract provides specifications for the emulsion and aggregate. The contractor is responsible for selecting the material suppliers, developing mix designs, submitting pre-qualification samples for the emulsion and aggregate, and providing testing for the pre-qualification and field samples.

When the test results for the pre-qualification samples show compliance with the contract, construction is allowed to begin once ambient and pavement temperatures are present. Sampling and testing of materials delivered to the field (construction site) are then done on a daily basis to insure contract compliance.

Because it is not practical to pre-qualify each shipment of materials (emulsion and aggregate) delivered to the construction site, these materials are delivered with a certificate of compliance from the material supplier. 
Split field samples are taken daily and tested for contract compliance. For the benefit of the reader, split field samples are one set of samples taken at the same time so test results can be compared between the county's materials lab and the independent testing laboratory (and sometimes even the emulsion supplier's laboratory). For example, if the county materials lab and the independent testing laboratory each need 2 quarts of chip seal emulsion for testing, then 4 quarts of chip seal emulsion will be taken at the same time and from one distributor truck. This allows both labs to compare their test results on the exact same material.

\section{Independent Testing Laboratory}

The county of San Diego's materials testing laboratory is capable of performing the necessary testing. However, due to the number of construction projects that are occurring in the summer, the county lab does not always have the resources available to provide daily testing of the emulsion and aggregate. Because of the importance to test emulsion samples in a timely manner (as soon as possible after placement in the field), the county decided to require the contractor to provide testing through an independent testing laboratory.

The contract provides requirements the independent testing laboratory must meet to be considered qualified for use on the project. For example, in order to get unbiased test results, the testing laboratory must be independent of the contractor's work force including the contractor's subcontractors and material suppliers. The testing laboratory must be AASHTO certified and have qualified testing staff. The independent testing laboratory must furnish test results within $24 \mathrm{~h}$ of receiving the samples. This allows the contractor and the county to review the test results for contract compliance soon after product placement. The test results also allow the contractor to decide if a change to the emulsion's formulation is necessary.

There are those that argue that testing the emulsion during construction just adds cost to the contract. This is true, but the cost of 1 day's test is small compared to the cost a full day's production of chip sealing. And, if problems do occur, the test results are a great resource in identifying how the emulsion's formulation should be modified for the remaining work.

\section{What Do the Test Results Show?}

Testing determines the values of the various items evaluated in the emulsion and aggregate, to determine if they are in compliance with the contract specifications.

Test results of the chip seal emulsion will demonstrate the various properties such as, demulsibility, penetration, percent asphalt residue, softening point, torsional recovery, and viscosity. Test results will not show the emulsion's application rate.

Test results of the aggregate (chips) will demonstrate the gradation and cleanness value. Cleanness value is a California Test Method used to determine the amount of fines present. Test results will not demonstrate if the aggregate was too wet or dry at the time of application, or the aggregate's application rate.

When testing shows compliance or non-compliance, the test results can serve as a good indicator how the chip seal will perform in the future. 


\section{Materials Furnished to the Construction Site}

As mentioned earlier, the chip seal emulsion and aggregate (chips) are delivered to the construction site with a certificate of compliance. The agency's onsite resident engineer is responsible for daily sampling of the chip seal emulsion and aggregate (chips).

Representative samples of the chip seal emulsion are taken every 10,000 gal $(37,855 \mathrm{~L})$ delivered to the construction site on any work day; a minimum of one representative set of field samples is taken per work day (Figure 1).

When sample valves are not present on the emulsion distributor truck, samples are taken from a nozzle used on the spray bar and when the truck is at mid load. It is important not to take a sample from the spray bar before the distributor truck starts spreading emulsion because there could be other materials present in the spray bar that will be captured in the samples. This will result in skewed test results.

The resident engineer takes a representative set of field samples daily (typically 4 quarts), and will deliver 2 quarts to the county materials lab and 2 quarts to the contractor who will deliver them to the independent testing laboratory for testing.

Representative samples of the aggregate (chips) are taken for every 300 tons delivered to the construction site. Each sample is taken from the conveyor belt or the gates of the chip spreader. The aggregate sample is delivered to the county materials lab for testing.

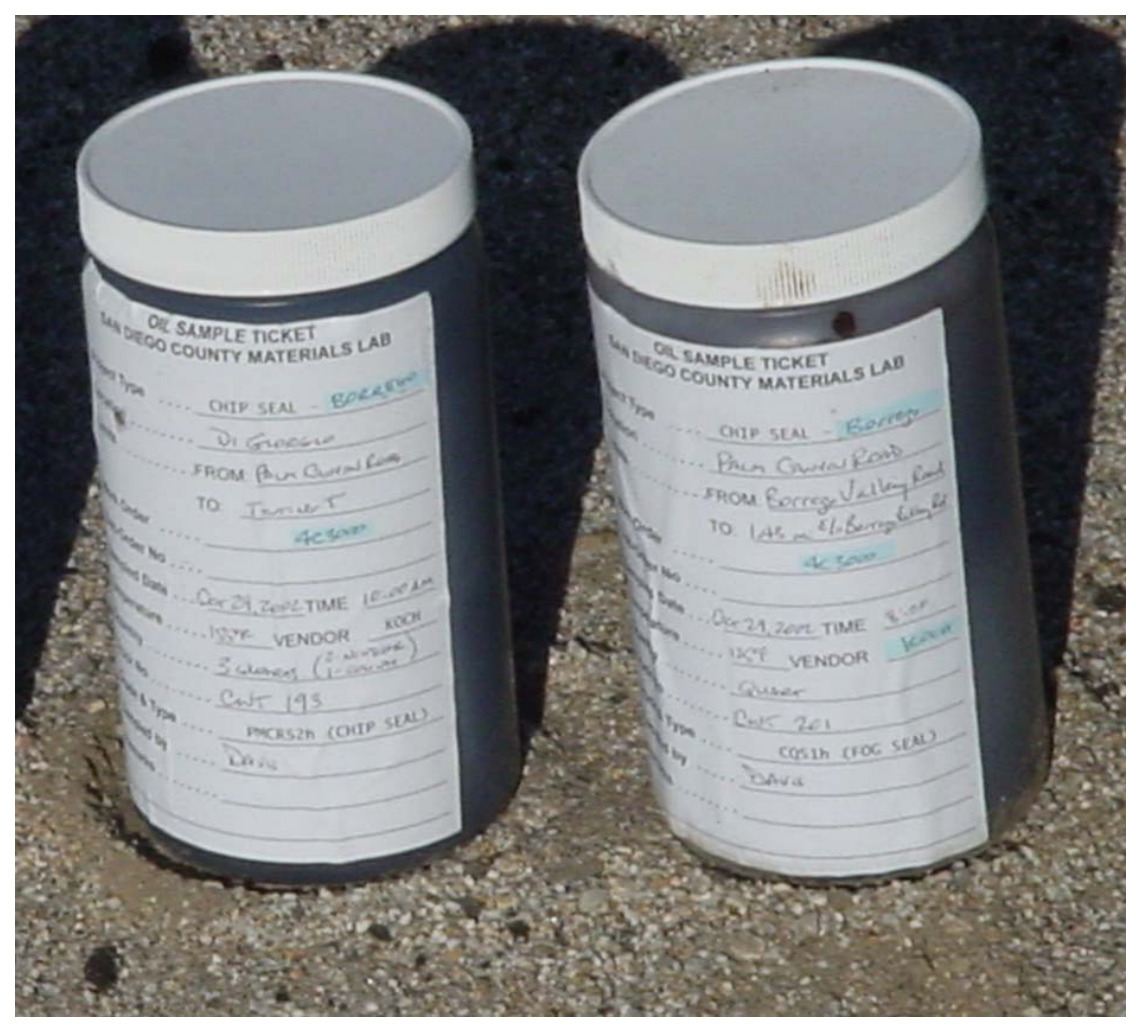

FIGURE 1 Sample and test construction materials on a regular basis for contract compliance. 


\section{VISUAL INSPECTION OF MATERIALS AT THE CONSTRUCTION SITE}

As stated earlier, there are not enough resources to pre-qualify each shipment of materials to the construction site; so material shipments are delivered with a certificate of compliance. Also, test results do not arrive until 2 days after the material is placed so it is important to visually inspect the materials' performance on the construction site for any potential problems.

\section{Visual Inspection of the Chip Seal Emulsion}

Test results are received 2 days after the material is placed. For example, you will receive the test results from Monday's emulsion sample at the end of the day on Wednesday. If you are not watching how the emulsion is performing in the field, then you may not realize you have a problem until the test results arrive 2 days later. In the meantime, you just placed 3 days of chip seal. A knowledgeable and proactive contractor and inspector will watch how the emulsion is performing in the field, in an effort to identify any potential problems.

Chip seal emulsion should not run, streak, ridge, or cure (break) too fast or slow. There are ways to watch for this in the field.

Running results in a non-uniform thickness of the chip seal emulsion to the roadway surface and can cause raveling or flushing (bleeding) due to the reduced or uneven distribution of the asphalt binder. An emulsion can be formulated to prevent running even if the road is not flat. Proper formulation can prevent emulsion from running in the field, even on a hill.

Raveling results when aggregate is not adhering to the emulsion. A substantial amount of raveling can expose the underlying emulsion. If a substantial amount of emulsion is exposed, this can cause lower skid friction values. Loose aggregate left on the road surface can cause windshield damage.

Flushing (bleeding) occurs when the emulsion rises above the surface of the aggregate. If a substantial amount of emulsion is exposed, this can cause lower skid resistance values.

Streaking and longitudinal ridging of the chip seal emulsion, regardless if it was caused from the application or quality of material, can cause raveling or flushing (bleeding).

Rapid curing (breaking) can cause premature hydration of the chip seal emulsion before the aggregate is embedded into the chip seal emulsion. Slow curing (breaking) can delay the bonding of the asphalt binder to the aggregate and/or road surface, and can also delay postsweeping operations of the loose or excess aggregate from the chip seal surface.

You can also check and see if you have polymer in the emulsion. After curing has begun, try to remove an aggregate from the emulsion. If there is a band of emulsion stretching between the aggregate and the roadway surface, then polymer is present. This simple field test will not tell you how much polymer is present in the emulsion.

\section{Visual Inspection of the Aggregate (Chips)}

Aggregate should be crushed and cubical in shape to allow interlocking with the adjacent aggregate. River rock (round edges) prevents interlocking from happening. Aggregate slivers should be kept at an absolute minimum to non-existent to prevent flushing (bleeding) in the finished chip seal surface. Aggregate should be surface damp, not wet or dry, to insure proper bonding to the asphalt binder that is present in the chip seal emulsion. Aggregate should also 
be placed one layer thick on top of the emulsion. It is the first layer of aggregate that bonds to the emulsion, not the second, third and so on.

\section{QUALITY CONTROL ON THE JOB SITE}

As stated earlier, the materials are the most important factor in obtaining a successful chip seal. However, a successful chip seal cannot be obtained from quality materials alone. QC is also important during the various phases of the construction operation.

\section{Roadway Preparation}

If a roadway is a proper candidate to receive a chip seal, its structural section should be in no need of repair. However, sometimes a road may need some isolated repair work, such as crack sealing, digouts, or weed abatement, and still be a good candidate for chip sealing. The isolated repair work should be completed before the chip seal operation begins. How long before a chip seal operation begins? The longer, the better, depending on the materials used for the repair work.

Immediately before applying the chip seal emulsion, obstructions on the roadway surface should be removed and the roadway surface cleaned. Obstructions include reflective pavement markers, delineators, thermoplastic striping, or legends. Also, the road surface should be swept to remove any debris, dirt, or dust present on the roadway surface.

After the roadway surface is cleaned, and prior to applying the emulsion, the contractor should place temporary reflective pavement markers to give traffic lane delineation to the driving public. The temporary markers also provide the striping crew the color, location, and pattern of the striping and traffic legends that need replacement.

\section{Traffic Control}

Adequate traffic control should be planned in advance to provide a safe construction work zone for the public and construction crew. The county of San Diego lists the average daily traffic for each road in the contract. This assists the contractor in determining the traffic control work force they need to provide on a road-to-road basis.

Low traffic speeds are important on a chip seal construction site. The county will evaluate each road's speed limit and list which roads need pilot car assisted traffic control. The purpose of the pilot car is to guide traffic through the construction zone at a speed of $25 \mathrm{mph}$ $(40 \mathrm{~km} / \mathrm{h})$, or less, to prevent windshield damage and to provide a safe work environment for the public and construction crew (see Figure 2).

\section{Pumping and Transporting Chip Seal Emulsion}

Hoses used to pump chip seal emulsion between the emulsion plant's tanks and the booster trucks and the distributor trucks should be clean and free of material to prevent contamination of the emulsion. 


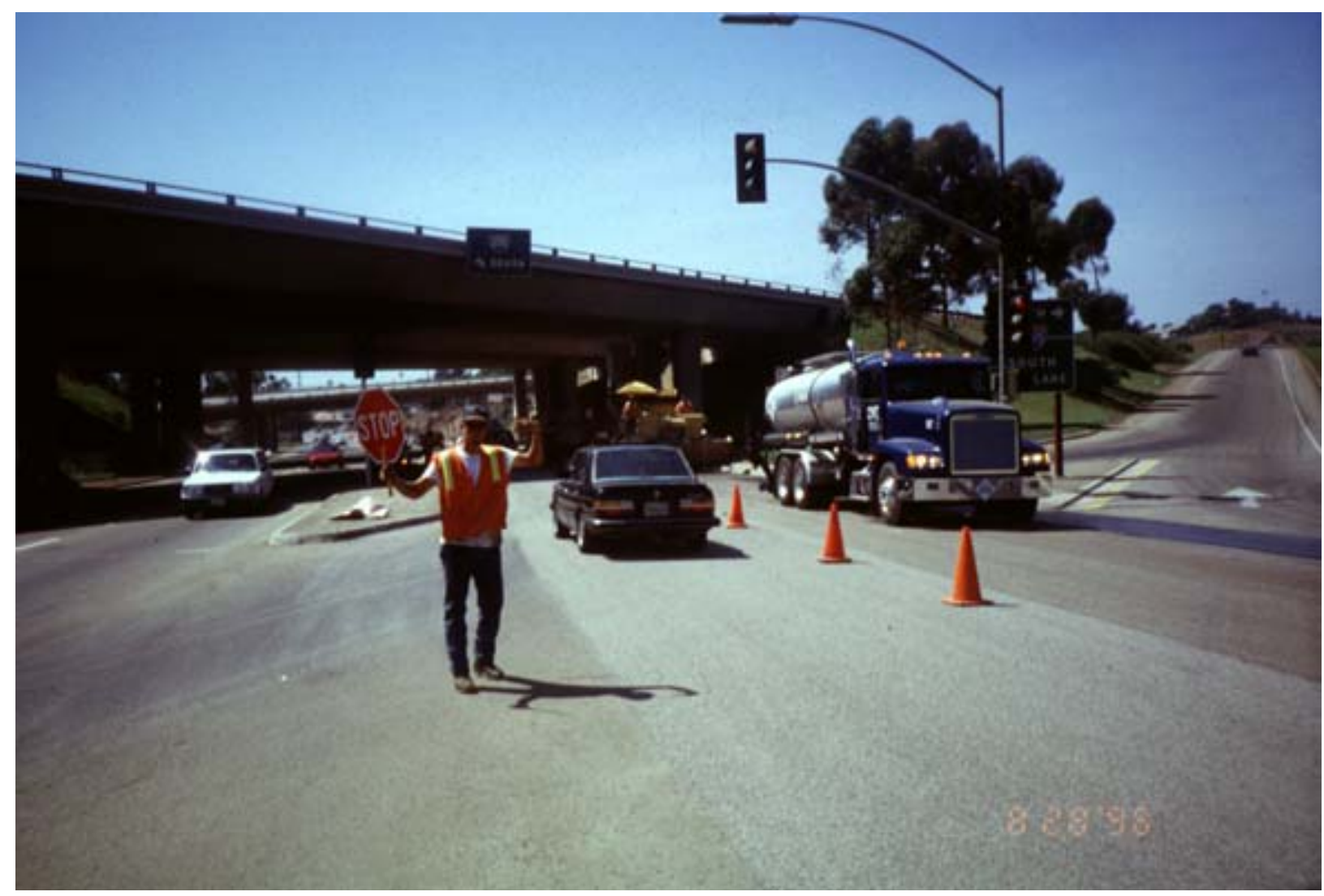

FIGURE 2 Maintain low traffic speeds to prevent damage to the chip seal and windshields.

Cleansing agents should not be present in the truck's tank when loading the emulsion. Cleansing agents should not be left in the distributor truck's spray bar when applying emulsion to the roadway.

A minute amount of foreign objects (cleansing agents, diluents, etc.) that are allowed to mix with the emulsion can affect the whole truckload, thus affecting the finished chip seal.

Chip seal emulsion should be delivered and applied at the temperatures specified in the contract. There are temperature gauges normally on the outside of the distributor truck's tank and display the temperature of the emulsion in the tank. In San Diego, the temperature of the chip seal emulsion is applied between $130^{\circ} \mathrm{F}$ and $180^{\circ} \mathrm{F}\left(55^{\circ} \mathrm{C}\right.$ to $\left.82^{\circ} \mathrm{C}\right)$.

\section{Transporting Aggregate (Chips)}

Typically, end dumps are used on a chip seal project. These are transfer trucks that come with a pup and trailer, or an over-sized pup with no trailer.

When the trucks arrive at the aggregate supplier's plant, it is important that the bed of the truck be clean and free of any foreign objects, to prevent contamination of the aggregate. A large foreign object left in the bed prior to loading the chips can also cause damage to the chip spreader while spreading the aggregate.

It is important that the aggregate be surface damp when they arrive at the construction site. If the surface of the aggregate is dry, this will affect the bonding the asphalt binder to the 
aggregate. If the surface of the aggregate is too wet, this dilutes the emulsion and not only affects the bonding of the asphalt binder to the aggregate but also to the roadway surface.

If you think a truck is delivering wet aggregate, bring it to the contractor's attention. The truck driver can tip the bed high enough to allow any excess water to drain out the back of the bed. If water is draining when this occurs you have two choices: have the truck bed (pup and trailer) stay tipped until all excess water is out, or reject the load. Draining excess water on the job site causes a delay in construction and the contractor will want to bring this to the material supplier's attention in order to avoid future construction delays.

If the aggregate is dry, this too prevents bonding of the asphalt binder to the aggregate. Dry aggregate also affects visibility for construction traffic and public traffic in the work zone.

\section{Quality of Construction Equipment}

It is a good day when all construction equipment is functioning properly. Routine maintenance and frequent inspections will keep construction equipment in good working order and reliable on the construction site. Following are some important aspects of the various construction equipment used on a chip seal project.

\section{Asphaltic Emulsion Distributor Trucks}

Asphaltic emulsion distributor trucks are used for applying chip seal emulsion. Each truck should be calibrated on the first day it appears on the construction site and at monthly intervals during construction. If the truck cannot be calibrated to meet contract specifications, it should not be used on the project.

The proper size nozzles should be installed on the spray bar and maintained daily to prevent plugging. Spray bar nozzles should be aligned at the proper angle to insure uniform coverage of the chip seal emulsion onto the roadway surface, and at the application rate selected.

Pumps should be in good working order with accurate read-out gauges to provide proper circulation and application of the emulsion. Over circulation of the chip seal emulsion should be avoided to prevent sheering.

\section{Aggregate (Chip) Spreader}

A well-maintained chip spreader will apply a uniform application of the aggregate. Frequent maintenance of the hydraulic lines, belts, gates, conveyor belts, and tailgate mounts are necessary for good performance on a daily basis.

To prevent waste of aggregate, the rear rubber should be adjusted to prevent aggregate spillage where the transfer trucks hook up to the chip spreader. Excess waste of aggregate can also be avoided by not over-filling the hopper located at the front of the chip spreader. Excess spillage of the aggregate needs to be removed from the roadway surface and also causes a delay in the construction operation. Even a small pile of excess aggregate has to be raked smooth, so the pneumatic-tired rollers can properly seat the first layer of aggregate into the emulsion. 


\section{Finishing Rollers}

Pneumatic-tired rollers (finishing rollers) are used to seat the aggregate (chips) into the emulsion. Maintaining the hydraulic lines and insuring proper tire inflation is necessary to prevent damage to the chip seal surface. The weight of the roller should also be checked to insure proper embedment of the aggregate.

Rollers should be kept at a maximum speed of $10 \mathrm{mph}(16 \mathrm{~km} / \mathrm{h})$ to prevent windshield damage and to insure proper embedment of the aggregate.

There should be enough pneumatic-tired rollers behind the chip spreader to provide full coverage in one pass. With the invention of variable width chip spreaders, which can reach widths of 16-ft wide, you may need three pneumatic-tired rollers to accomplish this task.

The county of San Diego requires a minimum of three passes to insure proper coverage.

\section{Applying Materials to the Roadway}

\section{Orchestrating the Construction Operation}

The chip spreader operator orchestrates the material placement via radio communication between the drivers of the emulsion distributor truck, aggregate trucks, and pilot car. Contractors typically use $\mathrm{CB}$ radios for on-site communication.

Before chip seal placement begins the roadway must be prepared and traffic control and construction signs in place. Once this occurs, the chip spreader operator will have the equipment get in position for operations to begin.

Chip sealing is a very fast operation and it is important that the equipment stay close together to insure the placement of a successful chip seal project. This means the chip spreader stays close behind the emulsion distributor truck.

The aggregate truck hooked to the chip spreader can empty a load within a minute, so the next aggregate truck should be in line to allow a quick hook-up to the chip spreader. Once the aggregate trucks are emptied, the chip seal operation must stop until enough aggregate trucks are available to continue. The pneumatic-tired rollers follow closely behind the chip spreader to insure the aggregate is being embedded before the emulsion begins to cure (break). It is important to limit the number of trucks between the chip spreader and rollers to allow for proper embedment.

It is also important that public traffic, including pedestrians, not be allowed to cross the road between the equipment; this can be fatal to the public or the construction crew. Proper traffic control and radio communication can help prevent this from happening (Figure 2).

Some contractors also provide $\mathrm{CB}$ radios to the roller operators and pilot car drivers. This is beneficial because they can report concerns regarding the chip seal surface, or a car has entered into the work zone. The contractor sometimes provides a different form of radio communication for the pilot car driver and flaggers so the can run traffic control operations without interfering with the construction operation.

As you can see, communication on the construction site is important in placing a successful chip seal. 


\section{Applying the Chip Seal Emulsion}

Proper application of the chip seal emulsion is necessary to obtain the proper embedment of the aggregate, and to insure an adequate amount of aggregate is exposed for good skid resistance.

Each roadway surface should be evaluated when determining the proper application rate of the emulsion. An AC surface that is smooth or relatively young will require a lesser application rate than an $\mathrm{AC}$ surface that is porous and oxidized. The chip seal emulsion application rate is also dependent of the size and porosity of the aggregate (chips) that is being used.

Over application of the chip seal emulsion can cause flushing (bleeding) and can provide a lower skid resistance. Under application of the chip seal emulsion can cause the aggregate to ravel and expose the underlying chip seal emulsion; this too results in a lower skid resistance. Both of these instances could require repair work.

Chip seal emulsion should be applied to a clean and dry asphalt road surface, when ambient temperatures are $65^{\circ} \mathrm{F}\left(18^{\circ} \mathrm{C}\right)$ and when pavement temperatures are $80^{\circ} \mathrm{F}\left(27^{\circ} \mathrm{C}\right)$. All of these conditions must be met, whether the road surface is in the sun or shade, if you want to have a successful chip seal (Figure 3). Chip sealing should not occur when there is a risk of inclement weather (Figure 4)

Although ambient and pavement temperature requirements are stated for the time of placement, it has become common knowledge there is a greater chance of a successful chip seal project when warm temperatures are also present during evening hours.

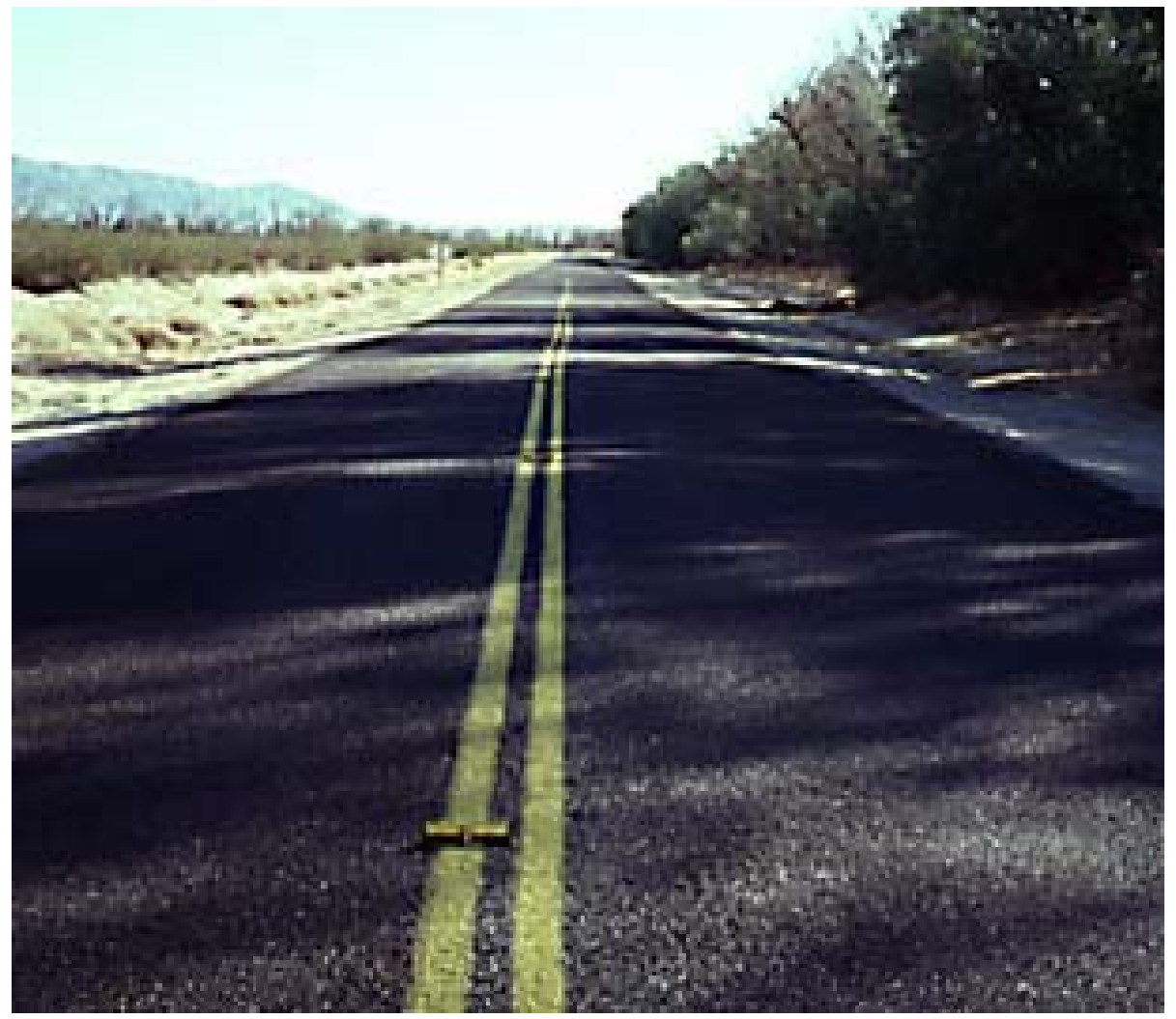

FIGURE 3 Minimum ambient and pavement temperatures, in the sun and shade, must be present before chip sealing begins. 


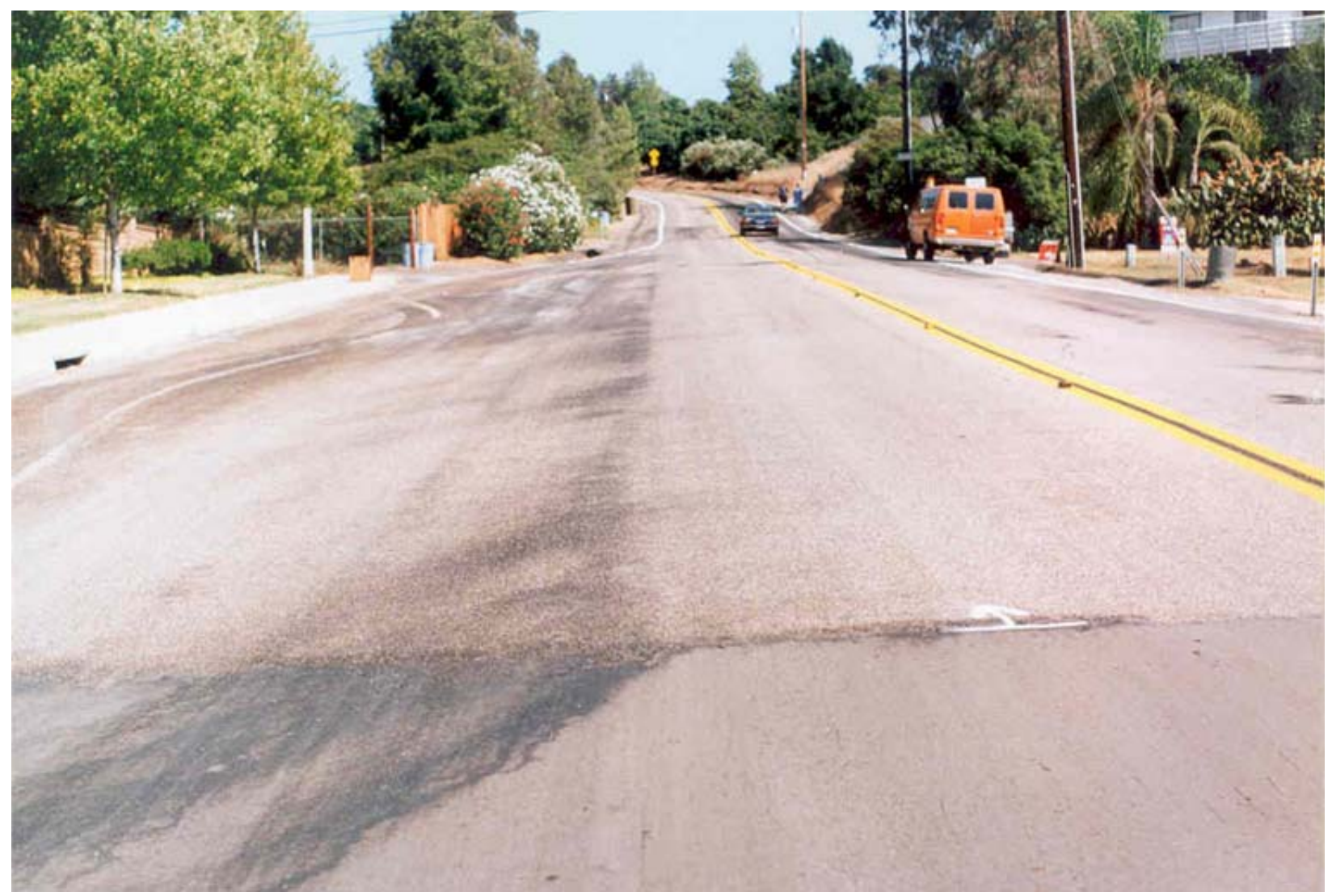

FIGURE 4 Effects of a rain storm that occurred within $24 \mathrm{~h}$ after chip sealing.

\section{Applying the Aggregate}

In order to obtain a successful chip seal, only one layer of aggregate (chips) should be applied to the chip seal emulsion. Aggregate that is applied greater than one layer will most likely not adhere to the chip seal emulsion and will require removal from the road surface to prevent windshield damage. Aggregate that does not adhere to the asphalt binder is considered excess aggregate.

Placement of excess aggregate can affect the embedment of the first layer of aggregate during the finishing operation with the pneumatic-tired rollers. For example, if the aggregate is placed thick on top of the chip seal, the rollers cannot get in contact with the first layer of aggregate. If the first layer of aggregate does not get properly embedded, it is at risk of raveling and causing windshield damage.

It is important to watch for excessive placement especially if the contractor is getting paid by the ton for the amount of aggregate placed at the construction site. To prevent this from happening, you can insert language into your contract that addresses how deductions will be calculated when excess aggregate is placed. 


\section{Finishing the Placed Chip Seal}

Pneumatic-tired rollers (finishing rollers) follow immediately behind the aggregate truck hooked to the chip spreader, or the truck(s) waiting to be hooked to the chip spreader.

Due to the variable widths chip spreaders now have, it is important that enough finishing rollers follow the spreader to provide complete coverage in one pass. This may require you have three finishing rollers to accomplish this task.

The finishing rollers make a minimum of three passes to insure proper embedment of the aggregate into the chip seal emulsion. Finishing rollers also reduce the amount of voids between the aggregate with the natural kneading operation provided by the rubber tires.

In San Diego County, the goal is to reach 30\% to 50\% embedment of the largest aggregate after finishing is completed. Due to weather conditions, other parts of the country may require a higher embedment because of the road's exposure to snow, or a lower embedment because of the road's exposure to heat.

\section{Removing Excess Aggregate (Chips) from the Roadway}

You can tell when the chip seal emulsion is beginning to cure (break) because it changes color from brown to black.

Curing is the displacement or hydration of water from the emulsion and the surface-damp aggregate. The curing stage allows the asphalt binder, which is present in the emulsion, to bond to the aggregate and to the asphalt roadway surface.

Curing time ranges from 2 to $4 \mathrm{~h}$ depending on the formulation of the chip seal emulsion and the weather at the construction site. Once a substantial amount of asphalt binder has bonded to the aggregate and roadway surface, sweeping of the loose aggregate from the road surface can begin. Sweeping before adequate curing has occurred can result in the asphalt binder not bonding to the roadway surface, or can result in the aggregate being removed from the chip seal emulsion.

The county of San Diego has loose aggregate removed with mobile sweepers (pick-up and vacuum). Kick brooms are not allowed to remove loose aggregate from the roadway for several reasons:

- Increased risk in damaging vehicle paint or windshield;

- Reduced visibility for adjacent traffic;

- Aggregate kicked onto shoulders are later transported back to the road surface by rainfall, vehicles, or foot traffic ; and

- Local air pollution and storm water protection regulations.

Proper traffic control not only provides safety for the public and construction workers, but also keeps an orderly and controlled flow of vehicular and pedestrian traffic through the construction zone. The controlled flow of vehicular traffic also assists in embedding the aggregate into the emulsion.

To keep windshield claims to a minimum on roads with speeds of $35 \mathrm{mph}(55 \mathrm{~km} / \mathrm{h})$ or greater, traffic control remains in place from the time the emulsion application begins to the time the removal of loose aggregate is completed. Pilot car-assisted traffic control is also used to maintain traffic speeds at $25 \mathrm{mph}(40 \mathrm{~km} / \mathrm{h})$ or less. Upon completion of removing the loose 
aggregate, the road is ready to have traffic control removed and opened to the normal flow of public traffic.

Congratulations, by following the above recommendations, you may have just placed a successful chip seal.

\section{SUMMARY}

In California, private industry and public agencies share ideas to obtain QC/QA in their efforts to obtain successful chip seal projects. This is done between contractors and agencies, and at the annual California Chip Seal Association (CCSA) convention. The CCSA convention is held in the winter and speakers and attendees consist of educators, materials suppliers, private constructors, and public agencies. All who attend benefit from the presentations and networking with each other about various aspects of chip sealing.

If ever a public agency were to stop chip sealing, due to an unsuccessful chip seal project, this could impact the decision of other public agencies to continue with their chip seal projects. The long-term effect from one public agency reducing or eliminating its chip seal program can limit its ability to maintain roads at a reasonable cost with taxpayers' funds.

The county of San Diego and private industry's cooperative effort to develop performance-based specifications and a QC/QA program has resulted in successful chip seal projects. Performance-based specifications and a QC/QA program will not guarantee a successful chip seal project; however, they will provide the essential tools for constructing and completing a chip seal project within the specified time limits, and increasing the opportunity for success.

The benefit derived from implementing a QC/QA program is directly proportional to the efforts applied by all the participants. Successful implementation of a QC/QA program insures the customer (taxpayer) will receive the desired end product, and that chip sealing will remain viable option agencies can use to maintain its roadways. 


\title{
Lessons Learned from the Long-Term Pavement Performance Program and Several Recycled Sections in Texas
}

\author{
DAR-HaO CHEN \\ Texas Department of Transportation \\ JEROME DALEIDEN \\ Fugro Consultants
}

\begin{abstract}
The performance of recycled asphalt pavement (RAP), the effects of milling, and overlay thickness are important factors for pavement engineers to consider when making decisions on rehabilitation and maintenance activities. Specific Pavement Studies- (SPS-) 5 sections were built 10 years ago to address this issue. Performance data under well-documented SPS sections has provided valuable insight that could not have been achieved otherwise. SPS-3, SPS-5, and three hot-in-place (HIP) recycled sections were studied. One of the HIP recycled sections was adjacent to an SPS-3 and a SPS-5 section, thus they all possessed the same underlying subsurface layers.

It was found that after more than 10 years of service, the RAP sections perform as well as the virgin asphalt concrete (AC) sections. This indicates that the RAP can be effective when used properly. Also, little difference was found in terms of performance on milled and non-milled sections. However, to date, there is less distress on the $125-\mathrm{mm}$ sections than $50-\mathrm{mm}$ sections. It is important to note that all SPS-5 sections are able to resist reflective cracking when a mixture of $30 \%$ RAP and a softer binder is used, the result is a high penetration number ( 30 to 45$)$, with a flexible mixture able to resist cracking. In contrast, cracks came through the HIP recycled sections in just a few weeks for US-175 and US-84. Low penetration numbers in the range of 20 to 21 were found. A $75 \%$ mixture of RAP was found to be too high, because aged binder tends to become brittle, and consequently does a poor job resisting cracking. The HIP recycled process was used satisfactorily on US-281 where no cracking potential existed. Thus, concluding that high percentage RAP mixture should not be used on any location where cracking potential is present. Also, a lower viscosity AC should be added to the RAP to increase the flexibility. The results in the SPS-3 sections indicated that chip seal is the most cost-effective, preventive maintenance (PM) treatment. Although rehabilitation strategy on SPS-5 sections cost more than PM treatments on SPS-3 sections, SPS-5 sections performed better than the SPS-3 sections. The most important factor influencing pavement performance on SPS-3, SPS-5, and HIP recycled sections is these types of surface AC treatments.
\end{abstract}

$\mathrm{T}$ he Long-Term Pavement Performance (LTPP) program was designed to be a 20-year research program studying various pavement structure performances over time. LTPP was initiated in 1987 by the Strategic Highway Research Program (SHRP). Texas has been one of the major contributors to the LTPP program with a total of 91 General Pavement Studies (GPS) and 23 Specific Pavement Studies (SPS). Some of the sections were taken out of the study due to maintenance and rehabilitation activities. Currently, 62 GPS and 11 SPS sites are still being monitored. The SPS sections are newly constructed and built for a specific purpose, while the GPS sections are existing pavement sections that continue to be monitored. The first SPS section in Texas was built in 1990, and the last one was built in 1999. With more than 10 years of data collection, valuable insight has continued to emerge from these experiments.

It is reported that the specific performance of a preventive maintenance (PM) treatment and/or rehabilitation strategy may not be directly transferable from agency to agency or from one geographic region to another, due to many reasons such as the condition of the pavement at the time 
of treatment application, the type of base and subbase materials, surface and subsurface drainage conditions, and type of PM materials used and the quality of the workmanship in applying them (Smith et al. 1993). However, it is reasonable to expect that if a specific treatment performs well in one location it will perform equally well in comparison to other treatments, in another location with similar conditions if applied in a proper and timely manner (Geoffroy 1996). It is also documented in the NCHRP Synthesis of Highway Practice 223: Cost-Effective Preventive Pavement Maintenance that the majority of information regarding the cost-effectiveness of PM resides within agencies and is derived from observational experience (Geoffroy 1996). Even if it is based on observational experience, transportation agencies can still apply the knowledge and take advantage of the cost effectiveness of PM. Although information on the cost effectiveness of the PM treatments is important, literature addressing this issue is limited. Pavement performance information is important to maintenance and rehabilitation activities for overall planning and budgeting purposes.

The main objective of this study is to present lessons learned from SPS-3, SPS-5 and several other recycled pavement projects in Texas. The goals of SPS-3 and SPS-5 sections are to evaluate the PM and rehabilitation strategies, respectively. This study addresses the effectiveness of the rehabilitation strategies and the performance of several recycled projects on or near the SPS-3 and SPS-5 sections. SPS-3 and SPS-5 sections on US-175 are adjacent to one of the recycled sections, as shown in Figure 1. Hot-in-place (HIP) recycling is one of the maintenance treatments being used in several Texas Department of Transportation (TxDOT) districts. SPS-3, SPS-5, and HIP recycled sections were built in the fall of 1990, 1991, and 1999, respectively. These three sections involve different maintenance options that provide a valuable opportunity to determine the cost effectiveness of various treatments. After more than 10 years of service, SPS-3 and SPS-5 sections have performed well and exceptionally well, respectively. In the SPS-5 sections, cracks are observed on the shoulders but stop on the travel lanes where treatments were applied, as shown in Figure 2. In contrast reflection cracks were observed on the newly placed HIP recycled sections after only a few weeks of service. The key factor responsible for this difference in pavement performance, on SPS-3, SPS-5, and HIP recycled sections, is the type of surface asphalt concrete (AC) treatment.

The SPS-3 and SPS-5 sections have been in service for more than 10 years. Normally, TxDOT would expect a PM treatment on flexible pavement to last approximately 5 to 7 years. Under FHWA guidelines, a rehabilitation project is expected to provide service for 8 years. Clearly, both SPS-3 and SPS-5 sections exceed these expectations. PM treatments on SPS-3 sections have reached their service life, and Dallas District is planning to overlay SPS-3 sections in the near future.

\section{SITE DESCRIPTION}

US-175 is a moderately traveled highway with two lanes each direction. The SPS-3, SPS-5, and HIP recycled sections on US-175 were adjacent to each other as shown in Figure 1. The average daily traffic for this roadway in 2000 was 29,510 vehicles, about $14 \%$ of which were trucks. The three sections studied are located on US-175 near Crandall. The AC surface thickness varies from test section to test section. Under the surface treatment are $300 \mathrm{~mm}$ (12 in.) of lime-stabilized base and $455 \mathrm{~mm}$ (18 in.) of lime-stabilized subgrade. The main problem associated with US-175 is cracking. Lime stabilization of the base and subgrade layers, provides a strong pavement foundation, which is prone to cracking. The pavement age for US-175 sections is approximately 22 years. 

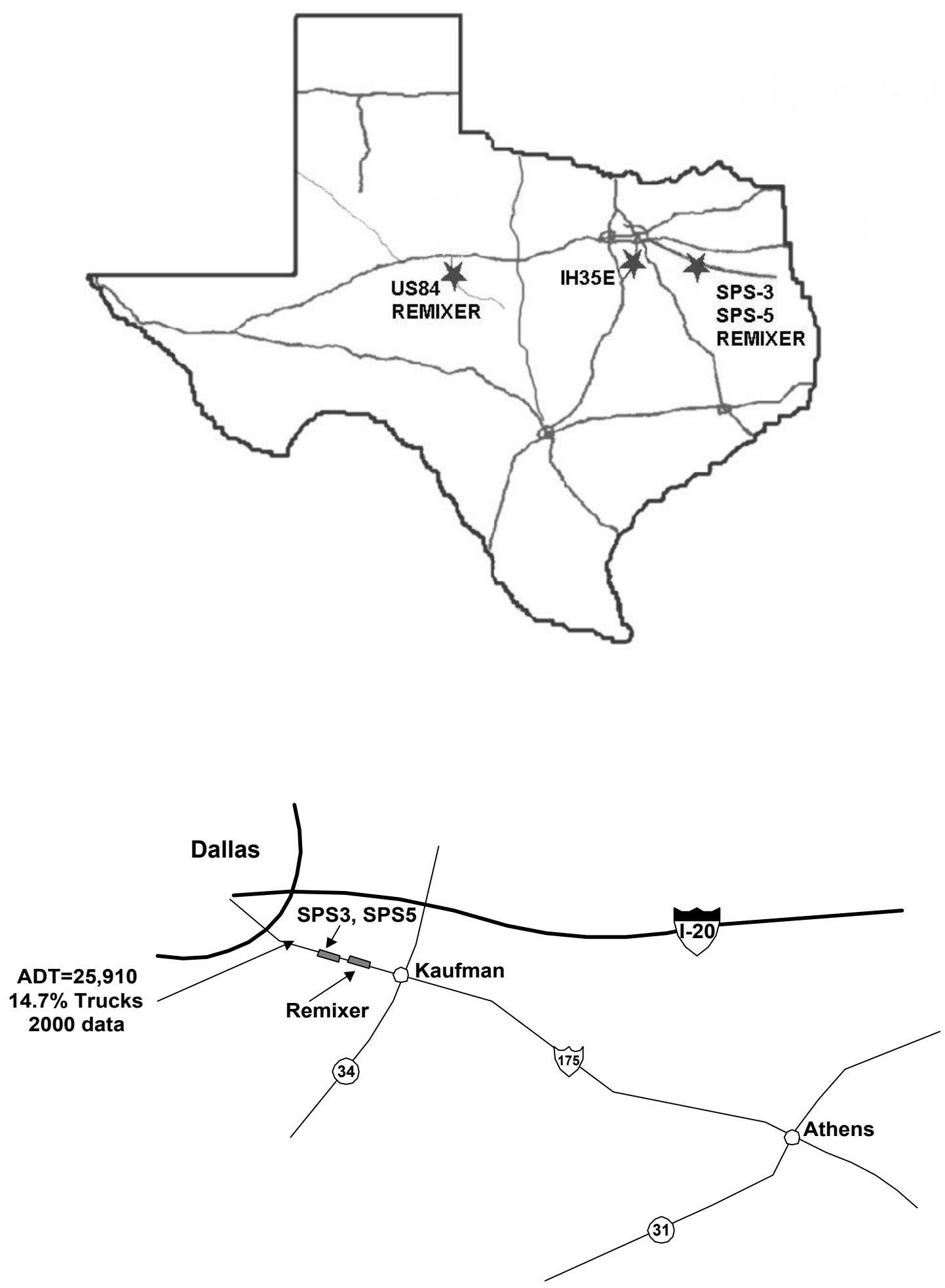

FIGURE 1 Traffic and location of the test sections (HIP recycled = remixer). 


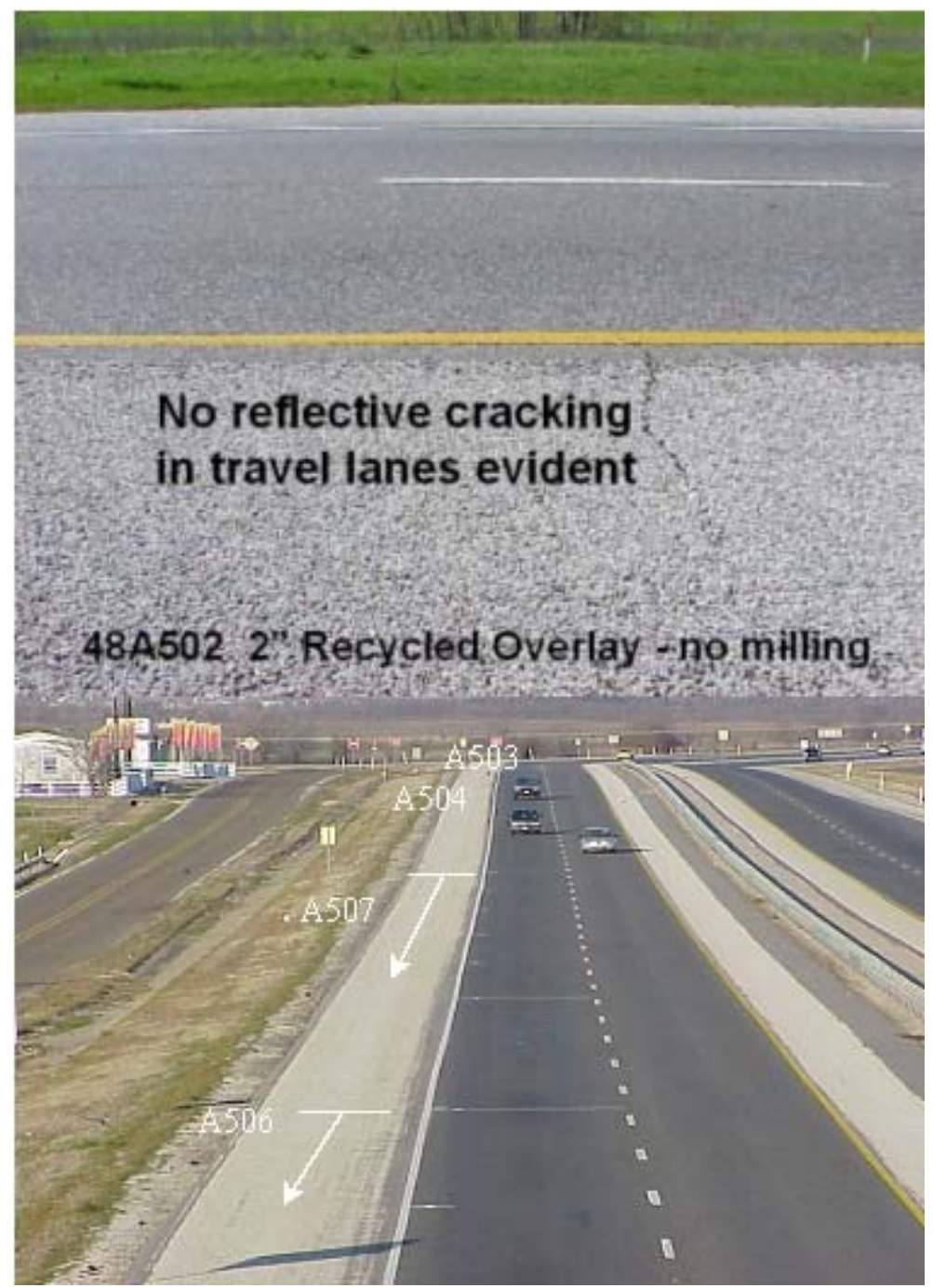

FIGURE 2 Current pavement conditions on SPS-5 section (US-175).

\section{SPS-5 REHABILITATION OF ASPHALT CONCRETE PAVEMENTS STUDY}

\section{Purpose}

The purpose of the SPS-5 experiment is to compare the effectiveness of rehabilitation treatments for thin and thick overlays, constructed with virgin and recycled hot mixes, on milled and nonmilled surfaces. The eight test sections representing the combinations of these three features are placed adjacent to each other for comparison as shown in Table 1 and Figure 2. These eight SPS5 sections were built in 1991. The Dallas district used the experience gained from constructing the recycled SPS-5 sections on an 18-mi long recycled hot mix project on Interstate 35 (I-35) east (one of the busiest routes in Texas) near Waxahachie, as shown in Figure 3. Pavement performances on both I-35 east and US-175 have been excellent. As indicated in the SHRP report (Daleiden 1992) the SPS-5 sections were in fair condition before the rehabilitation. 
Recycled asphalt pavement (RAP) was used in four SPS-5 sections with 30\% recycled material added to the virgin mix. The $70 \%$ of the virgin $\mathrm{AC}$ had an $\mathrm{AC}-5$ grade binder. AC-10, with 3\% latex modifier, was used in four virgin SPS-5 sections. Mix designs were performed for both RAP and virgin sections. Note that a softer grade asphalt was used in the RAP section. The cores from virgin and recycled sections were taken and tested in the year 2000. The penetration numbers for the SPS-5 sections were all above 35.

As recently documented in the NCHRP Report 452: Recommended Use of Reclaimed Asphalt Pavement in the Superpave Mix Design Method: Technician's Manual (McDaniel and Anderson 2001), for higher RAP contents, RAP binder has to be extracted and recovered to determine its properties. Under the recommended guidelines for using RAP in Superpave mixtures, there are three levels, or tiers, of RAP usage. The limit of these tiers depends on RAP content and binder grade. With softer RAP binders, a higher percentage of RAP can be used. The first tier establishes the maximum amount of RAP that can be used without changing the virgin binder grade. The second tier shows the percentages of RAP that can be used when the virgin grade is decreased by one grade (a 6-degree increment), on both the high and low temperature grades. The third tier is for higher RAP contents; for these higher contents, it is necessary to extract, recover, and test the RAP binder to construct a blending chart.

TABLE 1 SPS-5 Test Section Set-Up

\begin{tabular}{|l|l|l|l|}
\hline Section ID & Overlay Thickness & AC Property & Milling \\
\hline 48 A502 & $50 \mathrm{~mm}$ & Recycled & no \\
\hline 48 A509 & $50 \mathrm{~mm}$ & Recycled & $50 \mathrm{~mm}$ \\
\hline $48 \mathrm{~A} 508$ & $125 \mathrm{~mm}$ & Recycled & $50 \mathrm{~mm}$ \\
\hline $48 \mathrm{~A} 503$ & $125 \mathrm{~mm}$ & Recycled & no \\
\hline $48 \mathrm{~A} 507$ & $125 \mathrm{~mm}$ & Virgin & no \\
\hline $48 \mathrm{~A} 504$ & $125 \mathrm{~mm}$ & Virgin & $50 \mathrm{~mm}$ \\
\hline $48 \mathrm{~A} 506$ & $50 \mathrm{~mm}$ & Virgin & $50 \mathrm{~mm}$ \\
\hline $48 \mathrm{~A} 505$ & $50 \mathrm{~mm}$ & Virgin & no \\
\hline
\end{tabular}

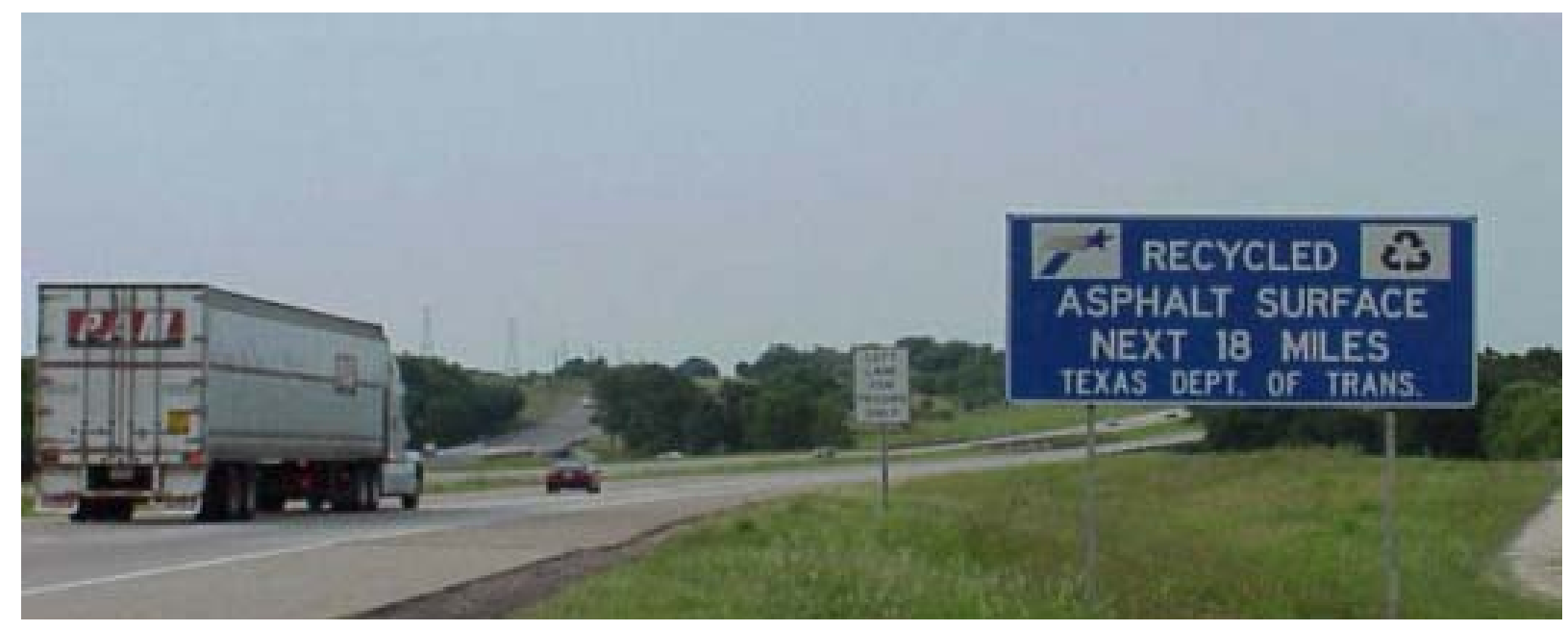

FIGURE 3 Recycled project on I-35 east in Dallas, Texas. 


\section{Outcome}

After more than 10 years of service, no significant distress can be identified on the SPS-5 sections. Although many transverse cracks are observed on the shoulder, they discontinue at the travel lanes. Under the FHWA guidelines a rehabilitation strategy is expected to provide 8 years of service. The performances for all SPS-5 sections has been excellent and exceeded the requirement. To date, there is no difference in terms of performance between $50-\mathrm{mm}$ milling and no milling, or between recycled and virgin asphalts. The 125-mm AC sections perform slightly better than the 50-mm AC sections.

Figure 4 shows the International Roughness Index (IRI) of selected sections. It is observed from Figure 4 that the IRI values remain about the same as when they were overlaid 10 years ago. Note that an IRI value less than $0.95 \mathrm{~m} / \mathrm{km}(60 \mathrm{in} . / \mathrm{mi})$ is considered excellent and between 0.95 and $1.42 \mathrm{~m} / \mathrm{km}$ (95 in./mi) is considered as good.

\section{HOT-IN-PLACE RECYCLING}

\section{Process}

The HIP project is approximately $5 \mathrm{mi}$ away from the SPS-5 sections. The HIP recycling was constructed using the Remixer process, which involves several propane heaters that travel ahead of the Remixer machine. The amount of heat transferred to the pavement depends on several variables including weather conditions and speed of operation. After the pavement has been heated enough to soften it the Remixer machine mills off the top $38 \mathrm{~mm}$ (1.5 in.) of AC and mixes in about $25 \%$ new material before replacement. Local undulations in the roadway are

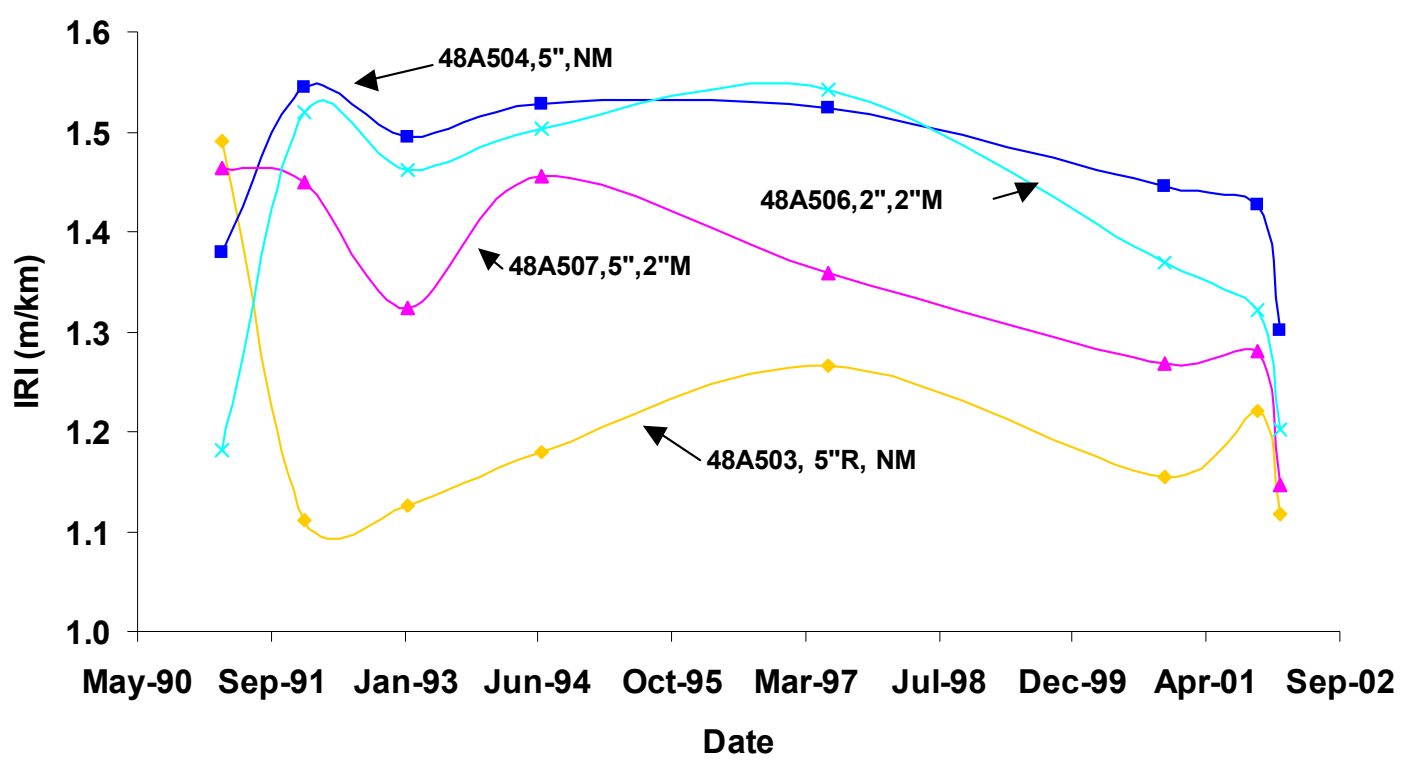

FIGURE 4 IRI values for SPS-5 sections. 
milled, leading to some variation in rehab depth and improved ride quality of the finished pavement. The recycled pavement is then compacted with a vibrating steel wheel and pneumatic rollers, as with a conventional overlay. The added material is a standard Type $\mathrm{C}$ mix utilizing aperformance grade (PG 64-22) binder. Approximately $0.5 \%$ of polymer-modified emulsified rejuvenator was added to the new mix. The $75 \%$ recycled component tends to lower both the penetration number and resistance to cracking. In this case, a nominal $38 \mathrm{~mm}$ of old AC was heated and milled off and $48 \mathrm{~mm}$ (1.9 in.) was replaced.

An FHWA report (1996) suggests that for RAP with contents greater than $15 \%$, the selection of the new asphalt cement or recycling agent added to recycled hot-mix asphalt should be based on a viscosity blending chart or equivalent procedure. However, the selection of new asphalt cement for mixes containing high RAP contents is sometimes done with little regard for the stiffening effect of aged/recycled material. Some state materials engineers have shown this to be a problem leading to greater frequency of transverse cracking or premature fatigue cracking. The FHWA report (1996) also documented that the majority of the RAP is actually less than $35 \%$ recycled material. In this case of $75 \%$ recycling, no effort was made to design the mix using a viscosity blending chart. Since the HIP project is from the maintenance fund with thickness less than $50 \mathrm{~mm}$, no mix design is required in this case.

The underlying pavement of these sections was badly cracked, both transversely and longitudinally, as shown in Figure 5. However, the average falling weight deflectometer deflection is low in the range of about $0.127 \mathrm{~mm}(5 \mathrm{mils})$ at $40 \mathrm{kN}(9,000 \mathrm{lbs})$. The deflection level is compatible to those normally observed on Interstate highways. The underlying structure is considered sound, as the westbound lanes now have $200+\mathrm{mm}(8+\mathrm{in}$.) of AC. Under the surface treatment are $300 \mathrm{~mm}$ (12 in.) of lime-stabilized base and $455 \mathrm{~mm}$ (18 in.) of limestabilized subgrade.

It was found that the penetration of the Remixer ranges from 20 to 21 . Normally, for a typical new surface mix, the penetration number is about 30 to 45 .

\section{Outcome}

Many reflection cracks have been observed on the Remixer section. Figure 6 shows the crack development over a $2 \frac{1}{2}$ year period. It has been concluded that the Remixer treatment with $75 \%$ RAP is not a viable treatment in cases where there is a problem with cracking (Chen and Bilyeu 2001). It is suggested that for US-175, the RAP content should be lowered and a lower-viscosity asphalt used to reduce cracking. Longitudinal cracks were observed in spring of 2002, as shown in Figure 6. The Remixer section on US-175 was overlaid with a seal coat in June 2002. The asphalt used was AC15-5 TR (5\% tire rubber) and supplied by Gulf States Asphalt Co., which is based in Houston.

Remixer was also used on US-281 in the Fort Worth District in 1996. There were no severe preexisting cracks, and the performance has been excellent. Detailed results have been presented elsewhere (Chen and Hugo 2001). However, the Remixer process was also used on US-84, in the Abilene District, where severe transverse cracks reflected through in only a few weeks, as shown in Figure 7. 


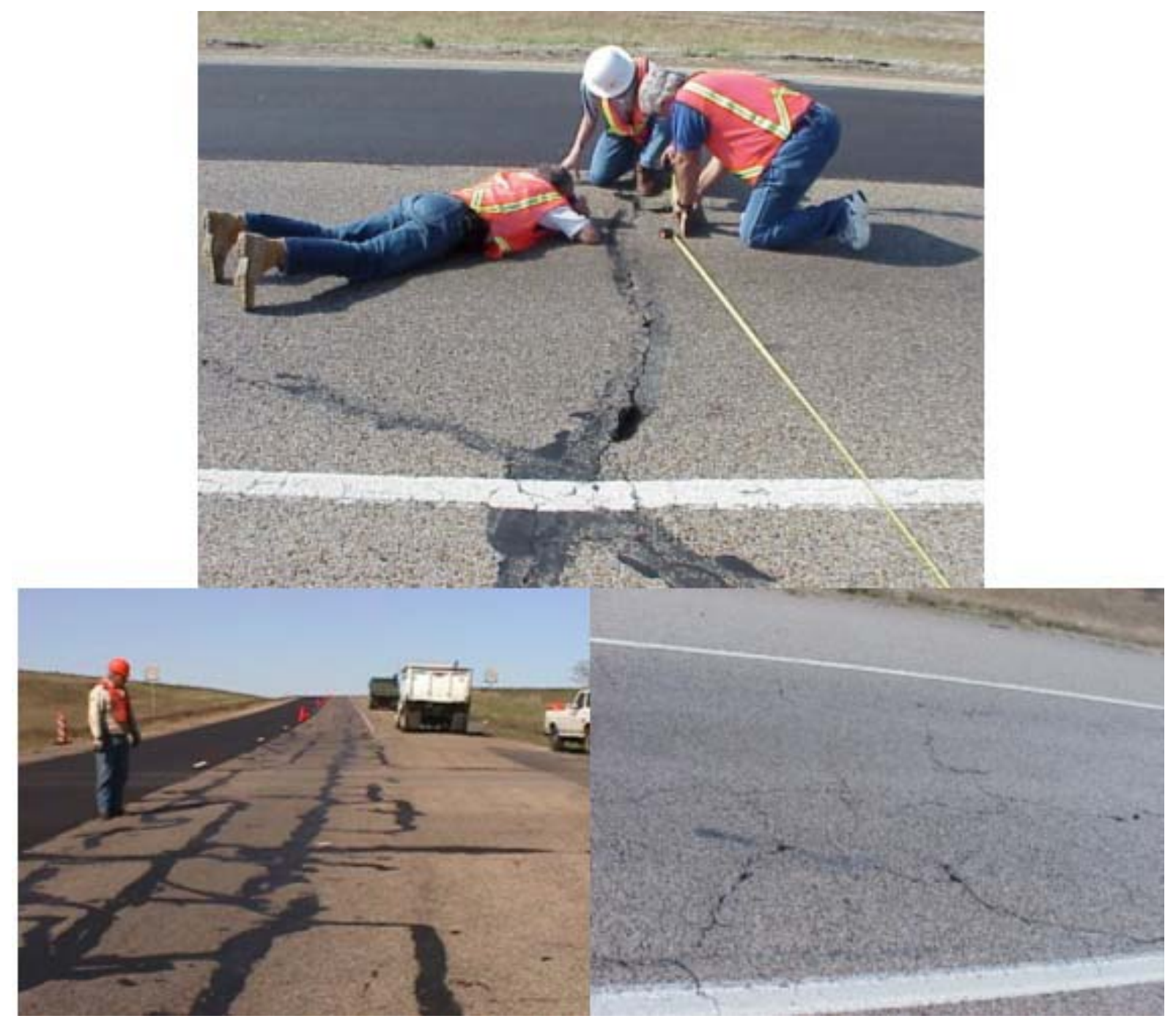

FIGURE 5 Pavement conditions before overlay on the HIP section (US-175). 


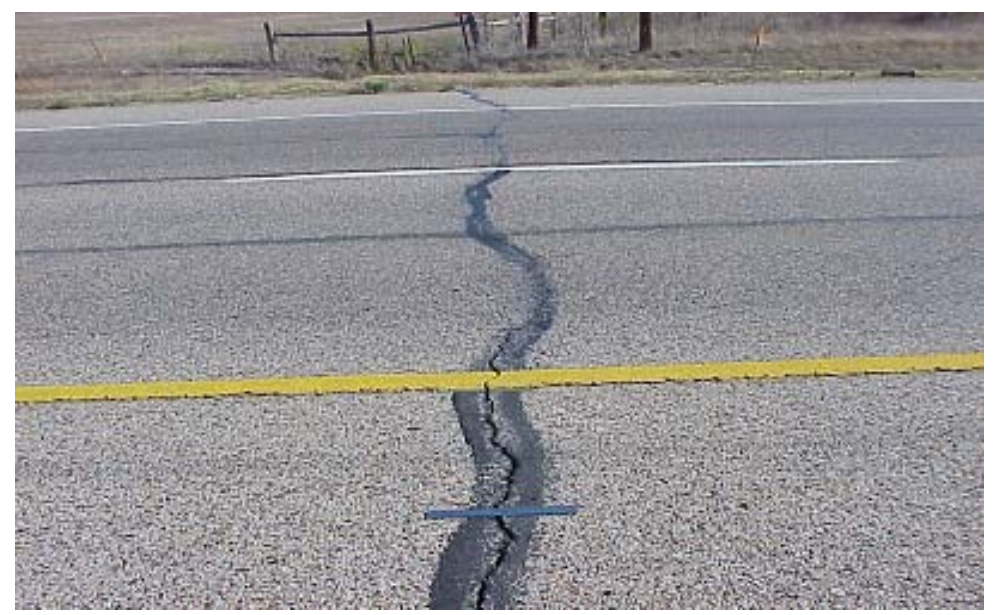

(a)

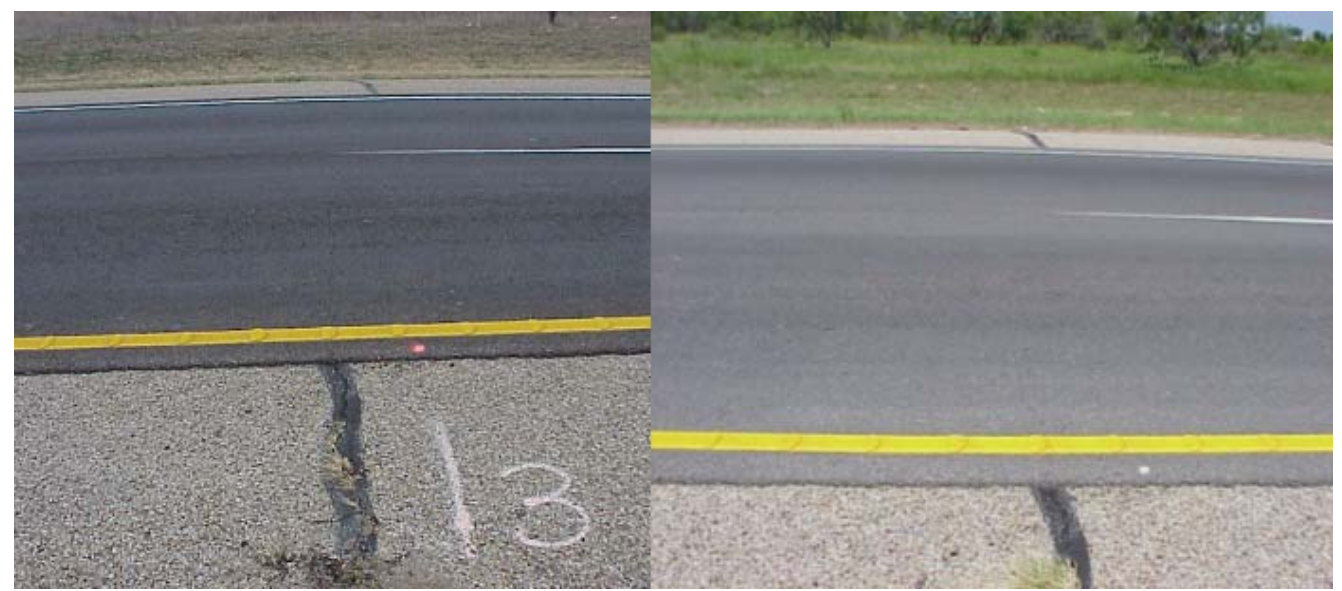

(b)

(c)

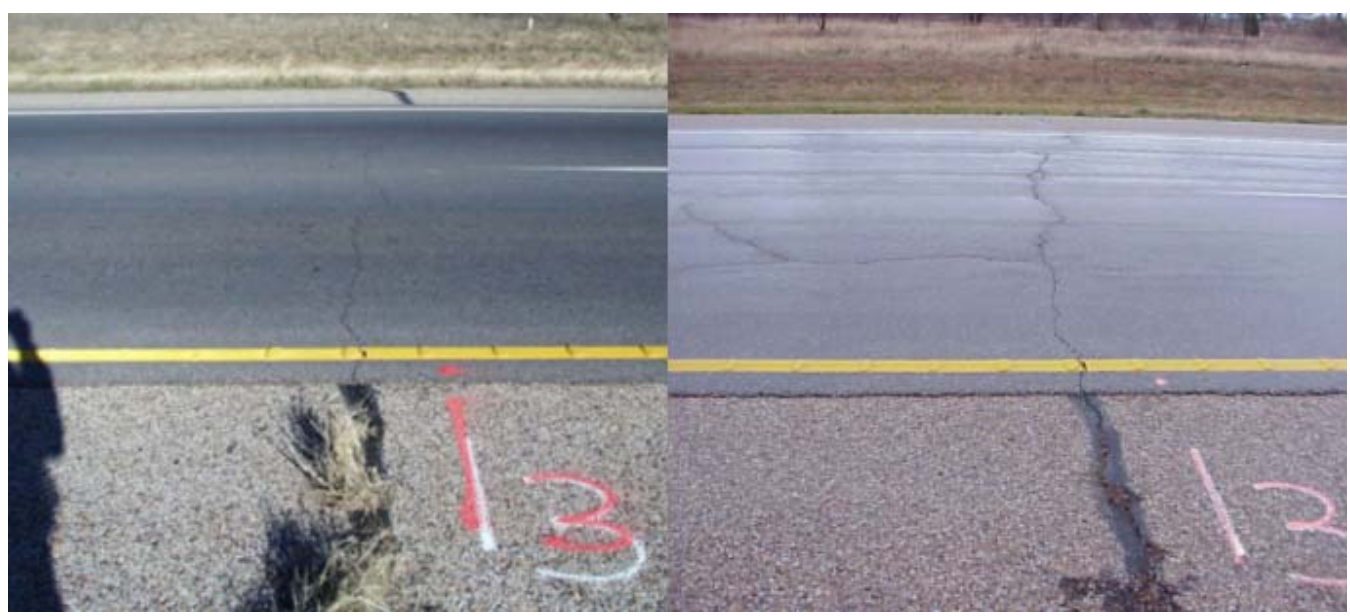

(d)

(e)

FIGURE 6 Crack developments on remixer section (US-175): (a) before overlay (remixer) October 1999; (b) February 2000, (c) July 2000, (d) December 2000, and (e) February 2002. 


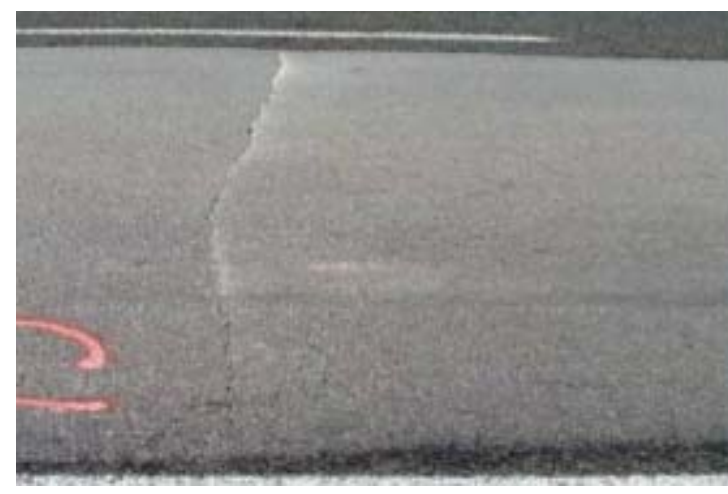

(a)

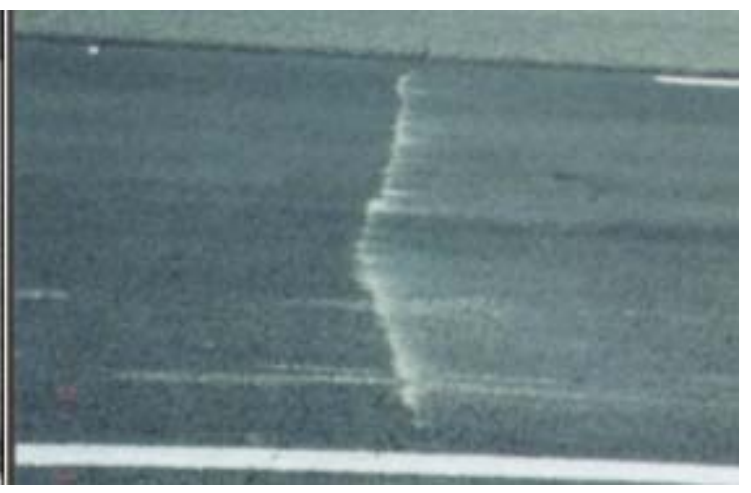

(b)

FIGURE 7 Crack developments on remixer section (US-84): (a) before remixer process (US-84) and (b) 2 months after remixer process (US-84).

\section{SPS-3 PREVENTIVE MAINTENANCE EFFECTIVENESS OF FLEXIBLE PAVEMENTS SECTION}

\section{Test Sites}

TxDOT has spent over $\$ 1$ billion maintaining its highway systems for FY2001. At least \$324 million has been allocated to PM treatments. Approximately 14,000 to 20,000 lane-miles receive PM treatment annually. TxDOT has a great interest in the effectiveness of PM treatments, and therefore participated in the SPS-3 study. There are 14 SPS-3 test sites in Texas and some of the results are presented in Chen et al. (2002B). It is important to note that all SPS-3 sections were built by the same contractor who is a slurry seal contractor.

Highway departments have found that applying appropriate low-cost PM treatments does prolong service life, which means a better investment, better service quality, and increased customer satisfaction and support. SPS-3 test sections were to address cost-effectiveness of various PM treatments such as a thin overlay, slurry seal, crack seal, and chip seal. Almost all SPS-3 sites have one control section that has been left alone without any treatment since the sites were built in 1990. It is not the intent of the PM treatments to improve the load-carrying capacity of pavements, but to extend the useful life and improve the level of service. Timing is crucial in PM, which should be performed well before any failure occurs (Geoffroy 1996; Chen et al. 2002a).

By performing survival analyses, Daleiden and Eltahan (2000) found that while the life expectancy of sound pavement with maintenance treatment is the longest, fair pavements receive the greatest benefit from maintenance treatments. No significant additional life will be gained by applying the treatment to pavements in either excellent or poor existing conditions. SPS-3 sections on US-175 had been rated "poor" before the PM treatments were applied (Daleiden and Eltahan 2000). It is reported that a sound underlying structural condition is one of the keys to the success of PM treatments (Geoffroy 1996). 


\section{Outcome}

All PM treatments on US-175 lasted for 10 years. Among the chip seal, slurry seal, and 50-mm overlay, chip seal is the most cost-effective alternative. The TxDOT PMIS method was used to compute the distress score. The distress scores are found to be 48.4, 36.8, 24.1, and 65.4 for thin overlay, slurry seal, crack seal, and chip seal, respectively. The distress scores range from 1 (very poor) to 100 (very good) (TxDOT 2000). For a distress score between 90 and 100, the pavement is classified as very good; scores of 80 to 89 are classified as good. Distress scores less than 70 are considered poor. The SPS-3 sections are scheduled for repair in the near future. TxDOT's policies recommend performing a rehabilitation whenever a distress score falls below 60 , and a PM treatment for distress score between 70 and 89.

Three different distress levels (high, medium, low) of cracks were collected in the LTPP sections. Average crack width less than or equal to $6 \mathrm{~mm}$ is treated as a "low" distress level. No minimum crack width was specified in the distress protocol. Thus, any visible cracks found by the raters walking on the pavement were recorded. The distress data collected using the TxDOT windshield practice yields higher distress scores than those using the LTPP method.

Chen et al. (2002b) studied 14 Texas SPS-3 test sites and found that only very few sections experienced premature failures. The chip seal has the most sites in which it is rated the best performer. The chip seals performed well on a wide range of pavement conditions. In fact, chip seals have the highest distress score for both high and low traffic areas. When initial cost is considered, crack seal provides the best alternative for low traffic routes that have a sound underlying pavement structure. For high traffic routes, chip seal is a better choice. However, a thin overlay is the most effective for rut resistance. Since the thin overlay has the highest initial cost, it is best used on high traffic routes where rutting is a major concern. If the rutting is not a concern, chip seal is the best choice for a high traffic area.

\section{LABORATORY TESTING}

As presented above, the substructures (base and subgrade) are the same for all three sections (SPS-3, SPS-5 and HIP). However, the SPS-5 sections are better able to resist cracking over a 10-year period, while the cracks on the HIP section come through in a few weeks. It is important for pavement engineers to be able to differentiate crack resistant properties in the laboratory, before placing them in the field. The overlay tester developed by the Texas Transportation Institute was used to test specimens from SPS-5 and HIP sections. The test beams were $150 \mathrm{~mm}$ long by $75 \mathrm{~mm}$ by $75 \mathrm{~mm}$, which were cut from the $150-\mathrm{mm}$ diameter field cores. In addition, a notch was cut at the bottom of the beam specimen, as shown in Figure 8. The specimen was glued to base plates, which were split about the notch. The specimen was then bolted in the overlay tester and one side was held fixed while the other was pulled horizontally under a constant displacement load.

Interestingly, it only took two repetitions to crack through the HIP specimens at $77^{\circ} \mathrm{F}$ and .04-in. opening distance. More than 300 repetitions were applied to SPS-5 cores; tests were terminated before the crack went through the specimens. Thus, the crack tester results seem to be able to make a distinction between mixes and their corresponding crack resistance. However, additional work is needed to establish a threshold for the crack tester on screening mixes before these mixes are placed on highways. 


\section{DISCUSSION OF FINDINGS}

The main problem associated with US-175 is cracking. Lime-stabilization of the base and subgrade layers provides a pavement foundation which is sound, but prone to cracking. The Remixer process contained $75 \%$ of RAP, which is much higher than the typical $35 \%$ used by most other states (FHWA 1996). The high percentage of RAP increases the mix stiffness which in turn, increases the resistance to rutting but causes premature cracking.

The Remixer process demonstrated its ability to resist rutting on the US-281 rehab where there was no underlying stripping or cracking problem (Chen, Dar-Hao, and Hugo 2001). Three months after the rehab on US-175, more than half of the cracks observed in the shoulder had continued into the rehabilitated lanes. Crack seal will need to be applied after 1 to 2 years to prevent excessive water from entering the pavement.

There are several LTPP SPS-5 sections (48A502 through 48A509) $3.2 \mathrm{~km} \mathrm{(2} \mathrm{mi)} \mathrm{from}$ the HIP site. After 10 years of service, only a few cracks were observed in the SPS-5 sections. Recycled pavements were used in some SPS-5 sections with $30 \%$ recycling. The $70 \%$ of new AC had an AC-5 grade binder. The penetration numbers for the SPS-5 sections are all above 35. Base and subgrade structures are similar to the Remixer sections.

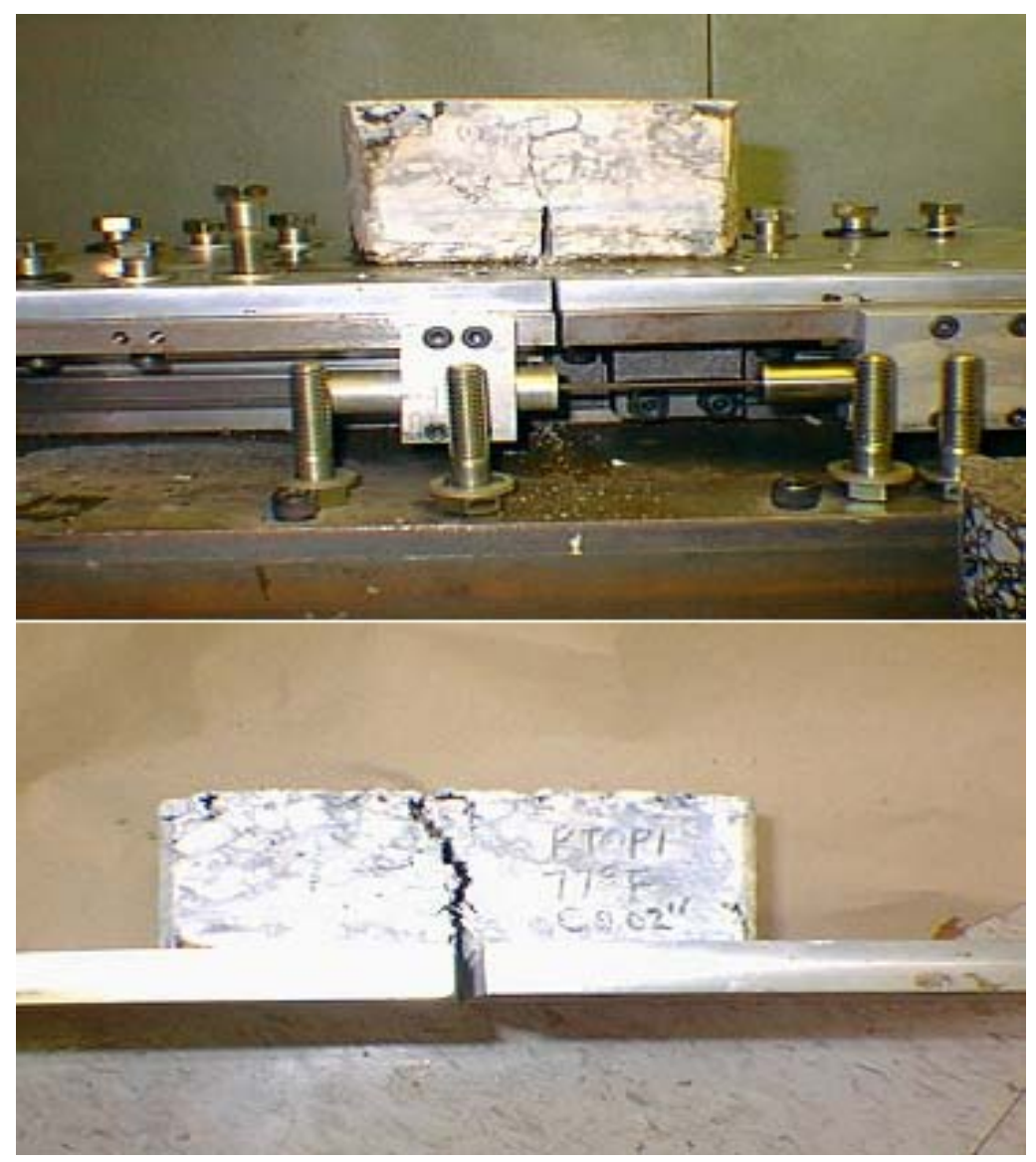

FIGURE 8 Overlay testers and failed specimen. 
It was found that the Remixer treatment with $75 \%$ RAP is not a viable treatment when there is an existing cracking problem. It is suggested that when applying the RAP to US-175, the reclaim content should be lowered to approximately $30 \%$ and a softer asphalt binder grade should be used to reduce cracking. With extensive cracks observed on the Remixer section, a seal coat was applied in the summer of 2002. This is far less than the 7-year life which is expected. It is clearly shown from the sections on US-175 and US-84 that Remixer processes with high percent RAP are a poor choice for sections were severe cracks preexist. However, a Remixer process could be a good choice when no severe preexisting cracks are present, as in US281. Table 2 presents the comparison among treatments.

Currently, TxDOT allows RAP to be used as a standard material. The contractor has the option to use up to 20\% RAP in surface mixtures and level-up, and up to $30 \%$ RAP in base course mixtures. Only RAP from designated state-owned sources may be used in surface mixtures.

The overlay tester showed similar results to a practical road surfacing application. Cracking through the HIP specimen appeared in 2 repetitions, while more than 300 repetitions were needed for the SPS-5 sections. Yet despite these promising results, additional research is needed to establish thresholds such as test temperature, opening distance, and number of repetitions.

\section{CONCLUSIONS}

Rehabilitation of our aging highway system is one of the primary concerns for highway agencies. Performance data under well-documented LTPP sections provides valuable information to address questions that could not be answered otherwise. Performance of RAP, milling effects, and overlay thickness are important factors that pavement engineers need to incorporate into their evaluation process concerning the rehabilitation and maintenance of the state maintained highway system. SPS-5, SPS-3, and HIP recycled sections were studied and the observations and conclusions are as follows:

TABLE 2 Comparisons of Various RAP Performances

\begin{tabular}{|l|l|l|l|}
\hline Section & SPS-5 & Remixer & Remixer \\
\hline Mix & Plant & HIP & HIP \\
\hline Highway & US-175 & US-175, US-84 & US-281 \\
\hline Year constructed & 1991 & 1999 & 1996 \\
\hline RAP contents & $30 \%$ & $75 \%$ & $75 \%$ \\
\hline Performance & Excellent & Poor (reflected cracking) & Good \\
\hline $\begin{array}{l}\text { Condition before } \\
\text { overlay }\end{array}$ & $\begin{array}{l}\text { Longitudinal and } \\
\text { transverse crack }\end{array}$ & $\begin{array}{l}\text { US-175-extensive longitudinal } \\
\text { and transverse crack; US-84- } \\
\text { transverse crack }\end{array}$ & $\begin{array}{l}\text { Few transverse } \\
\text { thermal crack }\end{array}$ \\
\hline Penetration No. & $30-45$ & $20-21$ & $20-21$ \\
\hline Overlay tester & 300 repetitions to failure & 2 repetitions to failure & NA \\
\hline Virgin asphalt & AC-5 & PG64-22 +0.5\% polymer-modifier & NA \\
\hline
\end{tabular}


- After more than 10 years of service, RAP sections perform as well as the virgin AC section. This indicates that the recycled AC can be used effectively when it is done properly.

- There is not much difference in terms of performance on milling and non-milling sections. However, up to the present, there is less distress on $125-\mathrm{mm}$ sections than the $50-\mathrm{mm}$ sections.

- All SPS-5 sections were able to resist cracks; $30 \%$ of RAP and lower viscosity AC was used, which resulted in a high penetration number (30-45) with a flexible mixture that is able to resist cracking.

- Cracks came through the HIP sections in only a few weeks for US-175 and US-84. Low penetration numbers in the range of 20-21 were found; $75 \%$ of RAP was too high, because aged AC tends to be brittle which is poor at resisting cracking. After $2 \frac{1}{2}$ years in service, a seal coat was placed on the US-175 Remixer section, this is far less than the anticipated 7 years of life.

- The Remixer process is used satisfactorily on US-281 where it has no preexisting cracks. Thus, it suggests that high percent RAP mixture should not be used on any location where cracking potential is present.

- The overlay tester did an excellent job on differentiating the crack-resistant properties for the SPS-5 and the HIP sections. Additional work is needed to establish a threshold for the overlay tester.

- The results from the SPS-3 sections indicated that chip seal is the most cost-effective treatment. Although the rehabilitation strategy on SPS-5 sections cost more than those PM treatments on SPS-3 sections, SPS-5 sections performed better than the SPS-3 sections.

\section{ACKNOWLEDGMENTS}

This work could not have been completed without the assistance of John Bilyeu and Debbie Walker, and Mike Murphy of TxDOT. People helping with data collection and processing include Joe Thompson, J. V. Herrera, Tom Connolly, Robert Light, Brian Stampley, Doug Chalman, and Craig Cox.

\section{REFERENCES}

Chen, D.-H., and H. Hugo. Comparison of the Effectiveness of Two Pavement Rehabilitation Strategies. Journal of Transportation Engineering, ASCE, Vol. 127, No. 1, 2001, pp. 47-58.

Chen, D.-H., and J. Bilyeu. Assessment of Hot-in-Place Recycling Process on US-175. Presented at 80th Annual Meeting of the Transportation Research Board, Washington, D.C., 2001.

Chen, D.-H., D.-F. Lin, and J. Bilyeu. Determination of the Effectiveness of Preventive Maintenance Treatments. International Journal of Pavement Engineering, Vol. 3, No. 2), 2000a, pp. 71-83.

Chen, D.-H., D.-F. Lin, and H.-L. Luo. Effectiveness of Preventive Maintenance Treatments Using Fourteen SPS-3 Sites in Texas. Accepted for publication in the Journal of Performance of Constructed Facilities, ASCE, $2002 \mathrm{~b}$.

Daleiden, J. F., and A. A. Eltahan. Report on the SPS3-3 Experiment of the Long Term Pavement Performance Project in the Southern Region. FHWA-IF-00-026. FHWA, U.S. Department of Transportation, 2000.

Fugro-BRE. SPS-3 Construction Report, 1991.

Daleiden, J. F. Asphalt Rehabilitation Study on US-175 in Kaufman County, Texas. Final Report SPS-5 Project. SHRP Southern Region Coordination Office, Fugro BRE, Inc., 1992.

Pavement Recycling Executive Summary and Report. FHWA report SA-96-060. FHWA, U.S. Department of Transportation, 1996. 
Geoffroy, D. NCHRP Synthesis of Highway Practice 223: Cost-Effective Preventive Pavement Maintenance, TRB, National Research Council, Washington, D.C., 1996.

McDaniel, R., and R. M. Anderson. NCHRP Report 452: Recommended Use of Reclaimed Asphalt Pavement in the Superpave Mix Design Method: Technician's Manual. Transportation Research Board of the National Academies, Washington, D.C., 2001.

Smith, R. T., T. Freeman, and O. Pendleton. Pavement Maintenance Effectiveness. SHRP-H-358. TRB, National Research Council, Washington, D.C., 1993. 
PART 2

Network 



\title{
Integration of Preventive Maintenance in the Pavement Preservation Program Ontario Experience
}

\author{
WAEL BEKHEET \\ KHALED HELALI \\ Stantec Consulting \\ TOM KAZMIEROWSKI \\ LI NingYuAN \\ Ministry of Transportation of Ontario
}

Traditional pavement preservation (PP) practices have mainly focused on corrective maintenance activities. However, with the constant demands on highway networks and the extensive costs required for rehabilitation, highway agencies have started to adopt preventive maintenance (PM) strategies into their PP programs. PM is a set of activities performed while the pavement is still in a good or fair condition to inhibit progressive failure and therefore extend the service life of the pavement. Potentially, PM can enhance pavement performance and reduce the life-cycle costs of highway facilities.

The Ministry of Transportation of Ontario (MTO) has been one of the pioneering agencies in applying pavement management system (PMS) analysis tools to its annual pavement maintenance and rehabilitation (M\&R) program at the network level. Currently, MTO is in the process of implementing a PP program that includes PM as a key component. In this program, a practical PM model is developed through a set of dedicated decision trees (DT). This determines the feasible maintenance activities for each pavement section based on a number of factors, including existing pavement surface layer, condition, age, and traffic. The PM work program is finalized through budget optimization to determine the most cost-effective maintenance activity for each candidate section.

The impact of the PM activities on the overall pavement performance is modeled as an immediate improvement in the pavement condition index and/or a slower rate of deterioration, depending on the nature of the PM activity. This impact is then accounted for and integrated with pavement rehabilitation analysis during the course of development of the final work program for the entire highway network.

Budget analysis is performed to determine the impact of incorporating the PM activities into the PP program as compared to a PP program that includes rehabilitation activities only. Analyses results showed that under the same budget scenarios, incorporating PM into the overall PP program resulted in a significant improvement to the network condition.

In this paper, an overview of the MTO PP program, with special emphasis on the integration of the PM program into the PMS, is presented. The development of PM DTs and performance modeling is discussed in detail. In addition, budget scenario analyses comparing the use of PM and M\&R activities, as opposed to $M \& R$ activities only, in the development of the final work program, are presented.

\footnotetext{
s we proceed into the 21 st century, highway agencies are undergoing a significant transition from the original focus on new highway construction to the preservation of the existing highway system. These agencies are facing a tremendous challenge in preserving and improving their highway infrastructure because of aging highway networks, budget constraints, and the continuous increase of traffic demand. As a result, highway agencies have started to adopt preventive maintenance (PM) strategies activities into their pavement preservation (PP) programs.
} 


\section{ESTABLISHING A SYSTEM}

The Ministry of Transportation of Ontario (MTO), that is mandated to maintain the provincial highway network, has been using pavement management tools since the 1980s. The first-generation pavement management system (PMS) was developed and successfully implemented in 1985. It included a mainframe-based database maintained by the pavement management section at MTO headquarters and a rehabilitation selection and priority ranking process applied at the regional level offices. The proposed rehabilitation treatments and the condition based priority rankings were used by the program management branch in MTO in the development of the annual capital funding program (1).

In 2001 MTO successfully moved to a second-generation PMS, referred to as PMS/2, in order to facilitate data management and to enhance the analytical components for the network level funding needs and project priorities. During the implementation process of $\mathrm{PMS} / 2$, the pavement management tools utilized by MTO were reviewed and new tools and processes were added to the system. Also, PMS/2 was integrated into the Ministry's information management system.

To ensure the long-term success of a PMS and to maximize its ultimate benefit to the agency, the system should periodically be reviewed. This periodic review allows for enhancements and modifications over the time. A PMS should be considered as a dynamic system, not static. Approximately 6 years passed since PMS/2 development was initiated, and several performance data cycles were completed. As part of MTO's continuous effort to enhance and update their PMS, the following enhancement initiatives were introduced to $\mathrm{PMS} / 2$ :

- Update the maintenance, rehabilitation, and construction unit costs;

- Enhance/update the current maintenance and rehabilitation (M\&R) decision trees (DTs); available;

- Enhance/update the current prediction models as more performance data became

- Enhance the PMS/2 geographic information system map;

- Upgrade the PMS/2 software to allow displaying digital images for performance data validation; and in $\mathrm{PMS} / 2$.

- Integrating PM strategies into the PMS/2, thus developing the entire PP program

PP is defined by the FHWA as "the sum of all activities undertaken to provide and maintain serviceable roadways; this includes corrective maintenance and PM, as well as minor rehabilitation projects. It excludes new or reconstructed pavements and pavements requiring major rehabilitation or reconstruction" $(2,3)$. An approach that adopts PM represents a departure from the traditional approach adopted by many highway agencies, where pavements were left until they required major rehabilitation or reconstruction. PP not only has the potential to increase pavement performance and service life, but also shows much promise in reducing the overall life-cycle cost of highway facilities. Also, a strong PP program is an essential need for asset management systems.

However, the introduction of preventive strategies involves some institutional issues such as funding allocation. With the large backlog of pavements in poor condition and the 
inadequate highway funding, it becomes difficult to provide the funding needed for preventive strategies because of political pressures and the public's questioning of fixing roads that are still in good condition. The public can perceive that the agency is misallocating funds by ignoring pavements that are in poor condition. One way to address this issue is to demonstrate the success of the PP program by showing the actual benefits of the program on the condition of the road network, on public perception of the roads, on improved safety, and on lower life-cycle costs (4).

In this paper, an overview of MTO PMS/2 is presented together with the process used by MTO for the implementation of a PP program that includes preventive strategies as a key component. The results of the budget analysis, which was performed to determine the impact of incorporating the PM activities into the PP program as compared to including M\&R activities only, is also presented.

\section{OVERVIEW OF MTO PMS/2}

MTO PMS/2 is a customized version of Stantec's Highway Pavement Management Application (5). PMS/2 is comprised of four subsystems: a database management subsystem, a network analysis subsystem, a project design and analysis subsystem, and an engineering feedback subsystem. The relationship between these subsystems is shown in Figure 1 (6).

The database management subsystem in the PMS/2 uses a two-level database: a detailed highway database and a summarized sectional database. All data are maintained in the detailed highway database, where each data type can be stored at its own representative resolution. The data that can be stored in the PMS/2 highway database include highway definitions, highway landmarks, geometrics (functional class, widths, lanes, etc.), traffic data (annual average daily traffic, equivalent single-axle load, growth rate), structural data (construction/rehabilitation project limits, M\&R histories, ground-penetrating radar, core thicknesses), and performance data (roughness, rutting, distress, friction, and deflection).

The sectional database is created within the system either by using predefined sections or by using the dynamic sectioning option. This second option allows the user to divide the highway network into a set of homogeneous sections based on user-defined sectioning parameters. The network analysis subsystem utilizes the sectional database, while the engineering feedback and project analysis subsystems utilize the detailed highway database.

The M\&R multiyear analysis component of PMS/2 provides a means for developing multiyear rehabilitation programs and for analyzing alternative budget scenarios. This involves the analysis of alternative rehabilitation treatments as well as network optimization. First, performance is predicted for all the sections for each year in the analysis period using the performance prediction models. Sections that reach the trigger level within the analysis period are identified as candidates for rehabilitation. The rehabilitation need year is then defined as the year in which the performance reaches or goes below the trigger level. Candidate sections are analyzed using the appropriate rehabilitation analysis DT. In this analysis, a list of candidate rehabilitation treatments and implementation years is selected for each section. 


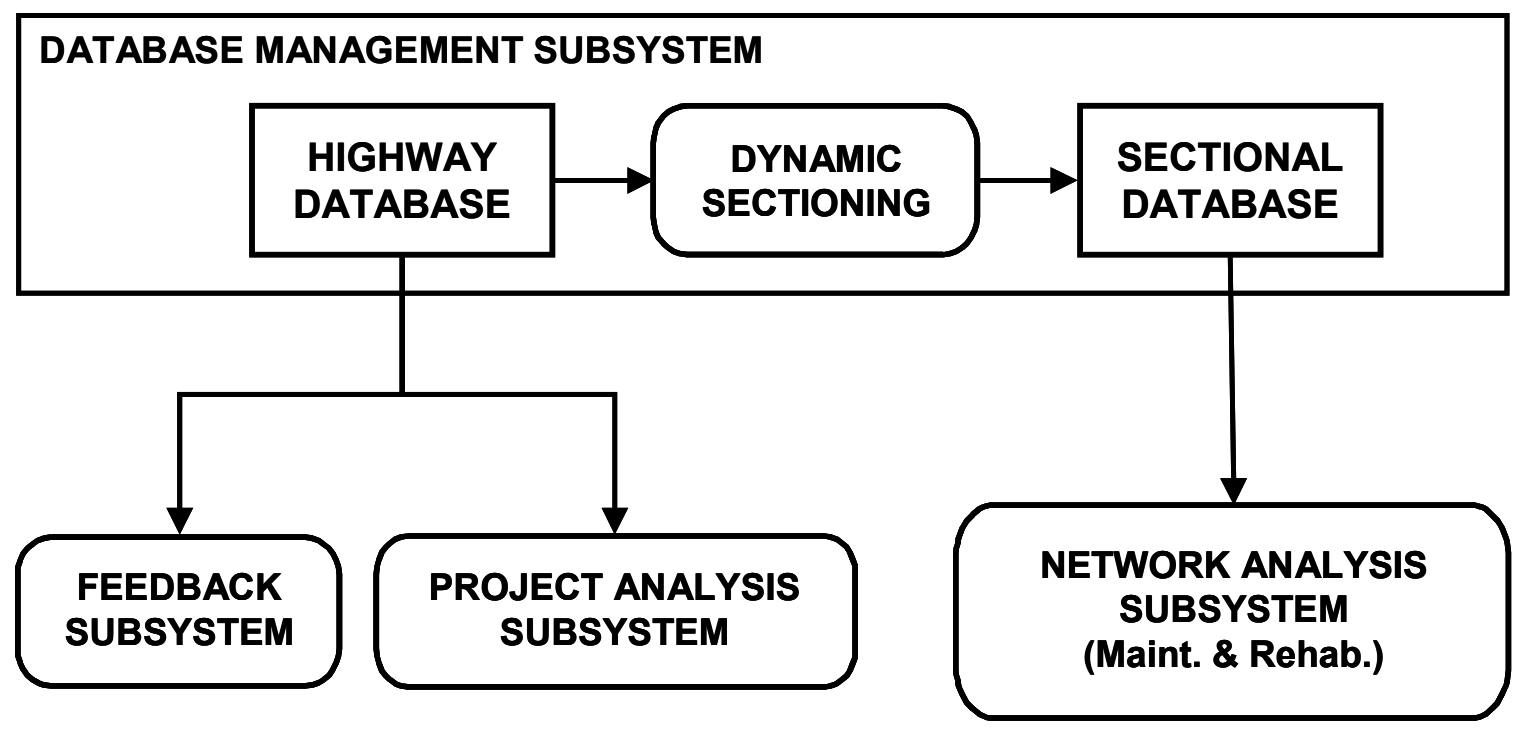

FIGURE 1 PMS subsystems.

Feasible rehabilitation strategies for each section are evaluated in terms of the cost effectiveness. The cost effectiveness is calculated as an effectiveness/cost ratio. The marginal cost effectiveness approach is used in the optimization analysis to select the rehabilitation strategies for each year in the analysis period. Optimization analysis is then performed on the selected rehabilitation treatments to determine the set of treatments, which provide the maximum overall effectiveness (effective maximization) or the minimum cost (cost minimization).

The main function of the project analysis subsystem is to evaluate and compare different design alternatives of a project to allow the selection of the optimum alternative. In PMS/2, lifecycle cost analysis is used to evaluate different design alternatives and to quantify the impact of different factors and treatments on pavement economics. The optimum design alternative is selected based on the results of the life-cycle analysis, as well as the performance of different design alternatives. Factors considered in the enhanced PMS/2 life-cycle analyses include direct agency costs, user costs, and non-monetary factors. The direct agency costs include the initial construction costs, M\&R costs, and the residual value at the end of the design period. On the other hand, user costs include vehicle operating cost, user delay costs, and emissions.

The engineering feedback subsystem of the PMS/2 provides functions for analyzing the historical database to evaluate the effectiveness of different rehabilitation activities and to determine appropriate model coefficients for use in the default models. This subsystem allows the user to review and analyze the default prediction models, the effectiveness of maintenance treatment options, and activity cost.

\section{APPROACHES OF INTEGRATION OF PM INTO PMS/2}

Three approaches were proposed for the integration of the PM strategies into MTO PMS/2, which are

- Using one DT that includes staged treatments that combine both rehabilitation and PM;

- Using two separate DTs: one for PM and one for rehabilitation; and 
- Integrating the preventive strategies into the main DTs of MTO PMS/2.

The first approach (7), predefining staged rehabilitation activities, is the simplest approach for integration. In this approach, the original rehabilitation DT is used in the analysis. However, the rehabilitation treatments are "packaged" with time-based PM strategies to form a staged activity. As an example, the "Mill 2 in. + Asphalt Concrete Overlay 4 in." rehabilitation activity would be packaged with a crack sealing preventive strategy at year 4, another crack sealing preventive strategy at year 8 , and a microsurfacing preventive strategy at year 12 . This approach has the advantage of forcing preventive strategies to be implemented at specific timebased milestones during the service life of the pavement sections. However, because these implementations are time based, the pavement condition is not considered when selecting the appropriate PM strategy. Furthermore, the PM strategies budget cannot be specified prior to performing the analysis.

The second approach, which is shown in Figure 2, is based on developing two separate DTs and performing the analysis in two stages. In the first stage, a PM DT is used only for the PM analysis and the PM needs for the network are identified. In the second stage, the rehabilitation analysis is performed using the rehabilitation analysis DT. The sections considered for PM strategies are transferred to the rehabilitation analysis and implemented as overrides as part of the overall program. The main advantage of this approach is that it ensures a specific budget allocation for the preventive strategies and gives increased flexibility by allowing the preventive strategies' implementation to be time based and/or performance based. However, this approach requires the analysis to be performed in two stages.

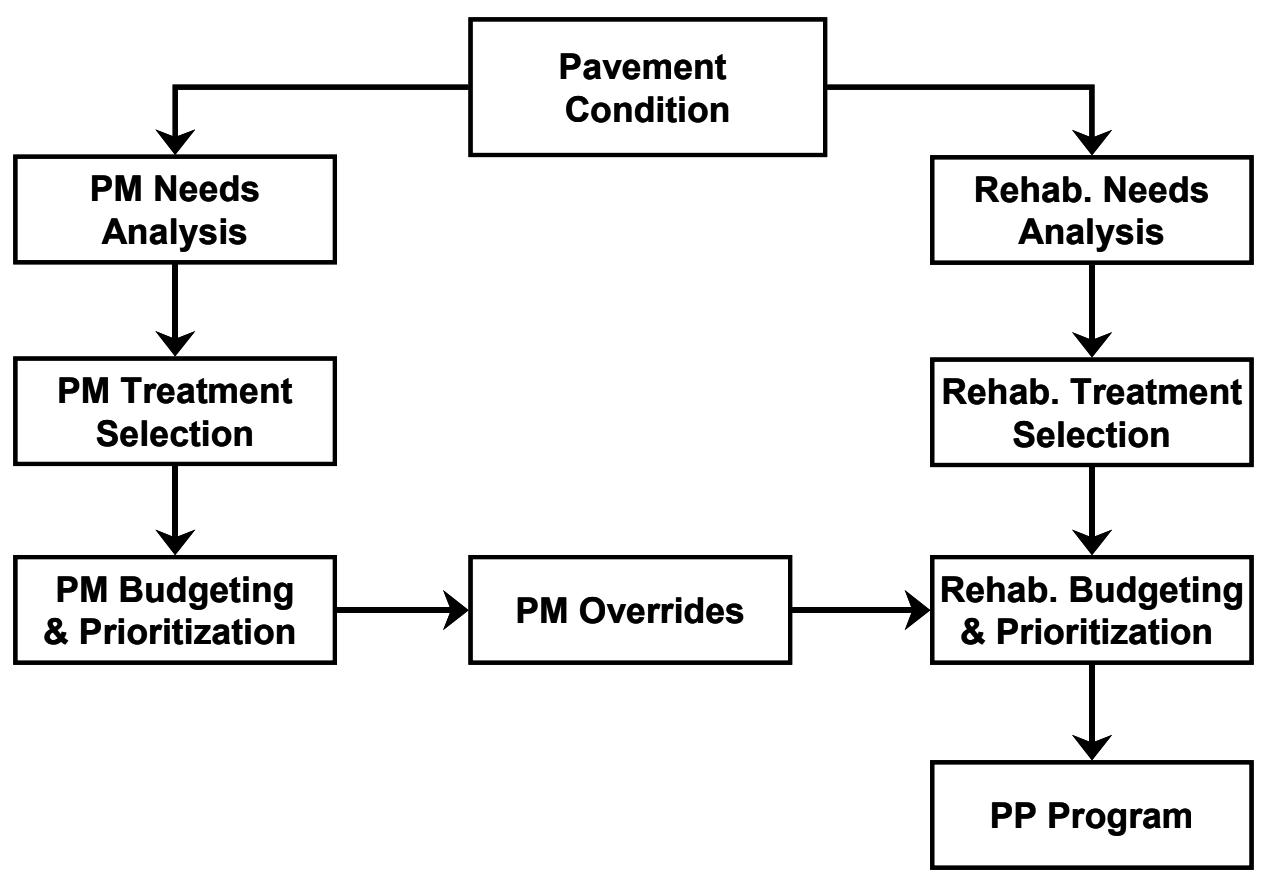

FIGURE 2 Integration of pavement maintenance within PP. 
The third approach requires the development of new DTs to include both the PM strategies and the rehabilitation activities. In this case the analysis is performed in one stage, where the feasible maintenance and/or rehabilitation activities for each section are determined based on this enhanced DT. Although this approach might be the most comprehensive, it is more difficult to model and cannot guarantee the selection and implementation of PM strategies.

\section{DEVELOPMENT OF MTO PAVEMENT PRESERVATION PROGRAM}

Considering the advantages and disadvantages of each of the proposed approaches, it was decided to implement the second approach for the integration of the preventive strategies within the framework of the overall PP program. The selected approach allows MTO to have dedicated funding allocated for preventive strategies and thus start with a smaller percentage of the overall PP budget. This budget can be increased in the future as public perception of the effectiveness of using the preventive strategies increases.

\section{Analysis Approach}

Analysis was performed to evaluate the long-term pavement performance of MTO's pavement network, which is in excess of 35,000 lane kilometers, using the approach described in Figure 2. The analysis process starts using the most recent data stored in PMS/2, including the pavement performance data, construction history, and traffic. The first stage of the analysis is to identify the PM needs using the PM models and DTs. These needs are then analyzed through a budget optimization to develop the PM work program.

The network rehabilitation needs are identified using the rehabilitation activities performance models and rehabilitation DTs. The rehabilitation budgeting and optimization analysis is then performed using the rehabilitation analysis results. The PM work program is loaded to the rehabilitation analysis results as an override to define the final work program based on the budget constraints in order to produce an overall PP work program.

It should be noted that in MTO PMS/2, three performance indices are used to define the pavement condition. These are the ride comfort index (RCI), the distress manifestation index (DMI), and the pavement condition index (PCI). RCI is a function of the international roughness index. It is on a scale of 0 to 10, with 10 being a very smooth pavement. Surface distress data, such as cracking and rutting, are stored in the PMS database and then converted to a performance index, DMI. DMI, which is on a scale of 0 to 10, with 10 being a perfect distress-free surface, is based on a deduct scheme weighted for severity and extent of each type of distress. PCI is an overall condition rating combining the RCI and DMI on a scale of 0 to 100 , with 100 being a perfect pavement.

The pavement performance is predicted in PMS/2 using site-specific models and/or a default models approach. Site-specific models are used to predict RCI and DMI using the available historic data. The model parameters are estimated for each analysis section based on historical performance observations using non-linear regression analysis. However, for sections which have insufficient historical data or when the historical data available in the PMS does not allow reasonable prediction for the future condition, the default models should be used. 


\section{Impact of PM Strategies on Pavement Performance}

The main benefit of implementing a PM strategy on the pavement is that it inhibits deterioration and therefore extends the pavement service life. As an example, sealing the cracks early on in the pavement life would reduce the amount of water infiltration into the pavement structure, reducing the stripping effect and the impact of freeze/thaw cycles on the pavement structure. The extension in the pavement service life is typically modeled as either an immediate improvement in the pavement condition or a slower rate of deterioration, as shown in Figure 3.

The impact of implementing a preventive strategy on the pavement performance can affect the RCI and/or DMI, which would in turn impact the overall pavement performance. Regularly monitoring and documenting the condition of these indices can quantify this impact. However, since MTO's PP program is at the development and implementation stages, the impact of the PM strategies cannot be identified based on actual data. Therefore, MTO engineers' experience and engineering judgment were used to estimate the expected improvement and service life expected from each of the preventive strategies considered in the analysis, as shown in Table 1.

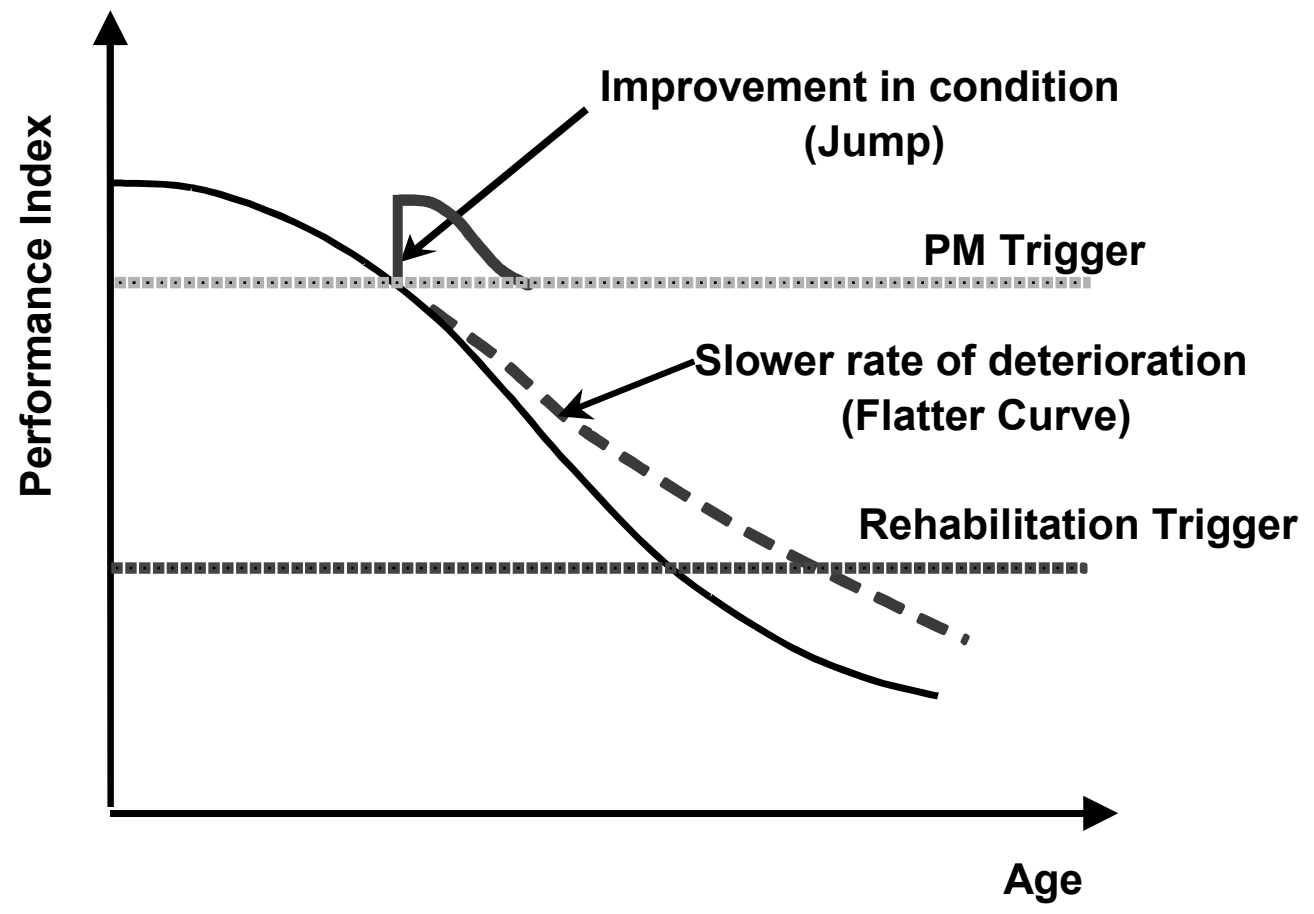

FIGURE 3 Impacts of pavement maintenance strategies on pavement performance.

TABLE 1 Impact of PM Strategies on Pavement Performance

\begin{tabular}{|l|l|}
\hline Strategy & Impact on Pavement Performance \\
\hline Rout and seal & Extension of service life by 2 to 3 years \\
\hline Mill and patch $(20 \%)$ & Improvement of PCI condition by 5 to 7 points \\
\hline Micro surfacing & Improvement in PCI condition by 10 to 12 points \\
\hline Mechanized spray patch $(20 \%)$ & Extension of service life by 2 to 3 years \\
\hline Mill and pave & Modeled using performance data \\
\hline
\end{tabular}




\section{Preventive Strategies Decision Criteria}

A complete set of DTs for the PM strategies was developed and implemented in MTO PMS/2. This set of DTs was defined as a function of the pavement type and functional classification, such that for each functional class/pavement type combination, a separate DT was defined. A sample of the developed DTs is shown in Figure 4.

The DTs were primarily developed in term of the MTO's overall PCI and the age of the pavement section. However, special cases such as faster deteriorating pavement sections or localized distresses were accounted for in the DT. Also, the traffic level of the highway was used in some decision nodes to define the appropriate PM strategy.

\section{BUDGET OPTIMIZATION ANALYSIS}

To assess the impact of introducing the preventive strategies on the overall network performance, the analysis was performed using two scenarios, which are:

- Scenario 1: Rehabilitation activities only.

- Scenario 2: Integrated preventive strategies and rehabilitation analysis.

Optimization analyses were performed for both scenarios using the same total budget, which is equal to the typical yearly budget for MTO PP spending. The analysis was performed for a programming period of 10 years, which is again the typical programming period for MTO PP planning. The objective of the analysis was to compare overall network performance in terms of the different performance indices, under the same budget, using both scenarios. Although the

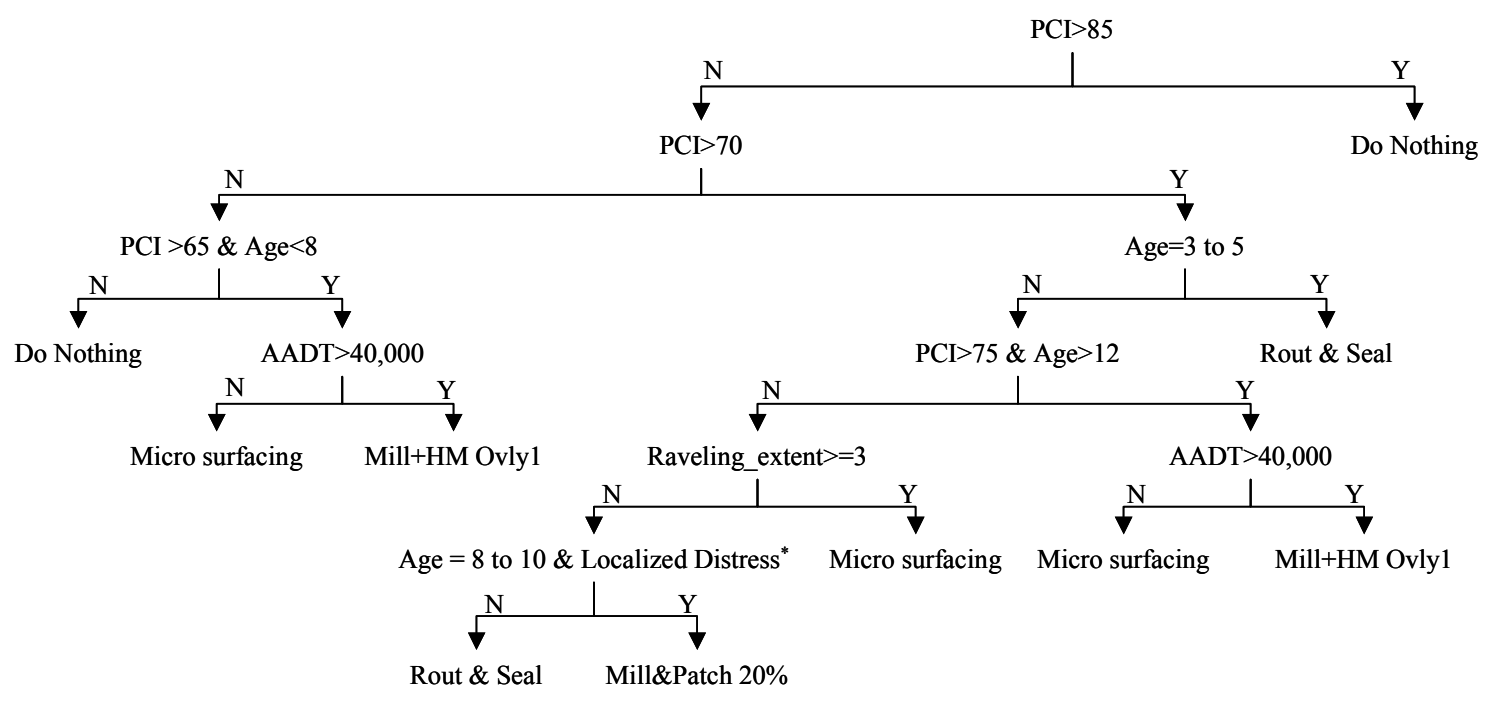

FIGURE 4 Sample PM strategies DTs. 
total budget used in both analyses was the same, the budget allocation within each scenario was different. For Scenario 1, 100\% of the budget was allocated for rehabilitation of pavement sections. For Scenario 2, 5\% of the budget was allocated for preventive strategies and 95\% was allocated for rehabilitation.

Figure 5 through Figure 7 show the average network performance over the 10-year analysis period in terms of the MTO pavement performance indices under the two PP scenarios, and also under the Do Nothing scenario. It should be noted that both scenarios receive the same funding levels. Therefore, any improvement in the network condition is related to the greater cost effectiveness of the selected option.

As can be noted from the figures, the network performance under Scenario 2, where the budget scenario included a specific allocation for pavement preventive strategies, was better than the performance under Scenario 1, where the entire budget was allocated for pavement rehabilitation. Also, it can be noted that the impact of the preventive strategies is more prominent in terms of distresses than in terms of roughness. This is expected since the PM strategies are mainly directed towards maintaining the surface condition rather than improving the smoothness of the surface.

Figure 8 shows the percentage deficiency of the entire network under both budget scenarios, together with the Do Nothing scenario, where deficiency is defined as the percentage of the network in need of rehabilitation. Again, the network condition under Scenario 2 seems to be better than the condition under Scenario 1.

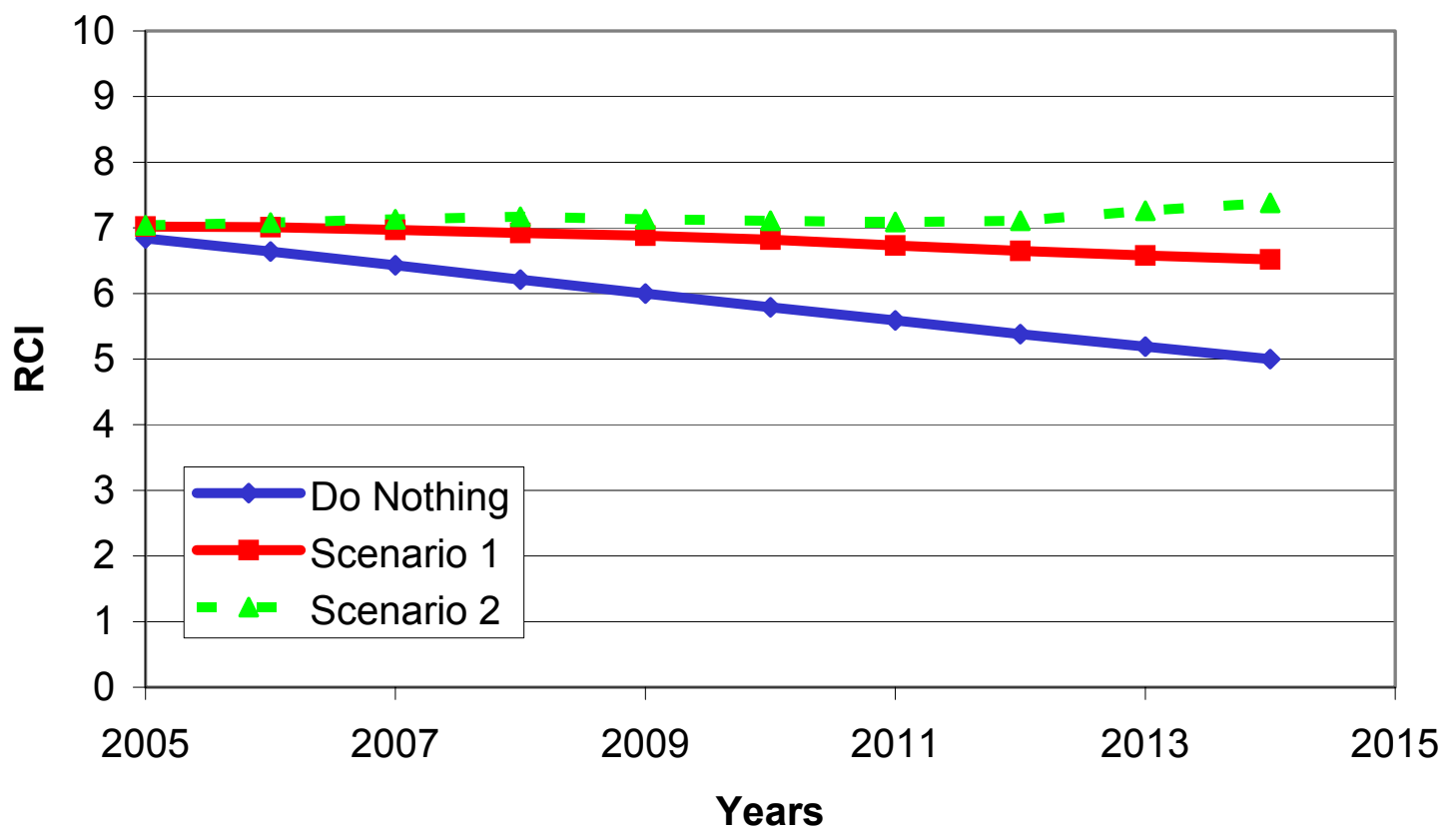

FIGURE 5 Average overall network condition in terms of RCI. 


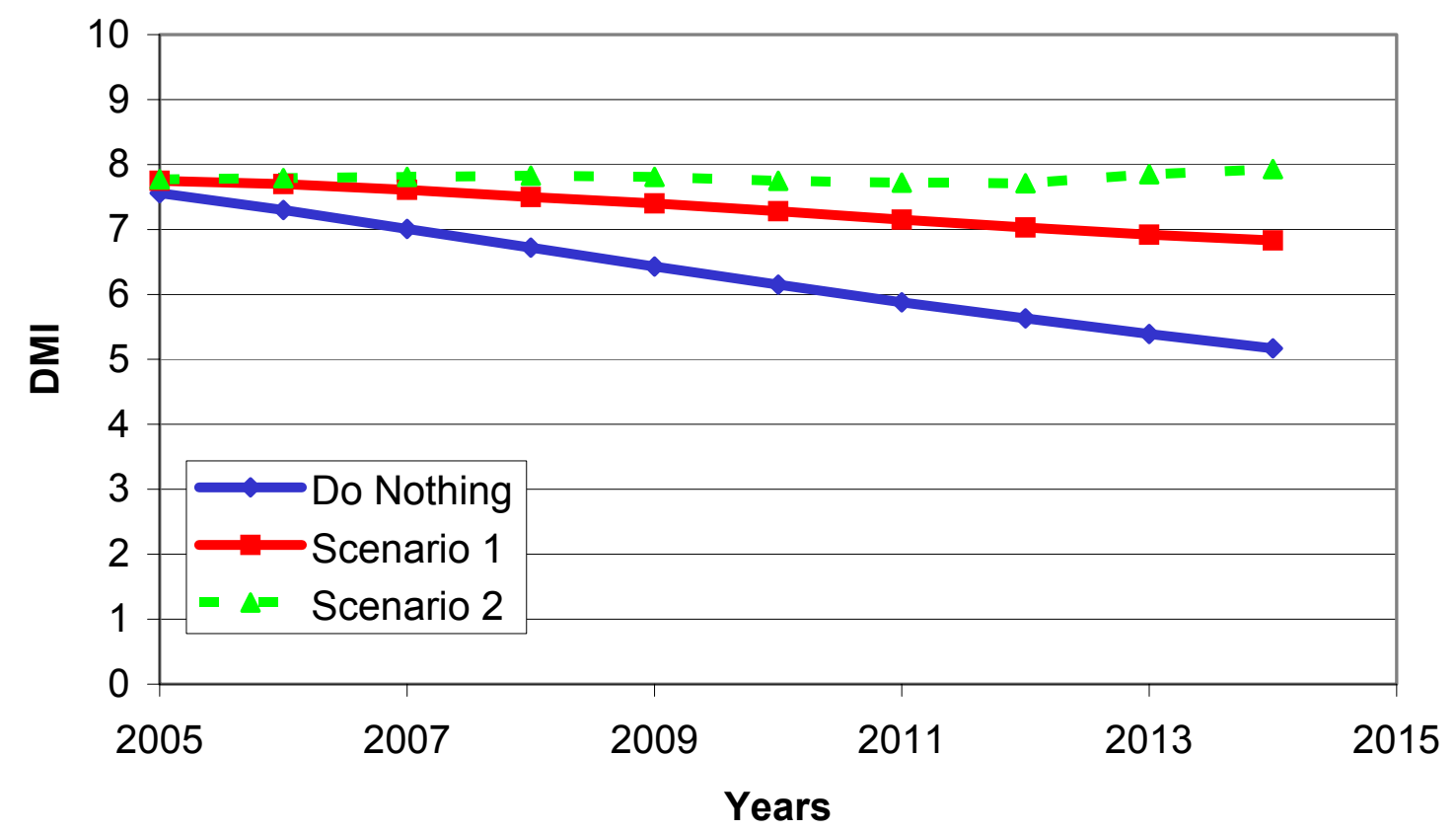

FIGURE 6 Average overall network condition in terms of DMI.

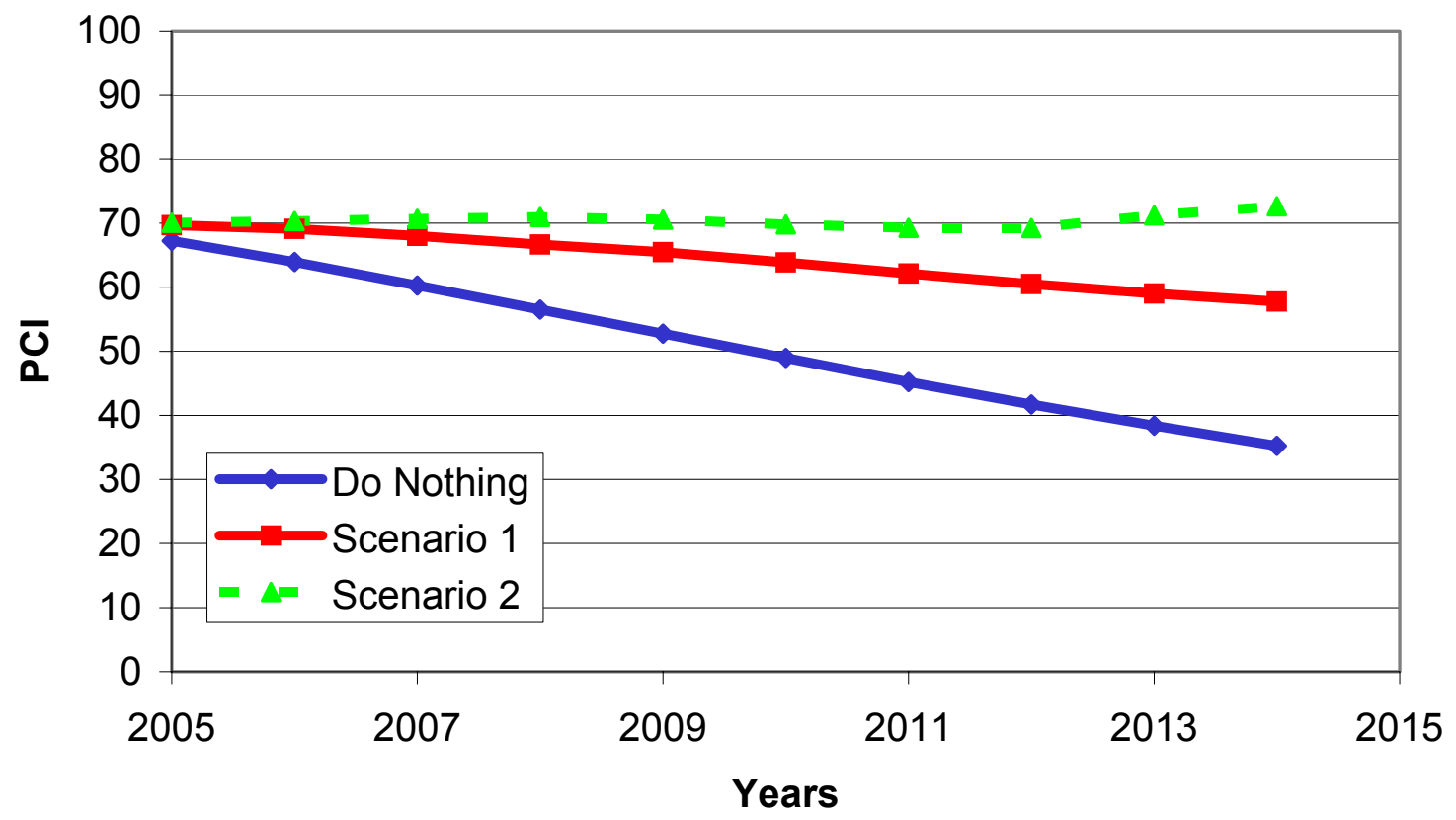

FIGURE 7 Average overall network condition in terms of PCI. 


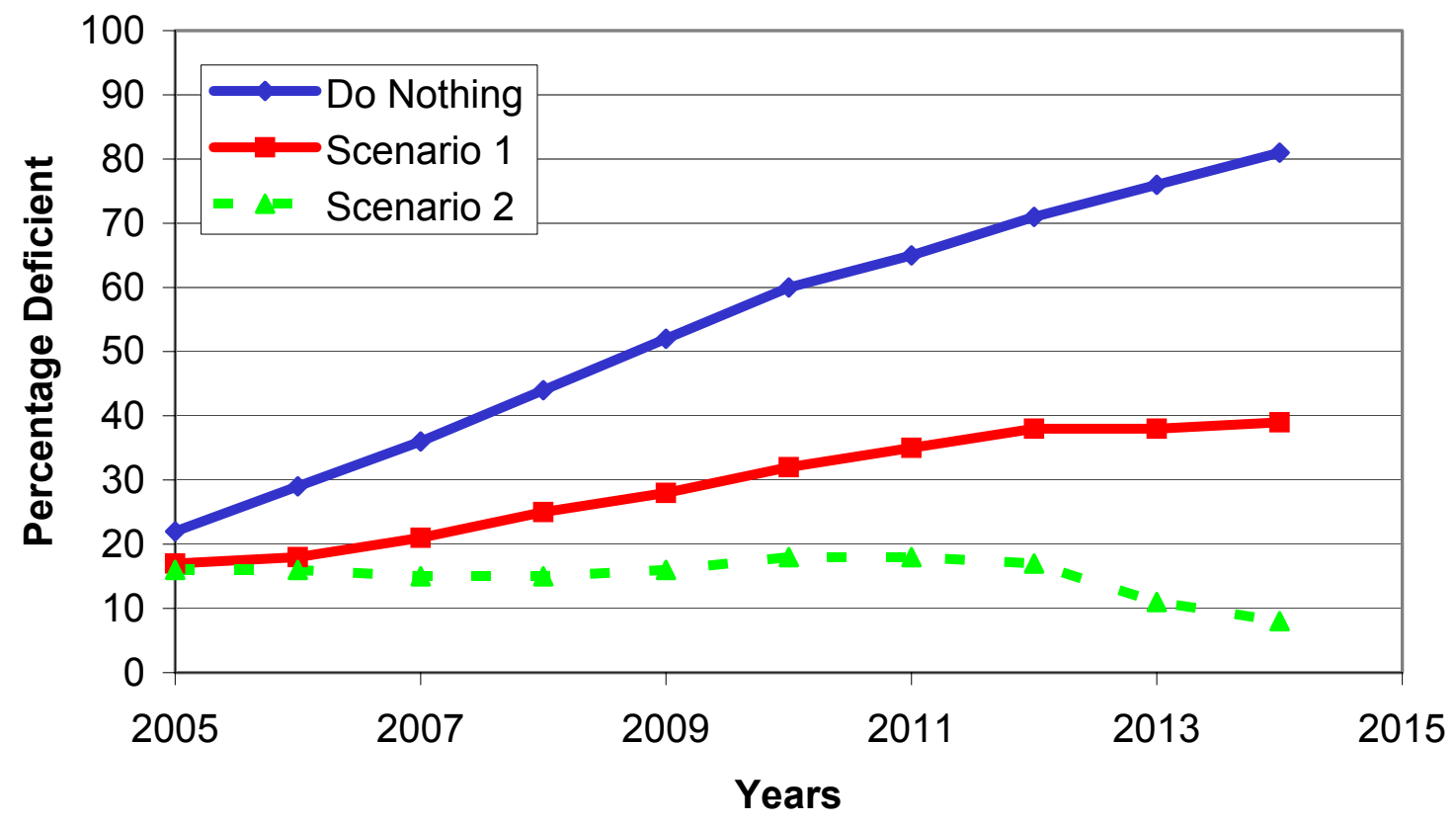

FIGURE 8 Network deficiency based on PCI trigger level.

\section{CONCLUSION}

In this paper, an overview of MTO PMS/2 was presented together with the approach used by MTO for the implementation of a PP program that includes preventive strategies as a key component. In this program, the PM strategies are selected through a set of dedicated DTs that determines the feasible maintenance activities for each pavement section based on a number of factors including the existing pavement surface layer, condition, age, and traffic.

The sections considered for preventive strategies are determined through budget optimization analysis and are then transferred to the rehabilitation analysis and implemented as overrides to be included in the final work program for the entire network. This approach ensures a dedicated budget for the PM strategies, which can be controlled by the Ministry.

Budget analyses were performed to determine the impact of incorporating the PM activities into the PP program as compared to a PP program that includes M\&R activities only. Analyses results showed that under the same budget scenarios, incorporating PM into the overall PP program resulted in a significant improvement to the network condition. 


\section{REFERENCES}

1. Kazmierowski, T., Z. He, and B. Kerr. A Second Generation PMS for the Ministry of Transportation of Ontario. Proc., 5th International Conference on Managing Pavements, Seattle, Wash., 2001.

2. Pavement Preservation: A Road Map for the Future. FHWA-SA-99-015. FHWA, U.S. Department of Transportation, 1999.

3. Insights into Pavement Reservation: A Compendium. FHWA, U.S. Department of Transportation, 2000.

4. Helali, K., T. J. Kazmierowski, and S. Zaghloul. Technical and Institutional Issues Associated with Integrating Preventive Maintenance into a Pavement Management System. Presented at 83rd Annual Meeting of the Transportation Research Board, Washington, D.C., 2004.

5. Highway Pavement Application (HPMA) User Manual. Stantec Consulting, Kitchener, Ontario, 2005.

6. Jackson, H., A. J. Eisdorfer, S. Zaghloul, R. W. Sauber, and A. A. Jumikis. Integration of Preventive Maintenance into New Jersey Department of Transportation Pavement Management System. Presented at 83rd Annual Meeting of the Transportation Research Board, Washington, D.C., 2004.

7. Helali, K., H. Jackson, S. Zaghloul, W. Bekheet, and A. A. Jumikis. Potential Benefits of Integrating Preventive Maintenance into New Jersey Pavement Management System. Presented at 84th Annual Meeting of the Transportation Research Board, Washington, D.C., 2005.

8. American Association of State Highway Officials. Pavement Preservation in the United States. In Pavement Preservation 2 State of the Art (CD Rom), FHWA, U.S. Department of Transportation, May 2003.

9. NCHRP Synthesis of Highway Practice 223: Cost-Effective Preventive Maintenance. TRB, National Research Council, Washington, D.C., 1996.

10. Zimmerman, K. A., and D. G. Peshkin. Pavement Management Perspective on Integrating Preventive Maintenance into a Pavement Management System. In Transportation Research Record: Journal of the Transportation Research Board, No. 1827, Transportation Research Board of the National Academies, Washington, D.C., 2003, pp. 3-9. 


\title{
Condition-Based Determination of Preservation Needs of a Road Network
}

\author{
RAJA A. SHEKHARAN \\ Douglas C. Gilman \\ Virginia Department of Transportation
}

For effective and cost-efficient preservation of a road network there is a need to evaluate the preservation needs, which are best determined with regular monitoring of pavement condition. Preservation needs are to be determined for budget estimation and subsequent allocation of the funds for various jurisdictions utilizing various maintenance categories. The preservation needs have been grouped together rather than individual activity assignment, i.e. preventative, corrective, restorative, and major RC. By estimating the preservation needs and the budget required, it is possible for further planning of the work needed, operation schedules, and required crew mobilization.

This paper describes a method that makes use of the condition of pavements based on sound engineering principles. The condition of pavements results in a condition state assignment of excellent, good, fair, poor, or very poor. The engineering principles relate to making preservation recommendations while achieving cost minimization optimization via transitional probability matrices defined by an absorbing state Markov chain. Condition data of homogenous pavement segments was obtained by consistently collecting surface distress condition "windshield" surveys. These surveys provide a means to evaluate the current health of the network, and (through the use of decision trees) aid in the determination of the recommended maintenance.

Employing the methodology presented, the answers regarding the network-level pavement preservation needs can be quantified and condition forecasts determined for trade-off analyses. Recommended preservation needs are determined for the following conditions: sustaining the current condition distribution of pavements, changing the distribution of condition to any specified level, the minimum cost to sustain the network at a specified distribution of condition level after attaining it, and the resulting distribution of condition of the network under a selected maintenance strategy. Virginia Department of Transportation (VDOT) analysis has revealed that under a fixed set of maintenance activities every year the network would reach a stable distribution of condition state. The method defined in this paper will determine the resulting stable state and the required time to reach it.

Additionally, there will be some brief discussion about the availability of condition data for both before and after major winter damage. This condition data has made it possible to actually quantify the effects of an increase in the rate of deterioration and the amount of damage to the network. Using the method defined in this paper VDOT can then calculate the minimum cost to bring it back to the pre-winter damage condition.

P reservation of road network is gaining greater importance among various agencies as the funds available for preservation are often limited. Therefore determination of preservation needs that meet agency-specified goals at minimum possible cost is essential. Preservation needs are also driven by the existing condition of the road network. Assessing preservation needs for a pavement network constitutes an important part of planning and budgeting. The planning process includes determination of preservation needs in terms of the type of treatment needed and the quantity of treatment needed to achieve specified goals. At the network level, the portions of the network that need preservation treatments can also be identified. 


\section{CONDITION-BASED DETERMINATION OF PRESERVATION NEEDS OF A ROAD NETWORK}

Network optimization models provide an ability to perform a simultaneous evaluation of an entire pavement network while considering multiple tradeoffs between various factors such as maximizing benefit or minimizing cost (1). One of the earlier studies (2) used annual budgets as constraints with the objective function of pavement performance chosen for maximization. Multi-objective and single objective optimization problems are solved in another earlier study (3). A network level optimization procedure with rules set up to include only feasible action list to improve the effectiveness of models was attempted in another study (4). Network optimization is considered a top down approach because overall network goals are established first so that projects and treatments can be selected to achieve the desired goal. Most network optimization models optimize the relationship between a measure of network condition and the program's budget level.

Preservation treatment needs and their timings need to be determined for the purpose of planning. There can be many objectives in the determination of preservation needs and their timing. A proper determination of these not only aids in planning, but also assists in the evaluation of alternatives. This paper documents some of the investigations carried out for the VDOT road network system. One of the initial objectives was to develop a condition evaluation of the existing network of pavements, and to estimate treatment needs for future years. The first question that arose at this time was what is the minimum budget required to sustain the current condition distribution of pavements? Answering this question is of interest since the minimum possible budget needed year after year to sustain the current condition distribution provides a baseline budget against which all other variations could be compared. It also determines the fixed amount of work needed year after year to maintain the current condition distribution of the pavement network. If a fixed amount of work has to be carried out every year, it would be much easier to plan the preservation work, prepare schedules, and allocate resources. A constant amount of work every year could potentially result in a lower price of contracts over multiple years compared to vastly varying amounts of work. Both from the state agency point of view as well as contractor's point of view, a fixed amount of work would be much easier for the mobilization of resources.

Apart from determining the budget for sustaining the existing condition distribution of pavements, the budget needed to bring the condition distribution of pavements up to a desired level is also of interest. Another question is once the desired condition distribution is achieved, what would be the minimum budget needed to sustain the new condition of the network steady year after year? Also, to ascertain the progression of network condition deterioration over the years, another question arose as to what happens if no preservation work is carried out for the next few years. These are all questions that could be important for managing pavements. During a particularly severe winter the network was observed to have deteriorated in a short span of time, and this phenomenon was termed winter breakup. Due to this what would be the increase in required preservation treatment needs? A study was conducted to determine the answers to questions such as these, and this paper presents a methodology for this purpose. The developed procedure is initially applied to flexible Interstate and primary roads. The methodology along with the results is presented here. 


\section{METHODOLOGY}

For evaluating the condition of pavements a composite index called critical condition index (CCI) on a scale of 0 to 100 is employed, with 100 representing pavements in perfect condition, and 0 representing pavements in unacceptable condition. The CCI is based on observed surface distresses that are further divided into load based and non-load based. Examples of distresses include fatigue cracking, transverse cracking, patching, and rutting. Deduct points are determined, from mathematical equations, based on type, severity, and extent of distresses. CCI is calculated using these deduct points. Based on the CCI, five condition states are assigned: excellent (e), good (g), fair (f), poor (p), and very poor (v); as shown in Table 1. Actual performance of the pavements, the typical distresses observed, and experiences of engineers from the state highway agency are some of the factors used in classification of the five condition states. Once the current distribution of pavement condition is defined, how pavements in each of these condition states deteriorate is needed.

Pavement deterioration is quantified by the rate of deterioration of pavements from one condition state to lower condition states in 1 year. Two consecutive years of consistently collected distress data are used. This allows for the initial estimation of the rate at which the pavements move from a given condition state to lower condition states. Rates of deterioration are expressed in terms of probabilities of pavements in a given condition state deteriorating into lower condition states, and are represented as a transition probability matrix. These are $n \times n$ matrices where $n$ is the number of possible condition states (5). The probabilities are assumed to be homogeneous or constant over time. If data is available for many years heterogeneous or probabilities varying with time could be determined. Therefore, homogeneous discrete-time Markovian type transition probability matrices are derived and these are employed to predict the condition states of pavements at the network level. This is a $5 \times 5$ matrix to account for the five condition states: excellent, good, fair, poor and very poor. The transitional probability $p_{x y}(t)$ that a homogeneous Markov chain moves from condition state $x$ to condition state $y$ after $t$ years can be calculated as

$P(t)=P(0) P^{t}$

where

$P(t)=$ condition state probability matrix, in the year $t$, with elements $p_{x y}(t)$;

$P(0)=$ matrix of initial condition state probabilities; and

$P=$ transition probability matrix.

The $5 \times 5$ transition probability matrix is therefore represented as follows:

$P=\begin{aligned} & P_{e e} \\ & 0 \\ & 0 \\ & 0 \\ & 0\end{aligned} \quad\left[\begin{array}{llll}P_{e g} & P_{e f} & P_{e p} & P_{e v} \\ P_{g g} & P_{g f} & P_{g p} & P_{g v} \\ 0 & P_{f f} & P_{f p} & P_{f v} \\ 0 & 0 & P_{p p} & P_{p v} \\ 0 & 0 & 0 & P_{v v}\end{array}\right]$


TABLE 1 Pavement Condition Definition

\begin{tabular}{|ll|}
\hline Pavement Condition & CCI \\
Excellent & 90 and above \\
Good & $70-89$ \\
Fair & $60-69$ \\
Poor & $50-59$ \\
Very poor & 49 and below \\
\hline
\end{tabular}

Transitional probability matrices provide information about the deterioration of pavements. The elements of the matrix indicate how the pavement sections move from one condition state to another, or stay in the same condition state. The elements with values of zero imply that no pavement section should show improvement in the condition state, i.e., cannot move from a lower condition state to a higher condition state, without any preservation work. The element $p_{v v}$ has a value of 1 , indicating that the pavements in the very poor condition state remain in the same condition state. Very poor condition state is the absorbing state from which there is a zero probability of exiting.

Each pavement section exists in only one defined condition state. At the end of the time period, each pavement section either moves to a new condition state or stays in the existing condition state for another period. Pavement condition states change one state to the next according to the transition probabilities that depend only on the current condition state, and do not take previous history into account. Since a homogeneous transitional probability matrix is assumed, the probabilities do not change over time, i.e., probability today is the same as it will be at any time in the future.

Planned pavement work is grouped into four categories: preventive maintenance (PM), corrective maintenance $(\mathrm{CM})$, restorative maintenance (RM), and rehabilitation/reconstruction (RC). Each of these categories includes individual treatment activities. For example, PM includes crack sealing and surface patching. An example of CM is partial depth patching. Full depth patching, milling and inlay, and overlay are some examples of activities included under the RM category. RC includes milling, overlay, and reconstruction as various individual activities. Depending on the extent and severity of distresses, and applied treatment activity, a given pavement section may either move to a higher condition state or stay in the same condition state. Some examples are provided here for illustrative purposes. PM in the form of crack sealing could result in a pavement staying in the same condition state. This is because after sealing, the severities of cracks reduce resulting in lower deduct values and consequent higher CCI values but CCI could stay in the same interval defined for a particular condition state. $\mathrm{CM}$ in the form of partial depth patching could eliminate some of the major distresses resulting in an increase of CCI value with pavement condition moving up by one condition state. Similarly RM in the form of full depth patching could move the pavement condition up by one condition state. RC always moves the pavement to excellent condition state irrespective of the condition state before. While the recommended preservation treatments are based on distresses, the condition states are defined by CCI as in Table 1 . Thus a pavement could stay in the same condition state or move to a higher condition state based on the applied treatment.

Based on the experience of pavement management engineers, decision trees have been developed for the determination of the type of preservation treatment needed for a pavement section for a given combination of distress types, extents, and severities. These decision trees employ the existing distress type, extent, and severity on a pavement as input. For each 
combination of type, extent, and severity of distresses the decision tree recommends needed preservation work. The outputs from these decision trees provide a pool of candidate recommended treatments that could be adopted in the case of unlimited funds, i.e., the decision trees provide recommendations of the proper type of required preservation treatment based on the existing combination of distresses. However, either when there are limited funds or a change in the overall condition of the network is desired, optimization procedures are necessary to make best use of the available budget.

Given the current condition of the pavement network, the future condition can be estimated from the transitional probability matrices. Two objectives are addressed in the estimation of the required work subject to logical constraints. The first objective is to estimate the preservation needs in each of the condition states to sustain the condition of the pavement network at the current condition level with minimum possible cost. The second objective is to estimate the preservation needs to bring the current condition distribution of pavements to a more desirable condition distribution or target condition distribution at minimum cost. The methodology adopted essentially captures deterioration of a pavement section from one condition state to the next, the possible improvement of a section due to a specified preservation work, and the minimum possible cost to achieve a given objective. Equations representing the pavement network in various condition states due to deterioration and preservation treatments are provided below along with an explanation of significance of the equations.

Pavements in various condition states are represented by the equations 3 through 7, and these equations show equilibrium of pavement sections in a given condition state. This includes the portion of the pavement sections remaining in the same condition state over a period of 1 year, pavement sections deteriorating from higher condition states, and pavement sections moving from other condition states due to preservation activities.

$$
\begin{aligned}
& E_{t}=E_{t-1}^{*} * p_{e e}+\sum M_{e e}^{i}+\sum M_{g e}^{i}+\sum M_{f e}^{i}+\sum M_{p e}^{i}+\sum M_{v e}^{i} \\
& G_{t}=G_{t-1}^{*} * p_{g g}+\sum M_{g g}^{i}+E_{t-1}^{*} p_{e g}+\sum M_{f g}^{i}+\sum M_{p g}^{i}+\sum M_{v g}^{i} \\
& F_{t}=G_{t-1}^{*} * p_{g f}+F_{t-1}^{*} * p_{f f}+\sum M_{f f}^{i}+\sum M_{p f}^{i}+\sum M_{v f}^{i} \\
& P_{t}=F_{t-1}^{*} * p_{f p}+P_{t-1}^{*} * p_{p p}+\sum M_{p p}^{i}+\sum M_{v p}^{i} \\
& V_{t}=P_{t-1}^{*} * p_{p v}+V_{t-1}^{*}
\end{aligned}
$$

where

$E_{t}=$ length of pavement sections in excellent condition in the year $t$;

$E_{t-1}^{*}=$ length of pavement sections in excellent condition with no treatment in the year $t-1$;

$G_{t}=$ length of pavement sections in good condition in the year $t$;

$G_{t-1}^{*}=$ length of pavement sections in good condition with no treatment in the year $t-1$;

$F_{t}=$ length of pavement sections in fair condition in the year $t$;

$F^{*}{ }_{t-1}=$ length of pavement sections in fair condition with no treatment in the year $t-1$;

$P_{t}=$ length of pavement sections in poor condition in the year $t$;

$P^{*}{ }_{t-1}=$ length of pavement sections in poor condition with no treatment in the year $t-1$;

$V_{t}=$ length of pavement sections in very poor condition in the year $t$; 
$V^{*}{ }_{t-1}=$ length of pavement sections in very poor condition with no treatment in the year $t-1$;

$i=$ type of preservation treatment (PM, CM, RM, and RC);

$t=$ year $t$;

$M_{x y}^{i}=$ length of pavement sections where $i$ type of preservation treatment is applied resulting in a change of pavement condition from $x$ to $y$;

$p_{x y}=$ transition probability from condition state $x$ to condition state $y$ as obtained from transition probability matrix defined in Equation 2; and

$x$ and $y=$ condition states of the pavement sections (e, $\mathrm{g}, \mathrm{f}, \mathrm{p}$, and $\mathrm{v})$.

Equation 8 represents the cost function, and the goal of the optimization procedure is to minimize this cost subject to the specified constrains.

minimize $C=\sum_{i} \sum_{x} \sum_{y} M^{i}{ }_{x y} U_{i}$

where

$C=$ Cost of preservation treatments; and

$U_{i}=$ Unit cost of preservation treatment type $i$.

Constraints presented in the Equations 9 through 13 assure that different preservation treatments on the section lengths do not exceed the length of sections in various condition states.

$\sum \sum M_{e y}^{i} \leq E$

$\sum \sum M_{g y}^{i} \leq G$

$\sum \sum M_{f y}^{i} \leq F$

$\sum \sum M_{p y}^{i} \leq P$

$\sum \sum M_{v y}^{i} \leq V$

To insure that the solution provided by the optimization procedure is valid from an engineering point of view, the constraint in Equation 14 is added. Thus the solution is based on the output from the decision trees but variations are allowed to arrive at an optimal solution satisfying the given requirements. This assures that the recommendations are based on sound engineering judgment with the right type of preservation treatments being suggested for pavement sections in a given condition state, and those recommendations that do not confirm to sound engineering judgment such as reconstruction of pavements in excellent condition or PM on very poor condition pavements are precluded. Without this constraint the solutions developed would just be based on mathematical equations that would be able to satisfy other constraints without the input based on engineering considerations.

$R_{x}-D_{x}^{i} V \leq L_{x} \leq R_{x}+D_{x}^{i} V$ 
where

$x=$ condition state, i.e., e, $\mathrm{g}, \mathrm{f}, \mathrm{p}$ and $\mathrm{v}$;

$R_{x}=$ vector of various preservation treatments as recommended by the decision tree for sections in a condition state $x$;

$L_{x}=$ a vector of section lengths where various preservation treatments are applied to sections in a condition state $x$;

$D_{x}^{i}=$ a diagonal matrix for pavements in condition $\mathrm{x}$ receiving various preservation treatments $i$ as recommended by the decision tree; and

$V=$ a vector of maximum allowable variation in $D$.

For the determination of the steady state wherein the network condition remains constant from one year to the next, the constraints in the equations 15 through 19 are employed. These constraints specify that the portion of the network in each condition state remains the same from one year to the next. Steady condition state constraints:

$E_{t-1}=E_{t}$

$G_{t-1}=G_{t}$

$F_{t-1}=F_{t}$

$P_{t-1}=P_{t}$

$V_{t-1}=V_{t}$

Desired condition state constraints:

$E_{t}=E^{D}{ }_{t}$

$G_{t}=G^{D}{ }_{t}$

$F_{t}=F_{t}^{D}$

$P_{t}=P^{D}{ }_{t}$

$V_{t}=V_{t}^{D}$

where $E^{D}{ }_{t}, G^{D}, F^{D}{ }_{t}, P^{D}$, and $V^{D}$ are desired condition states of the network in the year $t$ in terms of section lengths in excellent, good, fair, poor, and very poor condition states, respectively. As before, $E_{t}, G_{t}, F_{t}, P_{t}$, and $V_{t}$ are condition states of the network in the year $t$ in terms of section lengths in excellent, good, fair, poor, and very poor condition states, respectively. When the network condition is to be brought to a desired level of condition states, the constraints specified in equations 20 through 24 are employed. These are equated to $E_{t}, G_{t}, F_{t}, P_{t}$, and $V_{t}$ respectively in the equations 3 through 7 , and the required preservation work is determined to bring the 
network condition to the desired level. Here the network is brought from the existing condition level in year $(t-1)$ to a desired condition level in the year $t$.

This is a linear optimization problem in which the minimum cost solution is determined from the set of all solutions satisfying the constraints set. Employing the constraints mentioned above, the preservation needs either for a steady state condition distribution or to attain a desired condition distribution can be determined.

\section{EVALUATION OF PRESERVATION NEEDS}

With the methodology developed above, preservation needs of the network are determined for various scenarios. Preservation work needed at a minimum cost to sustain the existing condition distribution, to bring the existing condition up to a desired condition, and deterioration of the network under various combinations of preservation treatment options are described below.

\section{Steady Distribution of Current Condition States}

First a set of preservation treatments needed to sustain the existing condition distribution the same over the years is identified. Steady state distribution of condition states indicates that the portion of the network in each condition state remains constant every year. Current condition distribution of the network is presented in Figure 1.

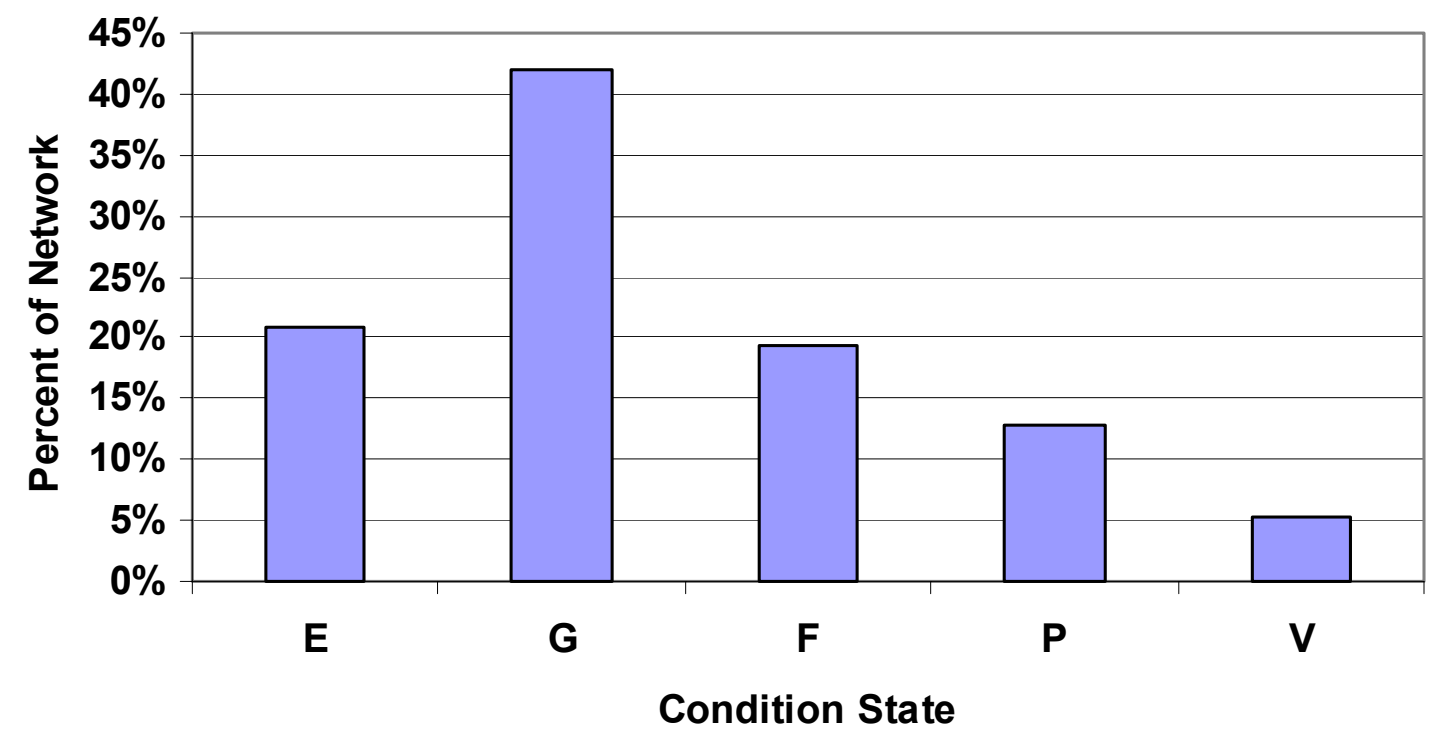

FIGURE 1 Current condition distribution of the pavement network. 
Employing Equations 3 through 7 along with constraints in Equations 9 through 19, the minimum cost of sustaining the current condition distribution the same in the next year with a set of preservation treatments is solved using the cost function in Equation 8. The amount of preservation work needed for this case as a percent of the total network is PM $22.4 \%, \mathrm{CM}$ $14.2 \%$, RM 3.1\%, and RC $1.8 \%$.

\section{Desired Distribution of Condition States}

To solve for an optimal amount of preservation work needed to arrive at a desired distribution of condition states, again the Equations 3 through 7 are utilized along with the objective function in Equation 8. Constraints as in Equations 9 through 14 and 20 through 24 are employed. This again is an optimization problem and is solved to provide a minimum cost to bring the network to a desired level of condition distribution. For example purposes, a hypothetical desired condition of the network is considered. Figure 2 shows the current network condition and a hypothetical desired condition of the network.

To bring the condition distribution up to the hypothetical desired condition distribution, the amount of preservation work as a percent of the total network needed is PM $23.9 \%, \mathrm{CM}$ $38.7 \%$, RM $1.2 \%$, and RC $0.3 \%$. It is observed that the preservation treatments needed to improve the condition distribution to the desired state is more than that needed to sustain a steady state with a consequential higher budget as expected.

\section{Steady Distribution of Desired Condition States}

Suppose the network is brought up to a desired state by a set of preservation treatments, what would be the minimum cost to maintain the network in the same condition state year after year. An example of a hypothetical desired condition could be $30 \%$ of the pavement network in excellent condition state, $40 \%$ in good condition state, $20 \%$ in fair condition state, $5 \%$ in poor condition state, and $5 \%$ in very poor condition state. Once the network is brought up to a

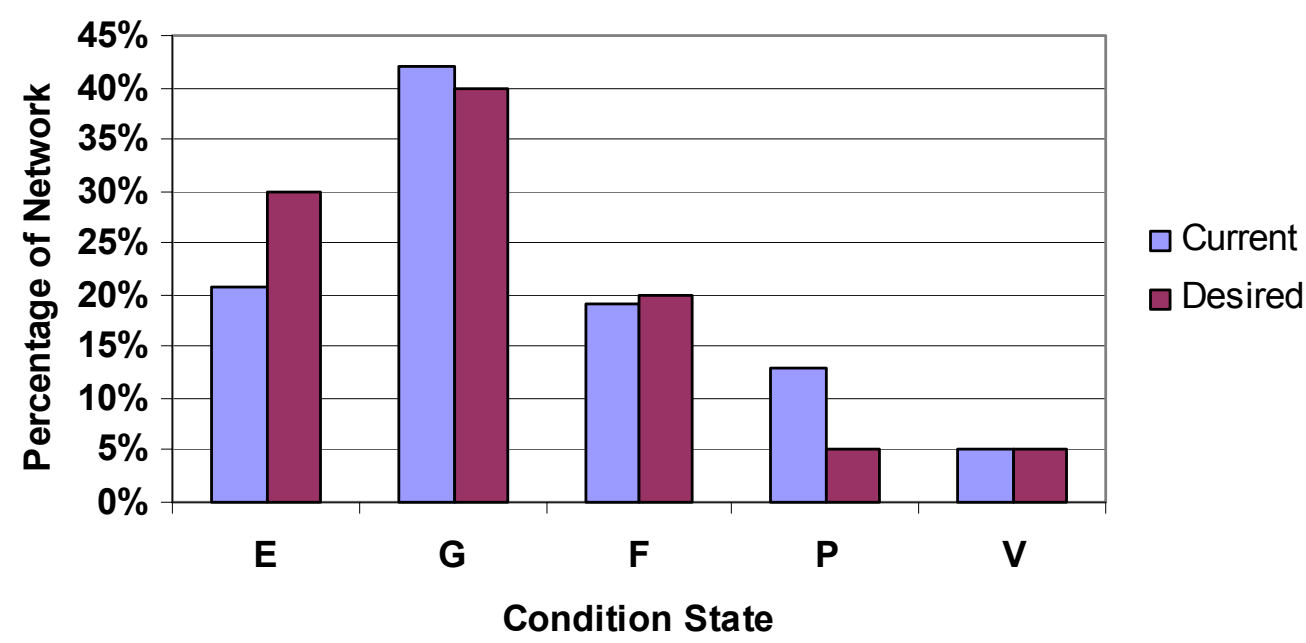

FIGURE 2 Current and a hypothetical desired condition distribution of network. 
hypothetical desired state what would be the minimum cost to sustain it at the same level over future years? To answer this question, the procedures described above are adopted but instead of the current condition levels the desired condition levels are used as the initial input for starting the optimization procedure. For sustaining the desired condition state once it is attained, the following statewide quantities of work as a percent of the total network are identified for minimum possible cost: $31.8 \% \mathrm{PM}, 20.1 \% \mathrm{CM}, 1.3 \% \mathrm{RM}$, and $0.3 \% \mathrm{RC}$. It is also observed that the budget needed to sustain the network at the current condition state is lower that that needed to sustain the desired condition state. Therefore, in general, a higher funding level is needed to sustain the network at a higher condition level than to sustain it at a lower condition level. While this observation is not surprising, the methodology developed here could quantify the minimum budget needed to achieve any desired condition level capturing the preservation treatments from the decision tree. As a corollary a lower level of funding could only sustain the network condition at a lower level, and would cost more for the network to be brought up to a desired condition level later on.

\section{Preservation Needed to Repair Winter Damage}

The methodology illustrated here can be used in the determination of preservation work needed to restore the network to its original condition after damage due to severe winter conditions. Initially condition data was collected in several maintenance jurisdictions in the state before the onset of winter. However, during the ensuing winter the road network was observed to have undergone rapid deterioration that was termed the "winter-breakup." Due to this phenomenon the pavement condition states after winter break up were worse than that before the winter breakup. Therefore, condition data was collected again after the observation of this phenomenon. Initially the analysis is carried out, to determine the preservation work needed to sustain the existing condition states for two conditions, one with the pre-winter damage data, and the other with the data after the winter-breakup phenomenon. In Table 2 below, the preservation work needed to sustain the condition of the network before and after winter breakup are shown.

Another set of analysis is carried out to bring the network to a desired condition state with the pre-winter data, and with data after winter-breakup. Preservation work needed for these two cases are shown in the Table 3.

TABLE 2 Preservation Work Needed to Sustain the Current Condition Before and After Winter Breakup

\begin{tabular}{|l|l|l|}
\hline $\begin{array}{c}\text { Preservation Work to Sustain the } \\
\text { Original Condition }\end{array}$ & $\begin{array}{c}\text { Before Winter-Breakup, } \\
\text { \% of Network }\end{array}$ & $\begin{array}{c}\text { After Winter Breakup, } \\
\text { \% of Network }\end{array}$ \\
\hline DN & 54.0 & 54.9 \\
\hline PM & 19.4 & 20.8 \\
\hline CM & 25.4 & 22.6 \\
\hline RM & 1.1 & 1.4 \\
\hline RC & 0.1 & 0.3 \\
\hline
\end{tabular}


TABLE 3 Preservation Work Needed to Bring the Network to a Desired Condition State with Before and After Winter-Breakup Data

\begin{tabular}{|l|l|l|}
\hline $\begin{array}{c}\text { Preservation Work to Bring to a } \\
\text { Desired Condition }\end{array}$ & $\begin{array}{c}\text { Before Winter-Breakup, } \\
\text { \% of Network }\end{array}$ & $\begin{array}{c}\text { After Winter Breakup, } \\
\% \text { of Network }\end{array}$ \\
\hline DN & 54.0 & 49.2 \\
\hline PM & 19.4 & 27.2 \\
\hline CM & 25.4 & 19.3 \\
\hline RM & 1.1 & 3.7 \\
\hline RC & 0.1 & 0.6 \\
\hline
\end{tabular}

From Table 2 and cost calculations it is observed that the budget needed for sustaining the current condition states is higher with the pre-winter damage data than after the winter break up. This is because it is found that higher budget is necessary to sustain the network at a higher condition level than at a lower condition level. On the other hand, from Table 3 and cost calculations it is noted that the budget needed to bring the network to a desired condition state costs more with the after winter breakup data than with the before winter breakup data. In other words, it costs more to repair the network that is in a worse condition than to repair a network in a better condition, and the methodology described aids in the determination the actual minimum cost. After the determination of preservation needs and budget, for both pre-winter breakup and post winter breakup cases, cost comparisons can be carried out with the suggested methodology.

\section{Network Deterioration}

In order to understand the progression of network deterioration over time, the condition of the network is determined by Equations 3 through 7 with no preservation treatment options included. It has been observed that the network condition deteriorates over time with the pavements in one condition state deteriorating to lower condition states over a period of time as shown in Table 4.

Under the no preservation treatment case, the network deteriorates as shown graphically in Figure 3. From Figure 3 it is seen that the percentage of pavements in excellent condition decreases. This is both due to the deterioration of pavements in excellent condition, and the fact that no pavement is being brought into excellent condition due to no preservation treatment. Similarly, the percentage of pavements in good condition decreases but initially at a lower rate. This is because though the pavements in good condition deteriorate to lower condition states, there is also deterioration of excellent pavements into good condition state. Pavement percentages in fair condition state increase in the initial years due to deterioration, and then decrease. Deterioration from excellent and good condition is more rapid than deterioration from

TABLE 4 Deterioration of the Network Under No Preservation Work

\begin{tabular}{|l|l|l|l|l|l|l|l|}
\hline & Year 0 & Year 1 & Year 2 & Year 3 & Year 4 & Year 5 & Year 7 \\
\hline Excellent & $20.85 \%$ & $8.47 \%$ & $3.44 \%$ & $1.40 \%$ & $0.57 \%$ & $0.23 \%$ & $0.04 \%$ \\
\hline Good & $41.90 \%$ & $37.02 \%$ & $26.80 \%$ & $17.80 \%$ & $11.29 \%$ & $6.98 \%$ & $2.55 \%$ \\
\hline Fair & $19.26 \%$ & $28.88 \%$ & $32.67 \%$ & $30.74 \%$ & $25.87 \%$ & $20.25 \%$ & $10.84 \%$ \\
\hline Poor & $12.80 \%$ & $17.26 \%$ & $24.43 \%$ & $31.31 \%$ & $35.72 \%$ & $37.09 \%$ & $32.95 \%$ \\
\hline Very poor & $5.19 \%$ & $8.38 \%$ & $12.67 \%$ & $18.76 \%$ & $26.55 \%$ & $35.45 \%$ & $53.62 \%$ \\
\hline
\end{tabular}




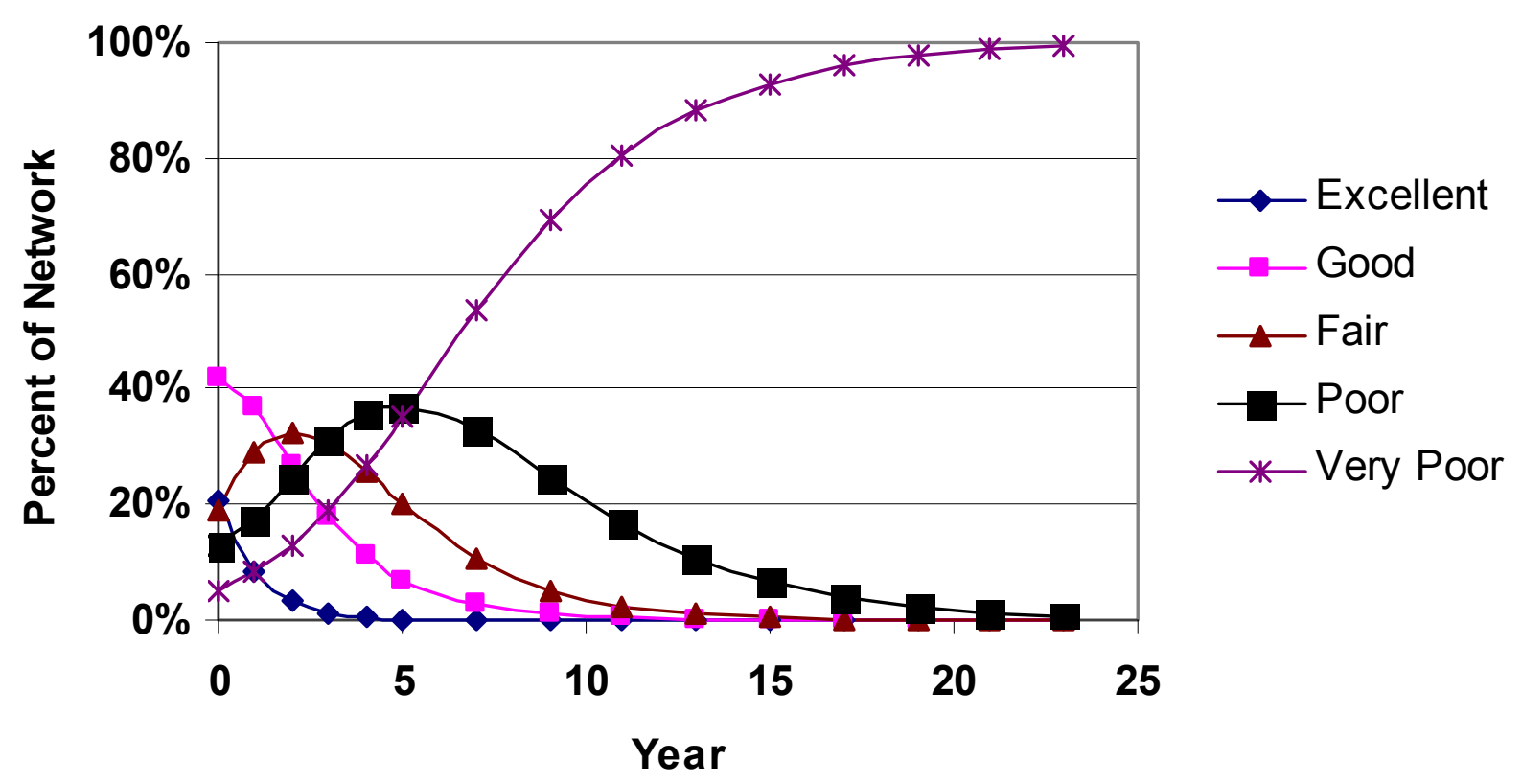

FIGURE 3 Deterioration of network under no preservation work.

fair to lower condition states in the initial years. Later on as the percentage deterioration from excellent and good condition decrease, there is decrease in the percentage of pavements in fair condition. Percentage of pavements in poor condition increases initially due to deterioration of pavements from higher condition levels and then decreases. Later on this percentage decreases as the deterioration into very poor condition is higher than deterioration from higher condition states into poor condition. There is monotonic increase in the percentage of pavements in very poor condition as the pavements deteriorate from higher condition states into very poor condition state. The very poor condition state is the absorbing state from which pavement sections have zero chance of exiting.

\section{Variation of Preservation Work}

The effect of no preservation work is explained previously and is a representation of deterioration of pavements. Similar to no preservation work, a fixed amount of preservation work is included every year in Equations 3 through 7 to determine the condition of the network. As a first case, a set of preservation treatments, which is expressed as a percent of the total network, is considered as follows: $\mathrm{PM}=8 \%, \mathrm{CM}=5 \%, \mathrm{RM}=2 \%$, and $\mathrm{RC}=1 \%$. The amount of preservation treatments is less than that required to sustain a steady distribution of condition states, and is chosen intentionally to evaluate the slower deterioration of the network as a whole. Deterioration of the network is slower compared to the case of no preservation work, and is shown in Figure 4.

An interesting phenomenon observed here is that under a fixed preservation treatment option every year the network condition distribution changes and reaches a steady state after 


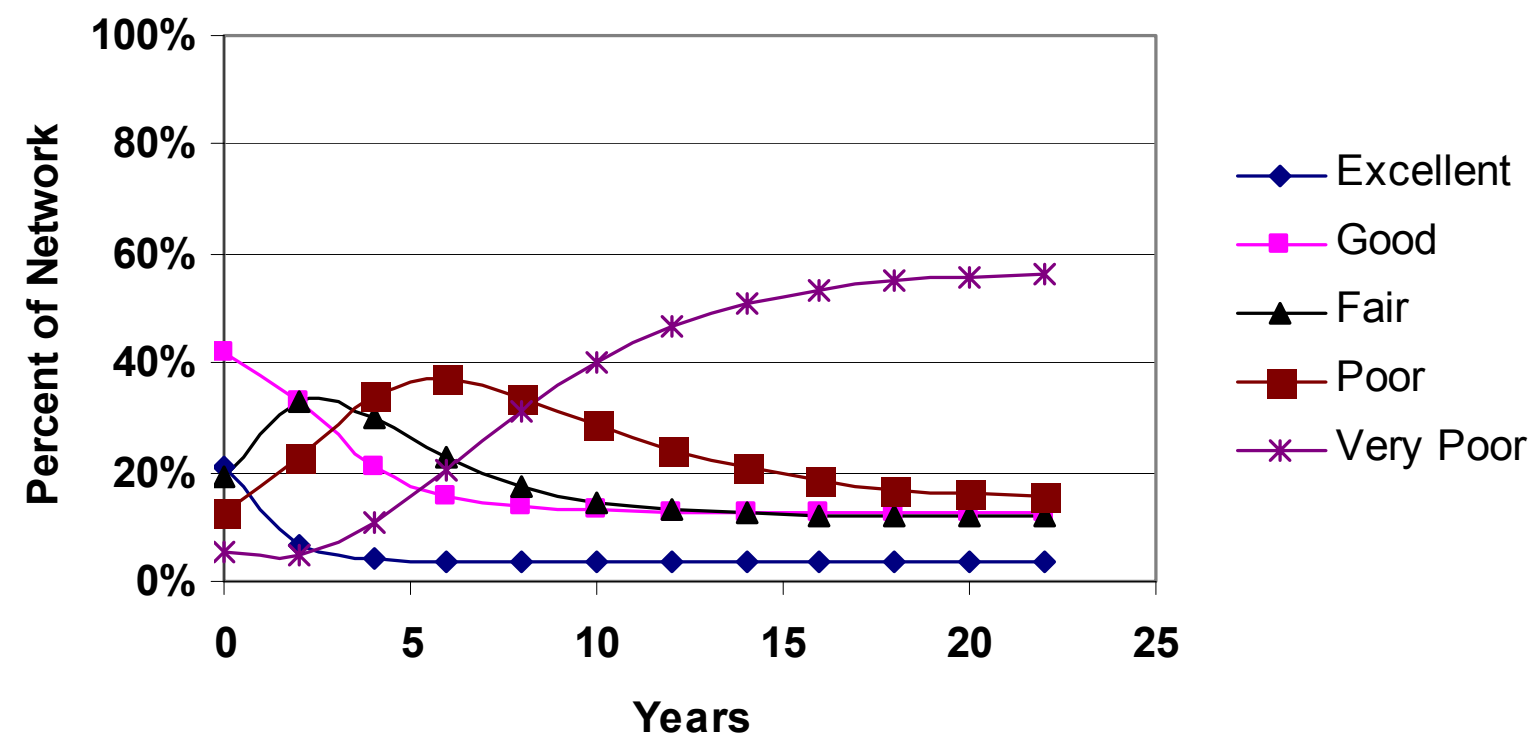

FIGURE 4 Deterioration of network under first set of preservation treatments.

a certain number of years. In this case, the steady state for the given preservation work is reached after about 20 years.

Another set of preservation treatments is employed to evaluate the deterioration of the network. Now a higher amount of work, as a percent of the total network, is considered compared to the previous case as follows: $\mathrm{PM}=20 \%, \mathrm{CM}=14 \%, \mathrm{RM}=3 \%$ and $\mathrm{RC}=2 \%$. In this case the network continues to deteriorate but at a slower rate as shown in Figure 5, and a steady state condition for the given preservation work is reached after about 6 years.

\section{SUMMARY AND CONCLUSIONS}

Many questions regarding preservation arise including the work needed year after year, current condition of network, condition of network resulting from a given set of preservation categories, effect of deferred preservation, reduced preservation work, etc. In an effort to answer these questions a methodology has been developed that forecasts the condition of the network under various specified conditions.

Solutions are developed that specify the preservation treatments needed to sustain the current condition distribution of pavements the same year after year at minimum possible cost. As explained previously, this may be considered a base line for the purpose of planning to avoid or reduce backlogs in the preservation work that could build up over the years if lesser preservation work is adopted. Answers regarding the preservation work needed to bring the pavement network from its current condition to a desired condition with minimum cost may also be explored using this methodology. In order to understand the nature of network deterioration, the condition distribution is determined for future years under the case of no preservation work. 


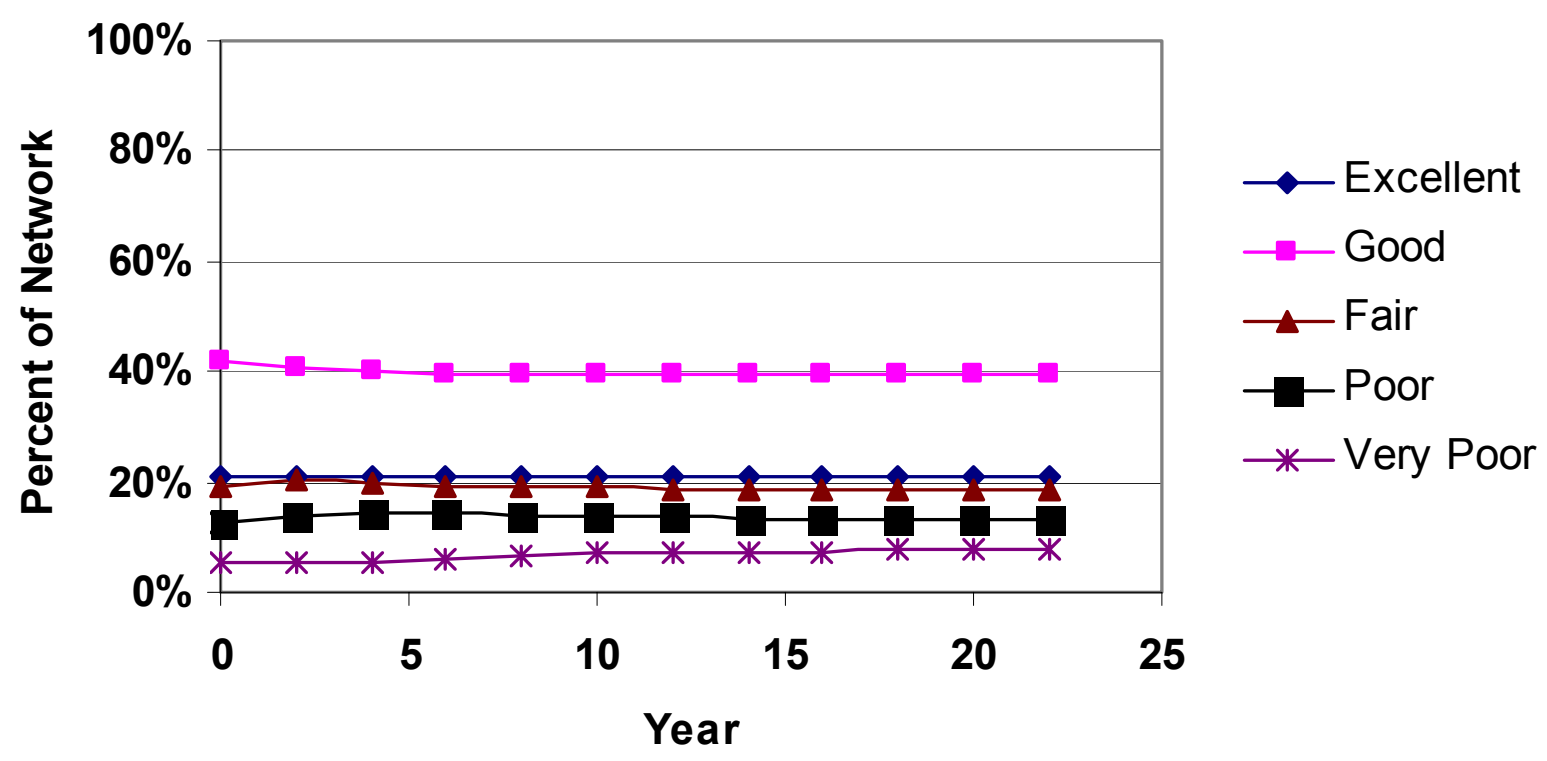

FIGURE 5 Deterioration of network under second set of preservation treatments.

Similarly, the effect of two sets of preservation works is evaluated during which an interesting phenomenon of steady state equilibrium after a few of years of application is observed. Adopting this methodology winter damage to a portion of the network is evaluated. For this case, preservation needs for sustaining the current conditions and also the increase in the preservation needs due to winter breakup is determined.

The methodology developed can be used to determine the minimum cost set of preservation activities for current and desired distribution of pavement conditions. Furthermore, it provides management with a tool to explore multiple planning and budgeting alternatives, and understand the severity and timing of impacts from different budget scenarios. Also, this methodology can be used to investigate a statewide or district wide network level analysis. The output could support such decision making as funding allocation, establishing required performance measures either strategic or operational depending on the desired output.

\section{DISCLAIMER}

The contents of this paper reflect the views of the authors, who are responsible for the facts and the accuracy of the data presented herein. The contents do not necessarily reflect the official views or policies of the VDOT, the Commonwealth Transportation Board, or the FHWA. This paper does not constitute a standard, specification, or regulation. 


\section{REFERENCES}

1. Zimmerman, K. A. NCHRP Synthesis of Highway Practice 222: Pavement Management Methodologies to Select Projects and Recommended Preservation Treatments. TRB, National Research Council, Washington, D.C., 1995.

2. Wang, K. C. P., and F. Liu. Pavement Performance-Oriented Network Optimization System. In Transportation Research Record 1524, TRB, National Research Council, Washington, D.C., 1996, pp. 86-93.

3. Pilson, C., W. R. Hudson, and V. Anderson. Multiobjective Optimization in Pavement Management by Using Genetic Algorithms and Efficient Surfaces. In Transportation Research Record: Journal of the Transportation Research Board, No. 1655, TRB, National Research Council, Washington, D.C., 1999, pp. 42-48.

4. Wang, K. C. P., J. Zaniewski, and J. Delton. Analysis of Arizona Department of Transportation's New Pavement Network Optimization System. In Transportation Research Record 1455, TRB, National Research Council, Washington, D.C., 1994, pp. 91-100.

5. Tack, J. N., and Y. J. Chou. Pavement Performance Analysis applying Probabilistic Deterioration Methods. In Transportation Research Record: Journal of the Transportation Research Board, No. 1769, TRB, National Research Council, Washington, D.C., 2001, pp. 20-27. 


\title{
Warranty Administration in the Michigan Department of Transportation's Capital Preventive Maintenance Program
}

\author{
KEVIN KENNEDY \\ Michigan Department of Transportation
}

Preventive maintenance (PM) is a planned strategy of cost-effective treatments to an existing roadway system and its appurtenances that preserves the system, retards future deterioration, and maintains or improves the functional condition of the system without substantially increasing structural capacity. The Michigan Department of Transportation (MDOT) established its Capital Preventive Maintenance (CPM) program to preserve the structural integrity and extend the service life of the state trunkline network through a series of construction contracts. The program was initiated in 1992 with an approximate budget of $\$ 8$ million and has grown to $\$ 77$ million in 2004 . Future budgets are projected to be $\$ 81$ million in 2005 , $\$ 85$ million in 2006 , and $\$ 89$ million in 2007 . In addition, there will be $\$ 43$ million of additional Preserve First funds spent on PM in 2005-2007. Preserve First is a program that puts increased emphasis on preservation of MDOT's existing transportation system rather than expanding it. It was instituted in 2003 due to budgetary concerns and the department's goal of having $90 \%$ of roads in good condition by 2007. Warranties play a major role in the department's CPM program.

With the growing number of warranty projects, the task of administering warranties and tracking the status of warranties is becoming increasingly important and increasingly difficult. Recognizing the importance of uniform criteria for administering warranties and reporting on warranties, the department created the Statewide Warranty Administration Team and has developed the Statewide Warranty Administration Database (SWAD). SWAD has been operational since October 2003. Through a series of canned reports that are produced monthly, it allows the department to track when warranty inspections are due, when warranties expire, and warranties that have had corrective action completed. These reports provide information on a statewide basis and also can break down information by region and by individual offices within a region (transportation service centers). The reports list projects with warranties (active and closed), total number of warranties (active and closed), warranties in conflict resolution, warranties requiring inspections (interim and final), and warranties with corrective action completed. In addition, SWAD allows the department to obtain detailed information on individual warranties. Contractors are also allowed access to the database to assist them in managing their warranty projects. The information provided to contractors is for informational purposes only and contractors must agree to a disclaimer stating such before entering SWAD.

Tracking warranties in the CPM program aids the department in making good decisions regarding project selection. The department has an annual call for projects in which the regions submit candidate projects for road and bridge projects. CPM projects are submitted only a year in advance to try to ensure that the right fixes are being done on the right pavements at the right time. By tracking performance of warranty projects through SWAD, the department can determine where corrective action has been needed and determine areas of concern regarding performance. This is important to verify the appropriateness of project selections and to maximize the life extension of the CPM fixes and improve overall network pavement condition.

\footnotetext{
his article is intended to report on the Michigan Department of Transportation (MDOT's) use of road warranties in the Capital Preventive Maintenance (CPM) program and the development of the Statewide Warranty Administration Database (SWAD) to help manage these warranties. This article will include
} 
- Definitions,

- Background information including legislative influence on the use of warranties,

- Components of warranties,

- Improving quality through warranties,

- Emerging technology program,

- Warranty administration, and

- Results.

\section{DEFINITIONS}

CPM. A planned strategy of cost-effective treatments to an existing roadway system and its appurtenances that preserve the system, retard future deterioration, and maintain or improve the functional condition of the system without substantially increasing structural capacity.

Emerging technology. A new treatment that is promising but whose performance and cost effectiveness is unproven.

Initial acceptance. The date when warranted work is complete and has been determined by the department to be in compliance with the contract specifications and is continuously open to traffic. This is the start date for a warranty period. There may be more than one initial acceptance for a project.

Material and workmanship warranty. The contractor is responsible for correcting deficiencies in the pavement caused by materials and workmanship during the warranty period. The contractor assumes no responsibility for deficiencies that are design related since the owner is responsible for pavement design.

Performance warranty. The contractor assumes full responsibility for pavement performance during the warranty period and is responsible for materials selection, workmanship, and certain aspects of design. The contractor is responsible for deficiencies under his control.

Reconstruction. A fix that typically removes and replaces the entire pavement structure. Sometimes the sand subbase may be left in place and incorporated in the new pavement structure.

Reconstruction fixes have a fix life of 20 years or more. The fix is typically applied to pavements with a remaining service life of 2 years or less.

Rehabilitation. A fix that has an estimated fix life of 10 to 20 years. Rehabilitation fixes are typically applied to pavements with a remaining service life of 2 years or less. These fixes include multiple course bituminous overlays, concrete patching and diamond grinding, crush and shape with bituminous overlay, and unbonded concrete overlays.

SWAD. Statewide Warranty Administration Database.

SWAT. Statewide Warranty Administration Team.

Warranty bond. A bond issued by a surety that guarantees the warranty requirements will be met. Warranty lane(s). The portion of the pavement considered warranted work. Each of the following is considered a separate warranty lane.

- Each individual mainline lane and mainline shoulder.

- The sum of all ramp lanes and the associated acceleration/deceleration lanes.

- The sum of all auxiliary lanes, such as passing lanes and turn lanes.

Warranted work. Work that is guaranteed to meet the warranty requirements throughout the warranty period. 
Warranty work. Corrective action taken by the contractor to bring the warranted work into contract compliance.

\section{BACKGROUND}

Preventive maintenance (PM) is a planned strategy of cost-effective treatments to an existing roadway system and its appurtenances that preserve the system, retard future deterioration, and maintain or improve the functional condition of the system without substantially increasing structural capacity. The MDOT established its CPM program to preserve the structural integrity and extend the service life of the state trunkline network through a series of construction contracts. The program was initiated in 1992 with an approximate budget of \$8 million and has grown to \$81 million in 2005. Future budgets are projected to be $\$ 85$ million in 2006 and $\$ 89$ million in 2007. In addition, there will be $\$ 43$ million of additional Preserve First funds spent on PM in 2005-2007. Preserve First is a program that puts increased emphasis on preservation of MDOT's existing transportation system rather than expanding it. It was instituted in 2003 due to budgetary concerns and the department's goal of having $90 \%$ of roads in good condition by 2007 . Warranties have played a major role in the department's CPM program and continue to do so as the investment level increases.

The MDOT has been using pavement warranties on projects since 1996 when MDOT let a design-build job with a performance warranty. Public Act 79 of 1997 states "Of the amounts appropriated for state trunkline projects, the department shall, where possible, secure warranties of not less than five year full replacement guarantee for Contracted Construction Work." In addition to this, language in the department's FY 1999/2000 and 2000/2001 appropriation bills states "The legislature encourages the department to work with the road construction industry to develop performance and road construction warranties for construction contracts. The development of warranties shall include warranties on materials, workmanship, performance criteria, and design/build projects." In response to this legislation, the department has worked to develop warranty specifications "where possible." The department has seen an increase from one warranty project in 1996 to 150 in 2004, 113 of which were in the CPM program. Through the 2004 construction season, there have been a total of $685 \mathrm{CPM}$ projects with warranties. The warranties on CPM projects have consisted mainly of 2-year performance warranties and 3-year material and workmanship warranties, and over $80 \%$ of the projects in the 2004 CPM program were warranted.

\section{WARRANTY COMPONENTS}

There are several components of a warranty including, but not limited to, initial acceptance, warranty bond, rights and responsibilities of the department, rights and responsibilities of the contractor, evaluation method, warranty requirements, conflict resolution, and corrective actions.

The initial acceptance date is the date when warranted work is complete and has been determined by the department to be in compliance with the contract specifications and is continuously open to traffic. This is the start date for a warranty period. There may be more than one initial acceptance for a project.

The warranty bond is provided by the contractor. For CPM projects, the bond is for $100 \%$ of the warranted work. For reconstruction and rehabilitation projects, the bond is for $5 \%$ of the contract or for a fixed dollar amount. 
The rights and responsibilities of the department include the right to approve materials, methods, and schedules for warranty work, to perform (or have performed) routine maintenance, and to perform emergency repairs if necessary. The department has the responsibility to monitor the pavement throughout the warranty period and to notify the contractor of any corrective action required.

The rights and responsibilities of the contractor include performing all warranty work within the warranty period at the contractor's expense, including costs for maintaining traffic.

The evaluation method consists of dividing the project into segments (typically one-tenth of a mile or $528 \mathrm{ft}$ ) with the first segment starting at the point of beginning of the project. The evaluation may include use of the department's pavement management system and/or field reviews.

Warranty requirements provide criteria when warranty work will be required.

Conflict resolution is necessary when there is a dispute between the contractor and the department regarding application or fulfillment of the warranty. The sole responsibility of the conflict resolution team is to make decisions regarding these disputes. The conflict resolution team consists of two members selected by the department, two members selected by the contractor, and one member mutually selected by the contractor and the department.

Corrective actions are required when a project has been found to be in violation of the warranty. The goal of corrective actions is to address the underlying cause of the condition that requires warranty work. By addressing the underlying cause, the pavement can be returned to a level of expected performance and excessive future maintenance costs can be avoided. Depending on the specific warranty and the specific distress causing a warranty to be in violation, the corrective actions can range greatly in cost and the amount of effort required by the contractor.

\section{IMPROVING QUALITY THROUGH THE USE OF WARRANTIES}

On June 25, 2004, a 1-day strategic forum on quality and warranties (1) was held in Lansing, Michigan. The 68 participants included representatives from MDOT, FHWA, industry, local agencies, and academia. A main focus of the forum was construction quality and warranties.

Conclusions from the forum are that warranties, if properly structured and administered, will improve quality on Michigan highways by

- Drawing contractor's attention to quality during construction.

- Eliminating the true lemons and premature failures.

- Allowing MDOT to optimize the use of a limited inspection work force.

- Allowing MDOT to better address public concerns with quality of work.

- Fostering innovation with new materials and processes.

- Increasing the contractor's awareness of product performance.

\section{EMERGING TECHNOLOGY PROGRAM}

One of the conclusions from the strategic forum on quality and warranties is that properly structured and administered warranties will improve quality on Michigan highways by fostering innovation. An example of this can be seen in MDOT's emerging technology initiative within the CPM program. Emerging technologies are new treatments that are promising but whose 
performance and cost effectiveness are unproven. Constructing emerging technology treatments under warranty provides the department with the opportunity to explore new and innovative products while reducing the risk of premature failure. The new treatments require monitoring and reporting of the findings. If through this reporting and monitoring a treatment proves to provide benefit to the department, it is moved out of the emerging technology category and becomes a standard fix, adding another tool to MDOT's toolbox.

\section{WARRANTY ADMINISTRATION}

It has been stated that warranties need to be properly administered in order to improve quality. With the growing number of warranty projects, the task of administering warranties and tracking the status of warranties is becoming increasingly important and increasingly difficult. Recognizing the importance of uniform criteria for administering warranties and reporting on warranties, the department created the SWAT and has developed the SWAD. The SWAD has been up and running since October 2003. It allows the department to obtain detailed information on individual warranties. In addition, it allows the department to track when warranty inspections are due and when warranties expire through a series of canned reports produced monthly. These reports provide information on a statewide basis and also can break down information by region and by transportation service centers (individual offices within a region). The statewide report lists projects with warranties (active and closed), total number of warranties (active and closed), warranties in conflict resolution, warranties requiring inspections (interim and final), and warranties with corrective action completed. In addition, the SWAD allows the department to obtain detailed information on individual warranties.

When SWAD was initially introduced, it was only available to department personnel. This was because the department wanted to make sure the information in the system was accurate and to verify the integrity of the software application. Contractors are now allowed access to the database to assist them in managing their warranty projects. The information provided to contractors is for informational purposes only and contractors must agree to a disclaimer stating such before entering the SWAD. While MDOT personnel have access to all warranty jobs, contractors have access to their jobs only. MDOT has retained a consultant to help manage the SWAD and to continually improve the system.

Also, the department has published Guidelines for Administering Warranties on Road and Bridge Construction Contracts (2) to help provide guidance to department personnel involved with warranty projects.

\section{RESULTS}

In the CPM program, approximately 3\% of projects have required corrective action. While there are obvious cost savings associated with contractors performing repair work at their own expense, there are cost savings associated with warranties that may be less obvious. One of the objectives of the department's warranty program is to raise awareness of the direct correlation between materials and workmanship and pavement performance. By placing emphasis on materials and workmanship, the department intends to get longer life out of its pavements, reduce pavement failures, reduce maintenance costs, and incur lower life-cycle costs for the 
pavement. To date, we have not seen an increase in bid costs on warranty projects versus nonwarranty projects. It is likely that over a long period of time the bids on performance warranty projects might be higher than non-warranty jobs as the risk is transferred from the department to the contractor. Cost savings are also realized in construction engineering since warranty projects require less construction oversight by the department. They do not however eliminate the need for inspection or take the place of initial acceptance requirements.

The monitoring of warranties in the CPM program also aids the department in decision making with regard to project selection. The department has an annual call for projects in which the regions submit candidate projects for road and bridge projects. CPM projects are submitted only a year in advance to ensure that the pavement fix selection is appropriate for the pavement condition. By tracking performance of warranty projects through the SWAD, the department can determine where corrective action has been needed and identify areas of concern regarding performance. This information assists the department in making any necessary changes to specifications. It also helps to verify the appropriateness of project selections, to maximize the life extension of the CPM fixes, to improve overall network pavement condition, and to ensure the department is doing the right fix on the right road at the right time.

\section{REFERENCES}

1. Farragut, T. Strategic Forum on Quality and Warranties. Draft report for Michigan Department of Transportation, 2004.

2. Guidelines for Administering Warranties on Road and Bridge Construction Contracts. Michigan Department of Transportation, Construction and Technology Support Area, 2002. 


\title{
Preventive Surface Treatments Versus Traditional Corrective Maintenance Measures
}

\author{
N. MIKE JACKSON \\ DEEPAK DAVE \\ University of North Florida \\ Peter E. Sebahly \\ University of Nevada-Reno
}

GaIL L. PorritT

Asphalt Systems, Inc.

Traditional asphalt maintenance practices have typically been dedicated to corrective measures as opposed to preventive measures. Corrective maintenance measures include a wide range of processes, from costly full-depth reconstruction to relatively inexpensive surface treatments. The temporal relationship between such maintenance activities and life-cycle cost has been well documented by many pavement experts in recent years, and most highway agencies have adopted asset management systems that address this relationship, if not in reality, then at least in concept. However, most highway agencies have not yet embraced the potential benefits of preventive surface treatments. Although preventive surface treatments are common in most non-pavement applications (we paint our homes, our cars, our bridges, etc.), this concept is not currently fully implemented in roadway applications.

Similar to other construction materials, the properties of asphalt binders change over time as a result of oxidation and hardening. This process is accelerated by the presence of water and sunlight. The resulting distress in pavements is most often manifest as cracking, and/or raveling of the pavement surface. Corrective maintenance measures focus on the repair and rehabilitation of such distresses. A preventive maintenance strategy recognizes the merits of applying preventive surface treatments to newer, good quality pavements to cost effectively retard the aging process, thereby greatly reducing the need for more expensive corrective measures in the future.

A number of example applications are documented in this paper, demonstrating the cost effective benefits of preventive surface treatments. These include state and county roadways in Pennsylvania and Ohio. This paper describes the desirable material properties of preventive surface treatments in contrast to corrective maintenance applications, and provides both qualitative and quantitative evidence to document the benefits of preventive surface treatments in roadway applications.

\footnotetext{
ccording to the American Association of State Highway and Transportation Officials (AASHTO), a pavement management system (PMS) is a set of tools or methods that assist decision makers in finding optimum strategies for providing, evaluating, and maintaining pavements in a serviceable condition (l). In attempting to identify such optimum strategies, highway agencies are being encouraged to explore the benefits of preventive treatments as opposed to traditional corrective maintenance measures. This is evidenced by the recent emphasis placed on such activities by the FHWA, with the development of a new National Highway Institute (NHI) course entitled "Pavement Preservation: Integrating Pavement Preservation Practices and Pavement Management." According to Jim Sorenson, Construction
} 
and System Preservation Team Leader in FHWA's Office of Asset Management, "Pavement preservation programs provide significant benefits to highway agencies, while pavement management systems provide the data that agencies need to measure the benefits" (2). Katie Zimmermann, President of Applied Pavement Technology, Inc., which developed this new NHI course, said "Integrating a pavement preservation program into an overall pavement management plan can help highway agencies develop a more comprehensive and coordinated road improvement plan, which includes maintenance needs as well as capital improvements" (2). This philosophy promotes the implementation of preventive surface treatments, recognizing the lifecycle cost benefits already commonly employed in non-pavement applications, as illustrated in Figure 1.

The single most important environmental effect contributing to the degradation of pavement serviceability is oxidation, or aging. The asphalt binder, which constitutes approximately $6 \%$ of the hot-mix asphalt (HMA), is a petroleum derivative consisting of oils and resins. In simple terms, the oils provide flexibility to the pavement and the resins bind the mixture in place. The exposure of the pavement surface to water and solar radiation enables oxidation to occur, resulting in hardening and deterioration of pavement over a period of time. This process can be observed as discoloration of the pavement surface with age. Oxidation results in a reduction of binding properties of the resin, leading to loss of fine aggregate, or raveling on the surface of pavement. This process will ultimately lead to hardening of the pavement and the initiation of cracking and other, more severe distress modes. A properly functioning PMS will intervene early in the life of a pavement with an appropriate pavement maintenance treatment to intercept this fatal scenario.

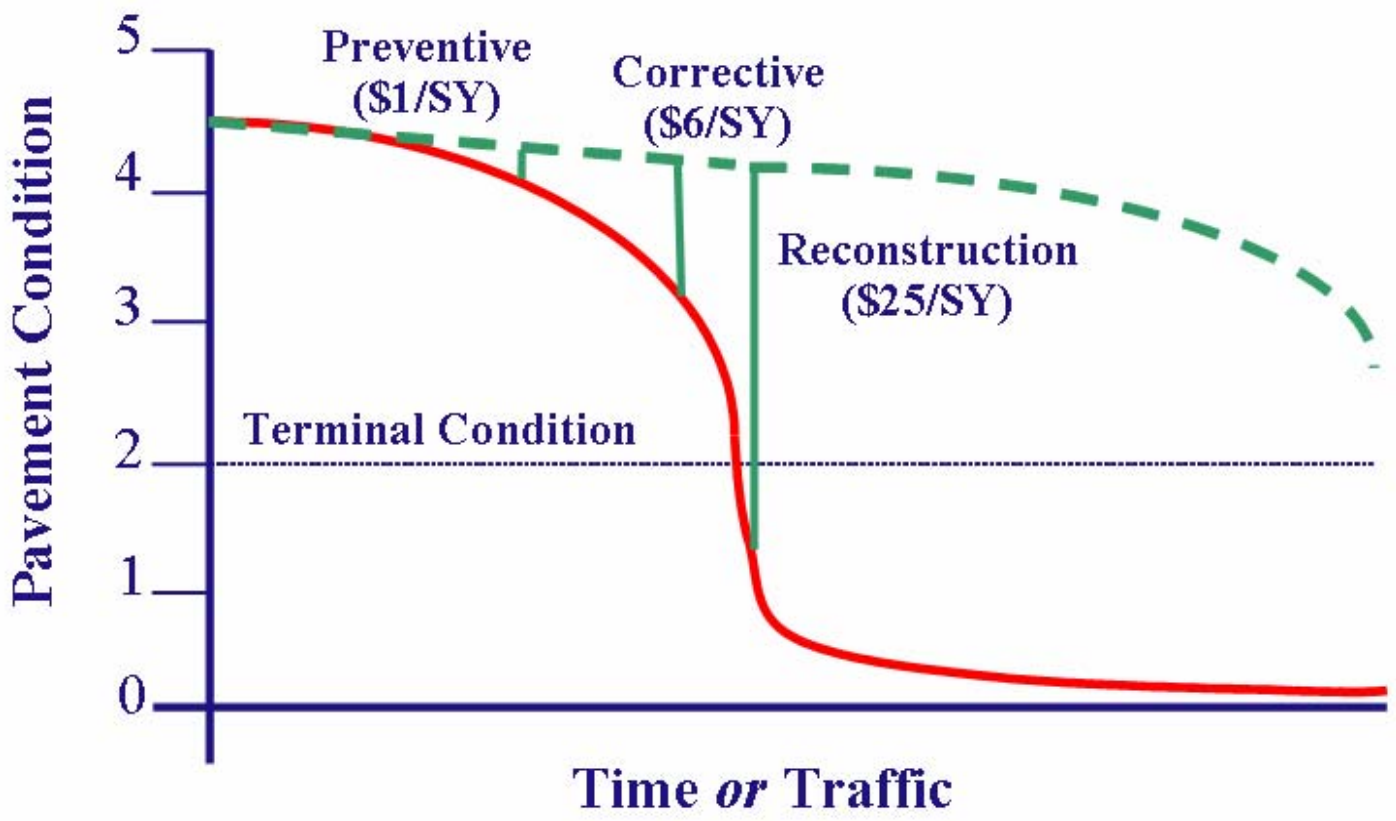

FIGURE 1 Schematic illustration of the cost benefits of preventive versus corrective treatments. 


\section{PAVEMENT MAINTENANCE TREATMENTS}

There are a number of different pavement maintenance treatments available for HMA.

- Crack sealing: used to prevent water and debris from entering cracks in the pavement.

- Fog sealing: a temporary application of diluted emulsion to enrich the pavement surface and protect from reveling and oxidation.

- Chip sealing: waterproofing the surface, sealing small cracks, and improving friction.

- Thin cold mix sealing: includes slurry sealing, cape seal, microsurfacing to fill cracks, and improve friction and ride quality.

- Thin overlay: HMA overlay on the pavement surface (typically (1 $1 / 2$-in. thickness) improves ride quality, water drainage, and friction.

In general, the most common treatments include overlays and sealing. Either type, or both, may be applied up to several times during the design period (3). The decision of which to use is primarily dependent on: $(a)$ structural aspects, i.e., distress, serviceability, etc., and (b) policy aspects. The shift from a reactive to a preventive treatment of pavements necessitates greater emphasis on the latter, policy aspects. Unfortunately, however, overlays have historically been the preferred treatment in almost all cases.

As part of a proactive philosophy, surface seals, or preventive surface treatments, are promoted as a means of minimizing the frequency of the more costly overlays by addressing the root cause of environmental distress. It is interesting to note that these treatment alternatives are not new; it is the timing of application, thus the policy aspects of the PMS that are changing.

\section{Preventive Surface Treatments}

The prime candidates for applications of preventive surface treatments are asphalt pavements that are likely to deteriorate primarily due to the environmental effects of surface oxidation. These include low traffic pavements such as residential streets, shoulders and rumble strips, parking areas, airport taxiways, ramps, and runway overruns, bike and running paths, asphalt staging areas, and pavements that are expensive and/or difficult to access and replace. Candidate pavements should be in good condition with little to no cracking. It is important to note that preventive surface treatments are designed primarily to inhibit surface oxidation, not correct it.

One example of a effective preventive surface treatment material is the Gilsonite (GSB-88) product. This material is a specially engineered asphalt emulsion designed to be applied to asphalt pavements while the pavement is still in good condition. Such applications have been shown to retard the natural surface oxidation process and cost effectively extend the life of asphalt pavements as described above.

Surface treatments are typically applied with a standard asphalt distributor and sand applicator in either a one- or two-pass operation. In the one-pass application, as presented in Figure 2, the asphalt distributor is equipped with a simple sand hopper and sand distribution system. In the two-pass application, the emulsion is applied and a separate sanding truck follows immediately behind the asphalt distributor. Applications of the emulsion will normally range from 0.10 to 0.15 gallons per square yard $\left(\mathrm{gal} / \mathrm{yd}^{2}\right)$, with an average application of around 0.12 $\mathrm{gal} / \mathrm{yd}^{2}$. Sand applications are generally applied at 0.50 to 0.75 pounds of sand per square yard $\left(\mathrm{lbs} / \mathrm{yd}^{2}\right)$. Applications may very depending on pavement circumstances. It should be noted that 


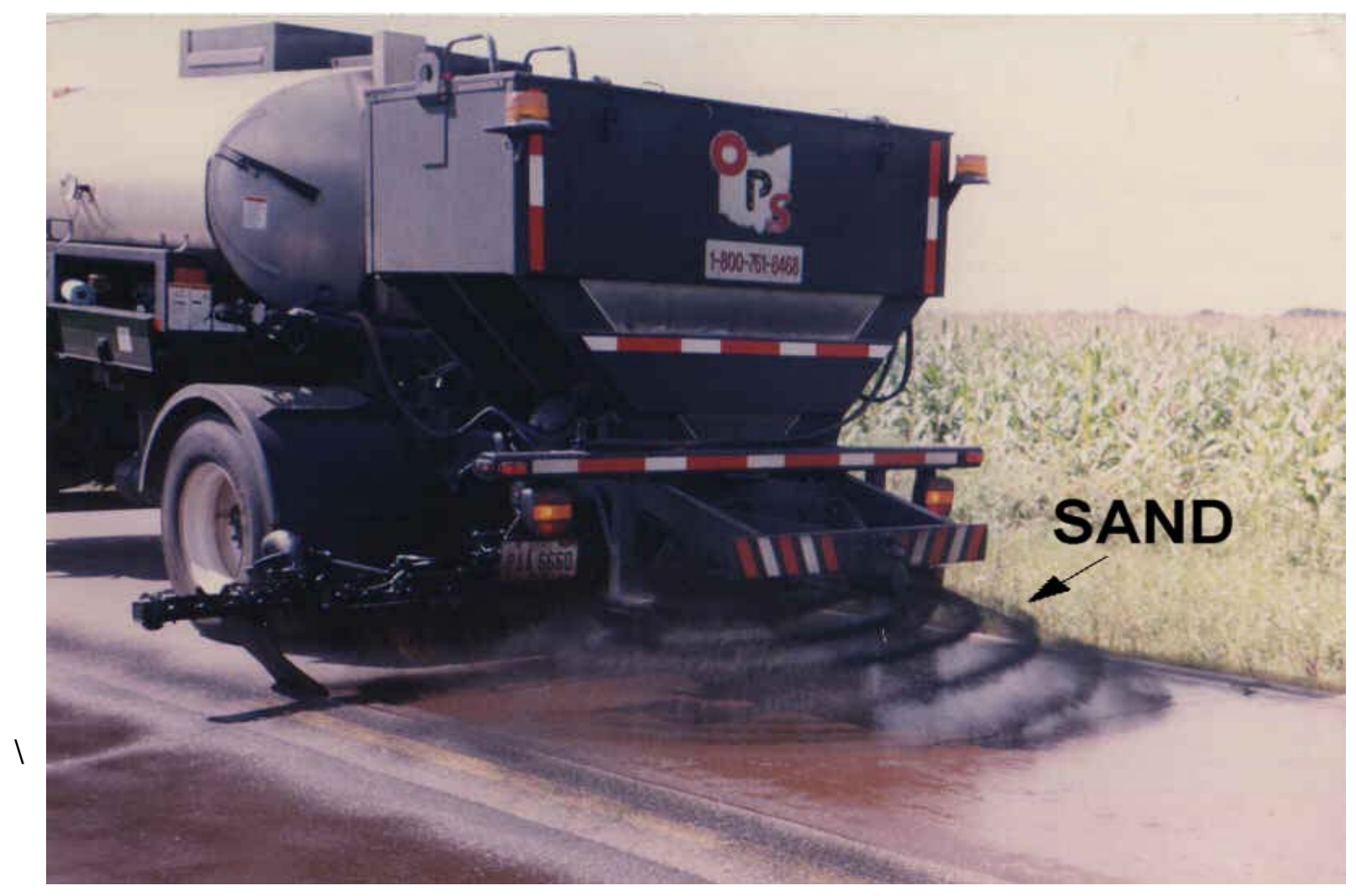

FIGURE 2 Asphalt emulsion distributor equipped with sand hopper for one-pass application.

application rates are highly material dependant and the material manufacturer should be consulted for specific rates for a given project.

\section{Qualitative Evidence of Benefits}

\section{State College, Pennsylvania}

A photograph of a residential street in State College, Pa., is presented in Figure 3. The pavement shown in the foreground was treated with a preventive surface treatment in the fall of 1999. The darker pavement to the far right was treated with the same material in the summer of 2001 . The photograph exhibited in Figure 3 was taken in the summer of 2002. A small strip of pavement between the two noted treatments was intentionally left untreated as a control section. The visible differences in oxidation between the three areas are readily apparent in the photograph. Figure 4 is a close-up view of the same pavement. The 3-year-old treated area on the right in the photograph in Figure 4 can be seen to have a much tighter matrix. It appears to have retained surface aggregate and retarded the natural oxidation process to a greater extent than the untreated surface. The untreated control strip, to the left in Figure 4 exhibits evidence of raveling and oxidation. These photographs demonstrate how timely applications of a preventive surface treatment to a structurally sound asphalt pavement can significantly retard the natural surface oxidation process, retain the aggregate that would normally be lost to raveling, and maintain the integrity of the surface matrix. 


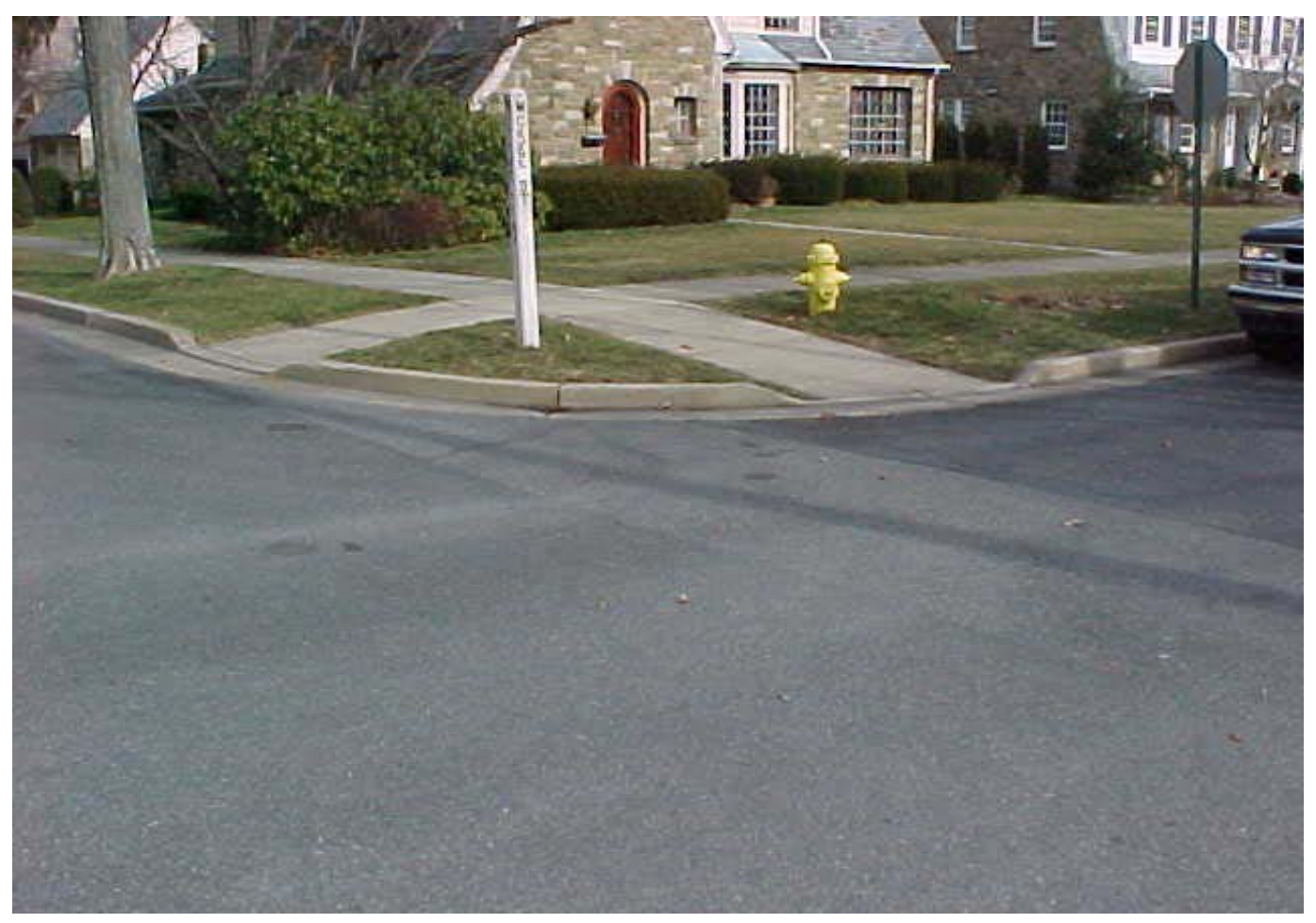

FIGURE 3 Residential street in State College exhibiting treated versus non-treated pavement.

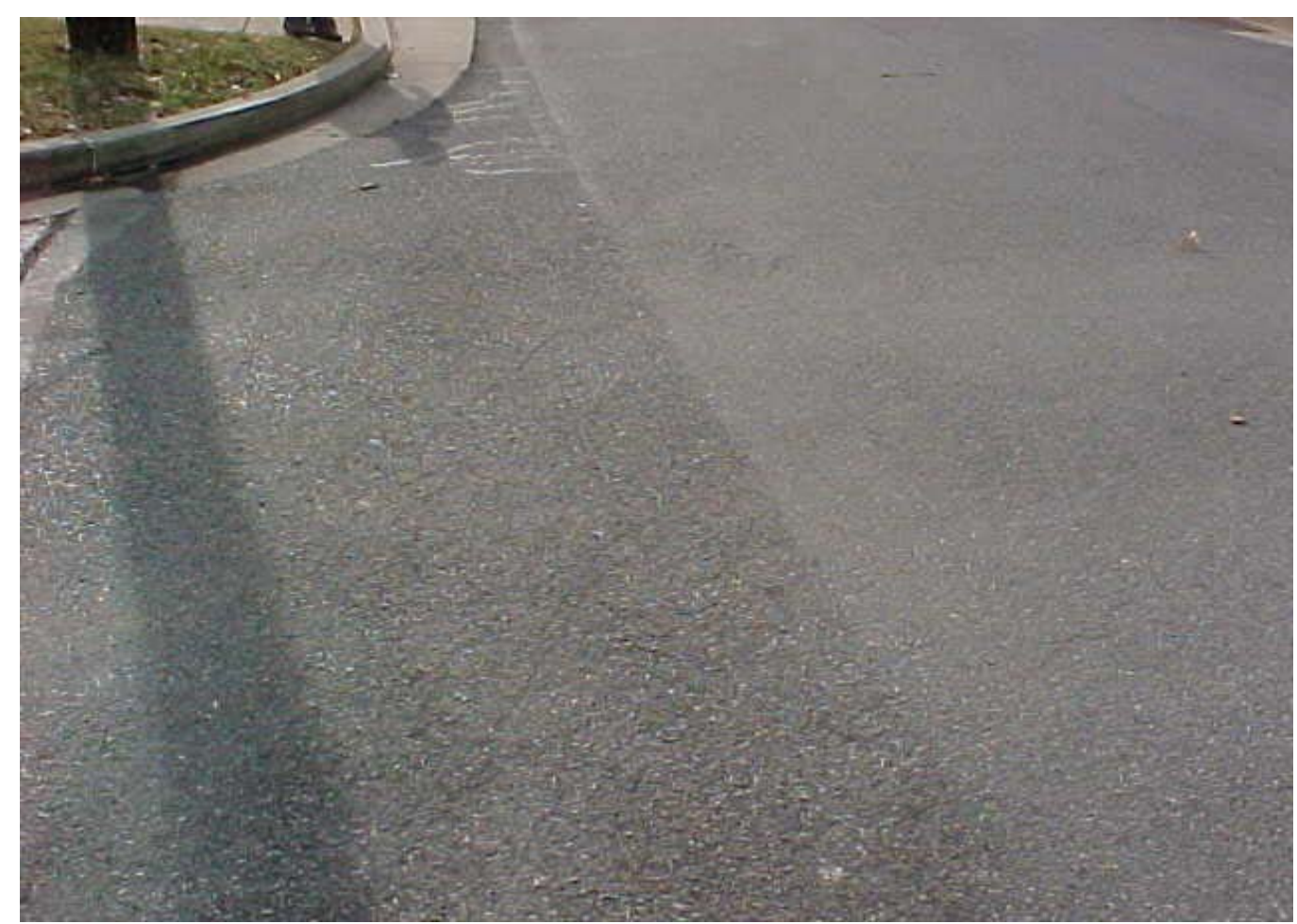

FIGURE 4 Close-up view of residential street in State College. 


\section{Logan County Road 154, Ohio}

Logan County Road 154, in Ohio, was designed with 24 in. of stone base and 3 in. of HMA surface. Construction of the pavement was completed in the fall of 1996. At the end of July 1997, a preventive surface treatment was applied on one lane with the parallel lane left untreated. Figure 5 exhibits close-up views of the two pavement surfaces, approximately 14 months after treatment. These and other photographs taken over a 5 -year period exhibit the qualitative value of preventive surface treatments. It is worth noting in Figure 5 that the treated pavement surface exhibits minimal loss of aggregate, whereas the untreated pavement exhibits evidence of raveling. Figure 6 exhibits the same pavement 24 months after the application of the surface treatment. Cracking, raveling, and oxidation of the untreated pavement are apparent. Also apparent, just above the word "Treated" in the photo, is the line where the application ended. The pavement below that line also exhibits raveling and oxidation, the treated pavement is still tight and oxidation has clearly been retarded. As exhibited in Figure 7, deterioration of the untreated lane is even more pronounced after a period of 5 years. General failure of the untreated pavement surface has occurred with extensive surface distress. The treated pavement remains in virtually the same useable condition it was in at the time of application.

\section{Quantitative Evidence of Benefits}

\section{U.S. Army Corps of Engineers Evaluation}

The U.S. Army Corps of Engineers (USACOE) completed a quantitative evaluation of selected preventive maintenance surface treatment materials in 2001 (4). Marshall stability and flow tests were conducted in accordance with ASTM D1559 (5) for both treated and untreated, aged and un-aged test specimens. The results of this study are summarized in Tables 1 and 2.

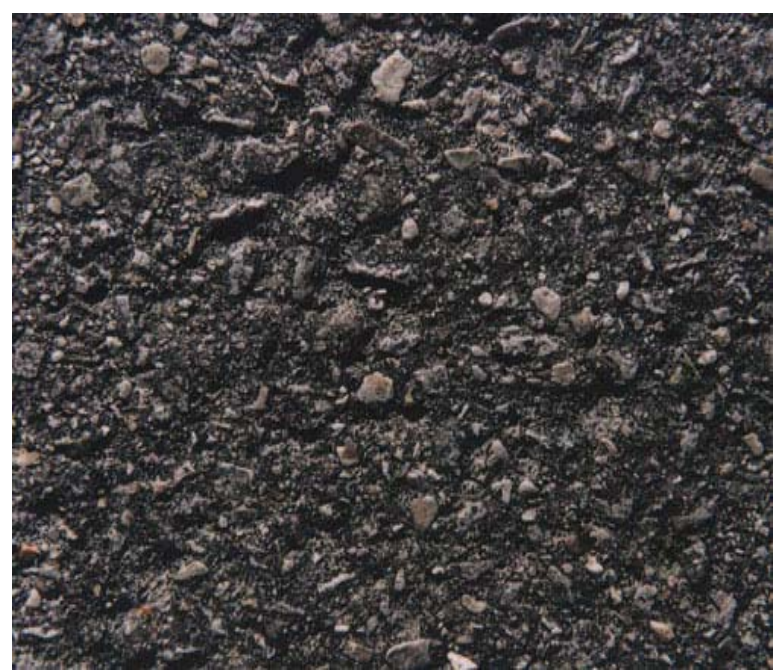

(a)

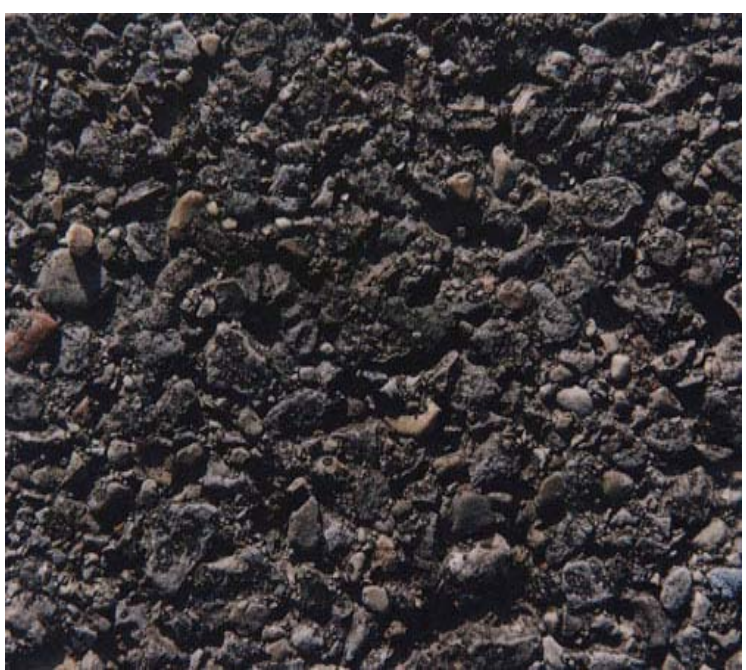

(b)

FIGURE 5 Logan County Road 154 in Ohio in September 1998, 14 months after treatment: (a) treated surface and $(b)$ untreated surface. 


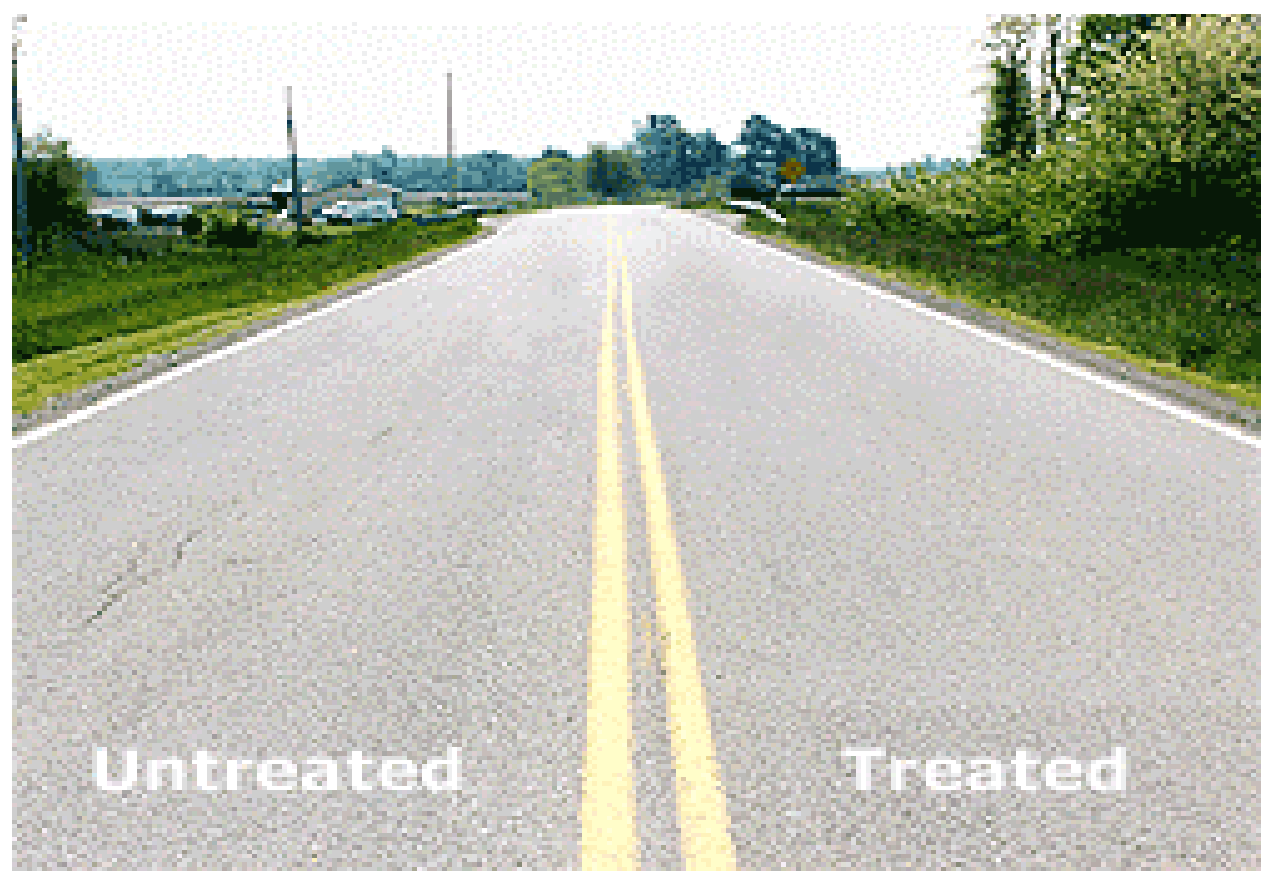

FIGURE 6 Logan County Road 154 in Ohio in July 1999, 24 months after treatment.

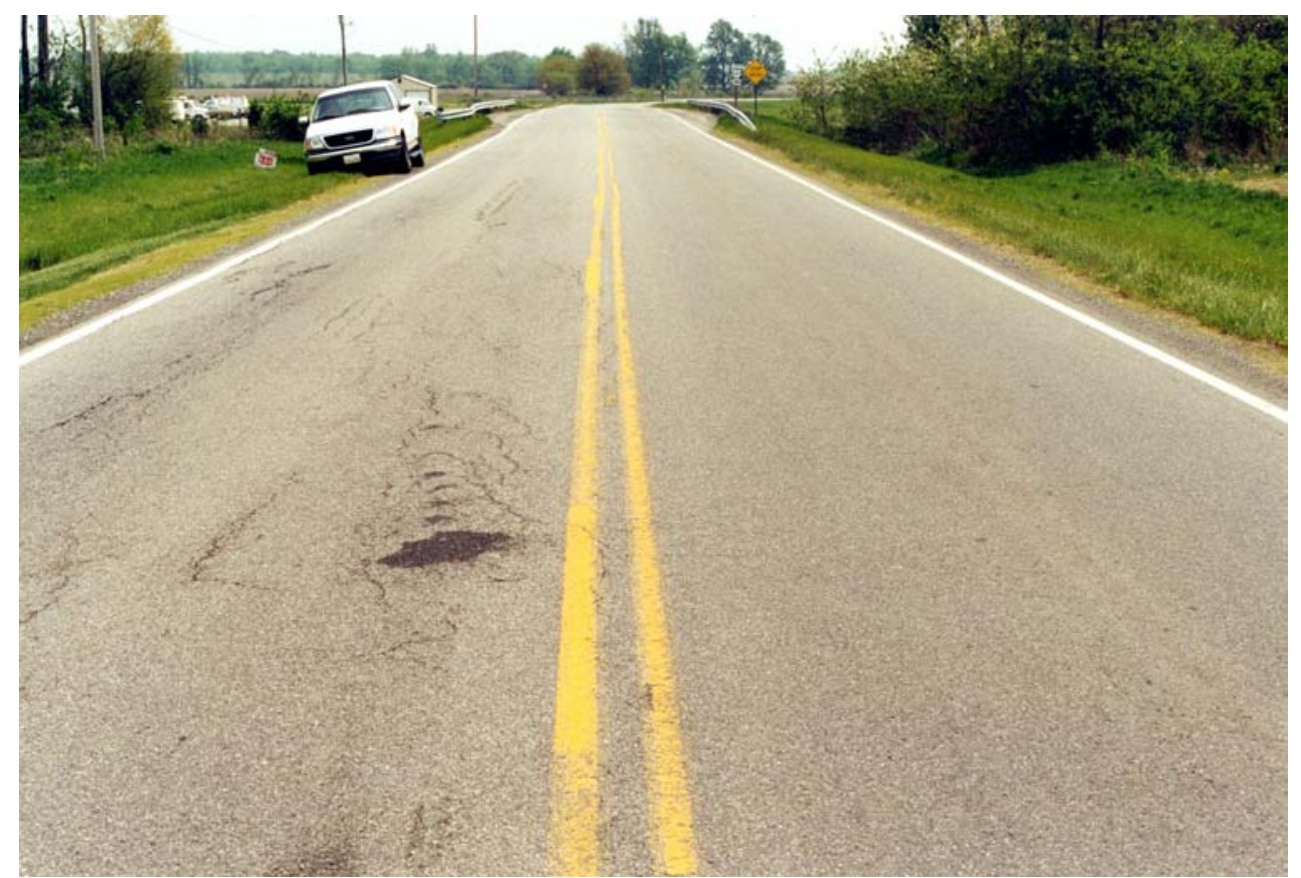

FIGURE 7 Logan County Road 154 in Ohio in July 2002, 5 years after treatment. 
The Marshall test specimens were fabricated in the USACOE laboratory in Vicksburg, Miss., using a common airfield aggregate gradation and a typical AC-20 asphalt binder. The specimens were compacted with 75 blows of a Marshall mechanical hammer on each side. The compacted Marshall specimens were each weighed to obtain the untreated weight. The selected treatment materials were applied with a paint brush, to provide a uniform application rate over the entire surface of each specimen. The specimens were then allowed to cure under laboratory conditions for at least $48 \mathrm{~h}$ prior to the commencement of oven aging. After the initial curing period, the coated specimens were weighed to determine the relative amount of material applied to the specimens. After oven aging for the prescribed time, Marshall stability and flow testing was conducted on each specimen and the corresponding stability and flow values were recorded.

The mean and coefficient of variation (COV) of the three individual Marshall tests for each material and treatment condition were calculated (Table 2). The COV values obtained for the coated specimens were found to be generally within the range of those obtained for the uncoated specimens. This was also found to be the case for the range of COV values obtained for the different aging times. The data shows that compared to the treated specimens, the untreated specimens had the highest mean stability values. This indicates that all of the different surface treatments evaluated were effective in protecting the underlying asphalt binder to some extent from the affects of oxidation and aging.

A statistical analysis was also conducted using SPSS software, Windows version 9.0. This analysis used the results from each individual test with a one-way analysis of variance (ANOVA). As part of this analysis, a multiple comparison procedure (homogeneity of variance analysis option) was conducted using the Duncan multiple-range test, with a $95 \%$ confidence level. The test results confirmed that regardless of the treatment applied, the untreated specimens developed the highest Marshall stability values, indicating these specimens experienced the most aging or hardening. Also, the specimens treated with a heavy application of the GSB-88 material exhibited the lowest Marshall stability values, regardless of the amount of aging.

Evaluation of the above-described Marshall test results provides quantitative evidence that the application of an effective preventive surface treatment does protect an asphalt pavement from oxidation and aging. As a result of this evaluation, the USACOE researchers concluded that asphalt preventive surface treatments can extend pavement life by $25 \%$ ( 5 years for a 20 -year pavement), thus reducing construction costs by approximately $10 \%$ and maintenance costs by $20 \%$ per year. The USACOE researchers estimated that for a typical military airfield with one runway (cost approximately $\$ 2.5$ million), the construction cost savings, not including maintenance savings, would be approximately $\$ 250,000$ per year, or $\$ 1.2$ million over the 5-year period. Since the Army has over 150 runways in service, this 5-year savings could be as much as $\$ 180$ million for runways alone. Including the rest of the asphalt on those airfields the cost savings could exceed $\$ 500$ million for Army airfields alone.

\section{Logan County Road 154, Ohio (Revisited)}

In April 2002, a private testing lab (Stoneco) was contracted to sample cores from both the treated and untreated lanes of Logan County Road 154 (Figures 5 through 7). These samples were tested in the laboratory for Marshall stability and viscosity of the recovered binder. The 
TABLE 1 Summary of USACOE Marshall Stability and Flow Test Data

\begin{tabular}{|c|c|c|c|c|c|c|c|}
\hline $\begin{array}{c}\text { Sample } \\
\text { No. }\end{array}$ & Treatment & $\begin{array}{l}\text { Days } \\
\text { Aged }\end{array}$ & $\begin{array}{l}\text { WT Before } \\
\text { Treatment }\end{array}$ & $\begin{array}{c}\text { WT After } \\
\text { Treatment }\end{array}$ & Difference & Stability & Flow \\
\hline 1 & Untreated & 1 & 1253.1 & 1252.2 & -0.9 & 2800.0 & 13.0 \\
\hline 2 & Untreated & 1 & 1255.2 & 1255.7 & 0.5 & 3600.0 & 12.0 \\
\hline 3 & Untreated & 1 & 1257.1 & 1257.7 & 0.6 & 3350.0 & 14.0 \\
\hline 4 & Untreated & 60 & 1257.1 & 1258.0 & 0.9 & 4310.0 & 15.5 \\
\hline 5 & Untreated & 60 & 1252.2 & 1252.8 & 0.6 & 4525.0 & 15.0 \\
\hline 6 & Untreated & 60 & 1261.5 & 1261.6 & 0.1 & 4350.0 & 15.5 \\
\hline 7 & Saran Wrap & 60 & 1249.8 & 1250.1 & 0.3 & 4250.0 & 15.0 \\
\hline 8 & Saran Wrap & 60 & 1256.7 & 1256.8 & 0.1 & 3960.0 & 14.5 \\
\hline 9 & Saran Wrap & 60 & 1250.6 & 1250.9 & 0.3 & 4200.0 & 15.5 \\
\hline 10 & Emulsion & 1 & 1256.1 & 1260.2 & 4.1 & 2550.0 & 14.0 \\
\hline 11 & Emulsion & 1 & 1245.9 & 1249.2 & 3.3 & 2750.0 & 14.0 \\
\hline 12 & Emulsion & 1 & 1253.8 & 1257.2 & 3.4 & 2750.0 & 14.0 \\
\hline 13 & Emulsion & 60 & 1249.9 & 1253.2 & 3.3 & 4625.0 & 15.5 \\
\hline 14 & Emulsion & 60 & 1253.9 & 1257.1 & 3.2 & 4000.0 & 15.5 \\
\hline 15 & Emulsion & 60 & 1254.9 & 1257.9 & 3.0 & 3550.0 & 15.0 \\
\hline 16 & Coal Tar & 1 & 1244.6 & 1249.1 & 4.5 & 2950.0 & 16.0 \\
\hline 17 & Coal Tar & 1 & 1255.9 & 1260.0 & 4.1 & 3100.0 & 14.0 \\
\hline 18 & Coal Tar & 1 & 1251.4 & 1255.5 & 4.1 & 3000.0 & 14.0 \\
\hline 19 & Coal Tar & 60 & 1254.1 & 1257.8 & 3.7 & 3860.0 & 14.0 \\
\hline 20 & Coal Tar & 60 & 1253.7 & 1257.4 & 3.7 & 3880.0 & 15.0 \\
\hline 21 & Coal Tar & 60 & 1260.3 & 1264.1 & 3.8 & 3775.0 & 16.0 \\
\hline 43 & Light GSB-88 & 1 & 1255.9 & 1260.5 & 4.6 & 2625.0 & 13.0 \\
\hline 23 & Light GSB-88 & 1 & 1254.1 & 1259.0 & 4.9 & 2900.0 & 15.0 \\
\hline 24 & Light GSB-88 & 1 & 1254.7 & 1260.4 & 5.7 & 2625.0 & 15.0 \\
\hline 25 & Light GSB-88 & 60 & 1256.3 & 1262.2 & 5.9 & 3925.0 & 17.0 \\
\hline 26 & Light GSB-88 & 60 & 1257.9 & 1263.3 & 5.4 & 4100.0 & 17.0 \\
\hline 27 & Light GSB-88 & 60 & 1256.1 & 1262.1 & 6.0 & 3775.0 & 17.0 \\
\hline 28 & Heavy GSB-88 & 1 & 1247.1 & 1258.7 & 11.6 & 2100.0 & 14.0 \\
\hline 29 & Heavy GSB-88 & 1 & 1253.3 & 1263.6 & 10.3 & 2100.0 & 15.0 \\
\hline 30 & Heavy GSB-88 & 1 & 1251.8 & 1263.9 & 12.1 & 2200.0 & 14.0 \\
\hline 31 & Heavy GSB-88 & 60 & 1255.2 & 1266.9 & 11.7 & 3072.0 & 18.0 \\
\hline 32 & Heavy GSB-88 & 60 & 1249.9 & 1261.4 & 11.5 & 3275.0 & 22.0 \\
\hline 33 & Heavy GSB-88 & 60 & 1249.9 & 1260.7 & 10.8 & 3325.0 & 19.0 \\
\hline
\end{tabular}


TABLE 2 Summary of USACOE Statistical Analysis

\begin{tabular}{|c|c|c|c|c|c|c|}
\hline \multirow{2}{*}{$\begin{array}{c}\text { Sample } \\
\text { No. }\end{array}$} & \multirow[t]{2}{*}{ Treatment } & \multirow{2}{*}{$\begin{array}{l}\text { Days } \\
\text { Aged }\end{array}$} & \multicolumn{2}{|c|}{ Stability } & \multicolumn{2}{|c|}{ Flow } \\
\hline & & & Mean & $\mathrm{COV}$ & Mean & $\mathrm{COV}$ \\
\hline 1 & Untreated & 1 & 2800.0 & & 13.0 & \\
\hline 2 & Untreated & 1 & 3600.0 & & 12.0 & \\
\hline \multirow[t]{2}{*}{3} & Untreated & 1 & 3350.0 & & 14.0 & \\
\hline & & & 3250.0 & 12.59 & 13.0 & 7.69 \\
\hline 4 & Untreated & 60 & 4310.0 & & 15.5 & \\
\hline 5 & Untreated & 60 & 4525.0 & & 15.0 & \\
\hline \multirow[t]{2}{*}{6} & Untreated & 60 & 4350.0 & & 15.5 & \\
\hline & & & 4395.0 & 2.6 & 15.3 & 1.88 \\
\hline 7 & Saran Wrap & 60 & 4250.0 & & 15.0 & \\
\hline 8 & Saran Wrap & 60 & 3960.0 & & 14.5 & \\
\hline \multirow[t]{2}{*}{9} & Saran Wrap & 60 & 4200.0 & & 15.5 & \\
\hline & & & 4137.0 & 3.75 & 15.0 & 3.33 \\
\hline 10 & Emulsion & 1 & 2550.0 & & 14.0 & \\
\hline 11 & Emulsion & 1 & 2750.0 & & 14.0 & \\
\hline \multirow[t]{2}{*}{12} & Emulsion & 1 & 2750.0 & & 14.0 & \\
\hline & & & 2683.0 & 4.3 & 14.0 & 0 \\
\hline 13 & Emulsion & 60 & 4625.0 & & 15.5 & \\
\hline 14 & Emulsion & 60 & 4000.0 & & 15.5 & \\
\hline \multirow[t]{2}{*}{15} & Emulsion & 60 & 3550.0 & & 15.0 & \\
\hline & & & 4058.0 & 13.3 & 15.3 & 1.88 \\
\hline 16 & Coal Tar & 1 & 2950.0 & & 16.0 & \\
\hline 17 & Coal Tar & 1 & 3100.0 & & 14.0 & \\
\hline \multirow[t]{2}{*}{18} & Coal Tar & 1 & 3000.0 & & 14.0 & \\
\hline & & & 3017.0 & 2.53 & 14.7 & 7.87 \\
\hline 19 & Coal Tar & 60 & 3860.0 & & 14.0 & \\
\hline 20 & Coal Tar & 60 & 3880.0 & & 15.0 & \\
\hline \multirow[t]{2}{*}{21} & Coal Tar & 60 & 3775.0 & & 16.0 & \\
\hline & & & 3838.0 & 1.45 & 15.0 & 6.67 \\
\hline 43 & Light GSB-88 & 1 & 2625.0 & & 13.0 & \\
\hline 23 & Light GSB-88 & 1 & 2900.0 & & 15.0 & \\
\hline \multirow[t]{2}{*}{24} & Light GSB-88 & 1 & 2625.0 & & 15.0 & \\
\hline & & & 2717.0 & 5.84 & 14.3 & 8.06 \\
\hline 25 & Light GSB-88 & 60 & 3925.0 & & 17.0 & \\
\hline 26 & Light GSB-88 & 60 & 4100.0 & & 17.0 & \\
\hline \multirow[t]{2}{*}{27} & Light GSB-88 & 60 & 3775.0 & & 17.0 & \\
\hline & & & 3933.0 & 2.71 & 14.3 & 4.03 \\
\hline 28 & Heavy GSB- 88 & 1 & 2100.0 & & 18.0 & \\
\hline 29 & Heavy GSB- 88 & 1 & 2100.0 & & 15.0 & \\
\hline \multirow[t]{2}{*}{30} & Heavy GSB-88 & 1 & 2200.0 & & 14.0 & \\
\hline & & & 2133.0 & 2.71 & 14.3 & 4.03 \\
\hline 31 & Heavy GSB-88 & 60 & 3072.0 & & 18.0 & \\
\hline 32 & Heavy GSB-88 & 60 & 3275.0 & & 22.0 & \\
\hline \multirow[t]{2}{*}{33} & Heavy GSB-88 & 60 & 3325.0 & & 19.0 & \\
\hline & & & 3224.0 & 4.16 & 19.7 & 10.59 \\
\hline
\end{tabular}


results of this testing are in support of the qualitative evidence previously described regarding the observed difference between the treated and the untreated pavement sections. The recovered binder from the untreated pavement exhibited a 30.4\% higher viscosity, which indicates significantly greater oxidation had occurred on the untreated pavement over the 5 -year period. In addition the cores obtained from the treated pavement exhibited a 38.3\% higher Marshall stability, resulting primarily from the degradation of the untreated pavement.

\section{Economic Benefits}

A simple economic analysis of the potential benefits of a preventive pavement maintenance plan is summarized below. The scenario presented here contrasts two alternative maintenance treatments for a $100,000 \mathrm{yd}^{2}$ pavement surface with a design life of 18 years. In summary, the two alternatives are:

- Alternative I: Conventional Mill/overlay

- Milling cost: $\$ 1.5 / \mathrm{yd}^{2}$

- Overlay cost: $\$ 4.0 / \mathrm{yd}^{2}$

- Alternative II: Employ a preventive surface treatment such as GSB-88

- Sealer cost: $\quad \$ 0.5 / \mathrm{yd}^{2}$

It is conservatively assumed that the conventional Mill/Overlay events will occur in the first year and the ninth year. In the second alternative, for consistency purposes it is again assumed that a conventional Mill/Overlay event will occur in the first year, followed by four surface treatments at $6,9,12$, and 15 years, as shown below:

- Alternative I:

- Mill/overlay@ Year 1

- Mill/overlay@Year 9

- Alternative II:

- Mill/overlay@ Year 1

- Four surface treatments at Years 6, 9, 12, and 15

If we consider a simple worth (PW) value approach, assume a discount rate of $3 \%$ and ignore the routine annual maintenance costs for the pavement surface in the first alternative, we have:

- Alternative I:

$$
\mathrm{PW}=5.50+\frac{5.50}{(1+0.03)^{9}}=\$ 9.72 / \mathrm{yd}^{2}
$$

- Alternative II:

$$
\mathrm{PW}=5.50+\frac{0.50}{(1+0.03)^{9}}+\frac{0.50}{(1+0.03)^{9}}+\frac{0.50}{(1+0.03)^{9}}+\frac{0.50}{(1+0.03)^{9}}=\$ 6.97 / \mathrm{yd}^{2}
$$

Thus, the cost savings associated with electing to employ Alternative II is: 
- $\quad$ Cost savings $=\mathrm{PW}$ (Alternative I) - PW (Alternative II)

$$
=\$ 9.72 / \mathrm{yd}^{2}-\$ 6.97 / \mathrm{yd}^{2}=\$ 2.75 / \mathrm{yd}^{2}
$$

- Total savings for a $100,000 \mathrm{yd}^{2}$ project:

$$
=100,000 \mathrm{yd}^{2} \times \$ 2.75 / \mathrm{yd}^{2}=\$ 275,000 \text {. }
$$

- Percent savings for a $100,000 \mathrm{yd}^{2}$ project

$$
=\frac{\$ 972,000-\$ 697,000}{\$ 972,000} \times 100=28 \%
$$

It is worth noting that this estimated percentage savings may actually be closer to $35 \%$ to $40 \%$ if routine annual maintenance costs are included in the analysis. Such annual maintenance would not occur for Alternative II. Thus, a cost savings on the order of $35 \%$ to $40 \%$ is not an unreasonable estimate.

\section{CONCLUSIONS}

Due to an ongoing shift from a reactive to a preventive treatment of pavements, highway agencies are exploring the benefits of preventive surface treatments as opposed to traditional corrective maintenance measures. Although preventive treatments are common in most nonpavement applications, this philosophy has not been fully adopted in roadway applications to date. As part of this proactive philosophy, surface seals, or preventive surface treatments, are promoted as a means of minimizing the frequency of more costly overlays.

Both qualitative and quantitative evidence are provided herein of the life-cycle benefits of utilizing preventive surface treatments on pavements that are yet in good serviceable condition. A simple economic analysis is used to illustrate that there are also real, present worth monetary savings associated with such a philosophy. Savings on the order of $35 \%$ to $40 \%$ are estimated. It is hoped that the evidence presented here will encourage others to integrate preventive pavement maintenance with their overall PMSs.

\section{REFERENCES}

1. AASHTO Guide for the Design of Pavement Structures. AASHTO, Washington, D.C., March 1993.

2. FOCUS. FHWA, U.S. Department of Transportation, McLean, Va., May 2005.

3. Haas, R., W. R. Hudson, and J. Zaniewski. Modern Pavement Management. Krieger Publishing Company, Malabar, Fla., 1994.

4. Newman, K., and J. Shoenberger. Results of Testing of Laboratory Manufactured Marshall Test Specimens, Both Coated and Uncoated, Aged and Unaged. Summary Report, USACOE, Vicksburg, Miss., Sept. 1, 2001.

5. Standard Test Method for Resistance to Plastic Flow of Bituminous Mixtures Using Marshall Apparatus. ASTM D 1559. American Society for Testing and Materials, 1999. 


\title{
Development of the Caltrans Maintenance Technical Advisory Guide
}

\author{
SHAKIR SHATNAWI \\ California Department of Transportation \\ Chistopher ANTONUCCI \\ Harris \& Sloan Consulting Group \\ R. GARY HICKS \\ $M A C T E C E \& C$
}

This paper presents the development of the Maintenance Technical Advisory Guide (MTAG) for the California Department of Transportation (Caltrans). The MTAG is a technical manual that covers pavement preservation and maintenance principles, materials used in maintenance treatments, treatment selection, crack sealing, chip seals, fog seals, slurry seals, and maintenance overlays. These are the main strategies that are being used by Caltrans for the pavement maintenance program. Guidelines for piloted strategies that utilize microsurfacing and bonded wearing course have also been developed in separate documents.

The MTAG was developed for the purpose of assisting maintenance personnel in making better and more informed decisions on selecting and applying maintenance treatments for their highways. It is designed for several levels of use, ranging from general instruction to specific work practice descriptions for the use of maintenance managers, maintenance supervisors, superintendents, and field personnel. Construction personnel and designers may also find use for this publication.

Each chapter contains guides for applying the treatments as well as information on troubleshooting problems. A checklist of important issues is appended to each chapter to provide the reader guidance on what to consider in achieving a successful outcome.

There has been excellent feedback from the users including maintenance managers, maintenance supervisors, superintendents, and field personnel. Strong and positive feedback also came from FHWA and several states that have used the guides. A training program is being developed that involves class instructions as well as self-directed web-based training.

\footnotetext{
$T_{\text {from }}$ he California Department of Transportation (Caltrans) maintenance program has shifted from a reactive effort to a pavement preservation effort. This along with a need for technical support and training in the use of various maintenance treatments prompted Caltrans to develop an advisory guide for the use of various maintenance treatments.

The Caltrans Maintenance Technical Advisory Guide (MTAG), developed in 2002, is a technical manual that covers pavement preservation and maintenance principles, materials used in maintenance treatments, treatment selection, and individual chapters on the main strategies currently in use by Caltrans (crack sealing, chip seals, fog seals, slurry seals, and maintenance overlays) (1). Guidelines for piloted strategies utilizing microsurfacing and bonded wearing courses have been developed as companion documents (1).

The MTAG was developed to assist maintenance personnel in making better and more informed decisions in selecting and applying maintenance treatments for their highways. It is a
} 
reference guide that will be used by all types of Caltrans personnel when selecting a maintenance treatment and understanding how it needs to be applied.

The MTAG was designed for several types of uses ranging from general instruction to specific work practice descriptions. The guide was also designed to be used by maintenance managers, maintenance supervisors, superintendents, and field personnel. Construction personnel and designers may also find use for this publication.

\section{Organization of MTAG}

The MTAG covers all the major treatment types, currently used by Caltrans and allows for the inclusion of future strategies. The completed document resides on the Caltrans website (www.dot.ca.gov/hq/maint). Currently the guide covers

$\begin{array}{ll}\text { Chapter } & \text { Maintenance Technical Advisory Guide } \\ \text { Cover } & \text { Cover page } \\ \text { TOC } & \text { Table of contents } \\ \text { Preface } & \text { Preface } \\ \text { Chapter 1 } & \text { Introduction } \\ \text { Chapter 2 } & \text { Treatment section } \\ \text { Chapter 3 } & \text { Crack sealing } \\ \text { Chapter 4 } & \text { Patching } \\ \text { Chapter 5 } & \text { Chip seals } \\ \text { Chapter 6 } & \text { Fog seals } \\ \text { Chapter 7 } & \text { Slurry surfacing } \\ \text { Chapter } 8 & \text { Maintenance overlays } \\ \text { Glossary } & \text { Glossary }\end{array}$

In addition, two guides have been developed for bonded wearing course pilot projects and microsurfacing pilot projects.

\section{TREATMENT SELECTION}

A brief summary of the strategy selection chapter of the MTAG is provided herein. This chapter provides guidance on the treatment selection process. It addresses the factors to be considered in the process of selecting an appropriate treatment for a pavement. These factors include pavement age, condition, traffic levels, expected future plans, and available funding and agency policy.

At the network level, a general relationship exists between pavement condition and pavement age. For a properly constructed new pavement, the only treatments required are preventive in nature (maintenance performed to delay the onset of distress). Then, as the pavement ages it becomes a candidate for routine maintenance (crack sealing, chip sealing, and thin overlays), later rehabilitation, and finally reconstruction.

Determining the appropriate maintenance treatment, based on the life-cycle and pavement condition index of the existing pavement, depends on the timing of the treatment. For example, the appropriate maintenance strategy for a relatively new pavement differs from the strategy required for to a pavement nearing the end of its life cycle. 
Once the appropriate maintenance strategy has been identified, the specific treatment is selected based on the specific distress mechanism acting on the pavement. The most important questions to consider when choosing the specific maintenance treatment are

- Does the treatment address the distresses present? (i.e., Will it work?)

- Can the required preparation for the treatment be carried out?

- Is the treatment cost effective?

- Can the treatment be performed before the situation being addressed changes?

\section{Selection Process}

There are three steps in the maintenance treatment selection process.

1. Assess the existing conditions. The pavement distress mechanisms are identified using field distress manual and pavement surveys $(2,3)$.

2. Determine the feasible treatment options. The "feasibility" is determined by a treatment's ability to address the functional and structural condition of the pavement while also meeting future needs. Feasibility is not a function of affordability, at this stage of the selection process the purpose is to determine what treatments might work. The MTAG contains the Caltrans matrix for identifying treatment options.

3. Analyze and compare the feasible options. Once selected, feasible options are compared in terms of cost, life expectancy, and extended pavement life resulting from the treatment. At this stage, a life cycle or other cost effectiveness assessment should be made to evaluate the optimum time to apply the treatment to provide maximum cost effectiveness. Figure 1 illustrates this concept.

\section{TYPICAL TREATMENTS}

This section presents an abbreviated treatment chapter to illustrate the way in which the MTAG presents the treatment topics. For full length copies of this and other treatments chapters, the reader should go to the Caltrans website (1).

\section{Types of Chip Seals}

Chip sealing is the application of a bituminous binder immediately followed by the application of an aggregate. The aggregate is then rolled to embed it into the binder. Multiple layers may be placed and various binder and aggregate types can be used to address specific distress modes or traffic situations.

Many different types of chip seals are in use by various agencies, but only treatments currently used by Caltrans are discussed in detail in this manual. A broad discussion of treatments not currently in use by Caltrans is included in the guide to promote understanding of other methods. Types of chip seal treatments include 


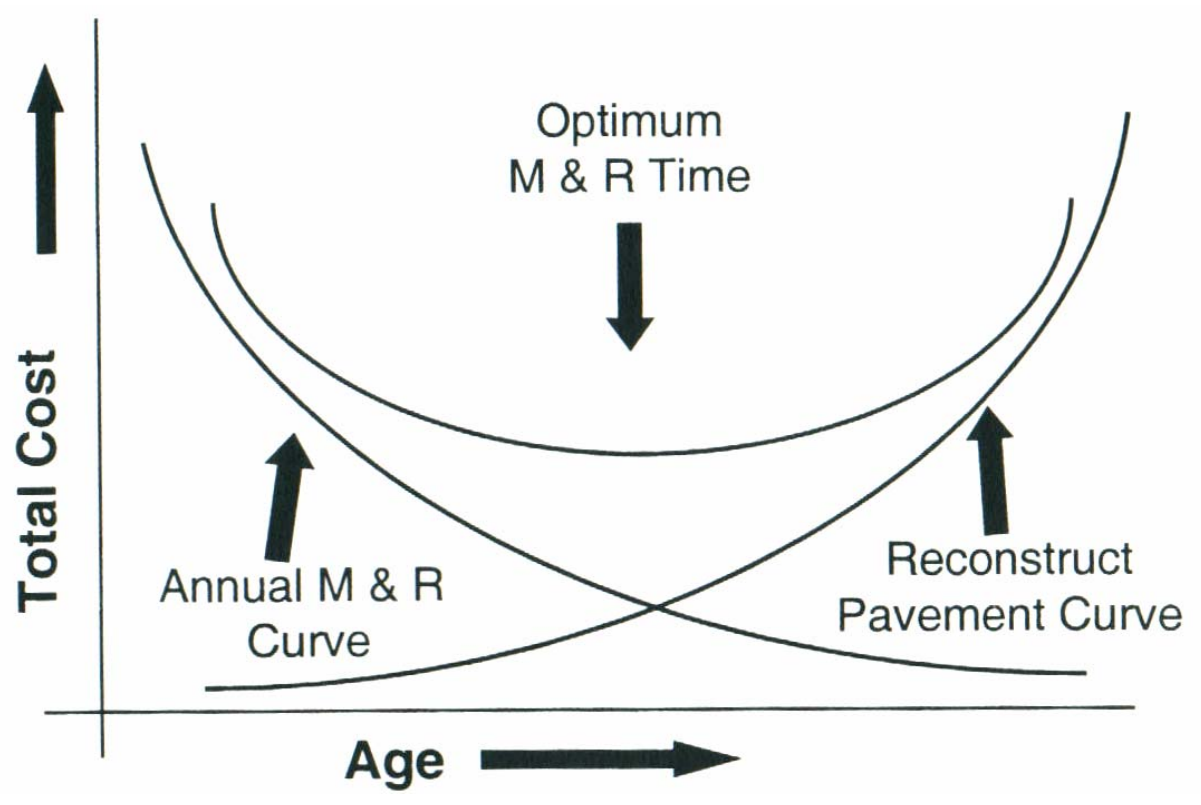

FIGURE 1 Treatment timing versus costs (4).

- Single chip seal: an application of binder followed by an aggregate. This is used as a pavement preservation treatment and provides a new skid-resistant wearing surface, arrests raveling, and seals minor cracks.

- Multiple chip seal (or armor coat): a built-up seal coat consisting of multiple applications of binder and aggregate. See MTAG for more detailed discussion.

- Stress absorbing membrane (SAM) seal: a single-chip seal in which a modified binder [normally asphalt rubber (AR)] is applied, followed by a layer of aggregate, and rolling. Binder applications are much higher than those used for conventional chip seals. Generally a SAM has been referred to as being used with AR binders.

- Stress absorbing membrane interlayer (SAMI): a membrane seal that is used to retard the rate of reflection cracking in new overlays. It consists of an application of modified binder followed by a layer of aggregate, spread, and rolled. An overlay is then placed over the membrane.

\section{Binder Types}

Binder type varies according to the type of chip seal being used. Binder types include

- Asphalt emulsion: polymer-modified emulsions (PME), such as PMCRS-2h, as included in the Standard Specifications, Section 94 (5).

- Performance-based asphalt (PBA) cements: hot-applied modified binders that can be placed at cooler temperatures than emulsion binders and can be placed at night. Examples include PBA 6 and PBA 6a binders (6).

- AR binder: binders modified with high levels of crumbed tire rubber and a high natural rubber content material (7). These binders are sprayed hot and require hot chips pre- 
coated with asphalt. Hot-applied AR binders can be placed at cooler temperatures than emulsion binders and can be placed at night.

- Rejuvenating emulsion: emulsions modified with rejuvenating oils (and sometimes polymers) that are used to penetrate and soften existing asphalt pavements.

\section{Project Selection}

The selection of a pavement for a chip seal project is based on the structural soundness of a pavement and the types of distress present. The ability of a treatment to address the current condition of a project is paramount in selecting an appropriate treatment. The most common chip seals and the corresponding pavement condition requirements include

- Conventional chip seals used on structurally sound pavements with minimal cracking;

- PME chip seals used to correct raveling and pavement oxidation;

- Rubberized chip seals, which cure quickly, restore skid resistance on worn surfaces, and resist reflection cracking; and

- Special binders AR and PBA, which may be used to address specific distress modes.

It should be understood that cracking, flushing, and base failures cannot be addressed with conventional or hot-applied chip seals; deformation, rutting, and shoving cannot be addressed with chip seals of any kind.

The main advantages associated with chip seals include

- Improved skid resistance: chip seals provide good skid resistance;

- Cost-effective treatments: chip seals are typically cost-effective when properly placed on the right type of pavement;

- Good durability: chip seals wear well and can have long service lives; and

- Ease of construction: chip seals are typically constructed rapidly and cause less disruption to the traveling public than do other treatments that take longer.

The main disadvantages associated with chip seals include

- Cure time: PME seals take several hours (depending on the climatic conditions) before opening to unrestricted traffic;

- Flying chips: chip seals must be swept to remove excess stone to avoid broken windshields and vehicle damage;

- Noise considerations: chip seals can be noisy to travel on;

- Weather considerations: cold-applied chip seals must be constructed during warm, dry weather and during the daytime only; and

- Performance: chip seals create a rougher surface and are generally not used for parking lots. Chip seals do not improve ride quality.

Other limitations include

- PMEs: not normally suitable for intersections or high stress areas; and 
- PBA seals: not suitable for very high stress areas due to their low initial strength.

\section{Material Specifications}

\section{Binders}

Binders are selected based on performance characteristics. They need to provide good adhesion and take into consideration climatic conditions, traffic levels, and types of loads associated with the project (e.g., snow plow use, annual average daily traffic, and percent trucks).

PME binders usually contain latex additives, although other elastomeric polymers are often used. Polymer improves stone retention during the early life of the treatment and increases the softening point of the binder after cure (i.e., the temperature at which the binder changes phase from primarily solid to primarily fluid). A general purpose base binder is an 85/100 penetration grade asphalt cement. This base binder mostly controls low temperature properties. For cold climates, a softer base binder (e.g., 120/150 penetration grade) may be warranted. For hot climates, a harder base binder (e.g., 40/50 penetration grade) should be considered.

PBAs are, by definition, performance-based. This means that they may contain a range of materials to enhance certain characteristics. PBA-6 and PBA-6a usually contain elastomeric polymers that increase the binder's softening point and improve its crack resistance.

AR binders contain high levels of crumbed tire rubber and high natural rubber materials, which raise the softening point of the binder, improves stone retention, and improves resistance to reflection cracking. In general, the base binder largely determines the low temperature properties; softer bases should be used in lower temperature areas.

\section{Aggregates}

For chip seals, the best performance is obtained when the aggregate used is

- Single-sized,

- Clean,

- Free of clay,

- Cubical (limited flat particles),

- Crushed faces, and

- Compatible with the selected binder type.

\section{Chip Seal Design}

Properly designed chip seals have proven to be cost effective in sealing pavements and providing a new riding surface with enhanced frictional characteristics. The basics of chip seal design are straightforward, as the binder application rate and the aggregate application rate are the only variables of major importance to consider. However, to correctly calculate these rates requires an understanding of the materials and the surface on which they are to be applied. Additional factors to consider include traffic, climate, and existing surface condition. The determination of the proper binder and aggregate application rates is discussed in greater detail in the following two sections. The design of multiple seal coats is also briefly described. However, sand seals and 
sandwich seals are designed strictly from experience and are not included in this discussion of design procedures.

\section{Binder Application}

In chip seal design, the residual binder application rate is the most important factor affecting seal performance. Adequate binder must be present to hold the aggregate in place, but not so much that the binder fills, or is forced by traffic action to cover the aggregate. The proper amount of binder ensures that the desired surface texture is maintained. Chip seal design is not like hot-mix asphalt design, in that film thickness is not as applicable a concept. Binder application rates are determined based on the average least dimension of the aggregate, as well as other aggregate properties such as shape, density, absorption, and grading. The optimum binder content also depends on how much binder flows into existing voids in the pavement, and how much binder is already present at or near the pavement surface.

The McLeod method is the most common design method for chip seals (8); however it is not routinely used by Caltrans. This method assumes that $70 \%$ of the voids in the aggregate must be filled (i.e., $70 \%$ embedment). In some states, this is adequate and has been adopted as the standard; however, modifications can be made for varying project conditions. A more detailed discussion on this design method can be found in "A General Method of Design for Seal Coats and Surface Treatments" by N.W. McLeod. The McLeod method also assumes the use of a cubical, single-sized aggregate. This may not always be the case (e.g., California specifications specify graded aggregates).

Corrections to the basic application rate for the aggregate address variables that affect the level to which it becomes embedded in the binder. The corrections are ultimately applied to the calculation of the binder application rate. These variables include

Aggregate Characteristics This includes absorption and shape. Corrections for absorption are based on experience and the characteristics of the local aggregates. Chip shape effects are variable: rounded chips leave greater voids and do not interlock and are not recommended. This type of chip also requires additional binder. Non-uniform sized aggregates produce uneven surfaces.

Traffic Volume This factor accounts for the role that traffic volumes play in achieving the ultimate embedment of $80 \%$ ( $20 \%$ void space). The traffic factor is lower for higher traffic volumes and higher for lower traffic volumes.

Loss of Aggregate Due to Traffic (Traffic Whip-Off) A traffic whip-off correction accounts for the effects of traffic operations on removing aggregates from newly chip sealed roads. Reasonable values for losses are 5\% for low volume roads and residential streets and $10 \%$ for high-speed roads and highways.

Existing Pavement Condition Existing pavement conditions play a very important role in determining the optimum binder content. A smooth surface will require less binder than will a rough or porous surface. 
Embedment Aggregates may be punched or embedded into soft pavement surfaces by roller compaction and traffic. Corrections based on surface hardness and related traffic volume using a Ball Penetrometer test is given in the guide (9).

Aggregate Application Calculation of the design aggregate application rate is based on determining the amount of aggregate needed to create an even, single coat of chips on the pavement surface. Though not routinely used by Caltrans, the amount of cover aggregate required is easily determined using the following equation (10):

$\mathrm{C}=(1-0.4 \mathrm{~V}) \times \mathrm{H} \times \mathrm{G} \times \mathrm{E}$

where

$\mathrm{C}=$ cover aggregate $\left(\mathrm{kg} / \mathrm{m}^{2}\right)$;

$\mathrm{V}=$ voids in loose aggregate $(\%)$;

$\mathrm{H}=\mathrm{ALD}(\mathrm{mm})$;

$\mathrm{G}=$ bulk specific gravity (see CT 206 and CT 208); and

$\mathrm{E}=$ wastage factor $(\%)$.

The bulk specific gravity of coarse and fine aggregates, G, can be determined using CT 206 and CT 208, respectively. The wastage factor (E) is to account for whip-off and handling and is normally estimated by the designer based on experience with local conditions.

The design of multiple coat seals is based on the same concepts as the single chip seal. First, a design is performed for each layer as if it were the only layer in the system. Next, the following three additional rules are applied as follows:

1. The maximum nominal top size of each succeeding layer of cover aggregate should be no more than half the size of the previous layer's aggregate;

2. No allowance is made for wastage; and

3. Except for the first application, no correction is made for the underlying surface texture.

The amounts of binder determined for each layer of aggregate are added together to calculate the total binder requirement. For two-layer chip seals, $40 \%$ of the total binder requirement is applied for the first layer of aggregate and the remaining $60 \%$ is applied for the second layer.

Application Rate for AR Modified Seals For asphalt rubber (e.g., SAMIs), typical binder application rates of 2.2 to $2.51 / \mathrm{m}^{2}\left(0.55\right.$ to $\left.0.65 \mathrm{gal} / \mathrm{yd}^{2}\right)$ are used by Caltrans. For AR seals, the binder application rate is significantly higher compared with the base application level calculated for unmodified binder. The higher binder rates are possible due to the higher viscosity of these binders. Application of cover aggregate should be the same in a SAM or SAMI to avoid damage to the membrane due to pick-up by the construction equipment or when the membrane is opened to traffic. Caltrans practices for these materials are summarized in its standard specifications, Section 37-1.05 (5). 


\section{Construction}

The sequence of construction events is included in the guide and covers the following steps.

- Project and surface preparation,

- Binder application,

- Aggregate spreading,

- Rolling, and

- Sweeping.

Details of the construction process are provided in the guide and are summarized below.

\section{Preparation}

Preparation of the surface is critical to the performance of the chip seal. Areas of the pavement exhibiting structural failures (such as potholes and deteriorated patches) should be addressed by the removal or patching and sealing of the failed area. Avoid the use of cold mix for patching prior to applying the chip seal. Finally, the prepared surface must be clean, dry, and free of any loose material before applying the binder. Preparation for a chip seal project typically includes:

- Milling of the surface (if there is extensive loose material or areas of bleeding that must be removed).

- Crack sealing or filling of cracks that are likely to reflect through the chip seal.

- Patching any deteriorated areas or dig outs where required.

- Cleaning or brooming any loose material from the pavement surface, such as areas of raveling.

- Removing pavement markers and delineators.

If the patched areas are generally more porous than the rest of the pavement, a tack coat prior to sealing may be required. Known shaded areas that seldom get sunlight (i.e., under bridge decks) may need a tack coat as well to prevent rock loss.

A work site needs to contain a facility for storing aggregate and binder. Generally, binders are trucked directly from the manufacturer and off-loaded for use. However, situations arise when distance and weather create the need for off-site storage. The site should be chosen well in advance of project start-up. The aggregate stockpile should ideally be placed on a sloped and paved surface, but at least on a sloped surfaced to promote drainage of the stockpile. It should also ideally be protected from contamination with foreign material. Once stockpiled, the aggregate should not be moved until it is to be transported to the road being chip sealed.

Following project completion, any remaining aggregate must be removed from the stockpile site and the site restored to its original condition before being used as a stockpile site

On the actual day when chip seals are constructed the weather should be clear and warm. In general, pavement surface temperatures should be $10^{\circ} \mathrm{C}\left(55^{\circ} \mathrm{F}\right)$ and rising, and the humidity should be $50 \%$ or lower. Wind may cause the emulsion spray to be diverted and compromise uniformity of application rate. A gentle breeze will assist in accelerating cure times. Any rainfall immediately before, during, or after the construction of the PME chip seal will contribute to failure of the treatment. Thus, placement of chip seals should be avoided during such conditions. 
The actual requirements vary for different binder types and are included in the Caltrans specifications.

The resident engineer examines and approves the contractor's traffic control plan prepared in accordance with the Caltrans Safety Manual (11) and the Caltrans Code of Safe Operating Practices (12). The signs and devices used must match the traffic control plan. The work zone must conform to Caltrans practice and requirements set forth in the Caltrans Safety Manual and the Caltrans Code of Safe Operating Practices. All workers must have all required safety equipment and clothing.

After chipping, pilot cars should be used for between 2 and $24 \mathrm{~h}$ to ensure that traffic speed is limited to approximately $30 \mathrm{kph}(20 \mathrm{mph})$.

\section{Binder Application}

Chip seal passes should begin and end on felt paper or equal. This ensures that the transverse joints are clean and sharp. Longitudinal joints may be made with an overlap. In this process, a wet edge (i.e., one without an application of aggregate) of 75 to $100 \mathrm{~mm}$ (3 to $4 \mathrm{in}$.) is left (not in a wheel path) and the next run overlaps this wet edge. The chip distributor then covers the whole run to the pavement's edge.

The spray distributor is the most important piece of equipment in the chip seal process. Its function is to uniformly apply the binder over the surface at the designed rate. Typically, spray distributors (boot trucks) are truck mounted, but trailer units have also been used. A distributor should have a heating, circulation, and pumping system, along with a spray bar, and all necessary controls to guarantee proper application.

The steps associated with preparing the distributor include:

- Calibrate the distributor by spraying a pre-weighed area of carpet (backed with a waterproof layer) and subtracting the initial weight from that of the sprayed carpet, then dividing the difference by the area of the carpet.

- Blow the spray nozzles to ensure there are no blockages and checking the nozzle angles to ensure they spray at an angle 15 to 30 degrees from the spray bar axis.

- Check the distributor bar's height. The height is usually set so that a double or triple overlap is obtained.

- Check the distributor bar's transverse alignment to ensure it is closely perpendicular to the centerline of the pavement

- Check the binder temperature to ensure it is in the appropriate range for proper application. Chip seal emulsion should be between $40^{\circ} \mathrm{C}$ and $85^{\circ} \mathrm{C}\left(104^{\circ} \mathrm{F}\right.$ and $\left.185^{\circ} \mathrm{F}\right)(4)$.

- Ensure an adequate supply of binder is available.

Visual checks should be made throughout the spraying process to ensure that the spray bars are clean and are spraying even fans. There should be no streaking of binder visible on the surface. If streaking occurs, the operation should be stopped to recheck proper functioning of the spray bar as well as proper binder temperature. The inspector should check application rates frequently. The application rate can be checked using the calibration method mentioned above or using the alternative method outlined in Appendix A of this chapter. The method above is recommended for equipment calibration while the alternative method is appropriate for quick spot-checking during construction. 


\section{Aggregate Spreading}

Chip spreaders must be able to spread an even coating of aggregate one layer thick over the entire sprayed surface. Prior to applying aggregate on a project, the following steps should be taken:

- Calibrate the spreader by spreading chips over a pre-weighed area of carpet and subtracting the initial weight from that of the carpet with chips spread onto it, then dividing the difference by the area of the carpet.

- Ensure all gates in the spreader open correctly.

- Ensure the spreader applies the aggregate is an even, single-layer thickness.

- Ensure that the spreader is not leaving piles of aggregate and is not spreading too thick a layer. Too thick a layer of aggregate can result in the aggregate being crushed under rollers or by traffic, compromising the seal. Too thick a layer of aggregate can also result in the lever and wedge effect, which also compromises the seal.

- Ensure an adequate supply of aggregate is available prior to applying the binder.

- Ensure proper moisture content of aggregate for PME chip seals.

The application of aggregate should follow the binder application by no more than $90 \mathrm{~s}$ in order to obtain the best possible aggregate retention. A good visual check is that the spreader should be no more than $30 \mathrm{~m}(100 \mathrm{ft})$ behind the distributor truck. The first chip spreading pass is usually done against traffic to allow good centerline match up. The direction for spreading is chosen mostly to minimize truck movements on the fresh oil.

Visual checks of the spreading include checking that the aggregate does not roll or bounce when applied. The flow of aggregate should also be checked. If a wave of binder forms in front of the blanket of aggregate, the binder application may be too heavy. The scalping screen should also be checked for build up of clay or other contaminants. If such contamination is heavy, it may be necessary to re-screen the stockpile. The spread pattern should be even without ripples or streaks. If ripples or streams occur, the spreading gates may need to be lowered and the machine slowed down.

Haul trucks are responsible for providing a continuous supply of binder to the site and aggregate to the spreader. Haul trucks should be in good mechanical condition. Leaking haul trucks can compromise the seal binder. Single axle trucks carry between 4,500 and 6,350 $\mathrm{kg}(5$ and 7 tons) and trucks with tandem axles between 9,000 and 12,700 kg (11 and 14 tons). For this reason, trucks with tandem axles are the preferred. The increased capacity requires fewer hook ups resulting in less chance for spillage and a more efficient operation.

Tires on the trucks should be examined for binder pick up. If pick up occurs, it may severely damage the mat. Tires should be cleaned and sanded. Trucks should not drive on the new surface unnecessarily and should never brake sharply. When driving on the fresh mat, wheel paths should be staggered to assist in embedding the aggregate uniformly. When pulling away from the spreader, trucks should move smoothly and slowly to prevent wheel spin and mat damage. Trucks shall not be allowed to lose or dump chips when pulling away from the chip spreader. No sharp turning movements or high speeds should be allowed on a newly constructed chip seal. 


\section{Rolling}

The function of the roller is to embed the aggregate into the binder and orient it into an interlocking mosaic. This is initially accomplished with pneumatic rollers; compaction applied by traffic finish the process. Rolling should be expedited in hotter weather to ensure proper embedment of the aggregate. Steel rollers are not normally recommended because they can crush the aggregate. The important variables when rolling chip seals are

- Contact pressure,

- Number of passes and pattern,

- Speed,

- Smoothness of tires, and

- Adequate number of rollers.

Contact pressure depends on the vehicle weight, the number of tires, tire size and rating, and the tire inflation pressure. Rollers that can be ballasted are very useful in assuring sufficient contact pressure. The ballasted weight should be 4500 to $5400 \mathrm{~kg}$ (4 to 6 tons), with a corresponding tire pressure of $600 \mathrm{kPa}(87 \mathrm{psi})$. Tires must have a smooth tread, should not vary more than $50 \mathrm{kPa}(7 \mathrm{psi})$ in pressure, and should not wobble during operation.

Rollers should follow aggregate spreading by no more than $150 \mathrm{~m}(500 \mathrm{ft})$ and should not be operated at more than $10 \mathrm{kph}(6 \mathrm{mph})$. The rolling pattern will depend on the number of rollers used. A minimum of two rollers should be used to cover the full width of the chip spreader. When two rollers are used, three passes are sufficient; one forward, one in reverse, and the final pass extending into the next section.

\section{Sweeping (or Brooming)}

Brooming is required before, after, and sometimes during the chip seal operation. Before applying the chip seal the pavement must be swept clean of dust and debris. During a multicoat sealing operation excess aggregate shall need to be broomed off between coats. After the chip seal has been constructed, excess aggregate must be broomed off to minimize whip-off by traffic.

Brooming is done using rotary brooms with nylon or steel bristles or with vacuum mobile pickup brooms. The broom should not be worn, and should not be operated in such a manner that removes embedded aggregate.

Mobile pickup brooms are usually capable of picking up aggregate and storing it. Sometimes so-called "kick brooms" are used. These brooms move the aggregate into a windrow so that is can be collected, but they often generate dust and may sweep aggregate into watercourses or gutters.

Brooming can generally be done within 2 to $4 \mathrm{~h}$ after sealing. Hot-applied chip seals can be swept within 30 min while conventional chip seals can be swept in 2 to $4 \mathrm{~h}$. A flush coat shall be applied after brooming to eliminate further rock loss and improve durability prior to opening the pavement to uncontrolled traffic. 


\section{Field Testing}

Most tests of constructed chip seals are empirical and provide the user an indication of what extra adjustments must be made on the job site. Though not used by Caltrans, the Ball Penetrometer Test (9) and the Sand Patch Test (ASTM E965) are useful methods for checking the original pavement and the final seal. In the Ball Penetrometer Test, a ball is hammered on the pavement surface using a Marshall hammer a predetermined number of times. The amount of ball penetration into the existing surface is an indicator of the pavement's hardness with typical values ranging from 0 to $0.5 \mathrm{~mm}$. The Sand Patch Test gives surface texture information for classifying surface type or examining seals with typical texture depths ranging from 1 to $2.5 \mathrm{~mm}$ depending on the aggregate size.

\section{Troubleshooting}

This section provides information to assist maintenance personnel in troubleshooting problems with chip seals. The troubleshooting guide presented in Table 1 relates common problems to their potential causes. In California, the most common problem is flushing. In addition to the troubleshooting guide, Table 2 lists some commonly encountered problems and some recommended solutions.

\section{Suggested Field Considerations for Chip Seals}

This section provides a brief description of field guidance check list on the important steps to ensure a successful chip seal project that are listed in Appendix A of the chip seal chapter. It covers preliminary reviews and checks, inspections and equipment calibration including project review, document review, material checks, surface preparation, brooming, distributor, chip spreader, rollers, haul trucks, weather requirements, application rates, traffic control, truck operations, joints, opening to traffic, and clean-up.

\section{ONGOING DEVELOPMENT}

The development of the MTAG has been a giant step toward providing reference materials for Caltrans personnel in the use of pavement preservation treatments. The task was not an easy one because it had to meet the expectations of not only Caltrans but also industry. The chapters on microsurfacing and thin bonded overlays were pulled from the main document to address concerns of some of the industry reviewers. These two chapters are now stand-alone documents, and are also available on the same website (1). This issue is discussed in more detail by Galehouse, Moulthrop, and Hicks (13).

Many additional sources have been used in this effort (14-25). The guide has received peer reviews from the national Pavement Preservation Expert Task Group, the California Pavement Preservation Task Group, the Caltrans Pavement Standards Team, Caltrans Maintenance Personnel, as well as from many experts from industry and public agencies. It has also received the endorsement of the FHWA who is currently funding the development of webbased training to support the use of the guide. The training materials are scheduled to be available in 2005. 
TABLE 1 Troubleshooting Chip Seal Problems (Hot/Emulsion/Asphalt Rubber)

\begin{tabular}{|c|c|c|c|c|c|c|c|c|c|c|c|}
\hline \multirow[b]{2}{*}{ Cause } & \multicolumn{11}{|c|}{ Problem } \\
\hline & 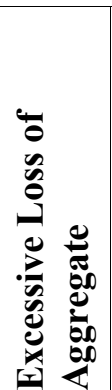 & 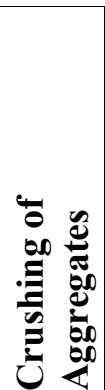 & 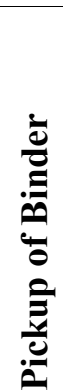 & 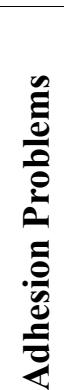 & 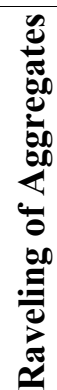 & 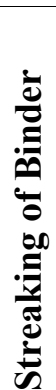 & 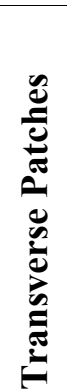 & 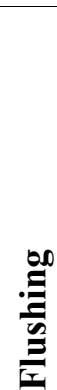 & 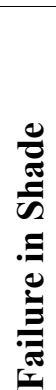 & 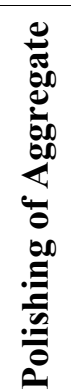 & 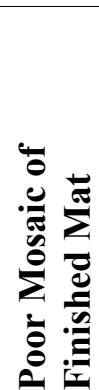 \\
\hline Poor traffic control & $\bullet$ & & $\bullet$ & & $\bullet$ & & & & $\bullet$ & & $\bullet$ \\
\hline Poor equipment & $\bullet$ & & $\bullet$ & & $\bullet$ & & $\bullet$ & $\bullet$ & $\bullet$ & & $\bullet$ \\
\hline Spray temperature & $\bullet$ & & $\bullet$ & & $\bullet$ & $\bullet$ & $\bullet$ & & $\bullet$ & & $\bullet$ \\
\hline Vehicle speeds & $\bullet$ & & & & $\bullet$ & $\bullet$ & $\bullet$ & $\bullet$ & $\bullet$ & & $\bullet$ \\
\hline Distributor nozzles & $\bullet$ & & & & $\bullet$ & $\bullet$ & & $\bullet$ & $\bullet$ & & \\
\hline \multicolumn{12}{|l|}{ Climatic Conditions } \\
\hline Cold surfaces & $\bullet$ & & & $\bullet$ & $\bullet$ & & & & $\bullet$ & & $\bullet$ \\
\hline Wet & $\bullet$ & & & $\bullet$ & $\bullet$ & & & & $\bullet$ & & $\bullet$ \\
\hline Windy & $\bullet$ & & & $\bullet$ & $\bullet$ & & & & $\bullet$ & & $\bullet$ \\
\hline \multicolumn{12}{|l|}{ Binder } \\
\hline Wrong binder & $\bullet$ & & $\bullet$ & $\bullet$ & $\bullet$ & $\bullet$ & & $\bullet$ & $\bullet$ & & $\bullet$ \\
\hline Too little binder & $\bullet$ & & & $\bullet$ & $\bullet$ & & & & $\bullet$ & & $\bullet$ \\
\hline Too much binder & $\bullet$ & & $\bullet$ & & & & & $\bullet$ & & & $\bullet$ \\
\hline \multicolumn{12}{|l|}{ Aggregate } \\
\hline Too little & $\bullet$ & & $\bullet$ & & & & & $\bullet$ & & & $\bullet$ \\
\hline Too much & $\bullet$ & $\bullet$ & & $\bullet$ & $\bullet$ & & $\bullet$ & & $\bullet$ & & $\bullet$ \\
\hline Wet & $\bullet$ & & & $\bullet$ & $\bullet$ & & & $\bullet$ & $\bullet$ & & $\bullet$ \\
\hline Dirty & $\bullet$ & & & $\bullet$ & $\bullet$ & & & & $\bullet$ & & $\bullet$ \\
\hline Quality & $\bullet$ & $\bullet$ & & $\bullet$ & $\bullet$ & & & & $\bullet$ & $\bullet$ & \\
\hline Wrong dize & $\bullet$ & & & & $\bullet$ & & & $\bullet$ & $\bullet$ & $\bullet$ & $\bullet$ \\
\hline \multicolumn{12}{|l|}{ Precoat } \\
\hline Too little & $\bullet$ & & & $\bullet$ & $\bullet$ & & & & $\bullet$ & & \\
\hline Too heavy & $\bullet$ & & & & $\bullet$ & & & & & & \\
\hline
\end{tabular}

\section{CONCLUSIONS AND RECOMMENDATIONS}

The guide is now a standard reference for Caltrans personnel. It is intended to be a dynamic and flexible document to be updated on an as-needed basis. It will likely include the following in the future.

- Expand the MTAG to include portland cement concrete strategies.

- Expand the MTAG to include recycling other new strategies.

As the training materials roll out in 2005 , the filed personnel will be able to train themselves in the use of the guide. 
TABLE 2 Common Problems and Related Solutions

\begin{tabular}{|c|c|}
\hline Problem & Solution \\
\hline $\begin{array}{l}\text { Streaking or drill } \\
\text { marks in the emulsion }\end{array}$ & $\begin{array}{l}\text { - Ensure emulsion is at correct application temperature. } \\
\text { - Ensure the viscosity of the emulsion is not too high. } \\
\text { - Ensure all the nozzles are at the same angle. } \\
\text { - Ensure the spray bar is not too high or too low. } \\
\text { - Ensure the spray bar pressure is not too high or too low. } \\
\text { - Ensure nozzles are not plugged. }\end{array}$ \\
\hline $\begin{array}{l}\text { Exposed emulsion after } \\
\text { chip application }\end{array}$ & $\begin{array}{l}\text { - Ensure the chip spreader gate is not clogged or malfunctioning. } \\
\text { - Ensure the chip spreader is covering all the binder }\end{array}$ \\
\hline $\begin{array}{l}\text { Excessive chips/Many } \\
\text { chips with small } \\
\text { amounts of emulsion }\end{array}$ & $\begin{array}{l}\text { Ensure the chip spreader gate is not malfunctioning or chipper } \\
\text { head is not overloaded. } \\
\text { - Lower the chip application rate. }\end{array}$ \\
\hline Uneven chip application & $\begin{array}{l}\text { - Recalibrate the chip spreader; ensure all spreader gates are set the } \\
\text { same. }\end{array}$ \\
\hline $\begin{array}{l}\text { Emulsion on the } \\
\text { top of chips }\end{array}$ & $\begin{array}{l}\text { - Ensure the chip spreader is not operating too fast. } \\
\text { - Ensure trucks, rollers, and pilot cars are operating correctly at low } \\
\text { speeds. }\end{array}$ \\
\hline Chips being dislodged & $\begin{array}{l}\text { - Ensure the emulsion application is not too light. } \\
\text { - Ensure the chips are not dirty or dusty. } \\
\text { - Ensure the traffic or equipment speeds are not too high. } \\
\text { set. }\end{array}$ \\
\hline $\begin{array}{l}\text { Emulsion bleeding } \\
\text { or flushing }\end{array}$ & $\begin{array}{l}\text { - Ensure the emulsion application is not too high. } \\
\text { - Ensure the aggregate application is not too low. }\end{array}$ \\
\hline $\begin{array}{l}\text { After brooming, loss of } \\
\text { chip at centerlines }\end{array}$ & $\begin{array}{l}\text { - Check centerline procedure. } \\
\text { - Check binder application rate. }\end{array}$ \\
\hline $\begin{array}{c}\text { Excessive splattering } \\
\text { of the emulsion }\end{array}$ & - Lower the spray pressure. \\
\hline
\end{tabular}

\section{REFERENCES}

1. Maintenance Technical Advisory Guide. California Department of Transportation, Sacramento, April 2002. www.dot.ca.gov/hq/maint.

2. Guide to the Investigation and Remediation of Distress in Flexible Pavements: Field Manual. California Department of Transportation, Sacramento, July 2002.

3. Caltrans Pavement Survey. California Department of Transportation, Sacramento, January 2000.

4. Hicks, R. G., and D. Jackson. Benefits of Pavement Maintenance: An Update. Western Pavement Maintenance Forum, Sacramento, Calif., 1998.

5. Standard Specifications. California Department of Transportation, Sacramento, 1999.

6. Standard Special Provisions Asphalt. S8 M20. California Department of Transportation, Sacramento, 1999.

7. Shatnawi, S., and G. Holleran. Asphalt Rubber Maintenance Treatments in California. Proc., Asphalt Rubber 2003, Brasilia, Brazil, 2003. 
8. McLeod, N. W. A General Method of Design for Seal Coats and Surface Treatments. Proc., Association of Asphalt Paving Technologists, Vol. 38, 1969.

9. Design of Sprayed Seals. Austroads, Surry Hills, New South Whales, Australia, 1990.

10. Jannisch, D. W., and F. S. Gaillard. Minnesota Seal Coat Handbook: Final Report. Minnesota Department of Transportation, December 1998.

11. Caltrans Safety Manual. California Department of Transportation, Sacramento, 1998.

12. Caltrans Code of Safe Operating Practices. California Department of Transportation, Sacramento, 1999.

13. Galehouse, L., J. S. Moulthrop, and R. G. Hicks. Principles of Pavement Preservation: Definitions, Benefits, Issues, and Barriers. TR News, No. 228, Sept.-Oct. 2003, pp. 4-9.

14. Stevenson, J. Maintenance Chip Seal Manual. Montana Department of Transportation, 1996.

15. Holleran, G. Chip Seal Design. California Chip Seal Association Annual Meeting, 2001.

16. Manual on Uniform Traffic Control Devices (Millennium Edition). FHWA, U.S. Department of Transportation, 2002.

17. TRH 3 Committee. Design of Bituminous Seals. South Africa Roads Board, 2002.

18. A Basic Asphalt Emulsion Manual. Manual Series No. 19, The Asphalt Institute, Lexington, Ky., 1999.

19. Cornell Local Roads Program. Hot and Cold Mixing Paving. Principles and Practices Report, Vol. 95, No. 4, 1995.

20. Koch Pavement Solutions. A Pocket Guide to Pavement Preservation. Form for Field Surveys, 2001.

21. Hicks, R. G., S. B. Seeds, and D. G. Peshkin. Selecting a Preventative Maintenance Treatment for Flexible Pavements. Report FHWA-IF-00-027, FHWA, U.S. Department of Transportation, 2000.

22. O'Brien, L.G. NCHRP Synthesis of Highway Practice 153: Evolution and Benefits of Preventative Maintenance Strategies. TRB, National Research Council, Washington, D.C., 1989.

23. Moulthrop, J., T. Thomas, W. Ballou, and H. King. Choose the Right Tool for the Right Distress. Asphalt Contractor, September 1999.

24. An Overview of Surface Rehabilitation Techniques for Asphalt Pavements. FHWA-PD-92-008. FHWA, U.S. Department of Transportation, 1992.

25. Bituminous Sealing Manual. South Australian Department of Transportation, 1995. 


\title{
Changing Our Way of Thinking Have We Succeeded?
}

\author{
JUDITH CORLEY-LAY \\ J. NeIL MASTIN \\ EMILY O. MCGRAW \\ North Carolina Department of Transportation
}

Like most departments of transportation, North Carolina has operated on a worst-first priority system for many years. Inadequate maintenance funding increased the pressure toward worst-first. During initial training in pavement preservation, calculations were done on North Carolina data that showed the benefit of treating roads in fair to good condition. The first step in developing a pavement preservation program was to provide widespread training in preservation "philosophy" and treating the right road at the right time. The initial training occurred in 2000 , with a second course in 2001 and a third in 2003, stressing selection of appropriate treatments.

North Carolina performs pavement condition surveys every other year on the primary and secondary systems. Unfortunately, it takes multiple pavement condition surveys to see a measurable change in pavement ratings. An alternate method of measuring the transformation to pavement preservation is from roadway treatment packages. Two such packages were evaluated: surface treatments and resurfacing (typically 1 to 1.5 in. of hot-mix asphalt).

We have assessed how successful we have been at changing the project selection for the secondary road system. This was done by comparing the before treatment condition for 2000, 2003, and 2004 surface treatment roadways and resurfacing roadways with pavement preservation criteria. The 2001 data reflects our "pre-pavement preservation training" period. We studied both the extent of work being conducted in a pavement preservation mode and that being done on a "worst first" mode, both collectively and by division.

We found one division that was ahead of the training and had been treating roads on a fixed interval for some time. The pavement condition rating (PCR) for that division reflects the early benefits of their approach. We found a number of divisions that were increasing the percentage of their programs that were addressing roads in a preservation mode. Finally, we found a minority group of divisions who had not moved as quickly to pavement preservation. For surface treatments, the result was a decrease in PCR for this category of divisions. Three specific divisions are discussed in detail. The evaluation of resurfacing showed that pavement preservation had not yet been adopted and implemented for thin overlays.

\footnotetext{
T $\mathrm{n}$ the fall of 2000, the North Carolina Department of Transportation (NCDOT) began training its personnel on pavement preservation by offering the pavement preservation courses provided by the National Highway Institute (NHI) $(1,2,3)$. The department recognized very early in the training that in order for NCDOT to have an effective pavement preservation program, our division field personnel needed to understand the concept of placing "the right treatment on the right road at the right time." In North Carolina, it is the field personnel who select roads for surface treatments as well as resurfacing. It is imperative for those putting the surface treatment and resurfacing programs together to have an understanding of what kinds and what levels of distress a road can have in order to make proper selections. At the same time, the decision trees for the pavement condition survey were expanded to include pavement preservation activities.
} 
NCDOT initiated a series of research efforts on the subject of surface treatments. The first project dealt with optimizing gradation of surface treatments. A second project, just approved, will address rolling patterns to improve surface treatment performance. Additional studies are expected on performance of polymer-modified emulsions and field tests to quantify performance of surface treatments.

Due to a legislative initiative in 2001, NCDOT was able to focus more dollars on pavement preservation activities. With a new funding mechanism, the department was able to fully fund our 14 Division Bituminous Units, the units that place surface treatments, or chip seals, on our roadways. With a more robust budget, the emphasis was not just on treating more miles but also on quality work. Quality chip seals begin with proper road selection. In addition to the initial training, the central maintenance unit encouraged field personnel to select and treat roads where chip seals would be most effective.

The purpose of this research is to determine how effective the department has been in changing the way we approach our chip sealing and resurfacing programs for the secondary road system. The pavement condition survey (PCS) is one tool used to determine if the department has been effective in encouraging pavement preservation activities.

\section{BACKGROUND}

North Carolina is comprised of 100 counties. These counties are grouped into 14 divisions that provide transportation services. While there are central offices and units located in the state's capital, each division has its own administration and engineering staff. These divisions have authority for project selection, contract administration, maintenance, and preservation of the state's 78,615 mi of roads. With such a large roadway network, it is important for NCDOT to consider a preservation strategy. Such a strategy should result in cost savings and performance improvement.

As mentioned in the introduction, a greater emphasis has been placed on the surface treatment, or chip-sealing program. In 1999, statewide, 1,094 mi of roads were treated with a surface treatment. Just a few years later in 2004, 2,889 mi of roads were treated with a chip seal. In just 5 years, the department has increased its chip sealing production by $164 \%$. For the past few years, the department has had a fairly strong resurfacing program. In 2000, 1,678 mi of roads were resurfaced. That number increased to 3,153 mi in 2004 . Field personnel selected all the miles for both surface treatment and resurfacing programs.

\section{DATA SOURCES AND PAVEMENT CONDITION}

The data analysis conducted for this paper used information found in the construction history tables and PCS tables of the NCDOT pavement management database.

The construction history tables are populated with data acquired from multiple sources, including project plans, contracts, the State Road Maintenance Unit surface treatment database and others. In this case, the primary data used was the last several years of surface treatment and resurfacing activities carried out on pavement sections in the secondary road network.

The PCS database is the result of our biannual visual survey of North Carolina's nonInterstate asphalt road network. Division personnel, trained by the Pavement Management 
Unit, conduct the survey. The survey is $100 \%$ coverage and section length is variable. Survey sections are kept the same from year to year wherever possible but can be modified by the field personnel as deemed necessary to account for changes in road geometrics and pavement type.

Distresses collected include: alligator cracking, transverse cracking (reflective and block), rutting, raveling, oxidation, bleeding, patching, and ride quality. Alligator cracking is collected on both a severity and extent basis with four levels of severity ranging through none, low severity, moderate severity, and high severity. The extent of each distress level is measured in $10 \%$ increments. The remaining distresses have the same severity levels as alligator cracking, but do not have a separate extent component. Extent is one of the criteria considered when estimating the distress level.

The collected distress data is used to calculate a composite pavement condition rating (PCR). The core of this rating was developed in the 1980s based on field studies and expert opinion. The distress deductions were designed around the concept that any combination of distresses that leads to a PCR of less than 70 should be cause for treatment. In the case of pavement preservation activities, the PCR at treatment should be well above 70 .

In analyzing data for this paper, surface treatment or resurfacing sections were used as the baseline network and PCS data was aggregated on to these sections. Where multiple PCS sections covered a project, a weighted average was used to calculate the value of each individual rating towards the overall rating.

\section{APPROACH}

As mentioned earlier, the PCS for secondary roads is conducted every other year. Surface treatment and resurfacing records for the years 2000, 2003, and 2004 reside in the Pavement Management Unit and were used in this study. PCS records from 1998 to 2004 were used to provide pavement rating information.

Each year, the divisions prepare a program for surface treatments that are applied by in-house forces, the Division Bituminous Units. The State Road Maintenance Unit maintains the list of treated roads as well as treatment types. In addition, a list of proposed resurfacing projects is prepared within each division. The lists of proposed and actually paved roads are maintained in the State Road Maintenance Unit. These two activities, surface treatments and resurfacing, are the focus of this paper.

Some divisions utilize purchase order contracts to handle some or all of their surface treatments and resurfacing programs. Purchase order contracts allow the divisions to contract work up to $\$ 1.2$ million with an informal bid process. Due to more limited data availability, these divisions were not included in this study, but they represent the minority of divisions.

Efforts to move toward pavement preservation began in 2000 with a training program including two NHI courses. NCDOT sponsored these courses for all pavement design engineers, state road maintenance engineers, county maintenance engineers, and division maintenance engineers. With a high level of support from upper management, implementation of pavement preservation was encouraged. An increase in the number of road miles treated occurred at the same time as this philosophical shift. We intend to provide feedback both to the divisions and to management on the extent and results of the effort thus far. 
In evaluating the extent to which pavement preservation has been implemented in the field, we looked at the PCR before treatment for roads treated with surface treatments and for roads resurfaced with HMA. The pre-pavement preservation initiative PCR values for treated roads should be lower than the PCR values after program implementation. Furthermore, we considered the percentage of roadways being treated using surface treatments and resurfacing that had PCRs greater than 75 as a measure of the percentage of pavement preservation activities. In other words, the work on roads in poor condition should decrease over time and work on roads in good condition should increase over time.

In addition to considering statewide averages, we looked at each division to assess their individual progress toward pavement preservation. We hoped to see a link between the PCRs and the extent of pavement preservation. This would greatly assist in targeting additional training activities and in selling the benefits to divisions who have been more reluctant to embrace pavement preservation techniques

In this study, three divisions are evaluated in more detail. Division 6 has employed a pavement preservation philosophy for some time. Is the benefit from earlier implementation clear in the data? Division 12 had been operating in a reactive mode prior to the major initiative toward pavement preservation. They are among the divisions who have adopted the philosophy and we evaluated their success to date. Finally, there are a number of divisions whose programs are not showing progress toward pavement preservation. We looked at one such division. In all three cases, we looked at measures such as overall PCR for secondary roads in the division, the percentage of treated roads that are pavement preservation treatments, and the percentage of treatments placed on roads in poor condition.

\section{RESULTS}

The years 2000, 2003 and 2004 are used to demonstrate various aspects of the changes in our operating philosophy. Table 1 below shows the marked increase in mileage covered under the surface treatment program and the resurfacing program on a statewide basis. Surface treatments constitute about $50 \%$ of the treatments for secondary roads.

Over the 4-year period, not only did the number of miles treated change but also the distribution of treatment types. According to 2000 records, more than 1,200 mi were treated with split seals, followed by $250 \mathrm{mi}$ of triple seals, and $200 \mathrm{mi}$ of mat and seals. Records in 2004 show that the total mileage for split seals is now about 1,400, of which $678 \mathrm{mi}$ included lightweight aggregate; 220 additional miles were split seals with screenings. Similarly, the mileage for triple seals increased to 780, but included components of triple seals, triple seals with lightweight aggregate, and triple seals with screenings. Use of mat and seal treatments had dropped from 2000 to 2004. Use of straight seals with lightweight aggregate also grew from 0 to $320 \mathrm{mi}$. We have increased not only the number of miles but also the variety of treatments. Table 2 contains the definitions for surface treatments used in North Carolina.

TABLE 1 Statewide Total Mileage for Surface Treatments and Resurfacing by Year

\begin{tabular}{|l|c|c|c|}
\hline \multicolumn{1}{|c|}{ Treatment } & 2000 Mileage & 2003 Mileage & 2004 Mileage \\
\hline Surface treatments & 1,884 & 2,991 & 2,889 \\
\hline Resurfacing & 1,678 & 3,046 & 3,153 \\
\hline
\end{tabular}


TABLE 2 Definitions of Surface Treatments Used in North Carolina

\begin{tabular}{|l|c|c|l|}
\hline $\begin{array}{c}\text { Treatment } \\
\text { Type }\end{array}$ & $\begin{array}{c}\text { \# of } \\
\text { Layers }\end{array}$ & Emulsion & \multicolumn{1}{c|}{ Description } \\
\hline Straight Seal & 1 & $\begin{array}{c}\text { CRS-2 or } \\
\text { CRS-2P }\end{array}$ & $\begin{array}{l}\text { Single application of asphalt emulsion followed by a } \\
\text { single layer of either No. 78 aggregate or 5/16 in. } \\
\text { lightweight aggregate }\end{array}$ \\
\hline Mat and Seal & $2-3$ & $\begin{array}{c}\text { CRS-2 or } \\
\text { CRS-2P }\end{array}$ & $\begin{array}{l}\text { Bottom layer is emulsion followed by No.6 or No. 67 } \\
\text { stone. Two more layers of emulsion and aggregate } \\
\text { are generally placed over the first layer. }\end{array}$ \\
\hline Split Seal & 2 & $\begin{array}{c}\text { CRS-2 or } \\
\text { CRS-2P }\end{array}$ & $\begin{array}{l}\text { Two alternating applications of emulsion and } \\
\text { aggregate. Either layer may be No. 78 aggregate or } \\
5 / 16 \text { in. lightweight aggregate. Screening material } \\
\text { may also be used for the top layer. }\end{array}$ \\
\hline Triple Seal & 3 & $\begin{array}{c}\text { CRS-2 or } \\
\text { CRS-2P }\end{array}$ & $\begin{array}{l}\text { Three alternating applications of emulsion and } \\
\text { aggregate. The lower layers may be No. 78 aggregate } \\
\text { or 5/16 in. lightweight aggregate. The top layer can } \\
\text { consist of No. 78 aggregate, 5/16 in. lightweight or } \\
\text { screening material. }\end{array}$ \\
\hline
\end{tabular}

The pavement condition survey is conducted on a 2-year cycle for secondary roads. It is normally completed just before the beginning of the paving season, so the PCRs from 2000 reflect the condition just weeks before roads resurfacing or treatment begins. For roads treated in odd numbered years, like 2003, the closest PCR in time preceding the treatment would be 2002 and the PCR would represent the condition a little more than a year before treatment. With these cautions in mind, Table 3 shows the PCR before and after surface treatments for 4 years of interest. Table 4 shows the same type of data for resurfacing. The bold type indicates the low rating before treatment. The data show that the "bump" in PCR from a surface treatment is lower than that from resurfacing and does not bring the roadway to $100 \%$.

Cumulative distribution functions of the percentage of treated mileage in various PCR bins were developed for Divisions X, 6, 12, and statewide for the years 2000, 2003, and 2004. Data from 2000 represents the time prior to the training and emphasis on pavement preservation. Training was taking place during 2002 and 2003.

Figures 1 and 2 show the cumulative distribution factors for PCR prior to surface treatment for treatment years 2000 and 2004. As the condition at time of treatment improves, the curves move to the right.

Division 6, which has been using a pavement preservation philosophy for some time, shows a smooth curve with low percent roads treated when in poor condition. Division 6 resurfaces roads based on a fixed treatment period. Over time, the percentage of roads in good condition has gradually increased. No roads having PCRs less than 40 were treated in either year; $70 \%$ of the treated roads had a PCR of 80 or higher.

Division 12 shows a dramatic change in PCRs prior to treatment. In 2000, about $48 \%$ of the treated roads had a PCR less than 50. This percentage decreased to $18 \%$ in 2004 . 
TABLE 3 PCR Before and After Surface Treatments (Statewide Weighted Averages)

\begin{tabular}{|c|c|c|c|}
\hline $\begin{array}{c}\text { Treatment } \\
\text { Year }\end{array}$ & $\begin{array}{c}\text { 2000 PCR } \\
\text { Weighted Average }\end{array}$ & $\begin{array}{c}\text { 2002 PCR } \\
\text { Weighted Average }\end{array}$ & $\begin{array}{c}\text { 2004 PCR } \\
\text { Weighted Average }\end{array}$ \\
\hline 2000 & $\mathbf{6 4 . 5}$ & 87.4 & 83.8 \\
\hline 2003 & 76.9 & $\mathbf{6 8 . 3}$ & 90.7 \\
\hline 2004 & 80.8 & 76.3 & $\mathbf{7 0 . 5}$ \\
\hline
\end{tabular}

TABLE 4 PCR Before and After Resurfacing with HMA (Statewide Weighted Averages)

\begin{tabular}{|c|c|c|c|}
\hline $\begin{array}{c}\text { Treatment } \\
\text { Year }\end{array}$ & $\begin{array}{c}\text { 2000 PCR } \\
\text { Weighted Average }\end{array}$ & $\begin{array}{c}\text { 2002 PCR } \\
\text { Weighted Average }\end{array}$ & $\begin{array}{c}\text { 2004 PCR } \\
\text { Weighted Average }\end{array}$ \\
\hline 2000 & $\mathbf{6 3 . 4}$ & 94.9 & 93.2 \\
\hline 2003 & 69.9 & $\mathbf{6 0 . 2}$ & 95.8 \\
\hline 2004 & 75.9 & 67 & $\mathbf{6 3 . 4}$ \\
\hline
\end{tabular}

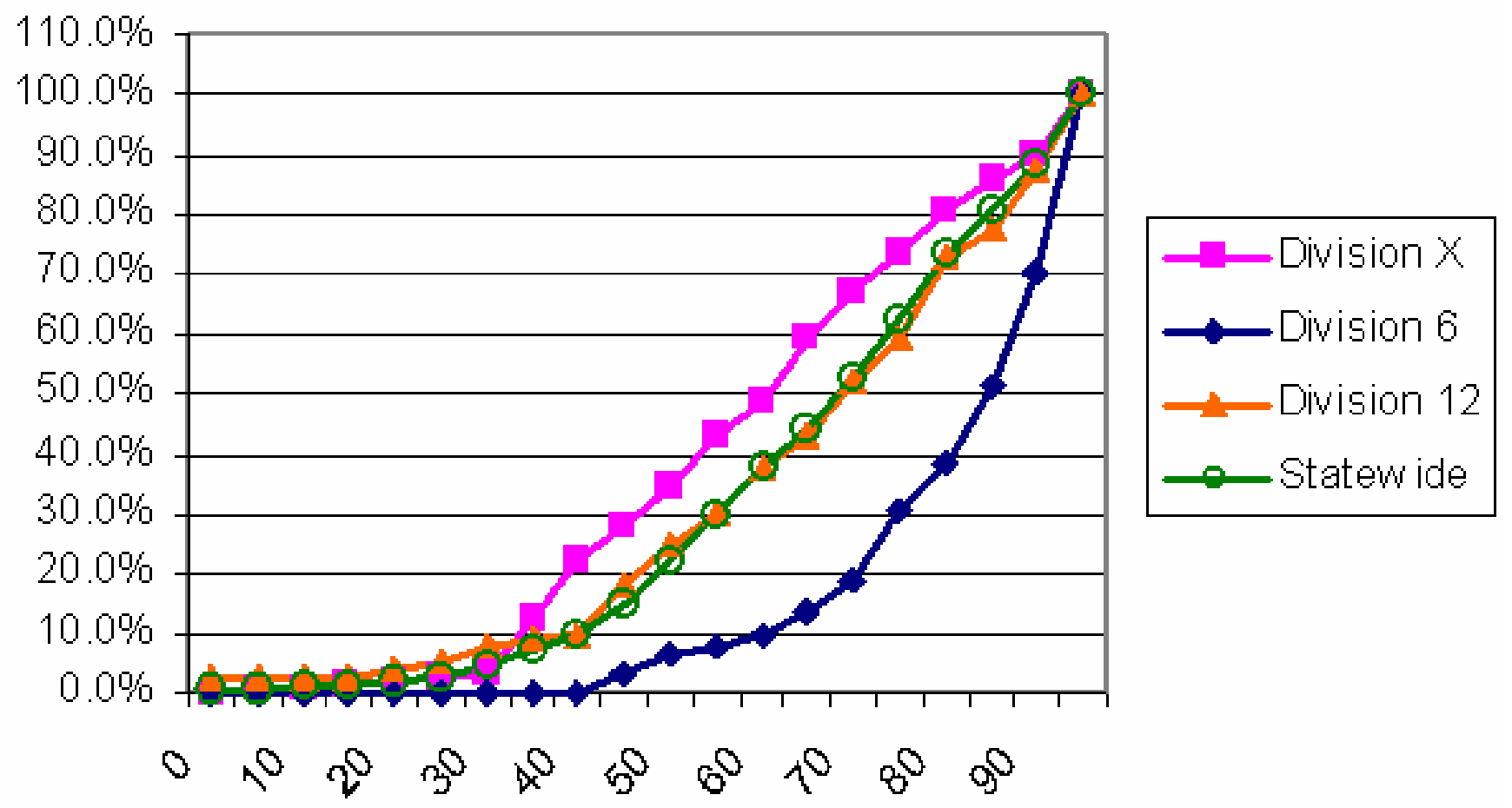

FIGURE 1 Cumulative distribution of surface treatments by PCR-2000. 


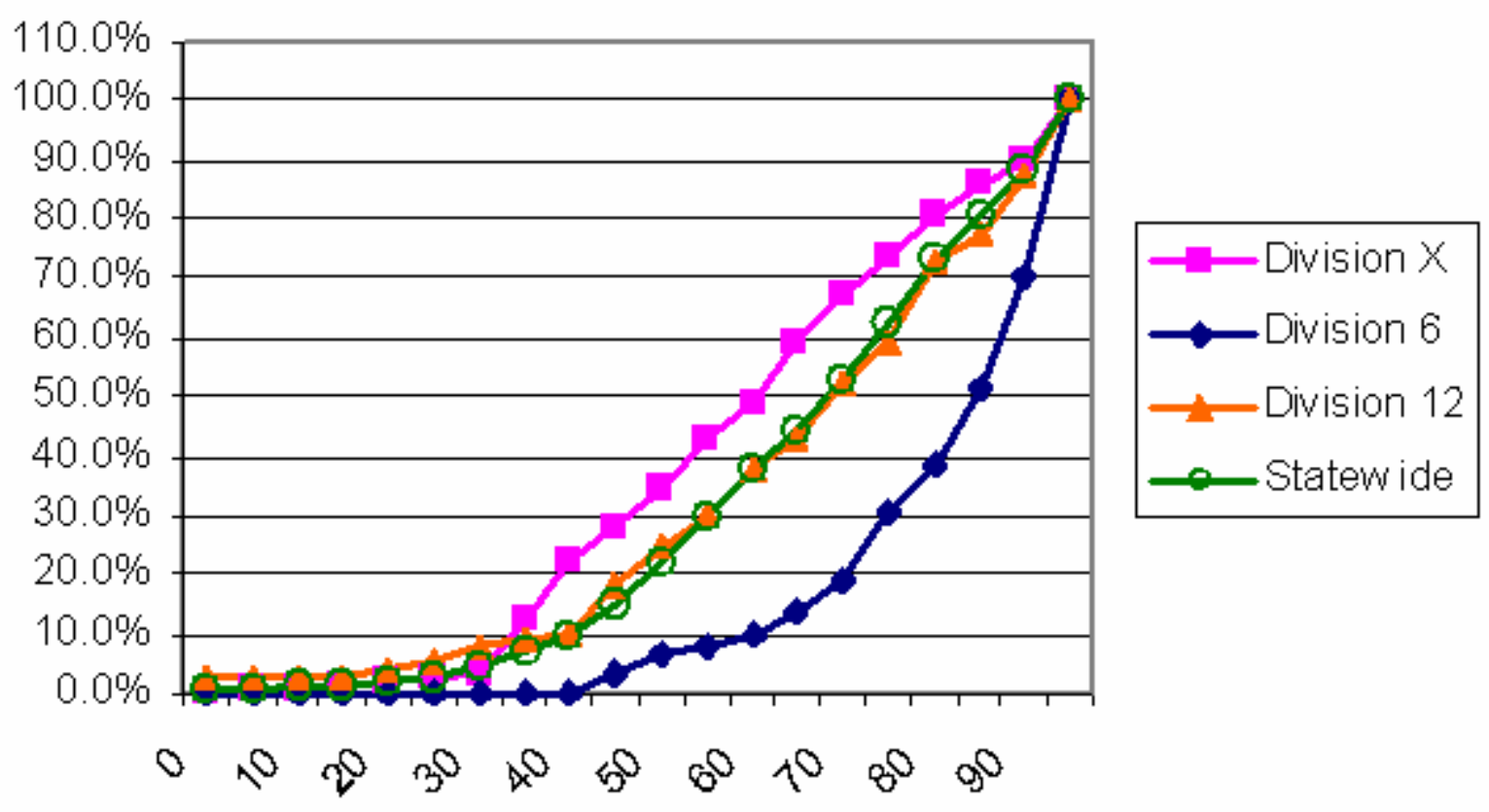

FIGURE 2 Cumulative distribution of surface treatments by PCR-2004.

Division $X$, that has been slow in implementing pavement preservation, has a cumulative distribution graph that is moving toward the left. In 2000, about $9 \%$ of surface treated secondary roads had a PCR of less than 50. In 2004, that percentage had grown to almost $30 \%$. Considering the statewide shift, Division X moved from being to the right of the statewide average distribution in 2000 to being to the left of the statewide average distribution in 2004.

Figures 3 and 4 show the cumulative distribution factors for PCR prior to plant mix resurfacing for treatment years 2000 and 2004. The impact of pavement preservation is less clear here than it was in the case of surface treatments. Just considering Graph 4, the three Divisions are following reasonably common treatment philosophies, although Division 6 resurfaces a higher percentage of roads in good condition and a lower percentage of roads in poor condition. The data for Division 6 suggests, however, that in comparison to 2000, the percentage of resurfaced roads in good condition, i.e. pavement preservation, has decreased from $40 \%$ to $30 \%$. Division 12 has increased the percentage of roads being resurfaced in a pavement preservation mode from 2000 to 2004, while Division X remains about the same.

\section{CONCLUSIONS}

The PCR can be used to measure the extent to which pavement preservation is being implemented. A PCR of 50 or less was used as the threshold for treating a poor road and 80 or greater as the threshold for "preservation." Statewide average PCRs prior to treatment increased for secondary roads receiving surface treatments from 64.5 to 70.5. No significant improvement in pretreatment PCR was noted for hot mix asphalt resurfacing over the same period. 


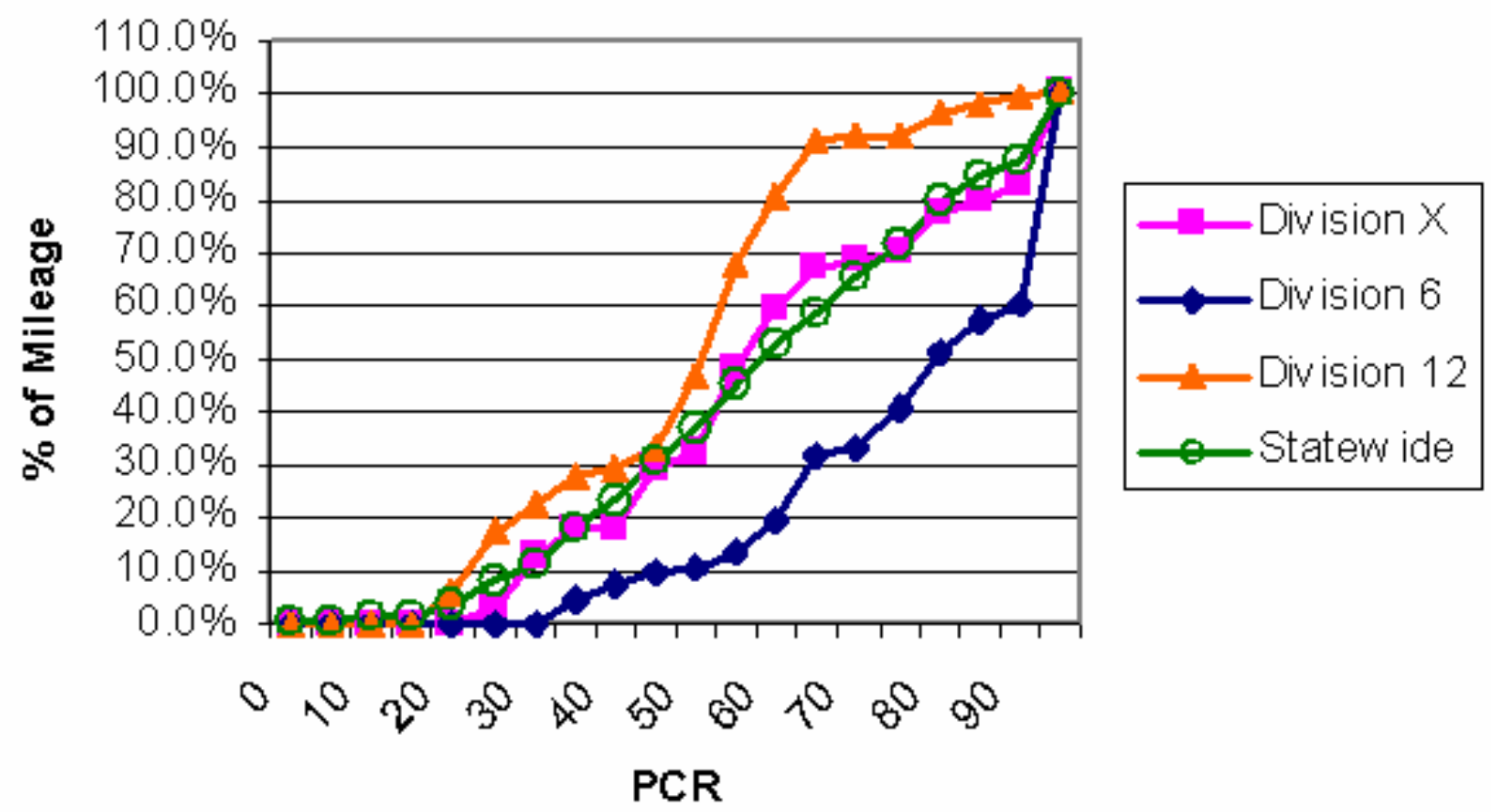

FIGURE 3 Cumulative distribution of plant mix resurfacing by PCR-2000.

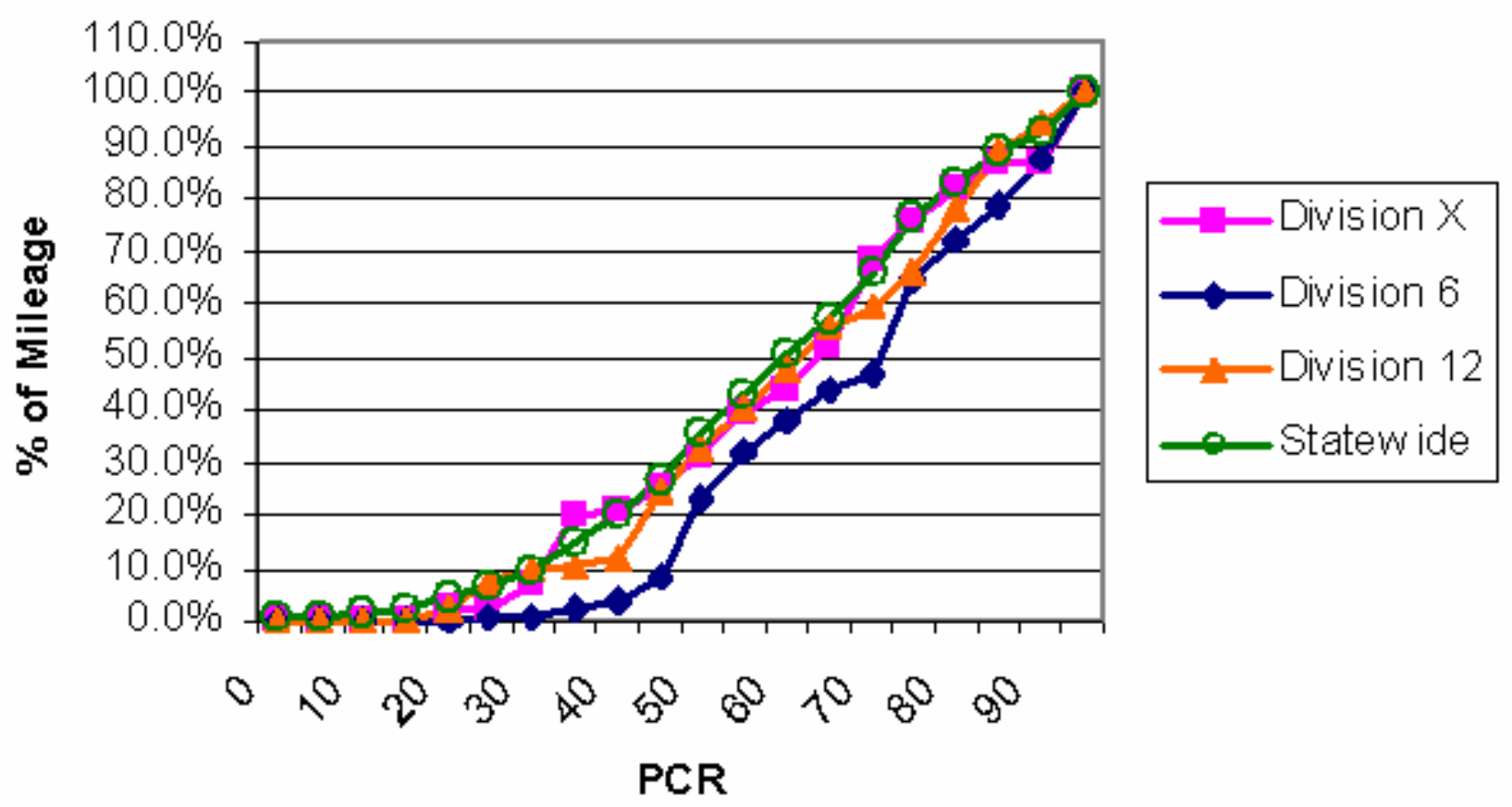

FIGURE 4 Cumulative distribution of plant mix resurfacing by PCR-2004. 
Evaluation of the PCR over time for each division indicated divisions who have been using a pavement preservation program for some time, those who have moved toward pavement preservation and those who have not. Division 6, which has used a timed program of surface treatments for many years, did not treat any roads in poor condition, and $70 \%$ of treated roads were in good condition. The Division 6 average PCR for treated roads was above the statewide average by about 13 points since 1998 .

Division 12 has moved toward pavement preservation since the training in 2000 and has increased the average PCR at the time of treatment from 54.8 in 2000 to 69.8 in 2004. At the same time, the percentage of roads treated while in poor condition dropped from $48 \%$ to $18 \%$.

Pavement preservation has not been uniformly adopted as illustrated by Division X. In this division, the average PCR prior to surface treatments has decreased from 70.1 in 2000 to 64.6 in 2004 and the percentage of roads treated while in poor condition increased from $9 \%$ to almost $30 \%$.

Over the 4 years from time of training, 8 of 14 divisions have increased the average PCR of their surface treated roads by an average of 6.2 points. Three divisions have had slight decreases, and three have had decreases of larger than 3 points. The data generated in this report and in the detailed division reports will provide feedback on their pavement preservation activities and will assist in targeting additional training to enhance the state program.

Data from our three example divisions also seems to indicate that increasing the PCR of treated roads, in other words, using a pavement preservation approach also increases the PCR of the overall network. Division 6 has maintained and/or increased their preservation activities and the overall condition of their surface treated roads has increased from 86.0 to 88.2. Division 12 has moved steadily from a reactive maintenance approach to a preservation approach and has been rewarded with a PCR increase from 72.6 to 81.7 in the 2000-2004 time period. Division X's experience indicates the result of continuing with a reactive approach: The average PCR of surface treated roads decreased from 79.0 in 2000 to 75.7 in 2004.

The data on plant-mix roads is quite mixed. In general, the majority of divisions have experienced a decrease in plant mix PCR from 2000 to 2004. The average rating of all plant mix roads has decreased from 84.9 to 83.5 . As no division was practicing pavement preservation on plant mix routes, we have no comparisons to make across division lines. Figures 5 and 6 illustrate the changing PCR of the surface treated and plant-mix roads respectively.

Has our program been effective? Our data suggests that the effort has changed behavior in more than half of our divisions. Continued training and monitoring will be needed due to turnover in personnel and the need to reemphasize preservation philosophy. We anticipate rerunning this analysis every 2 years as our pavement condition data becomes available to measure progress and pinpoint areas needing improvement.

In addition, as we are now tracking the types of treatments placed in greater detail, we also look forward to evaluating the performance of treatments based on type and PCR at time of application. This will aid us in determining the best treatments for preservation goals. We would like to expand our efforts beyond the secondary road system to suitable primary roadways. The ultimate goal is to increase the life of our asphalt pavements. 


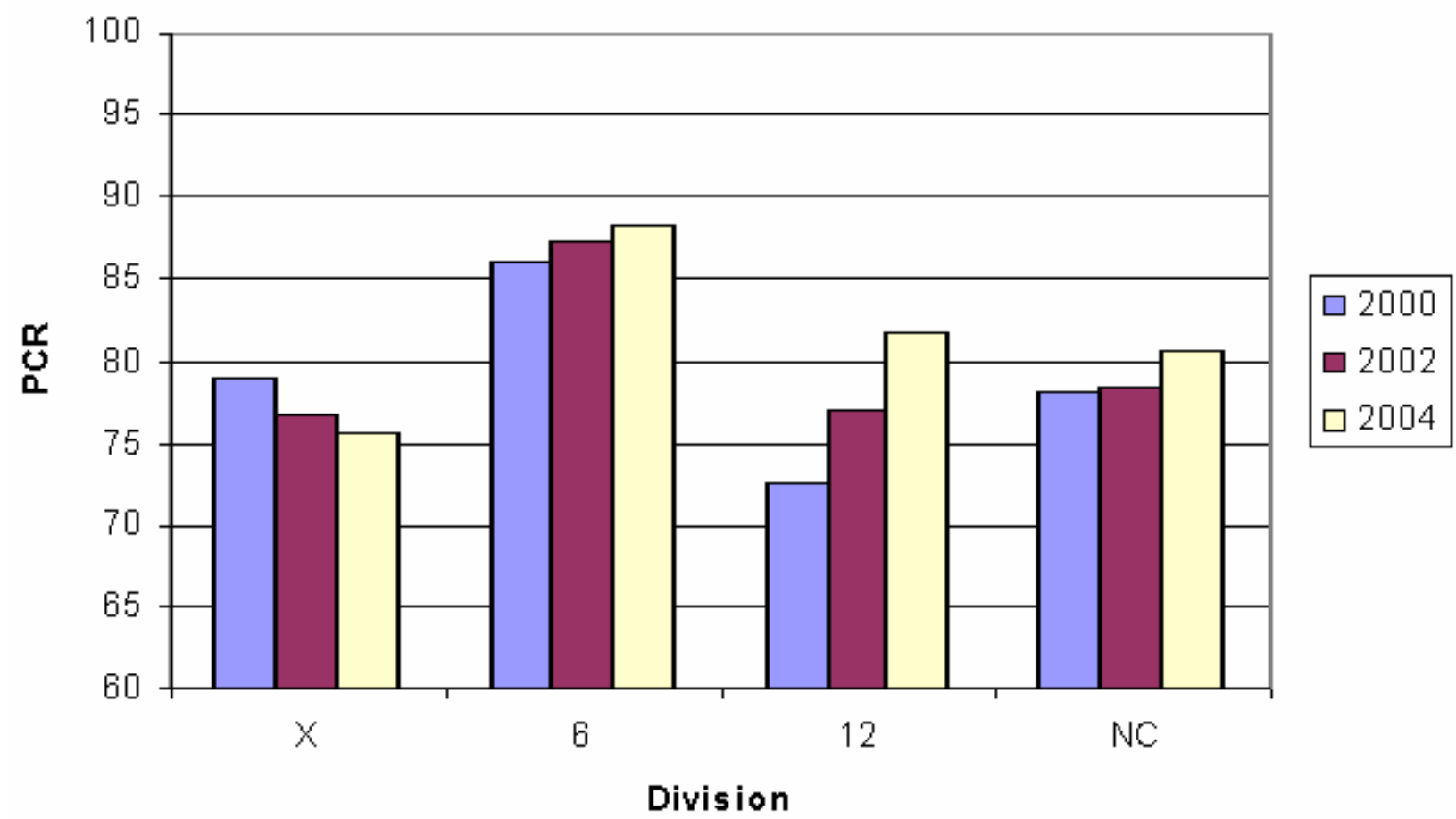

FIGURE 5 Average PCR for all surface-treated secondary roads by division.

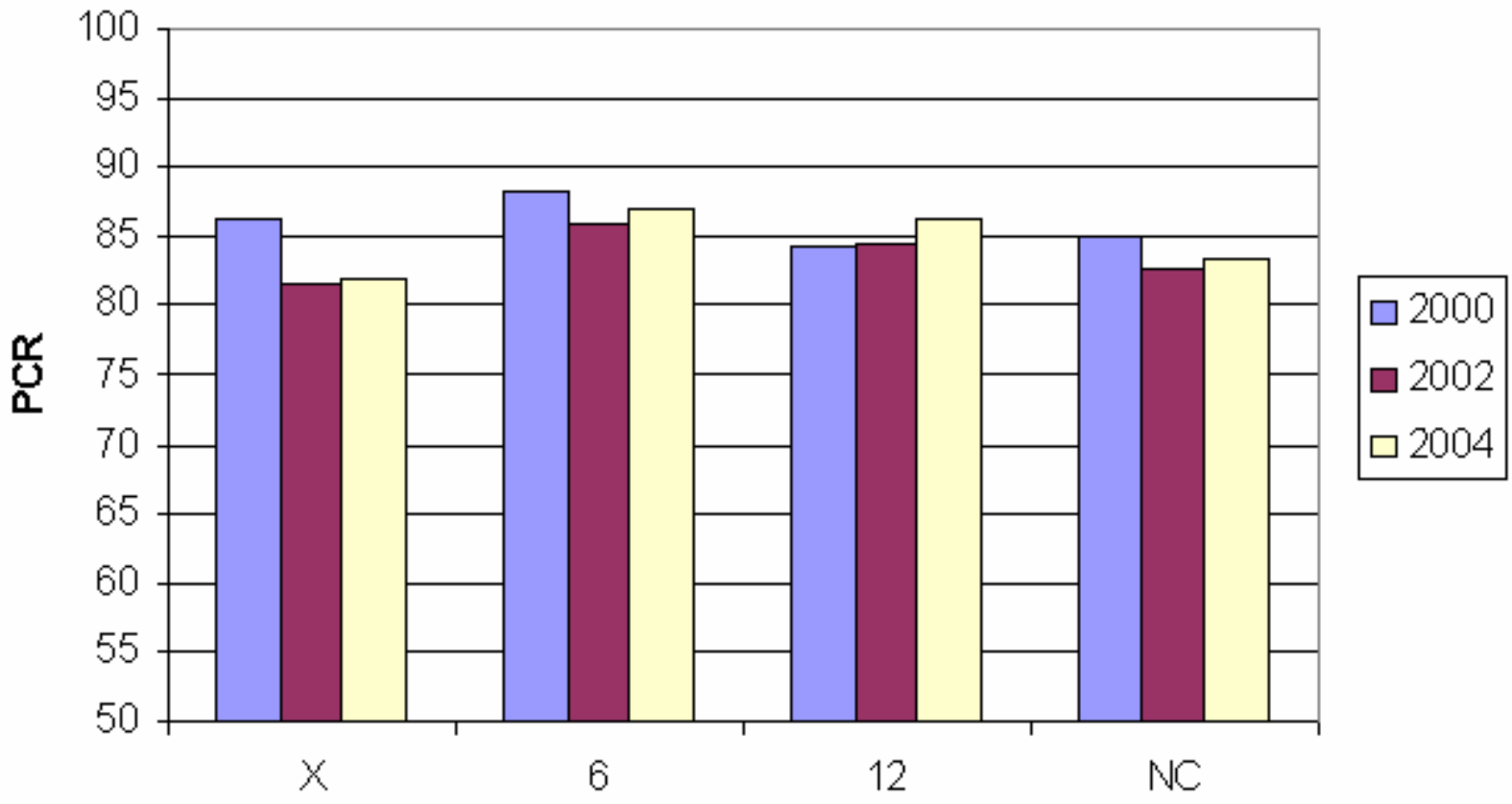

Division

FIGURE 6 Average PCR for all plant-mix surfaced secondary roads by division. 


\section{REFERENCES}

1. Pavement Preservation: Selecting Pavements for Preventive Maintenance. NHI Course No. 131058. FHWANHI-01-040, September 2001.

2. Pavement Preventive Maintenance. NHI Course No. 13154. FHWA-HI-00-007, September 1999.

3. Pavement Preservation: Integrating Pavement Preservation Practices and Pavement Management. NHI Course No. 131104, Draft, August 2003. 


\title{
Improving Safety as Part of a Pavement Preservation Program
}

\author{
KATHRYN A. ZIMMERMAN \\ ROGER LARSON \\ Applied Pavement Technology, Inc.
}

One of the benefits associated with the use of a pavement preservation program is improved safety characteristics. Improved safety can be realized in several ways. For instance, an agency with a pavement preservation program that includes the early application of preventive maintenance (PM) treatments can generally keep the road network in better condition for a longer period of time. As a result, the roads are relatively smooth, which reduces the cost of operating a vehicle and minimizes crashes associated with defensive driving to avoid potholes and other surface irregularities in the pavement. However, in addition to providing a smoother surface, PM treatments can be used to improve the surface characteristics associated with surface texture (friction) to reduce the likelihood of wet weather and dry weather crashes.

In the United States and abroad, an increased emphasis is being placed on safety issues to reduce the number of fatal and serious injuries caused by crashes and the resulting traffic delays. However, the effect of microtexture and macrotexture on crash rates has not been quantified. Past studies have often shown a weak link between increased friction and reduced crash rates.

Recently, there have been major advances in data collection and analysis capabilities that show promise for improving the ability of transportation agencies to better quantify the effectiveness of pavement preservation treatments on reducing crash rates by improving surface characteristics. For instance, it is now possible to collect continuous pavement macrotexture information at highway speeds. It is also possible to measure macrotexture under the tire during skid trailer friction testing. These technological advances will greatly enhance the ability of highway agencies to identify sites of potentially high accident rates and to proactively take preventive actions as part of a pavement preservation program.

This paper focuses on the safety improvements that can be realized as part of a pavement preservation program. Specifically, the following areas are discussed in this paper:

- The use of network-level evaluations (including features such as pavement macrotexture and annual friction surveys) as a means of identifying pavement sections that could benefit from the use of certain PM treatments to enhance or restore friction values (such a microsurfacing, grinding and/or grooving, or chip seals).

- The development of safety investigatory levels based on microtexture and macrotexture data for various site categories.

- The incorporation of safety features into a pavement management analysis.

The application of these characteristics are demonstrated using examples from transportation agencies worldwide. For instance, the Texas Department of Transportation's Wet Weather Accident Analysis Program is an example of the type of study used to illustrate the points raised. Internationally, work being conducted in the United Kingdom and New Zealand on continuous friction measurements and the use of the data to identify pavement sections where poor texture/friction may be contributing to higher than average crash rates are featured. Other examples, such as Australia's recently established goal of achieving $19 \%$ of their $40 \%$ per capita accident reduction by providing safer roads is also documented.

$\checkmark$ or the past several years, the statistics provided by the U.S. Department of Transportation 1 (USDOT) show a constant fatality rate of approximately 1.5 fatalities for every 100 million 
vehicle miles traveled (VMT) (FHWA 2004). Nationally, the USDOT and other transportation agencies have established a goal to reduce the number of fatalities to a rate of no more than 1.0 fatality for every 100 million VMT by 2008 (FHWA 2004). Clearly, improving the safety of our roadway network is a high priority within all transportation agencies.

There are a number of ways for a transportation agency to improve the safety of its road network since crash rates can be influenced by a number of factors, including geometric design, selection and placement of roadside hardware, driver behaviors, vehicle size and speed, and the use of traffic control devices. Pavement surface characteristics also influence crash rates although the interaction between pavement surface characteristics and crash rates is not well documented. However, recent advances in this area show promise for improving agencies' ability to collect and analyze surface characteristic data to evaluate its effect on highway safety. The recent emphasis that is being placed on providing safer roads by increasing the use of the Road Safety Audit (RSA) process is also an encouraging development that is discussed later in the paper.

The timing of these advances is especially advantageous because of the increased use of preventive maintenance (PM) treatments as part of a pavement preservation program. Originally intended to provide a cost-effective strategy for maintaining the functional characteristics of a road network for an extended period of time (so rehabilitation needs can be deferred), many PM treatments also provide improved surface characteristics that may serve to reduce crash rates associated with surface texture (friction) under wet weather and dry weather conditions. In addition, because PM treatments help an agency maintain its roads in a smoother condition, agencies may realize a reduction in the number of crashes caused by defensive driving maneuvers to avoid potholes and other surface irregularities.

In addition to summarizing some of the improved safety characteristics that can be realized from a pavement preservation program, this paper introduces the use of network-level evaluations as a means of identifying pavement sections that could benefit from the use of certain PM treatments to enhance or restore friction values (such as microsurfacing, grinding, grooving, or chip seals). The paper also introduces the use of pavement surface and accident data to evaluate the effectiveness of various treatments in reducing both wet weather and dry weather crashes and the development of safety investigatory levels for different site categories based on microtexture and macrotexture data. The paper concludes with strategies for incorporating safety characteristics into a pavement management system (PMS) for use in network-level and strategic-level decisions.

\section{IMPROVED SAFETY CHARACTERISTICS OF A PAVEMENT PRESERVATION PROGRAM}

Within the last several years, pavement preservation programs have been gaining nationwide attention as an asset management strategy for preserving pavement network conditions so that the need for costly rehabilitation activities is deferred. Since pavement preservation programs incorporate the use of low-cost PM treatments to retard deterioration, agencies can realize dramatic cost savings in the overall life-cycle cost of maintaining their pavements. At the same time, customer satisfaction tends to improve because the roads are maintained in a better condition for a longer period of time and delays associated with the construction of rehabilitation projects are postponed.

Agencies that have implemented pavement preservation programs recognize a number of benefits associated with the success of their programs, such as those listed below (FHWA 2001): 
- Higher customer satisfaction,

- Better information to assist with decisions regarding pavement preservation,

- Improved strategies and techniques,

- Improved pavement conditions,

- Cost savings, and

- Increased safety.

Agencies seeking to implement a pavement preservation program, or agencies striving to increase the funding for their pavement preservation program, have promoted these benefits in defense of their actions. In most cases, pavement preservation programs have been implemented to make more cost-effective use of the funding levels available or to improve network conditions over time. Other benefits, such as higher customer satisfaction and increased safety, are typically unplanned consequences that follow from the use of PM treatments. However, because of the real improvement to safety characteristics that can be realized through the use of PM treatments, there is merit in increasing the profile of safety improvements as a reason to implement a pavement preservation program.

The primary safety benefits that are provided from PM treatments are realized in three ways. First, since roads are maintained in good condition for a longer period of time, there are fewer safety-related defects such as potholes, weathering, raveling, and rutting present. Second, certain PM treatments can restore surface texture, which improves surface friction (both wet and dry) while also reducing the amount of water spray, hydroplaning, and road noise. Finally, since the construction period associated with PM treatments is very short, there are fewer disruptions in traffic flow patterns which help to reduce the number of crashes due to construction activities.

The literature includes documents that summarize the distress characteristics that can be addressed through the use of certain types of PM treatments. Those treatments that are primarily recommended to address safety deficiencies are listed in Table 1 along with the surface conditions they address. Table 2 presents a summary of the effect of PM treatments on surface characteristics. As presented in the tables, some treatments have a positive influence on improving surface characteristics, while other treatments have little to no effect (neutral effect in the table) or a possible adverse effect.

Studies have documented the improved safety characteristics that can be realized through the use of PM treatments as part of a pavement preservation program. For instance, when New York State initiated its PM program, the percent of roads in good condition increased by almost $20 \%$ while the percent of roads in poor condition decreased by approximately $5 \%$ (Zimmerman and Wolters 2003). During the period in which the change in network conditions took place, there was a corresponding change in the number of fatalities per 100 million VMT within the state. In 1990 , before the program was in place, New York's fatality rate equaled the national average of 2.07 fatalities per 100 million VMT. By the year 2000, the number of fatalities on the state's highways was reduced by $34 \%$ while the national percentage dropped by only $6 \%$. While a number of factors undoubtedly contributed to the reduction in the number of fatalities, improvements to road surface characteristics appears to be a major factor (since road geometry and other factors didn't change). New York's program to address deficiencies in skid resistance is well documented in the literature as an example of "best practice" (Neuman et al. 2003; Smith and Sack 2002). 
TABLE 1 Preventive Maintenance Treatments That Address Safety Deficiencies

\begin{tabular}{|l|l|}
\hline \multicolumn{1}{|c|}{ Treatment } & \multicolumn{1}{|c|}{ Condition Addressed } \\
\hline Slurry seals & Friction loss \\
\hline Scrub seals & Raveling and weathering \\
\hline Microsurfacing & Raveling and weathering \\
& Friction loss \\
& Bleeding \\
& Roughness \\
\hline Chip seals & Raveling and weathering \\
& Friction loss \\
& Bleeding \\
& Roughness \\
\hline Thin hot-mix asphalt (HMA) overlays & Raveling and weathering \\
& Friction loss \\
& Bleeding \\
& Roughness \\
\hline Ultrathin friction courses & Raveling and weathering \\
& Friction loss \\
& Bleeding \\
\hline Diamond grinding and/or grooving & Roughness \\
& Loss of skid on portland cement concrete (PCC) pavements \\
& Roughness \\
\hline
\end{tabular}

TABLE 2 Effect of Preventive Maintenance Treatments on Pavement Surface Characteristics

\begin{tabular}{|c|c|c|}
\hline $\begin{array}{l}\text { PM Treatments With a } \\
\text { Positive Impact on } \\
\text { Surface Characteristics }\end{array}$ & $\begin{array}{l}\text { PM Treatments With a } \\
\text { Neutral Impact on } \\
\text { Surface Characteristics }\end{array}$ & $\begin{array}{c}\text { PM Treatments With a } \\
\text { Potentially Negative Impact on } \\
\text { Surface Characteristics } \\
\end{array}$ \\
\hline Slurry seals & Crack filling and sealing & $\begin{array}{l}\text { Crack filling and sealing (if } \\
\text { overbanding is present) }\end{array}$ \\
\hline Scrub seals & Undersealing in PCC pavements & Fog seals \\
\hline Microsurfacing & \multirow{6}{*}{$\begin{array}{l}\text { Joint resealing and crack sealing } \\
\text { in PCC pavements }\end{array}$} & \multirow[t]{3}{*}{ Rejuvenators } \\
\hline Chip seals & & \\
\hline Thin HMA overlays & & \\
\hline Ultrathin friction courses & & \multirow{3}{*}{$\begin{array}{l}\text { Diamond grinding surfaces with } \\
\text { polishing coarse aggregates }\end{array}$} \\
\hline Asphalt cold-in-place recycling & & \\
\hline Asphalt hot-in-place recycling & & \\
\hline
\end{tabular}

Relatively minor improvements in surface texture, such as those realized from pavement preservation practices, can have a significant impact on reducing accident rates. Figure 1 from the United Kingdom shows the effect of skid resistance [from a sensor-measured mean texture depth (SMTD) or SCRIM device] and texture depth (in millimeters of SMTD) on accident rates (Viner et al. 2004). The report states that increases in texture depth from $0.3 \mathrm{~mm}$ to $1.5 \mathrm{~mm}$ can reduce the accident rate by approximately $50 \%$, while increasing the skid resistance from 0.35 to 0.6 reduces the accident rate by about $65 \%$. Treatments such as the United Kingdom's thin- 


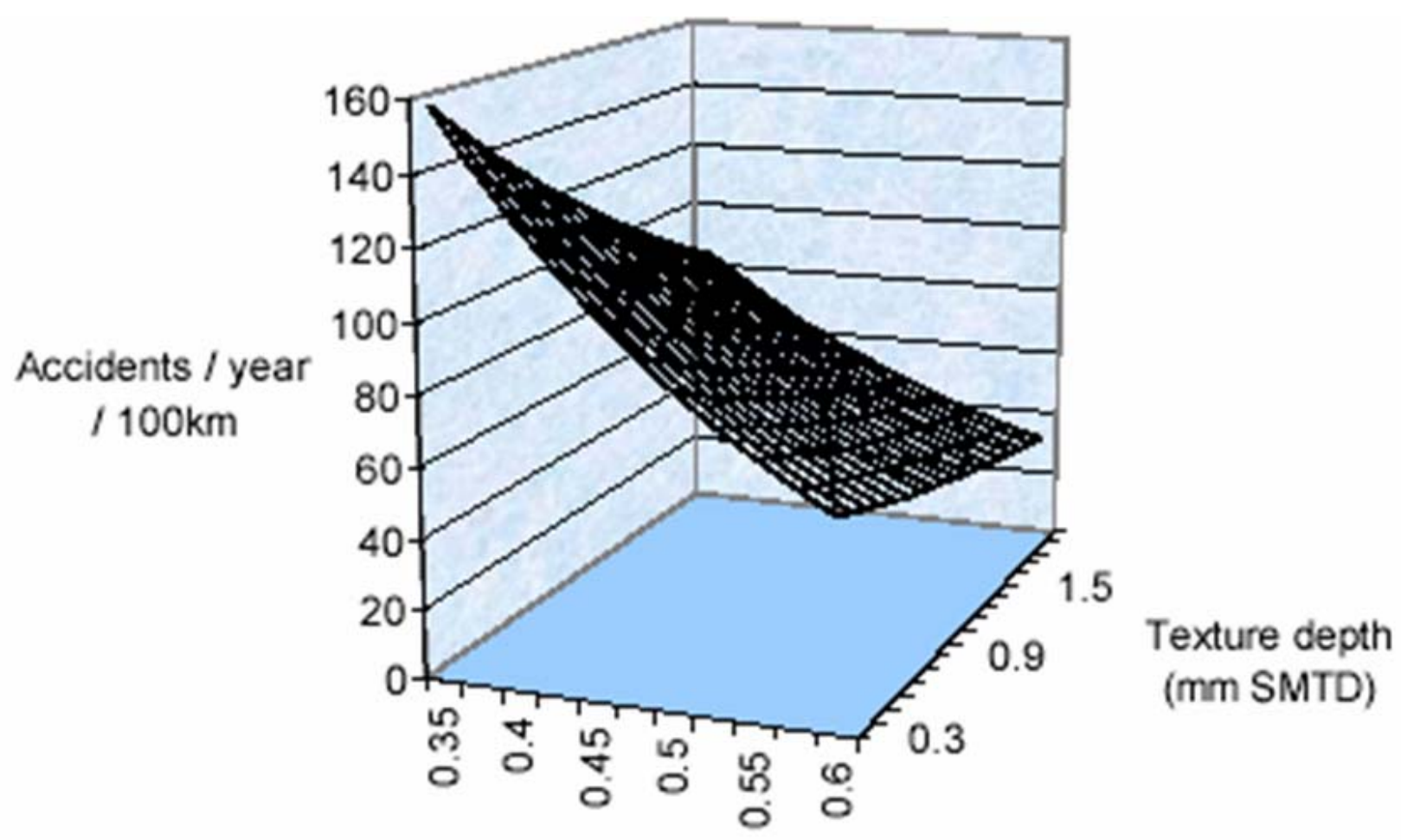

\section{Skid resistance}

\section{FIGURE 1 Accident model for skid resistance and texture depth on single carriageways (Viner et al. 2004).}

surface friction treatments show potential in the United States for improving road surface characteristics.

\section{COLLECTING SAFETY DATA AS PART OF A NETWORK-LEVEL EVALUATION}

Although agencies realize that there are safety benefits associated with the use of PM treatments, a November 2000 survey of state practice indicates that although 24 agencies reported that increased safety is an important benefit from implementing a PM program, only 11 agencies had any measures in place for documenting the improvements (FHWA 2001). These results can be contrasted to the numbers reported for improved pavement conditions. In the latter instance, 27 agencies reported that improved pavement conditions are an important benefit, and 20 agencies reported that they had the means in place to document the benefit.

To adequately address the attributes that influence the relationship between pavement surface characteristics and safety, several indicators should be considered. For instance, surface texture or friction indicators include macrotexture and microtexture characteristics [such as the International Friction Index (IFI)] and skid resistance or skid number (SN) measures (Tighe et al. 2000). Other, more common characteristics, such as pavement roughness [such as the International Roughness Index (IRI)] and pavement surface distress (such as cracking, rutting, and potholes), are regularly incorporated into the network-level data collection activities normally incorporated into an agency's pavement management practices. In fact, according to a 
recent synthesis of state highway agency practice, roughness is monitored at least on a biennial basis by almost every state agency to satisfy its Highway Performance Monitoring System reporting requirements (McGhee 2004). Rut depth, cracking, and joint faulting are also widely collected as part of an agency's pavement management surveys (McGhee 2004). Friction measurements, however, are more frequently collected on a case-by-case basis to monitor specific sites where pavement surface characteristics may reportedly contribute to slick spots or an increased number of crashes. If friction measurements are collected on a network basis, they typically are not incorporated into a pavement management analysis. These trends in the United States vary from recent trends being observed internationally. For instance, the United Kingdom and New Zealand have recently started collecting both continuous friction data (with a SCRIM device) and macrotexture annually.

With regard to safety, there are at least two important parameters to monitor: macrotexture and microtexture. Macrotexture is a characteristic of the longitudinal road profile that ultimately influences the interactions between vehicle tires and the road surface. For that reason, macrotexture most influences noise levels, hydroplaning, and tire wear. Microtexture, on the other hand, is a characteristic of the aggregate itself and relates more to friction or skid resistance of the pavement surface. The differences in macrotexture and microtexture are illustrated in Figure 2.

Techniques currently exist for monitoring texture parameters in coordination with networklevel pavement management surveys. For example, the same vehicles that are used to collect roughness, rutting, and faulting information from lasers have the ability to monitor road surface macrotexture at traffic speeds to produce profile statistics such as the mean profile depth (MPD). Studies have investigated the correlation of the high-speed testing devices with the more traditional sand patch test and report good correlation between the two (although the measures being reported are distinctly different) (Cairney and Styles 2005). In 2000, Texas began using macrotexture measurements for condition surveys, accident analysis, and noise studies (Henry 2000).

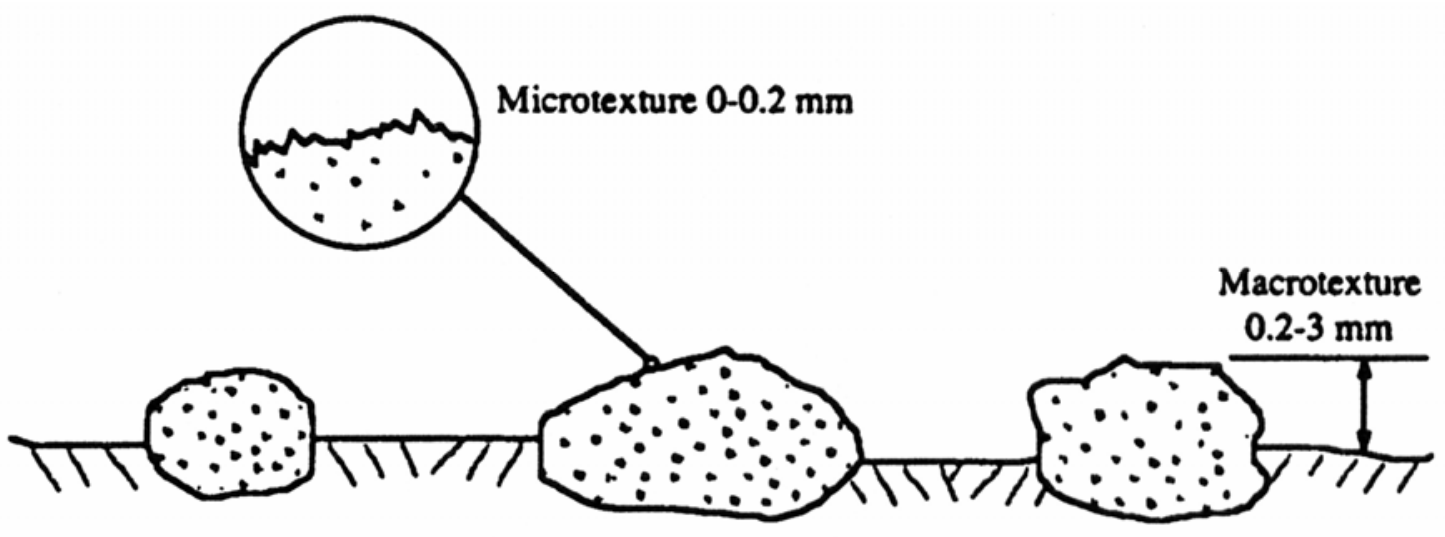

FIGURE 2 Illustration of macrotexture and microtexture of a road surface (Tighe et al. 2000). 
ASTM Standard E-1845 provides a method for calculating the MPD from a profile of pavement macrotexture (ASTM 1999). Information from these measures can be used at the network level to identify sections with low macrotexture (or high-speed friction) to determine if crash rates are higher than average for that type of route or category of site. The information can also be used to establish investigatory levels for the agency. The general approach used in the FAA Advisory Circular (AC) 120/5320-12C to develop guidelines for texture/friction on new construction, warning or investigatory levels, and minimum levels where correction is required, is considered a "best practice" to help ensure that safer roadways are provided to the highway user.

The FHWA requires states to have specifications and standards in place for the construction of pavements with adequate friction characteristics. In addition, states are required to monitor pavement surfaces in service to ensure that adequate levels of friction are maintained (Gramling 1994). There are four basic types of full-scale friction measuring devices: locked wheel (such as ASTM E-274 trailer), side force (such as the MuMeter or SCRIM), fixed slip (such as Griptester), and variable slip (such as Norsemeter) (Henry 2000). According to a recent survey of state practice, the locked-wheel skid trailer is the most common device for measuring skid resistance on highways (Henry 2000). ASTM Standard E-274 provides a method for testing skid resistance on paved surfaces using a full-scale tire (ASTM 1999).

While most states monitor SNs on a regular basis, the results are not typically incorporated into the pavement condition information reported as part of an agency's pavement management activities. However, it is reported that at least 84 different pieces of equipment are used to measure pavement friction (Gramling 1994) so research efforts have attempted to correlate the data from these different devices. One of the most promising outcomes is the development of an IFI by the Permanent International Association of Road Congresses (PIARC) (Henry 1996). ASTM Standard E-1960 documents the calculation of the IFI (ASTM 1999). The IFI consists of two parameters: the friction number at a slip speed of $60 \mathrm{~km} / \mathrm{h}(37 \mathrm{mph})(\mathrm{F} 60)$, which is controlled by the microtexture, and the slip speed number $\left(\mathrm{S}_{\mathrm{p}}\right)$, which is controlled by macrotexture (Henry 1996). Further studies have been conducted to correlate macrotexture measures and speed, resulting in a linear regression model that predicts the slip speed number from the mean value of macrotexture depth (or the average distance between the surface of the a pavement and the tire-road interface within a certain surface area) (Tighe et al. 2000). As discussed later in the paper, the parameters used to calculate the IFI can be used by pavement management engineers to identify treatment needs and safety intervention levels as part of the agency's normal pavement planning and programming activities. The IFI also provides a useful metric for reporting overall friction values within a highway agency.

There is, however, no known system capable of measuring microtexture profiles at highway speeds in traffic (Henry 2000). For that reason, agencies have developed surrogate measures for microtexture. In the United Kingdom, for example, the SCRIM values are synonymous with microtexture because the slip speed is low (Henry 2000). The need for microtexture values is avoided if macrotexture values are available in calculating an IFI, since only a macrotexture parameter and slip speed are required in its calculation.

The benefits to monitoring skid resistance are demonstrated through an example from New Zealand. Since its skid resistance measurement program was implemented in 1995, the skid resistance of the state highway network has improved sufficiently to result in a $29 \%$ reduction in wet-skid crashes at the treated sites (Ministry of Transport 2003). The skid resistance of the road surfaces is monitored annually to identify improvement areas.

In the United States, TxDOT estimates that its pavement surface texture measurement system will save 12 lives, prevent 1,100 accidents, and save $\$ 5,922,000$ in its first 10 years 
(TxDOT 2003). Initiated as part of its WWARP in 1999, laser macrotexture measurements are collected in conjunction with friction testing to develop correlations between macrotexture and friction numbers. Approximately $25 \%$ of the network is collected each year, with the exception of the Interstate where $50 \%$ of the network is collected each year.

\section{USING PAVEMENT SURFACE CHARACTERISTICS TO ESTABLISH SAFETY INTERVENTION LEVELS}

The use of a PMS at the strategic level can help an agency establish policies for addressing agencywide performance factors. While pavement condition indicators such as pavement distress, roughness, and rutting have been used to report pavement conditions by many agencies, a PMS can provide the information to establish agency guidelines for setting intervention levels that might help to reduce crashes related to surface texture or friction factors. To date, there has been little work done to incorporate road safety management with pavement management and PM programs (Tighe et al. 2000). However, relationships between road crash occurrences and pavement conditions can likely be made and pavement preservation activities can play a role in reducing the frequency of crash occurrences.

Previously, the use of the IFI, which is calculated from the friction number at a slip speed of $60 \mathrm{~km} / \mathrm{hr}(37 \mathrm{mph})$ and the slip speed number, was introduced as a way of comparing friction measures from various types of equipment. Using this information, an agency can develop guidelines for determining intervention levels for the use of PM treatments impacting friction, such as microsurfacing, grinding and/or grooving, or chip sealing. One approach is to use a chart similar to the one presented in Figure 3 (Tighe et al 2000). In this example, the chart is broken into four quadrants. The upper right-hand quadrant represents a pavement that meets the agency's conditions for friction and safety levels from a pavement surface point of view. The bottom right quadrant represents pavements that have good macrotexture $\left(\mathrm{S}_{\mathrm{p}}\right)$, but poor microtexture (F60). The opposite conditions exist in the upper left quadrant, where the microtexture is good but the macrotexture needs improvement. In the bottom left quadrant, both macrotexture and microtexture need improvements. Although each agency must develop its own chart for establishing the friction trigger levels based on the equipment being used to measure these values, the approach provides a framework for establishing guidelines to address a strategic issue such as safety in a consistent manner throughout the agency.

Internationally, the United Kingdom has used safety information to establish investigatory skid resistance levels for 10 different site categories of pavement ranging from SCRIM measures at $50 \mathrm{mph}$ of 0.35 to 0.55 . Using these SCRIM measures to identify safety projects, the United Kingdom reduced its fatalities from 1.1 fatalities per 100 million vehicle kilometers traveled (VKT) in 1991 to 0.8 fatalities per 100 million VKT in 1998 (UKDT 2003). Combined with an increased use of the RSA and certifying surface treatments for different levels of skid resistance, the United Kingdom fatality rate is one of the lowest in the world (ATSB 2002). On-going efforts are underway to further reduce the number of fatalities or serious injuries in the United Kingdom by $40 \%$ by the year 2010 (UKDT 2003). An example of the investigatory levels for low traffic volume paved facilities (lightly shaded boxes) and site specific ranges (with dark shading) is provided in Table 3. 


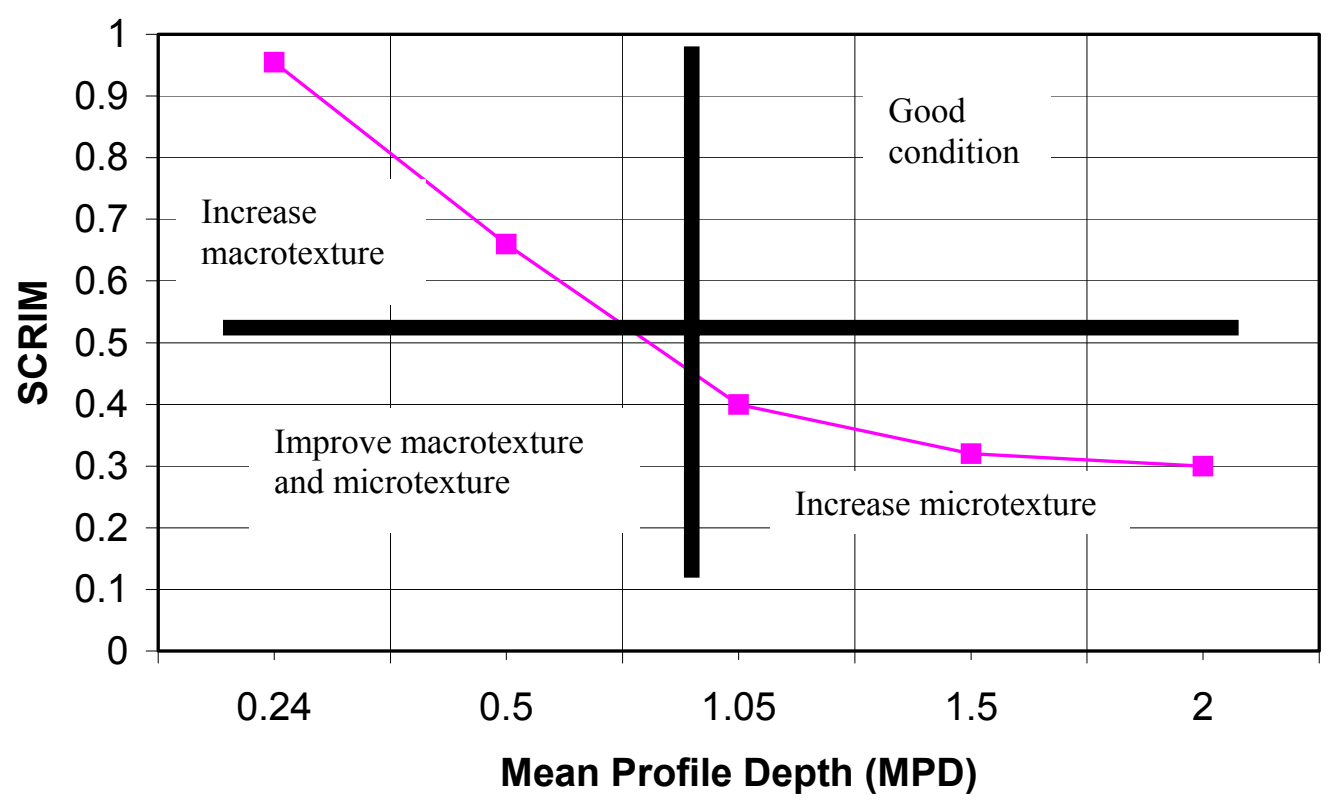

FIGURE 3 Safety intervention levels for a SCRIM texturemeasuring device (Tighe et al. 2000).

TABLE 3 Site Categories and Investigatory Levels Used in the United Kingdom (Viner et al. 2004)

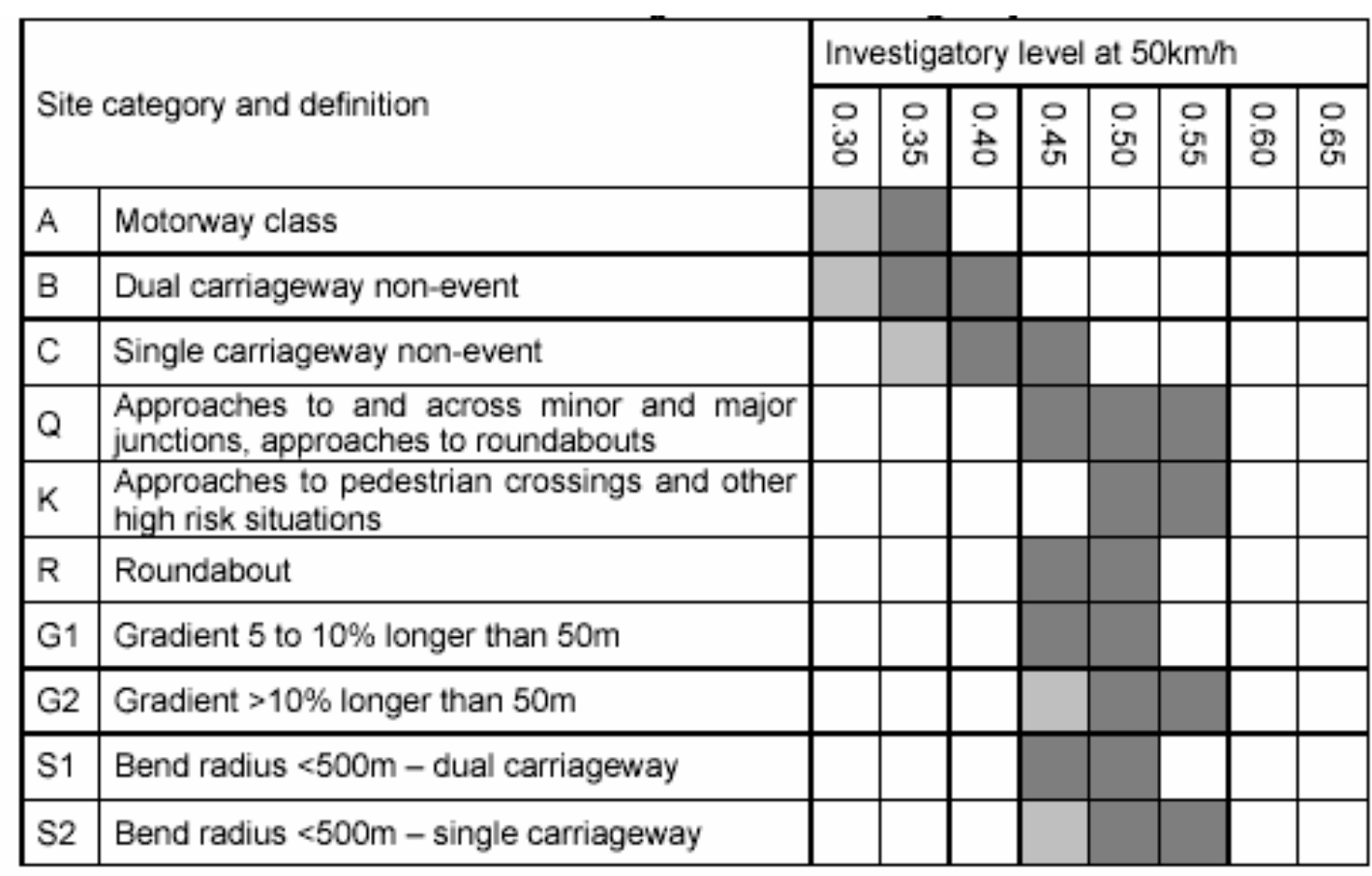


Larson reports that texture depths associated with investigatory levels for a range of commonly used surfacing types in Australia are provided in the literature (Larson 2005). As part of its policy to manage skid resistance, Larson reports that the Australian National Road Safety Action Plan for 2005-2006 targets a 40\% reduction in the national per capita fatality rate and associates $19 \%$ of the reduction to safer roads.

The use of investigatory skid resistance levels differs from current practice in the United States in an important way. In the United States, the emphasis has been on setting minimum texture or friction levels rather than desirable levels. The results of the United Kingdom's program to set desirable targets and levels at which actions are taken for various site categories (which are very project specific), clearly demonstrate the importance of managing safety in conjunction with other pavement characteristics. The fact that a road falls below the investigatory level does not necessarily mean that a road is unsafe, but it identifies the road as a site for further investigation, such as a review of the road's safety record to evaluate whether maintenance is needed (UKDT 2004). The United Kingdom also publishes the percentage length of roads at or below the investigatory level regularly for each highway class.

The results of a number of research studies document the relationship between pavement friction measurements and the number of wet weather and dry weather crashes. For instance, one study conducted in Kentucky documents the relationship between crash rates and pavement friction for rural, four-lane, controlled-access roads on Interstate, and parkway (expressway) systems in Kentucky (Rizenbergs et al. 1976). The study clearly demonstrates that as the SN increases, the number of wet surface accidents decreases. The greatest reduction in wet surface crash rates occurs as the SN increases to a value of 27. Beyond that level, further increases in SN had only slight reductions in the crash rate.

Although there are a number of studies linking friction levels to crash rates and macrotexture to friction, there are very few studies that compare the relationship between macrotexture and crash rates. The work in this area is summarized in the literature (Cairney and Styles 2005) and important observations are noted. Included in their report are observations from previous studies that crash rates increase with low macrotexture values and that the drainage aspect of macrotexture is of little importance to alter crash rates due to macrotexture alone. This latter observation highlights the importance of evaluating both macrotexture and microtexture to evaluate safety performance. Additional studies documented in the report indicate that wet road crash rates vary little for higher levels of macrotexture, but rise steeply when macrotexture falls (in terms of SMTD) below $0.5 \mathrm{~mm}$. While the various studies referenced in the paper vary in the threshold value at which crash rates increase, they clearly document the relationship between crash rates and macrotexture. The authors' study showed steep increases in crash rates at SMTD values of 0.3 to 0.5 on the three sites included in their study. These values correlated to 1.4 to 1.7 times the average risk that crashes will occur (Cairney and Styles 2005).

In its safety program, the New Zealand Ministry of Transport is focusing on making the most cost-effective use of its road safety engineering dollars. This is being done by targeting roads that have both a high risk for crashes and a high cost density in terms of social cost (Ministry of Transport 2003). As a result, most of the safety improvements are being focused on urban roads and state highway/motorways with high concentrations of crashes since they account for the largest proportion of social cost of road crashes.

One tool that might be useful in establishing investigatory levels is a RSA. Although primarily oriented toward safety issues associated with new road projects, a RSA can also be conducted on existing roads to evaluate all types of safety considerations. The key is that the 
audit provides an objective means of assessing crash risk because the auditors are expected to serve as independent observers rather than participants in the road design or maintenance activities. At a minimum, agencies should consider RSAs at sites with a history of high crash risk based on crash reports (FHWA 2004a). Since they are a relatively low-cost activity to implement, there is typically a high benefit to cost $(\mathrm{B} / \mathrm{C})$ ratio associated with an RSA. The United Kingdom reports a $\mathrm{B} / \mathrm{C}$ ratio of 15 to 1 , while TRANSIT New Zealand has estimated the ratio at closer to 20 to 1 (FHWA 2004a).

\section{INCORPORATING SAFETY INTO A PAVEMENT MANAGEMENT SYSTEM}

To fully integrate safety into a PMS, it is important that decisions regarding safety improvements be made concurrently with other decisions about pavement surface improvements. This involves incorporating safety intervention levels into treatment decision trees along with other considerations such as distress types and quantities, functional classification, traffic volumes, and speed limits.

Pavement surface characteristics can also be incorporated into an agency's maintenance management system in a manner similar to other performance targets that may be set. For instance, most agencies that have an enhanced maintenance management system in place have established targeted levels of service (LOS) for each of the highway assets being maintained. Maintenance LOS surveys are conducted to evaluate the actual conditions of these assets so they can be compared to the targets. An example from the North Carolina DOT is included as Table 4 (Zimmerman and Wolters 2003). The table reflects the average LOS for each highway system and the targeted LOS established by the department. The differences between the average and targeted LOS can be used to set maintenance priorities and maintenance budget requirements.

A U.S.-based scan tour of Australia, Canada, Japan, and New Zealand reports the impressive application of road safety performance measures to influence governmental policy and budget determinations in these countries and reduce the number of fatalities and injuries (FHWA 2004b). For example, VicRoads (the transportation authority for Victoria, Australia) has established a performance measure to identify the proportion of travel each year on roads below an IRI value of 4.2, which is benchmarked against other Australian states (FHWA 2004b). Another performance indicator is the ratio between total maintenance expenditures and length of road with surface roughness below an IRI value of 4.2. Although each agency visited during the scan tour approached safety issues in its own way, each was successful in reducing the number of fatalities dramatically in accordance with stated goals. For instance, New Zealand reduced its fatalities from 729 in 1990 to 404 in 2002 despite traffic growth (Ministry of Transport 2003).

TABLE 4 Average and Acceptable LOSs for Pavement Features in North Carolina

\begin{tabular}{|c|c|c|}
\hline System & Average LOS & Targeted LOS \\
\hline Interstate & C & B \\
\hline Primary & D & C \\
\hline Secondary & D & C \\
\hline Urban & D & C \\
\hline
\end{tabular}


New Zealand's new goal is to reduce fatalities to 300 by 2010 to put them more in line with other countries with the best safety records (Ministry of Transport 2003). A comparison of fatalities per 100,000 in population is provided in Figure 4, which illustrates the success other countries have had in this area when compared to statistics from the United States (FHWA $2004 \mathrm{~b}$ ). One of the recommendations from the scan tour is to encourage states to implement these best practices on safety performance measurement.

Once areas of safety improvement are identified through a pavement condition survey process that incorporates IFI and macrotexture values, the prioritization of projects lends itself very well to the type of $\mathrm{B} / \mathrm{C}$ analysis used in many PMSs. A number of agencies have reported the $\mathrm{B} / \mathrm{C}$ ratios associated with safety projects, as documented earlier. At a recent conference, New Zealand also reported a B/C ratio of 40 associated with its efforts to improve pavement surface characteristics (Dunlop 2005). Dunlop reports that the Ministry of Transport also predicts a savings of NZ\$395 million that will be realized over a 5-year period from its reductions in wet weather crashes.

\section{CONCLUSION}

Pavement preservation programs provide an excellent opportunity to make substantial contributions to reducing the number of accidents on the nation's roads through the use of costeffective functional improvements. By incorporating safety measures into a PMS, an agency can utilize a systematic approach for identifying and prioritizing pavement preservation needs due to pavement surface characteristics, distress, roughness, and other considerations.

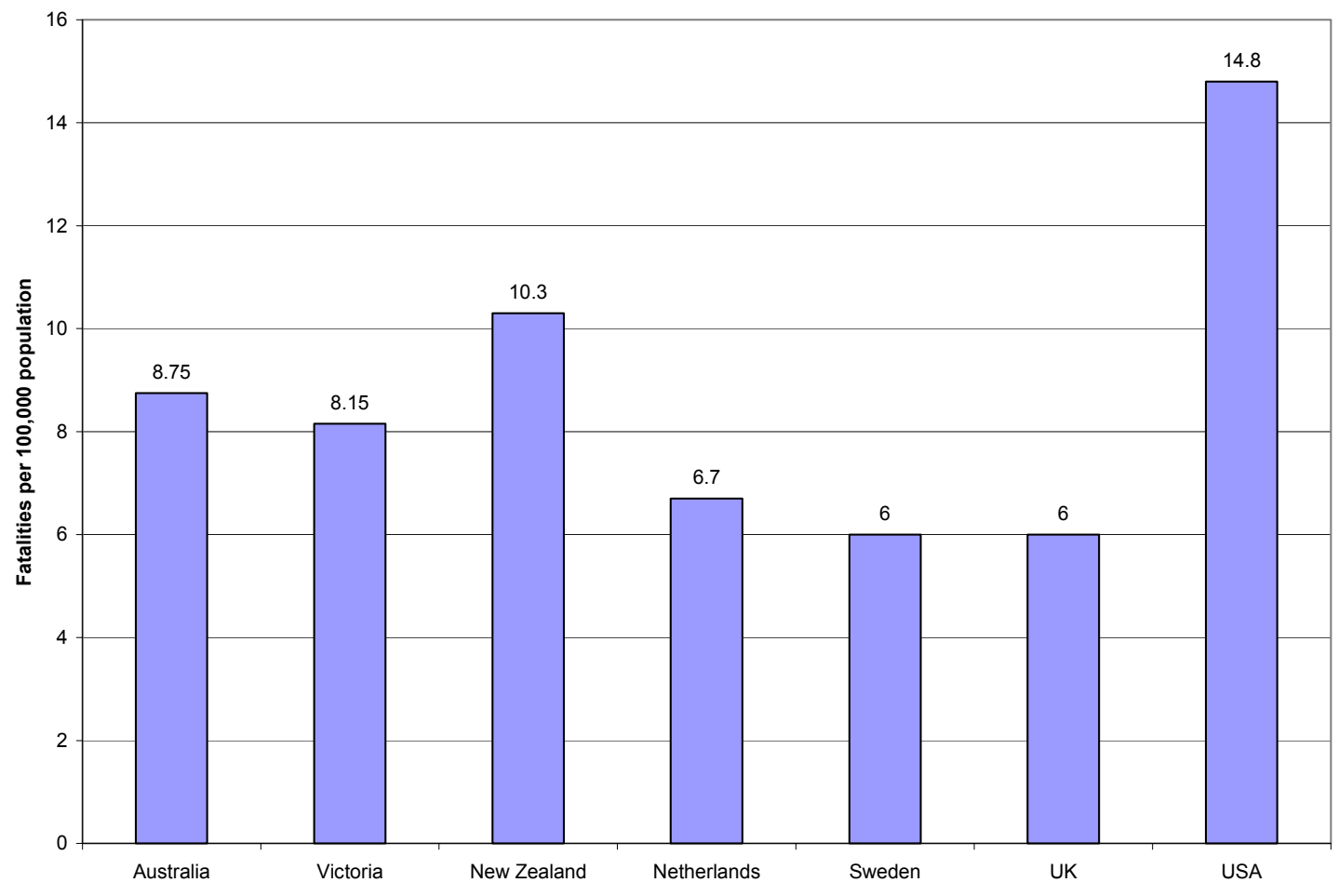

FIGURE 4 Benchmarking 2002 fatalities in other countries (FHWA 2004b). 
To reduce crash rates, it is important to identify the factors contributing to the crashes so that appropriate actions can be developed. For instance, after studying its crash data, Japan found that a large number of crashes involved pedestrians and bicyclists (FHWA 2004b). This led the Ministry of Land, Infrastructure, and Transport to implement pedestrian-oriented safety measures in its decision-making process to address these issues. The RSA process can be used to identify factors contributing to crashes at specific project locations.

If, after evaluating the contributing factors to crash rates, an agency determines that pavement surface characteristics have a role, then there are several steps the agency can take to reduce the number of crashes and improve network conditions within the framework of its pavement preservation program. However, to do this, safety measures need to be incorporated into the pavement preservation program through the agency's pavement management or maintenance management systems. By setting meaningful safety performance targets, it is easier for agency personnel to establish funding priorities and implement programs that enable the agency to accomplish its goals.

One of the keys to reducing crash rates due to pavement surface characteristics is to monitor the data needed to identify safety needs and establish budget requirements [including macrotexture, microtexture (IFI), and roughness] on a regular basis. Safety considerations also need to be taken into consideration in the pavement management models in the same manner that other characteristics are considered. For instance, macrotexture and IFI need to be incorporated into the treatment decision trees so that they receive full consideration as part of an agency's pavement preservation program.

With any pavement preservation program, it is important to monitor the success of the program at achieving agency goals. Similarly, it is important to monitor the success of the pavement preservation program at reducing crash rates to justify further expenditures in this area and to enable the agency to evaluate its success at meeting safety goals. Documenting the benefits of both the pavement preservation and the skid resistance management program should provide additional support for both funding and personnel to successfully implement these programs. Both wet and dry pavement crashes must be addressed along with the effect of friction and texture on crash rates to aid in the decision-making process. As a result of these efforts, other benefits will emerge, including improved surface conditions and higher levels of customer satisfaction.

Safety improvements must be managed and planned as part of an agency's normal planning and programming activities. To do this, safety intervention levels should be established to help identify sections requiring further investigation or pavement surfaces that might be addressed cost-effectively using a PM treatment.

Today's technology shows promise for improving road safety as part of a pavement preservation program. Through changes to an agency's data collection and pavement management modeling activities to incorporate safety, an agency can develop pavement preservation recommendations that incorporate safety needs with other functional improvements that are needed. As a result, the agency will be using its pavement preservation funds costeffectively while also making the roads safer for the traveling public.

\section{REFERENCES}

Cairney, P., and E. Styles. A Pilot Study of the Relationship Between Macrotexture and Crash Occurrence. CR 223. ARRB Transport Research LTD., Vermont South, Victoria, Australia, 2005. 
Calculating Pavement Macrotexture Profile Depth. ASTM Standard Practice E-1845. Book of ASTM Standards, Vol. 04.03. American Society of Testing and Materials, West Conshohocken, Pa., 1999.

Dunlop, R. The Imperative of Tackling the Skid Resistance Issue. Proc., International Conference on Surface Friction, Christchurch, New Zealand, May 1-4, 2005.

Gramling, W. L. NCHRP Synthesis of Highway Practice 203: Current Practices in Determining Pavement Condition. TRB, National Research Council, Washington, D.C., 1994.

Henry, J. J. NCHRP Synthesis of Highway Practice 291: Evaluation of Pavement Friction Characteristics. TRB, National Research Council, Washington, D.C., 2000.

Henry, J. J. Overview of the International PIARC Experiment to Compare and Harmonise Texture and Skid Resistance Measurements: The International Friction Index. Proc., Third International Symposium on Pavement Surface Characteristics, Christchurch, New Zealand, 1996.

International Road Safety Comparison: The 2000 Report. Australian Transport Safety Bureau, Australia, 2002.

Larson, R. M. Using Friction and Texture Data to Reduce Traffic Fatalities, Serious Injuries, and Traffic Delays. Proc., International Conference on Surface Friction, Christchurch, New Zealand, May 1-4, 2005.

McGhee, K. H. NCHRP Synthesis of Highway Practice 334: Automated Pavement Distress Collection Techniques. Transportation Research Board of the National Academies, Washington, D.C., 2004.

Neuman, T. R., R. Pfefer, K. L. Slack, K. K. Hardy, F. Council, H. McGee, L. Prothe, and K. Eccles. NCHRP Report 500: Guidance for Implementation of the AASHTO Strategic Highway Safety Plan, Vol. 6: A Guide for Addressing Run-Off-Road Collisions. Transportation Research Board of the National Academies, Washington, D.C., 2003.

Pavement Management Guide. American Association of State Highway and Transportation Officials, Washington, D.C., 2001.

Pavement Preventive Maintenance Guidelines. FHWA, U.S. Department of Transportation, 2001.

Rizenbergs, R. L., J. L. Burchett, and C. T. Napier. Accidents on Rural Interstate and Parkway Roads and Their Relation to Pavement Friction. In Transportation Research Record 584, TRB, National Research Council, Washington, D.C., 1976.

Road Safety Audits: An Emerging and Effective Tool for Improved Safety. Intersection Safety: Issue Briefs. FHWA, U.S. Department of Transportation, 2004a.

Road Safety to 2010. New Zealand Ministry of Transport, Wellington, 2003.

Smith, B. W. and R. L. Sack. Skid Accident Reduction Program. Engineering Instruction Report EI 02-007. New York State Department of Transportation, Albany, 2002.

Tighe, S., N. Li, L. Cowe-Falls, and R. Haas. Incorporating Road Safety into Pavement Management. In Transportation Research Record: Journal of the Transportation Research Board, No. 1699. TRB, National Research Council, Washington, D.C., 2000.

Transportation Performance Measures in Australia, Canada, Japan, and New Zealand. FHWA, U.S. Department of Transportation, 2004b.

United Kingdom Department of Transport. Annual Report 2003. Crown Copyright, HMSO, Norwich, U.K., 2003.

United Kingdom Department of Transport. National Road Maintenance Condition Survey: 2004. Crown Copyright, HMSO, Norwich, U.K., 2004.

The Value of Texas Transportation Research. Texas Department of Transportation, Austin, 2003.

Viner, H. R., R. Sinhal, and T. Parry. Review of UK Skid Resistance Policy. SURF 2004 (CD-ROM). 5th Symposium on Pavement Surface Characteristics. World Road Association, Paris, France, 2004.

Zimmerman, K. A., and A. S. Wolters. Pavement Preservation: Integrating Pavement Preservation Practices and Pavement Management. FHWA/NHI Training Course 131104. Reference Manual. FHWA-NHI-04-050. National Highway Institute, FHWA, U.S. Department of Transportation, Washington, D.C., 2003. 


\title{
The Role of Pavement Preservation in Privatized Maintenance
}

\author{
DENNIS A. MORIAN \\ JAMES W. MACK \\ Quality Engineering Solutions, Inc. \\ TANVEER CHOWDHURY \\ Virginia Department of Transportation
}

\begin{abstract}
The concept of privatized maintenance took hold in the late 1980s when the Virginia Department of Transportation awarded the first such contract, and within 2 years a second contract, for the preservation of 350 centerline miles of Interstate highways 95 (I-95), I-77, and I-81 in Virginia. The idea of these privatized maintenance contracts was to provide the contractor a fixed level of funding, and to establish a minimum pavement performance level that had to be maintained. While some sections required rehabilitation work, maximizing the use of pavement preservation strategies for suitable pavement sections is a key to successfully managing a pavement system with fixed funds. This paper discusses the application of pavement preservation strategies such as timely crack sealing, chip seals, and microsurfacing, and the valuable role pavement preservation has played in achieving the pavement performance and budget management objectives of privatized maintenance contracts. The discussion includes criteria for identifying the appropriate application of specific pavement preservation treatments. Pavement performance monitoring information from the project pavement management system is also provided, documenting the success of these treatments in preserving pavement condition level in a cost-effective manner, while at the same time providing an excellent tool for cash flow management.
\end{abstract}

Tn general there are two levels of maintenance: corrective and preventive. Activities that are L performed every day such as pothole filling and patching are generally considered corrective maintenance (CM). However, there is an important element of distinction that has to do with how much distress exists. When a fairly large amount of distress must be corrected in order to preserve the serviceability level of the roadway, the work is corrective in nature.

The concept of preventive maintenance (PM) varies significantly from this traditional approach of CM. While CM is entirely responsive to the deficiencies identified with the pavement structure and surface, PM uses a proactive approach to preserve the condition of the pavement before extensive deterioration related to structural failure takes place. Furthermore, it is done when minimal distress is present, with the objective of preserving a good serviceability level. Activities such as chip seals, microsurfacing, and Novachip are examples of PM.

When the pavement has deteriorated to the extent that PM is not feasible, and ongoing CM becomes expensive, it is generally time to employ restoration strategies to structurally enhance the pavement. Structurally enhancing pavement sections (strengthening) can be accomplished either by adding thickness to the existing pavement structure, or by replacing existing material with stronger material. Note that while this is not PM; it can be used to preserve a pavement structure. An example of this was the northern end of Interstate 95 (I-95) where the pavement was generally in acceptable condition in the two inside lanes, but the outside lane had severe stripping damage and poor drainage. Enhancement in this case consisted of removal and replacement of the deteriorated 
sections of pavement, with the intent of making them perform equivalently to the remaining sections in order preserve the entire pavement at minimal cost.

Pavement engineers and maintenance managers have discussed the concept of PM for many years. Many individuals and agencies have developed studies promoting this concept, and carried out local experiments to evaluate the effect of PM plans on pavement performance and budget control. The result of these studies and experiments has been a consensus that the use of PM is effective in both increasing the level of pavement performance and reducing in the demand on budgets over time. Still, one must recognize that structural enhancements are critical, and often beyond the scope of PM treatments. As such, eventually all pavements will require some type of structural enhancement

\section{PROGRAM IMPLEMENTATION}

The most difficult part of implementing a PM program is making decisions to spend limited maintenance funds on pavement sections which have not deteriorated to an unacceptable level, while other sections which are already in poor condition may be left untreated. Different from the traditional "worst first" approach, a balanced combination of rehabilitating poor pavement sections and preserving better pavements will ultimately result in improvement in the overall systemwide condition level without requiring large funding increases. The only way to make the transition from corrective to PM is to allocate a portion of each annual maintenance funds to pavement preservation. In other words, just start!

As an example of how to implement a program, the next portion of this paper describes the approach for evaluating pavement needs and developing treatment strategies for the privatized contract on I-95. Similar activities were also done for I-77 and I-81 sections. The final section of this paper will describe the effectiveness of the program for each of these roadways.

\section{I-95 Pavement Preservation Plans}

The I-95 privatized maintenance contract addressed the $101 \mathrm{mi}$ of pavement from the North Carolina state line to Mile Post 101 at the Hannover County line. Included in this section of highway were the urban areas of Richmond and Petersburg, Virginia. Among the constraints of the contract were

1. The contractor must have intimate knowledge of the condition of the highway. This included both the immediate functional condition as well the actual structural condition of the pavement, which would determine the functional performance in years to come.

2. A fixed operating budget for the entire 5-year contract term, and the necessity to distribute it among all maintenance activities. The implication of this is the need to optimize the investment in pavement maintenance, selecting strategies which provide cost effectiveness over the next several performance years.

3. The unpredictability of fiscal needs from year to year for winter maintenance needs provides a large variable in budget management.

4. Develop privatized maintenance strategies that do not leave the agency with depleted pavement life at the end of the maintenance contract. 


\section{Pavement Condition Evaluation}

The need to become thoroughly familiar with the highway in order to accomplish appropriate investment of limited funds is critical. A number of activities were carried out to assess the pavement condition, both structurally and functionally. The initial activity was the evaluation of a pavement condition assessment provided by the privatized maintenance contractor. Information provided included pavement condition index (PCI) and international roughness index (IRI) data. Once the initial assessment was completed, detailed field views and coring of various pavement sections were required to more closely assess pavement conditions, determine the configuration and condition of existing pavement structural materials, and determine potential PM candidates.

Two major defects were discovered quickly: open longitudinal paving joints and the presence of moisture-related damage and severe asphalt pavement stripping to the underlying pavement layers. These critical problems were the cause of great concern such that efforts to preserve the pavement could result in a continuous battle to maintain functional pavement condition. The result would not only be excessive expenditure of maintenance funds, but also a continuous battle to maintain the contract required functional pavement performance condition.

\section{Pavement Preservation Plan}

The outcome of this condition evaluation was a pavement preservation plan for I-95 from Milepost 0 to 101 whose intent was to maintain the condition of the pavement in good condition. The plan had two major components: the annual resurfacing program and the ongoing application of standard pavement maintenance activities which included drainage improvements, pothole repair, crack sealing, milling and functional overlays, and structural overlays. These strategies are intended to sustain both the structural and functional condition of the pavement and both components were critical to sustaining a high quality level of service (LOS) along the highway and optimizing the funding level expenditures.

The resurfacing program was further subdivided between highway sections that could be adequately maintained using thin surfacing, and those which would require more extensive treatment. The existence of the pavement stripping problem made it critical to distinguish these two levels of requirement prior to committing funds. A very real possibility existed that the application of thin resurfacing could result in a temporary and not cost effective repair of the surface.

The annual resurfacing plan was presented as three time-sequenced paving programs. The first program was proposed for the summer of 1998. These activities were intended to maintain the highway for the near term. The second phase was planned to take place during the later part of 1998 or during 1999. Primary emphasis for this phase of the plan included extensive drainage improvements, structural improvements to sections of the highway, and the implementation of innovative treatments being investigated at the present time. The third phase addressed plans for longer term pavement work. This phase includes structural enhancement of various pavement sections, and continued preservation of all highway sections.

\section{First Phase Pavement Maintenance Program}

Phase 1 included the work to be conducted during the initial construction period of 1998. This work can be characterized as a combination of ongoing routine maintenance activities and functional resurfacing. The sections selected for repair were carefully selected to represent those sections of the highway that 
1. Demonstrated a near term need for condition improvement, and

2. Could be adequately addressed by the use of a simple milling andlor overlay approach.

These two objectives are not necessarily mutually exclusive, and in certain cases, short-term condition preservation could be necessary which would not adequately provide for structural requirements over a period of time

The pavement sections included in this program were evaluated and designed to assure that no serious problems will be encountered as a result of poor drainage or extensive existing pavement material damage. The sections resurfaced are expected to perform for a period of from 5 to 8 years, depending on the level of traffic at various sections.

\section{Routine Maintenance Program}

While it was necessary to address the CM needs, the transition from corrective to PM, as discussed in the first section, also had to take place. For this, an extensive crack sealing program was implemented with the goal of improving the performance of the existing pavement. The Strategic Highway Research Program (SHRP) evaluation of asphalt pavement maintenance treatments, Maintaining Flexible Pavements: The Long-Term Pavement Performance Experiment SPS-3: FiveYear Data Analysis (FHWA, Pub No. FHWA-RD-97-102, March 1998) has resulted in substantiation of crack sealing as an effective way to preserve pavement condition. Crack sealing was found to be effective for pavements at all levels of condition, slowing the rate of deterioration as compared with an untreated control section. This was particularly effective in wet climates.

The SHRP evaluation also provided valuable information about other commonly used maintenance treatments, chip seals, slurry seals, and thin asphalt overlays. Application of the lessons learned about these treatments was pertinent to the development of the pavement preservation strategies. One very critical piece of information, which came out of the SHRP evaluation is that placement of seals on pavements with asphalt stripping potential, such as chip and slurry seals, serves to accelerate the stripping damage on high traffic volume roads. Note that hot-mix overlays do not accelerate the stripping damage.

With respect to the areas showing stripping damage, the near term recommendation for the majority of the pavements was continued routine maintenance. Distress levels were not sufficiently severe to warrant immediate resurfacing. However, spot pothole repair and crack sealing was used to maintain the condition of the pavement. Where pothole distress was concentrated in local areas, such as along the pavement shoulder edge in the vicinity of Mileposts 98 to 99, removal of the material with a small rotomilling machine and continuous patching of clustered potholes resulted in more durable repairs. Subsurface drainage was installed at strategic locations to prevent further moisture related damage to the pavement.

\section{Second Phase Pavement Maintenance Program}

The second phase included all work planned beyond the initial work, but within the next 18 months. This work was intended to result in longer term preservation of the pavement. Several elements of this phase of the program included major drainage improvements: structural base repairs and other pavement structural improvements, an anticipated performance assessment of the treatments planned, and life-cycle cost evaluation to assure cost effectiveness. 
It is not possible to overemphasize the importance of highway and pavement drainage systems to the performance of pavements. While this is true for highways in climates throughout the United States, it is particularly true in wet climates. The pavement evaluation carried out along I-95 revealed several locations where the condition of the drainage system required improvement in order to assure the best possible performance of the pavement. Problems such as silted pavement drain outlet pipes, water standing in parallel ditches, and stripping of asphalt pavement sections were identified. Addressing these problems was a vital element in assuring preservation of pavement conditions.

The extensive pavement evaluation carried out also identified specific sections of the highway which require more extensive structural improvement. These sections were designed for more extensive treatment, including base repair, and structural strengthening. The remaining sections of highway continued to be treated with CM as necessary and applications of PM as opportunities present themselves.

\section{Third Phase Pavement Maintenance Program}

This phase included all proposed work beyond the ensuing 18 months. The work plan provided for structural strengthening of numerous pavement sections, timed to sustain good functional pavement performance, and to optimize structural benefit. The estimates for this final phase were less precise than for stages 1 and 2 and as such, it was recommended that this work be reevaluated prior to plans development, and further refined at that time.

The details for this phase were developed on the basis of pavement evaluation and life-cycle cost analysis. It must be noted that all the pavement sections south of Milepost 22 were excluded from this plan as ongoing overlay placements were being constructed along this section of highway. Specific recommended activities included in this phase were the continued use of routine maintenance activities for the pavement sections in the areas that were generally in good condition as well as various structural improvements depending on the exact condition for a given location. The pavement restoration work identified was generally beyond the scope of this discussion.

For example, from Mileposts 96 to 99.8 , the plan was to first perform drainage improvements, which consisted of the installation of transverse drains, well functioning edge drains, and positive drainage outlets into clean and functioning parallel drainage ditches and where necessary, improvements to the fall within the ditch line to assure effective water removal. In association with this drainage improvement, base repairs were recommended. After these preparations, it was recommended replace the pavement structure with of 6-in. aggregate base, 9-in. asphalt base course, and 3.5 in. of asphalt surface material. The performance expectation following this series of corrective measures is a pavement which will perform well for 6 to 8 years with the traffic level present in that section of the highway.

However, selected sections of pavement that did fall within the PM treatment category are included. For example, the section from Mileposts 86 to 96 had recently had certain lanes inlaid. As such, it was recommended to surface mill 1.5 in. in depth and match inlays. Similarly, the section from Mileposts 99.8 to 101 had a recommended strategy of either a 2.5- to 3-in. overlay or a milling of 4 in. and overlaying with 6-in. surfacing. 


\section{PAVEMENT PERFORMANCE EVALUATION}

The evaluation of pavement performance information for the selected sections of Virginia Interstate highways was undertaken utilizing available information. As previously indicated, initial PCI and IRI data were available. Subsequent data gathering was not always continuous or consistent. VDOT contracted for pavement data collection utilizing automated data collection techniques as a part of the Inventory and Condition Assessment System (ICAS) project. Although two subcontractors worked to collect the necessary information over a 3-year period, data was not ultimately provided to VDOT from this effort. For the years 2002 to 2004, VDOT staff collected data in-house by the using windshield survey techniques. This information provides the majority of condition information used in this evaluation. Distress evaluation reported by VDOT identifies structural (LDR) and functional (NDR) condition levels. This approach to pavement condition assessment is conducive to the evaluation needed to determine the benefit from PM treatments.

As previously discussed, selected sections are available to evaluate PM treatments from the entire $350 \mathrm{mi}$ of pavement. These sections have been identified as follows.

Route
I-77
I-81/I-77
I-95

PM Treatment

Microsurfacing, Latex-C

Microsurfacing,

Novachip

Crack sealing with spot drainage

improvement

\author{
Approximate Location \\ Milepost 41 to $47 \mathrm{NB}$ and SB \\ Milepost 69 to $81 \mathrm{NB}$ \\ Milepost 74 to 79 \\ Milepost 95 to $101 \mathrm{NB}$ and SB
}

These treatments were applied in 1999 and 2000.

The discussion of pavement preservation strategies is prefaced with information about the traffic volumes using the various sections of roadway. Based on information for 2003, the sections of interest carry the following traffic volumes [in annual average daily traffic (AADT)] in one direction.

Route
I-77
I-81/I-77
I-95

AADT, Single Direction
14,000
26,000
38,000 to 52,000

\author{
AADT/Lane \\ 7,000 \\ 8,667 \\ 19,000 to 26,000
}

Each of these sections generally consists of two lanes in one direction, with the exception of the section where I-77/I-81 run together in the vicinity of Wytheville.

\section{I-77 Microsurfacing}

Figure 1 shows that the functional performance of the pavement section, represented by NDR, has remained quite good. As a comparison, data from some of the original pavement is also provided. In this case, the untreated surface sections are mixed among the treated sections, so traffic and other conditions are the same. The microsurfacing is found to have performed well through 2003, at which time the condition decreased rapidly.

The structural condition (LDR) of the pavement sections shows the conventional hot-mix pavement surface, [surface mix-2 (SM-2) designation] to have performed best. Again, the microsurfaced 


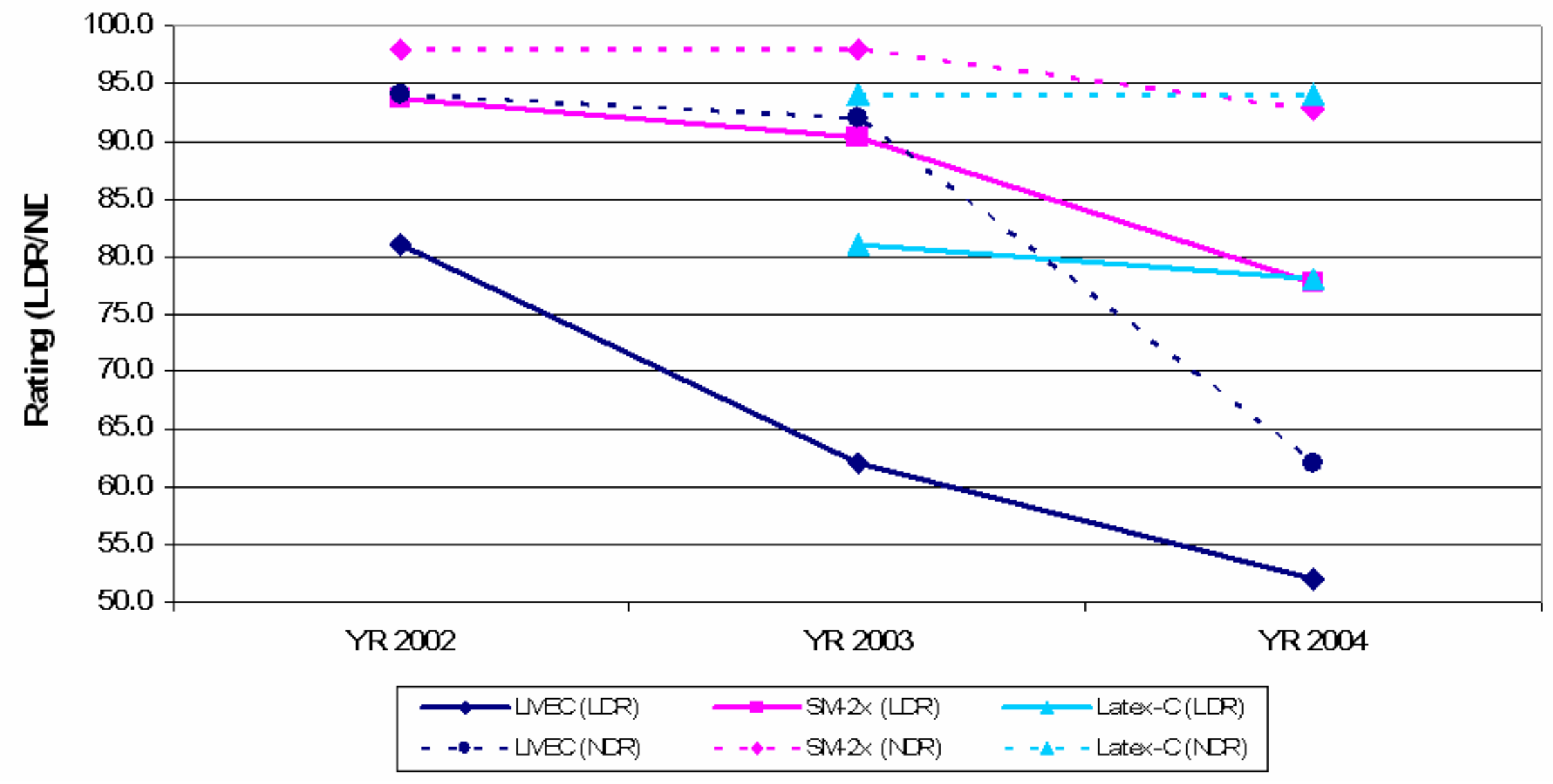

FIGURE 1 I-77 microsurfacing performance. 
section deteriorated significantly after 2002, and is the only section approaching a need for treatment. The Latex-C overlay is a latex-modified microsurfacing and it was placed in 2003. Its performance is being charted for comparison purposes only at this point. It is recommended that it be monitored in a similar manner as has been laid out here in order to determine its effectiveness.

\section{I-81/I-77 Microsurfacing and Novachip}

Performance information is illustrated for this pavement section in Figure 2. As in the previous discussion, sections to which PM sections were not applied are shown for comparison (SM-2). Again, these sections have continued to perform well both structurally and functionally. The Novachip section has also performed very well. The performance of this section is seen to be better from a functional condition than structural, but both remain in reasonably good condition. Once again, the microsurfacing section is seen to deteriorate structurally quickly after 2003 .

\section{I-95 Crack Seal with Spot Drainage Improvements}

As mentioned earlier, this section of pavement was identified as having two major defects; open longitudinal paving joints and moisture related damage to underlying asphalt pavement layers. Although moisture damage potential existed throughout the section, serious damage was isolated to specific locations. It was determined during the pavement evaluation that the damaged locations could be alleviated by the installation of subsurface drainage to remove excess water, and repaired with full depth patching. At the same time, early crack sealing was applied to the open longitudinal paving joints to prevent the intrusion of surface water. This approach was effective in deterring the further development of moisture damage.

Figure 3 presents the performance data for this section of pavement. As the figure shows, the installation of strategic drainage improvements together with crack sealing to prevent the intrusion of surface water has been very effective. Each of the treatment groups presented have worked well in maintaining the functional condition of the pavement. The crack seal sections have also been effective in preserving the structural condition of the pavement, at a reasonable level.

As a means of comparison, an adjacent section of pavement with original asphalt pavement surface of similar age is also shown in the figure. Both the structural (LDR) and functional (NDR) condition of this section is significantly lower than the treated section. (Note: Some variation in the reported condition data is evident. This is likely the result of the variability in the manual windshield survey process used to collect the data. Still, the trend is towards consistent performance.)

\section{Relative Treatment Costs}

The cost of crack sealing is lowest of the treatments evaluated. An average cost for this is $\$ 1.00 /$ lineal foot of material in place. Microsurfacing is next least expensive, having an average 


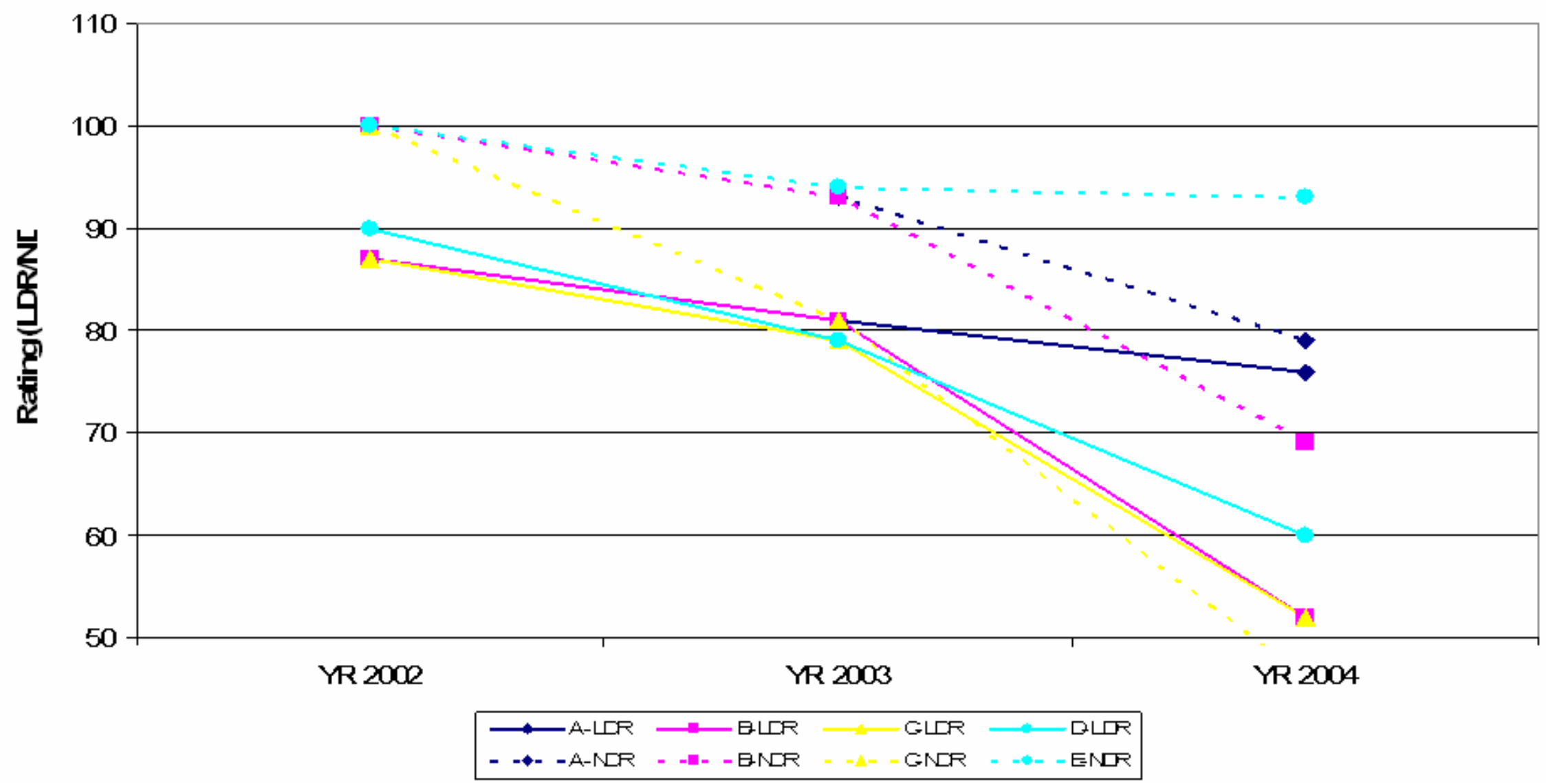

FIGURE 2 I-81/I-77 microsurfacing and Novachip performance. 


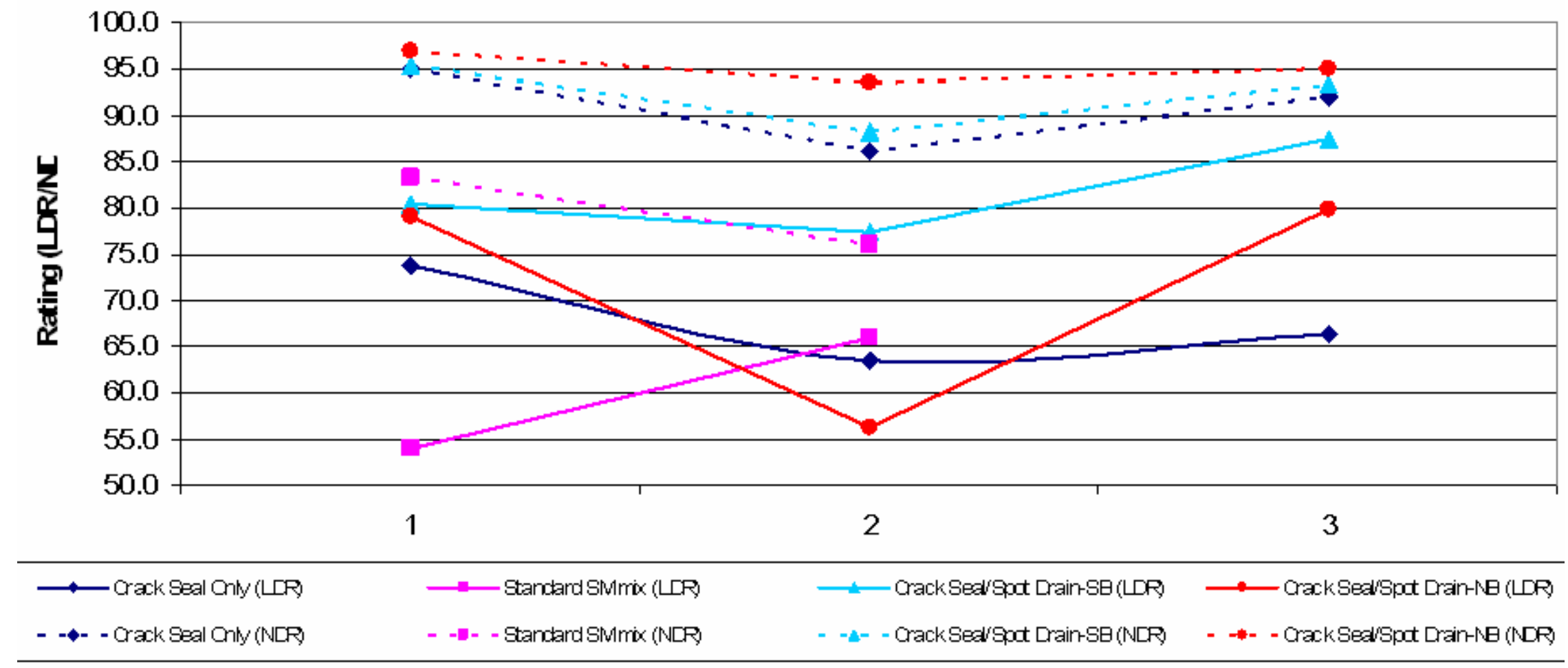

FIGURE 3 I-95 crack seal with spot drainage improvements performance. 
cost in the order of $\$ 2 / y^{2}$. The cost of asphalt pavement material has increase in recent years with the implementation of Superpave criteria and increases in crude oil prices. Generally, surface mix material is now in the range from $\$ 35$ to $\$ 40$ per ton. Novachip placed on this pavement cost approximately $\$ 5 / y^{2}$.

\section{CONCLUSIONS}

The assessment of these selected pavement sections indicates that PM treatments can indeed be successful in effectively extending the performance life of existing structural pavement sections, when applied sufficiently early to prevent or delay the progression of structural damage. However, it is also evident that the application of PM treatments alone cannot preserve the quality of pavements necessary to sustain pavement structural requirements over extended time periods, particularly when high traffic loading is present.

The crack seal sections with spot drainage installation have been very effective in preserving the condition of the pavement. When compared with a nearby pavement section of similar age, and only routine maintenance applications such as pothole repair, this pavement section shows significantly better performance.

The Novachip section has performed well. Both the structural and functional performance has been maintained at an acceptable level. The functional condition of the pavement remains very good. The microsurfacing sections have preserved the performance of the pavement for several years, but pavement condition has deteriorated since 2003. For the conditions found in Virginia, this treatment appears to have a limited effective life. The SHRP maintenance study previously mentioned found slurry seal applications to be most effective in no-freeze climates. While Virginia has limited freezing conditions, they do exist and can impact the performance of the pavement treatment.

\section{RECOMMENDATIONS}

Recommendations for the application of pavement PM treatments requires consideration of several factors.

1. The existing condition (stage of deterioration) of the pavement section.

2. Consideration of future pavement structural requirements, and appropriate evaluation of the $\mathrm{B} / \mathrm{C}$ of $\mathrm{PM}$ treatments in the context of pavement structural needs.

3. Incorporation of PM planning into an overall pavement preservation/rehabilitation plan.

When these issues are considered, appropriate application of cost effective PM treatments is a prudent course of action.

One additional item of interest which should be considered is the relative effectiveness of PM treatments in mitigating cracking which propagates from the top surface down, rather than from the bottom up. It seems reasonable to expect that these treatments can be more effective in preserving pavements with top down cracking than those with bottom up distress, since the top down cracking is not associated with structural failure of the entire pavement section. While it was not possible to consider this distinction in this evaluation, it may be worthwhile to consider it in future studies. 


\title{
Pavement Preservation Training in Texas
}

\author{
YETKIN YILDIRIM \\ University of Texas-Austin
}

Pavement preservation is an important, cost-effective means to maintain pavements. However, this technique is undervalued compared to other projects despite the economic advantages due to lack of knowledge amongst transportation professionals. The idea of pavement preservation is new to most agencies, requiring an understanding and appreciation of the overall purpose of pavement preservation as well as a change in the knowledge of the technical aspects of preventive maintenance. Agencies need to develop a program in order to be able to identify appropriate treatments and timing from among a number of different options. Research on the latest materials and methods should be gathered and disseminated throughout the maintenance community. There is some literature about pavement preservation at the national and local levels; in particular, the Center for Transportation Research at the University of Texas-Austin (UT) has been actively involved in communicating the idea and importance of pavement preservation to industry professionals, transportation agencies and students. This paper, using the current initiatives at UT as a model, describes available ways of disseminating information about preventive pavement maintenance. This paper isolates groups that should be targeted for training and identifies viable and available training options. Ultimately, efforts by UT provide a useful model for other agencies and educational institutions to follow to expand research on pavement preservation and provide training at all levels from students to maintenance professionals.

$\mathrm{D}$ ue to lack of knowledge among transportation professionals, pavement preservation is undervalued compared to other projects despite the economic advantages. The philosophy of pavement preservation is new to most agencies, requiring an understanding and appreciation of the overall purpose of pavement preservation as well as a change in the knowledge of the technical aspects of preventive maintenance (PM). Agencies need to develop a program in order to be able to identify appropriate treatments and timing from among a number of different options. Research on the latest materials and methods should be gathered and disseminated throughout the maintenance community.

University of Texas-Austin (UT) has been actively involved in communicating the idea and importance of pavement preservation to industry professionals and students. This paper, using the current initiatives at UT as a model, describes available ways of disseminating information about preventive pavement maintenance. This paper isolates groups that should be targeted for training and identifies viable and available training options. Ultimately, UT's efforts to expand research on pavement preservation and provide training at all levels from students to maintenance professionals provides a useful example for other maintenance agencies and educational institutions to follow.

\section{IMPORTANCE OF PREVENTIVE MAINTENANCE}

PM involves treatment of pavement to maintain or improve its quality before problems arise and can extend the life of structurally sound pavement 5 to 10 years (1). PM decreases the life-cycle costs of the pavement both by extending its life and by avoiding the need for major repair. It also improves overall pavement condition. An FHWA course on the subject lists the following as possible benefits 
of a PM program: higher customer satisfaction; better informed decisions; improved strategies and techniques; improved pavement condition; cost savings; and increased safety (2).

PM should be distinguished from routine maintenance, which involves tending to a problem after it has occurred. The two types of maintenance used together comprise pavement preservation. The idea of routine maintenance is what is usually conjured up by the term "maintenance" and it is essential that people within and outside the highway management industry become aware of PM being as or more important than routine maintenance. While the importance of PM is recognized by those who manage highway maintenance, due to the lack of immediate effects and the poor understanding of its benefits funding gets directed away from PM to more high-profile projects.

The importance of pavement PM is reflected in the industry. As of 1999 , about $20 \%$ of the AASHTO program was devoted to preventative maintenance $(1,2)$. Additionally, the Foundation for Pavement Preservation $\left(\mathrm{FP}^{2}\right)$ was established in 1992 as the Foundation for Pavement Rehabilitation and Maintenance Research. $\mathrm{FP}^{2}$ undertakes research projects to improve pavement preservation techniques and programs and is involved in education about PM (3).

Although the concept of PM has been around for some time, not all state departments of transportation (DOTs) have put it to use. In 1996, the Lead States Team, a group designed to take the findings of the SHRP effort to the state level, carried out a survey to determine the status of PM at that time. In that survey, $82 \%$ of the 43 responding agencies reported having extensive or moderate programs (4). In December 1999, another survey was conducted that included responses from 39 states and Puerto Rico. Thirty-four, or $85 \%$, of the 40 respondents have established PM programs and 2 more are in the process of developing them. All respondents indicated using a variety of pavement PM treatments. It should be noted that 11 U.S. states and the District of Columbia did not respond to the 1999 survey (4). While a lack of response cannot be taken to indicate a complete lack of PM, it is likely that if all the DOTs who were sent surveys had responded, the proportion of programs that included PM would have been lower than $85 \%$.

In the United States, alongside recognition of the importance of pavement preservation and the contribution of PM, there has been an increased appreciation for long-lasting pavements. An understanding of the value of PM has developed over time, in large part due to the efforts of individual state's DOT.

In terms of cost, some states have used pavement managing system software to model the effects of this type of maintenance. The New York State Department of Transportation determined that for a certain stretch of highway, a PM strategy involving crack sealing every 4 years, substituted by a thin asphalt concrete overlay at year 12 , would cost $\$ 144,036$ versus a cost of $\$ 382,590$ at year 24 without PM. "The comparison indicates that preventive maintenance strategy is about one-third the cost and 3.65 times more cost efficient than the second alternative" (5). In Michigan, Galehouse (6) claims that, per lane mile, rehabilitation and reconstruction projects cost about 14 times as much as PM projects. Michigan has saved over $\$ 700$ million since 1992 as a result of its PM program, compared to the cost of more major projects that would have been necessary if the pavement system had been allowed to deteriorate. Finally, in Wisconsin, it has been shown that PM in combination with reactive maintenance is more economical and avoids project backlogs (7).

PM programs also have safety benefits. A decreased number of ruts and potholes result in increased safety. Additionally, pavement surface texture can have a positive effect on surface friction, wet weather friction, surface water spray, and headlight glare. "With a heightened interest in improving roadway safety, many studies are showing the impact that preventive maintenance treatments can have" $(1,2)$. 


\section{NEED FOR TRAINING}

A 1997 SHRP Lead State Team for Preventive Maintenance survey of the 50 states, Washington, D.C., and Puerto Rico on their PM practices resulted in responses from 45 states (8). Many of the states suggested a two-tiered approach, in which information presented to the legislature and top management differs from the information presented to field personnel. Sixteen states said that top management was unreceptive to the concept of PM. Sixteen states also said they needed technical assistance with specific treatments. Eighteen states needed assistance to determine the size of the PM program needed. Clearly, there is a need for information.

\section{Training Courses}

There is literature available of pavement preservation/PM. $\mathrm{FP}^{2}$, in conjunction with the FHWA, has produced a variety of publications, ranging from brochures and newsletters to fully designed workshops available on CD-ROM. FP ${ }^{2}$ and the FHWA publications target, for the most part, state and local highway maintenance managers. Useful resources include the Pavement Preservation Toolbox which contains videos, CD-ROMs, reports, brochures, and other materials that provide a wealth of information on the state of the practice in pavement preservation (1); A Pocket Guide to Asphalt Pavement Preservation (1); and the Pavement Preservation Checklist Series, a collection of information on various pavement preservation techniques, designed to guide the reader from deciding whether a technique is appropriate for a stretch of pavement through maintenance to troubleshooting the process.

The FHWA, the National Highway Institute, AASHTO, and $\mathrm{FP}^{2}$ co-sponsored the development of a series of courses on PM which is available on compact disc. The courses introduces the components of a pavement PM program, defining treatment techniques and materials and explaining cost/benefit concepts of PM (2). Also, courses help maintenance engineers, planners, and field personnel select pavements for PM and design and construct treatments (10).

Furthermore, several states have developed their own maintenance manuals and short courses on related topics (such as Montana, Michigan, and California) (2). Texas offers a 24-h course on PM (MNT 210) aimed at coordinators, shop technicians, maintenance supervisors, maintenance assistant supervisors and maintenance lead workers.

Due to the increased interest in PM, new techniques are being developed, and it is important to get information about them out to the people who oversee highway maintenance. For engineers, pavement preservation includes more than just treatments; it involves deciding which pavements to tend to first, and requires an understanding of long-term costs and benefits. Once a PM program is in place, it is essential that treatments be applied correctly to get the full benefit of the program. To accomplish this, field personnel must be kept up-to-date on materials, methods and machinery. According to the Bureau of Labor Statistics, highway maintenance workers get most of their significant training on-the-job (11). While this is certainly practical in such a hands-on area, it is important to supplement on-the-job training with an understanding of recent advances in techniques and equipment. 


\section{University of Texas Center for Transportation Research}

The Center for Transportation Research (CTR) at UT has been actively involved in promoting pavement preservation programs and PM. It has organized seminars on the subject, and has also been involved in developing specifications for pavement preservation techniques for the Texas DOT (TxDOT). Additionally, the UT civil engineering department offers courses on pavement preservation at both the graduate and undergraduate levels.

CTR, in conjunction with industry organizations, has sponsored the 3-day pavement preservation seminar in Austin in 2003 and 2004. The next seminar is scheduled to take place in Austin in October 2005. The seminar is offered in conjunction with the 21st Associated General Contractors (AGC) Trade Show, and incorporates its opening luncheon into the scheduling. This trade show is an excellent venue in which to showcase PM; the 2003 AGC Trade Show boasted over 3,000 participants. Attendees earn one continuing education unit (CEU), which provides an incentive for attendance, since this is proof of skill building for participating engineers.

The seminar is a combination of theoretical and technical training about pavement preservation and related techniques. The last day of the seminar is devoted to demonstrating the various techniques for maximum impact. The techniques in question include scrub seals, fog seals, hot-mix overlays, microsurfacing, slurry seals, and chip seals, all of which will have already been introduced during the theoretical portion of the seminar. Presentations at the seminar have included "Crack Sealing Techniques and Latest Research," "Hot-In-Place Recycling," "Chip Seal/Best Practices," and "Equipment and Materials Innovation." Presenters included experts such as Dan Dipprey of Zack Burkett Co.; Steve Douglas of Ergon Asphalt/Western Emulsions, Inc.; Gary Fitts of Asphalt Institute; Doug Gransberg of the University of Oklahoma; Mark Ishee of Ergon Asphalt \& Emulsions; Kevin King of TXI; Tim Martin of Fugro-BRE; Bill O'Leary of Prime Materials and Supply Co.; John Rathbun of Cutler Repaving; and Jim Sorenson of the Office of Asset Management for FHWA.

In association with the UT Center for Lifelong Engineering Education, CTR offers an online seminar on pavement preservation, composed of the proceedings of the 2003 seminar. Students earn 1.2 CEUs and receive a certificate of completion from UT. The course includes a syllabus, videos, reading assignments, and an online quiz, and is followed by an evaluation form. The online course management tool Blackboard, widely used at UT, allows students and the instructor to perform virtually all work within that single application, including e-mail correspondence, file posting, online test taking, reading assignments, and video/Powerpoint viewing. Students are expected to complete all parts of the course within 2 weeks. This course is designed as a "means for promoting awareness of pavement preservation as a feasible and practical maintenance strategy while providing training in preservation methods" (12).

As mentioned earlier, undergraduate and graduate courses are offered on pavement preservation at UT. Graduate students are expected to submit a research paper on the topic to enrich their understanding of pavement preservation programming. One of the course requirements at both the undergraduate and graduate levels is a permanently bound notebook submitted at the end of the semester containing the student's notes from the course, which can function as a reference document. The course covers different pavement preservation techniques from recycling asphalt to crack and joint sealing. The distresses that occur in both rigid and flexible pavements are discussed, and selection criteria for different treatments are presented.

CTR with the Texas Transportation Institute have taken steps to create the Texas Pavement Preservation Center (TPPC) with TxDOT, intended to provide training locally, 
evaluate techniques and procedures, provide research management and generally support pavement preservation programs. Training options proposed for the TPPC are CEUs in cooperation with UT, development of UT civil engineering courses, online 15 to 20 min training modules, and regional hands-on training for engineers and technicians. The TPPC "could also be available for forensic analysis and trouble shooting, certification programs, and technology transfer" (13). Training materials such as technical briefs and manuals will also be developed. The center will have flexible duties, depending on the needs of DOTs and the industry. One proposed project is the development of a decision matrix to facilitate selection of appropriate preservation strategies. Organizations proposed to support the TPPC activities include CTR, the FHWA, the Asphalt Institute, $\mathrm{FP}^{2}$, the International Center for Aggregate Research, AGC, and the Texas Concrete Pavement Association (13).

In addition, CTR is currently producing a series of training videos for highway maintenance workers, detailing the application process for various PM techniques. For instance, a video on crack filling and sealing has already been completed for the TxDOT. It includes descriptions of the importance of crack treatments, the steps involved, and possible problems and how to avoid them. The desirable results of a crack treatment procedure are illustrated both theoretically, with clear diagrams, and in application, with images of crack sealed stretches of pavement.

\section{CONCLUSION}

The benefits of a pavement preservation program are manifold, but the one that is most often emphasized is its financial prudence. There is ample information on pavement maintenance, much of it made available by the FHWA and $\mathrm{FP}^{2}$. The CTR has been successful in communicating the idea and importance of pavement preservation and PM to industry professionals and students training to be engineers. They have also produced materials aimed at construction workers to provide them with training on PM techniques. What is lacking, though, is an understanding of PM among lay people, whose support is necessary for PM to become the norm in roadway management. It is suggested that more be done to inform the public and policy making officials by creating materials on the subject that target a non-expert audience and making them available to the public through public service announcements. After all, helping save taxpayers money through maximizing efficiency is a public service.

The ideas of pavement preservation and PM are being communicated to people within the construction industry, but more needs to be done. Those outside construction do not have any awareness of these concepts, even though both taxpayers' and policy makers' knowledge of the ideas could lead to an increase in their application and the resultant increased efficiency in the expenditure of transportation funding. Pavement preservation and PM can be publicized to the industry and the public through mainstream journalism and advertising, neighborhood meetings, presentations, training videos, conferences and seminars, and university and DOT courses.

\section{REFERENCES}

1. Construction and Maintenance Fact Sheets Pavement Preservation: Toolbox Resources. FHWA. U.S. Department of Transportation, 2001. Available at www.fhwa.dot.gov/ construction/fs02010.htm. 
2. Peshkin, D. G., K. D. Smith, K. A. Zimmerman, and D. N. Geoffroy. Pavement Preservation: The Preventive Maintenance Concept: Executive Overview. Course No. 13154. FHWA, U.S. Department of Transportation, 1999.

3. Foundation for Pavement Preservation. Website. Available at www.fp2.org.

4. AASHTO Innovative Highway Technologies. Pavement Preservation: Transition Plan. Draft. Washington, D.C.: AASHTO. 2000. Available at leadstates.transportation.org/pp/transition/

5. Peshkin, D. G., K. D. Smith, K. A. Zimmerman, and D. N. Geoffroy. Pavement Preservation: The Preventive Maintenance Concept: Module 4: Cost Analyses. Course No. 13154. FHWA, U.S. Department of Transportation, 1999.

6. Galehouse, L. Innovative Concepts for Preventive Maintenance. In Transportation Research Record 1627, TRB, National Research Council, Washington, D.C., 1998, pp. 1-6.

7. Geoffroy, D. N. NCHRP Synthesis of Highway Practice 223: Cost-Effective Preventive Pavement Maintenance. TRB, National Research Council, Washington, D.C., 1996.

8. Lead State Members on Pavement Preservation. Survey of States' Preventive Maintenance Needs. Texas Department of Transportation, 1997.

9. Foundation for Pavement Preservation. A Pocket Guide to Asphalt Pavement Preservation. FHWA, U.S. Department of Transportation.

10. National Highway Institute. Course catalog. 2004. Available at www.nhi.fhwa.dot.gov/ coursec.asp.

11. Bureau of Labor Statistics._Construction and extraction occupations. Available at stats.bls.gov/oco/oco20057.htm

12. Center for Lifelong Engineering Education. Pavement Preservation Seminar (online), 2004. Available at lifelong.engr.utexas.edu/shortcourse.cfm?course num $=814$ and lifelong.engr.utexas.edu/pdf/pavements/flyer_jan12_2004.pdf.

13. Fults, K., and Y. Yildirim. Proposal for the Texas Pavement Preservation Center. Center for Transportation Research, University of Texas-Austin. 2003. 


\title{
Sustaining Toll-Road Operation Through Performance-Based Management
}

\author{
GEORGE TANNER \\ New York State Thruway Authority \\ YUNG-CHING SHEN \\ Siena College
}

Built in the mid-1950s, the New York State Thruway is one of the longest toll superhighways in the nation. To preserve the infrastructure condition at an acceptable level for safe operation, the Thruway pavements in particular require regular maintenance and repair. Performance-based management in this context aims at monitoring and improving the pavement's life-cycle performance with timely, strategic preventive maintenance (PM) and minor repair. Preservation of the Thruway system is achieved by compiling relevant input information and interpreting the output results from life-cycle inventory analysis and impact assessment. The management approach combining facility performance with life-cycle analysis has been particularly effective and beneficial in identifying and prioritizing maintenance actions necessary for Thruway operation as an Interstate toll road. Preserving this primary roadway using the life-cycle approach brings the subject of performance and PM to the forefront of sustainable practices.

$\mathrm{O}$ peration of a toll road depends upon having the facility in a condition such that it is available for safe and serviceable use by travelers. This makes it possible for tolls to be charged and collected for the roadway's use. Performance-based management of the roadway infrastructure using a life-cycle approach provides the means for achieving a safe, serviceable, and sustainable roadway.

The Governor Thomas E. Dewey Thruway (1), the 641-mi superhighway crossing New York State, is the longest toll superhighway system in the United States. The Thruway's mainline connects New York City and Buffalo, the state's two largest cities. Other Thruway sections make direct connections with Connecticut, the Massachusetts Turnpike, New Jersey's Garden State Parkway, and other major Interstate facilities that lead to New England, Canada, the Midwest, and the South. A majority of New York State's 62 cities, which encompass more than $80 \%$ of the state population, are located within $30 \mathrm{mi}$ of the Thruway corridor. Like its predecessors the Erie Canal and the Railroads, the Thruway has had a tremendous impact on the Empire State's economy. Following World War II, industries and commercial enterprises were quick to take advantage of the safe, swift, and sure travel afforded by the Thruway. Nearly every community along the Thruway route experienced economic benefit in both business and a growth in real estate values.

The New York State Thruway Authority (NYSTA), an independent public authority created in 1950 by the New York State Legislature, operates the cross-state superhighway. NYSTA was established to build, operate, and maintain the system. It was structured as a selfliquidating project, to be financed through bonds which would be retired from proceeds of tolls and other income. Today bond proceeds and toll revenues finance the maintenance and ongoing capital 
work needed to sustain the Thruway operations. NYSTA, like most toll road authorities, receives no appropriations of tax money from the legislature to meet the cost of its operations. NYSTA issues bonds for financing long-term capital projects for both new and replacement facilities. NYSTA also pays all operating and maintenance expenses for toll and toll-free sections of the system. Specially trained crews maintain the Thruway throughout the year. The workforce is divided geographically into four divisions (New York, Albany, Syracuse, and Buffalo). These divisions are further subdivided into sections, each of which maintains about $30 \mathrm{mi}$ of roadway.

The design of Interstate highway infrastructure constructed decades ago was consistent with the vehicle characteristics of the time. Generally the designs did not contemplate modern traffic demands in terms of volumes, mix of traffic vehicles both in size, weight, the number of axles, and their loadings (2). The planning and design of these primary roads did not fully contemplate the demands of economic growth, environmental concerns, and global issues present today. Despite local instances of some early pavement and bridge component failures, the roadway due to maintenance practices has been able to endure much a longer service life and load than considered in the initial design. The roadway pavement, for example, requires regular maintenance and repair to preserve the infrastructure condition at an acceptable level for safe operation (3).

Recent advances in information technology (IT) over the past decade have led to an increasing application of remote sensors, distributed computing, and network communication within the NYSTA. In August 1993, the NYSTA became the first agency to implement the EZPass electronic toll collection system. The deployment of traffic data system monitors, augmented by the presence of dedicated state police personnel and a centralized communications center help provide minute-to-minute information of the roadway's performance and the condition of traffic. Additional sensors in the pavement detect pavement surface temperatures and local weather conditions. The development of Infrastructure Inspection and Inventory Systems (IIIS) and various IT facilities provides for Thruway engineers and managers an integrated information system to support interdisciplinary approaches of a collaborative working environment and to identify sustainable practices for monitoring and extending the service life of the Thruway infrastructure.

Managing pavement infrastructure using a life-cycle analysis approach brings the subject of performance and PM to the forefront of sustainable practices for preserving pavements. Life-cycle analysis assists in identifying those strategies, which can both preserving the investment in the roadway infrastructure to extend its service life and meeting traffic's growing demands. Life-cycle analyses are a major activity undertaken by the Department of Maintenance Engineering to ensure that maintenance and capital efforts result in serviceable roadways through use of carefully selected surface treatments, including corrective maintenance and PM, as well as minor and major pavement rehabilitation. Adoption of this approach (along with other prudent cost control monitoring) enabled the NYSTA to maintain operations, introduce new services, and delay a need for a toll increase for 17 years.

\section{TECHNICAL APPROACH}

The performance-based management of infrastructure places emphasis on executing timely critical PM and minor repairs selected based on life-cycle analyses to achieve a long-term performance goal of maintaining a rideable, safe pavement surface. A life-cycle assessment process based on system performance most appropriate for preserving existing pavement infrastructure, is incorporated to fully evaluate the impact on roadway performance associated with physical condition, functional capacity, and operating cost. The prime objectives are to provide as complete 
a picture as possible of the interactions of various environmental loads and human activity interactions with life-cycle performance and to provide decision makers with information which identifies opportunities and strategies for determining the "best" long-term performance improvement and treatment (5). The Thruway's IIIS is integrated with assessment parameters to record and monitor pavement performance change over time. Assessment parameters for life-cycle performance consist of geographic location, traffic pattern, structural material, construction details, inspection, and maintenance and rehabilitation work histories, all of which impact facility service life.

Figure 1 illustrates the framework of performance-based management approach for infrastructure preservation. Life-cycle performance assessment starts with the definition of a goal (or goal set). The goals state the rationale for establishing a project, setting boundaries for its study and framing the parameters of the proposed scope of work and the key assessment parameters for reviewing and assessing the project. Inventory analysis involves data collection with the various calculations and procedures to quantify relevant inputs and outputs necessary for effective project development and management. Impact assessment examines and evaluates the performance impact on pavement infrastructure associated with alternative current and projected physical conditions, functional capacity, and treatment costs. Performance assessment parameters consist of geographical location, traffic characteristics, treatment/material(s), construction details, inspection and condition reports, and maintenance and rehabilitation historic performance/issues, which have potential impacts on the infrastructure's service life.

While these elements are essential to conducting performance-based management, they do not fully accommodate a wide range of issues compounding the considerations that must be made when operating a large traffic volume of Interstate facility. For example, original design details, based on the highest standards of their time are 50 years old. They generally are not friendly to sustained operation concepts. Most highway elements were designed with a finite service life in mind, and assumed disposal of pavement at the end of the useful life, while recycling had not been integrated in the management practice. This approach to pavement longevity needs modification to become truly "sustained." Also life-cycle analysis is an idealized view of expected performance, it is a useful tool but it is not "reality." Reality is limited resources, competing priorities and interests, some of which may not lend themselves to a straightforward simple economic analysis (i.e., environmental and energy conservation concerns, public expectations, etc.) Performance based management also requires exercise of human judgment, and a flexibility to permit consideration and accommodation of unexpected events.

\section{PAVEMENT INFRASTRUCTURE}

Thruway pavements were originally constructed in the period 1949 to 1960 in accordance with New York State Department of Public Works Specifications. Typically they were 9-in. thick, wire mesh-reinforced portland cement concrete (PCC). Normal slab length was $100 \mathrm{ft}$ with expansiontype load transfer devices. The pavement top was placed on a 12-in. thick granular box section subbase course. Original shoulders were chloride treated granular material or sod.

A cross section of the Thruway pavement would show a compacted sub-base of compacted "suitable material," a 9- to 36-in. compacted course of gravel, a 9-in. thick concrete (PCC) pavement slab, and $1 \frac{1}{2}$ to 3 in. or more of asphalt overlays. The exception would be patched sections where full depth asphalt relief joints are placed. For the past 20 to 25 years the pavement 


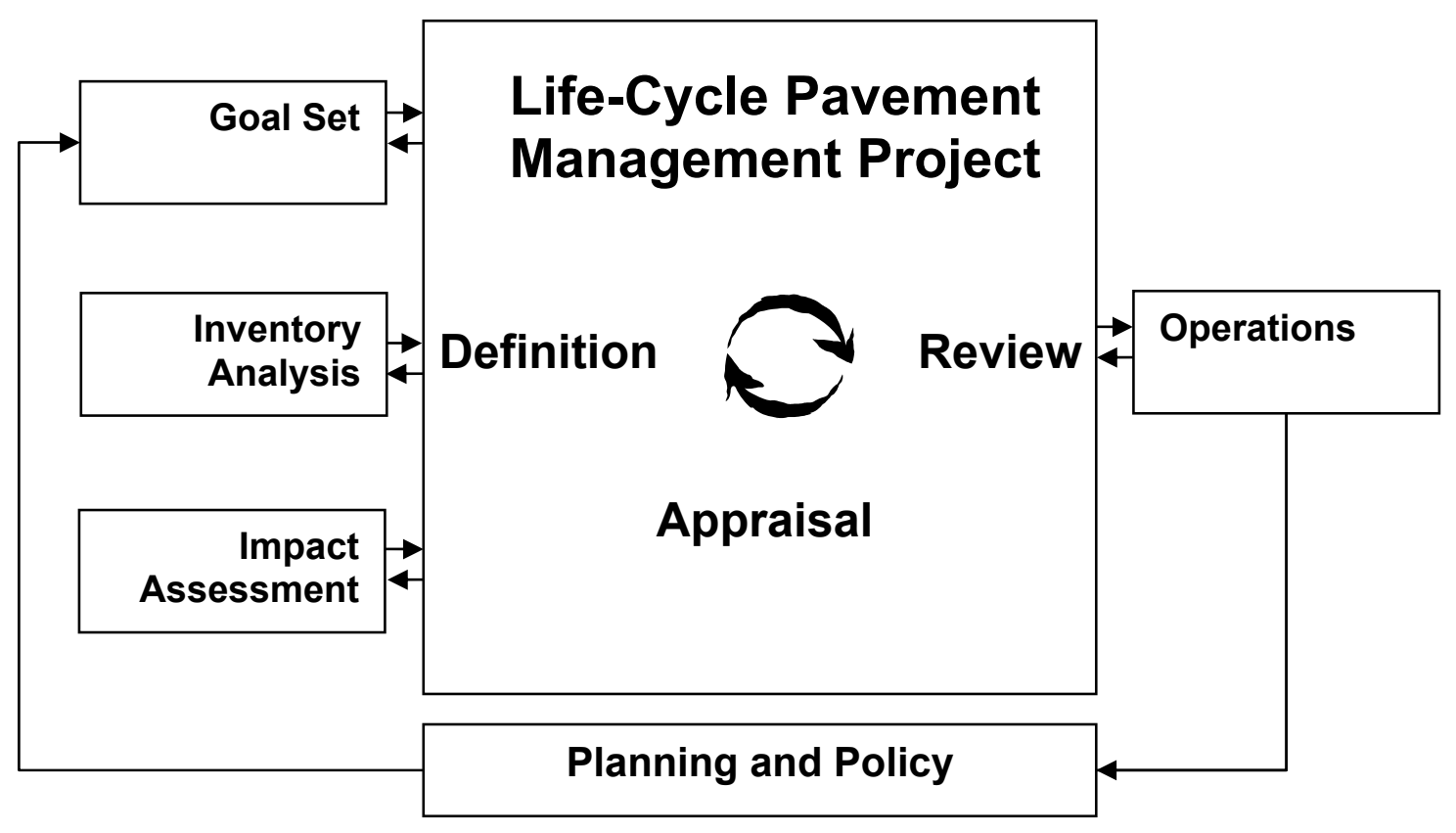

FIGURE 1 Performance-based management process.

has had its overlays repeatedly "milled and filled." Several short segments of pavement have been reconstructed as full depth asphalt concrete or PCC meeting newer standards for slab length and/or joint treatment. While this provided a fresh paved riding surface, the underlying original concrete pavement and sub-base were found to have been steadily deteriorating. Much of this deterioration has been caused by the heavier vehicle loads now permitted, vehicle speeds, and even the repeated cycles of milling and filling using mechanical devices.

The preservation program for Thruway pavements encompasses a wide range of preventive maintenance techniques and strategies, such as micro-surfacing, thin-lift overlays, white-topped overlays, crack sealing, PCC joint sealing, dowel-bar retrofit, full- and partialdepth concrete pavement repair, and milling and grinding. Each of these techniques has service life performance expectations under particular operational and environmental conditions. Each has their respective costs as well as, impact on the traveling public, and impact on the agency, its resources, and its actions. Figure 2 illustrates what takes place over time over a fixed segment of pavement. A variety of treatments occur over time, each of these treatments addresses a problem, has attendant costs and imparts an effect on the remaining operational life of a facility (6). Depending upon how the original pavement was designed the effect could be dramatic for pavements with a "short" life expectancy, to long with pavements that have been conservatively designed and constructed. The inventory database fortunately captures this historic record and provides useful information crucial to performance-based decision making. 


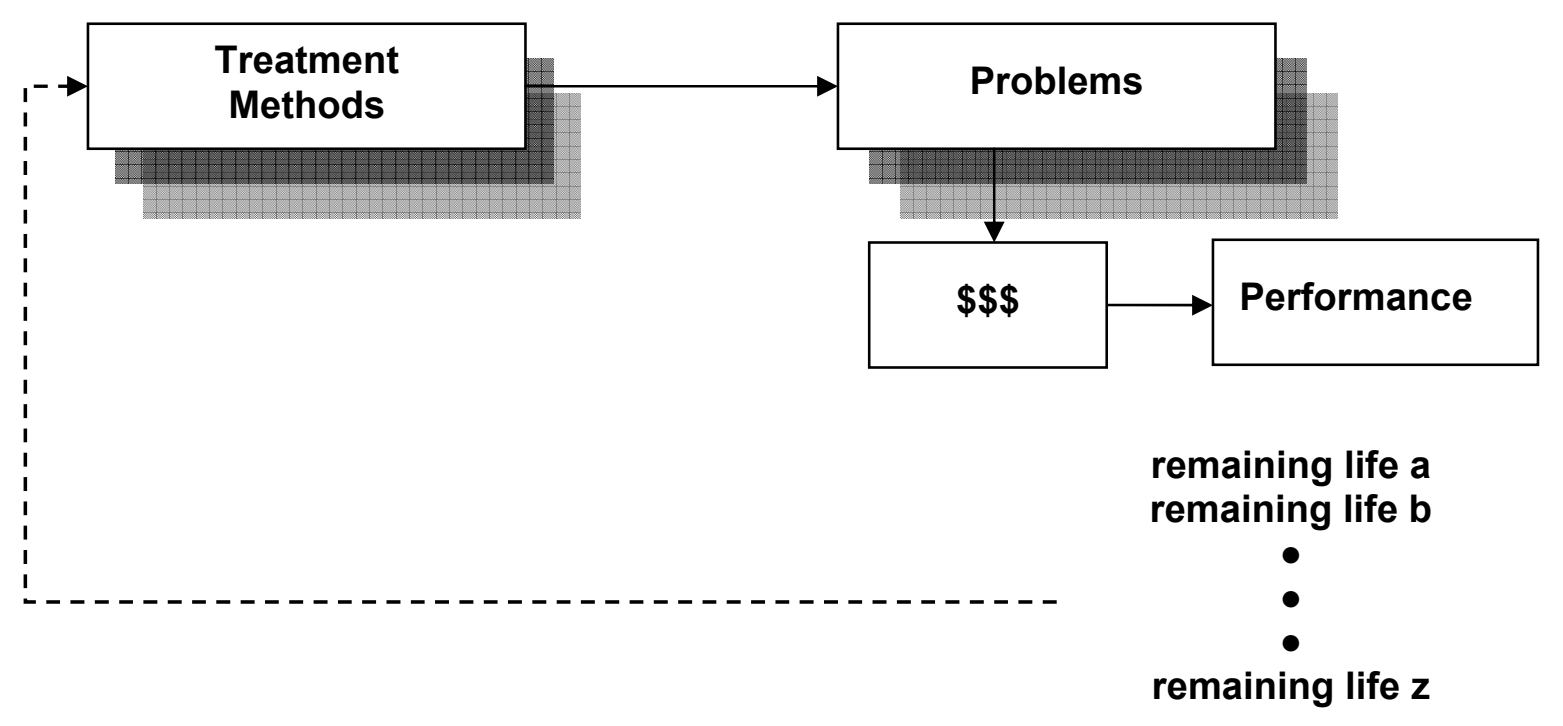

FIGURE 2 Pavement project details.

\section{LIFE-CYCLE ASSESSMENT}

The life-cycle consideration of infrastructure preservation recognized the important role of maintenance, minor and major rehabilitation to achieve pavement performance goals. Assessments built upon life-cycle performance are depicted in Figure 1, the three basic components of performance management process, namely initiation (goal set); where is the project/work location, what are its key descriptors and boundaries, inventory; what pertinent data needs to be extracted from the data base, assessment; both parameters and criteria key to the issues for the defined project location. The $641 \mathrm{mi}$ of Thruway provides a useful laboratory to examine pavement action/reaction over time. Through a collaborative effort, the life-cycle study of the pavement was initiated with a selection of specific pavement segments on the Thruway mainline. An information-based decision support system $(7,8)$ was created to capture information through interviews, field trips and examination of available records maintained by the NYSTA. The assessment parameters and criteria for performance impacts unique for a project are described and included in processing impact assessments, which evaluate the information obtained from the inventory analysis.

Table 1 presents a performance matrix, which outlines the relationship of specific impact categories to the areas of infrastructure performance. For example, traffic volume increases over the years will affect the physical condition as well as the functional capacity, while deicing in the winter season and other environmental loads will impact on the physical condition and cost. Impacts are classified into physical condition, functional capacity, and cost. Characterization is a process to aggregate the performance impacts within each category based on scientific information about pavement deterioration process. Infrastructure condition and economic factors generally affect the decision on the scope of major work to extend service life. The outcome of the characterization step will be referred to as impact 
profiles, consisting of a number of impact measures. Classification is the step in which the assessment parameters are grouped together into a number of impact categories. This grouping will result in such a way that one entry from the performance matrix may well be included in more than one category.

The life-cycle assessment of infrastructure performance offers a way to predict future performance, maintenance requirements, and life-cycle cost. The analytical results provide decision-makers with information that identifies opportunities for long-term performance improvement and allows answering many agency questions, such as: Where are the worst pavement segments? When is the best time to repair, reseal, or resurface a pavement? What are the factors that influence the performance of pavements and the need for maintenance?

\section{PERFORMANCE MANAGEMENT}

Life-cycle analysis of performance management is a proactive approach to pavement preservation. Relatively low-cost preservation strategies are applied at a more frequent interval, which results in an extended serviceable roadway. A typical performance management framework is presented in Figure 3 that indicates serviceability of pavement infrastructure over the years. In contrast, the traditional approach allows the original pavement to deteriorate to fair or even poor condition, at which point structural damage has often occurred and diminished the effective service level.

\section{Life-Cycle Performance}

Structural performance and life of pavements are dependent on factors, which generally are not explicitly determined at the planning and design stages. Highway infrastructure generally has a "long" life. These structures were expected to remain functional for as long as required, and for as long as it was economically justified to carry out maintenance or repair works. There is not an elaborate set of tool for a precise forecast of pavement failure as a result of roadway use; however, rates of deterioration are monitored and future expected condition states can be grossly "predicted" within a range of accuracy. Assessment parameters for structural performance generally consist of geographical location, traffic pattern, material, construction details, inspection, and maintenance and rehabilitation, which have potential impacts on the service life. Practical issues related to financing,

TABLE 1 Pavement Infrastructure Performance Associated with Impact Categories

\begin{tabular}{|l|c|c|c|}
\hline \multirow{2}{*}{\multicolumn{1}{c|}{ Impact }} & \multicolumn{3}{c|}{ Infrastructure Performance } \\
\cline { 2 - 4 } \multicolumn{1}{c|}{ Category } & Physical & Functional & Cost \\
\hline Traffic volume & $\sqrt{ }$ & $\sqrt{ }$ & $\sqrt{ }$ \\
\hline Environmental load & $\sqrt{ }$ & & $\sqrt{ }$ \\
\hline Deicing (corrosion) & $\sqrt{ }$ & $\sqrt{ }$ & $\sqrt{ }$ \\
\hline Structural materials & $\sqrt{ }$ & $\sqrt{ }$ & \\
\hline Mobility & & & \\
\hline
\end{tabular}


LIFE CYCLE

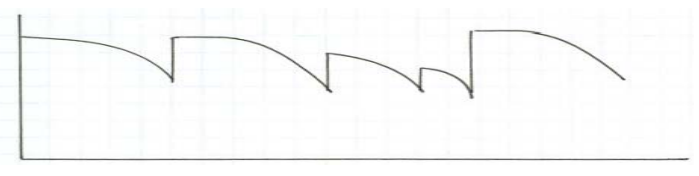

\section{$\rightarrow \$ \$ \$ \$$ \\ Manage Performance $\rightarrow$ Selected Treatment Service Life \\ \ Resulting Performance Factors' Service Level}

\section{FIGURE 3 Performance management framework.}

various events and circumstances have a far greater influence on the exact scheduling of projects, than the information obtained from hard data and forecasts based only on physical condition.

In addition to physical aspect of performance, the infrastructure system performance in this context is considered the degree to which infrastructure provides the services to the motoring community $(4,9)$. The community may choose to measure performance in terms of specific indicators reflecting the functional aspect of performance. This task will identify measuring parameters from social, environmental and technical (physical) aspects of infrastructure performance. To meet the challenges of growing demands for infrastructure facilities, the management process carries through its lifetime from the design of a rehabilitation to renew or reuse the facilities. On one hand, the analyses of infrastructure development process ensures establishing the performance requirements; and, on the other hand, social and environmental objective of performance assessment will reduce environmental impacts, congestion and health risks caused by construction and maintenance of civil infrastructure systems.

For a successful pavement preservation program, a long-term commitment and financial support from management is required. Pavement preservation is more than just a collective set of specific pavement maintenance techniques. It is a way of thinking and the guiding force behind an agency's financial planning. A preservative or proactive approach entails the application of a series of low-cost, PM treatments that individually may last for only a few years. The key is to apply the treatment when the pavement is still in relatively good condition with no structural damage. Once structural damage occurs, a preventive maintenance treatment is no longer a viable option. Timely preventive maintenance treatments will significantly reduce traffic delays. Figure 4 illustrates the cost saving over increasing serviceability of pavement performance when preventive treatments are applied in meeting the demands of life-cycle performance.

Time is the element by which cost-effectiveness is defined. Placing a treatment on the road too late, meaning structural damage has already started to appear, will result in poor performance because pavement preservation treatments are not designed to increase structural capacity. On the other hand, placing the treatment too early will result in the unnecessary expenditure of much-needed funds, and too late can cause other pavement problems, such as faulting, severe cracking or rutting. Neither scenario is cost-effective. The optimal time will maximize the return on investment of a given treatment by allowing for the most efficient use of funding to extend the life of the pavement. To determine the optimal timing, performance 


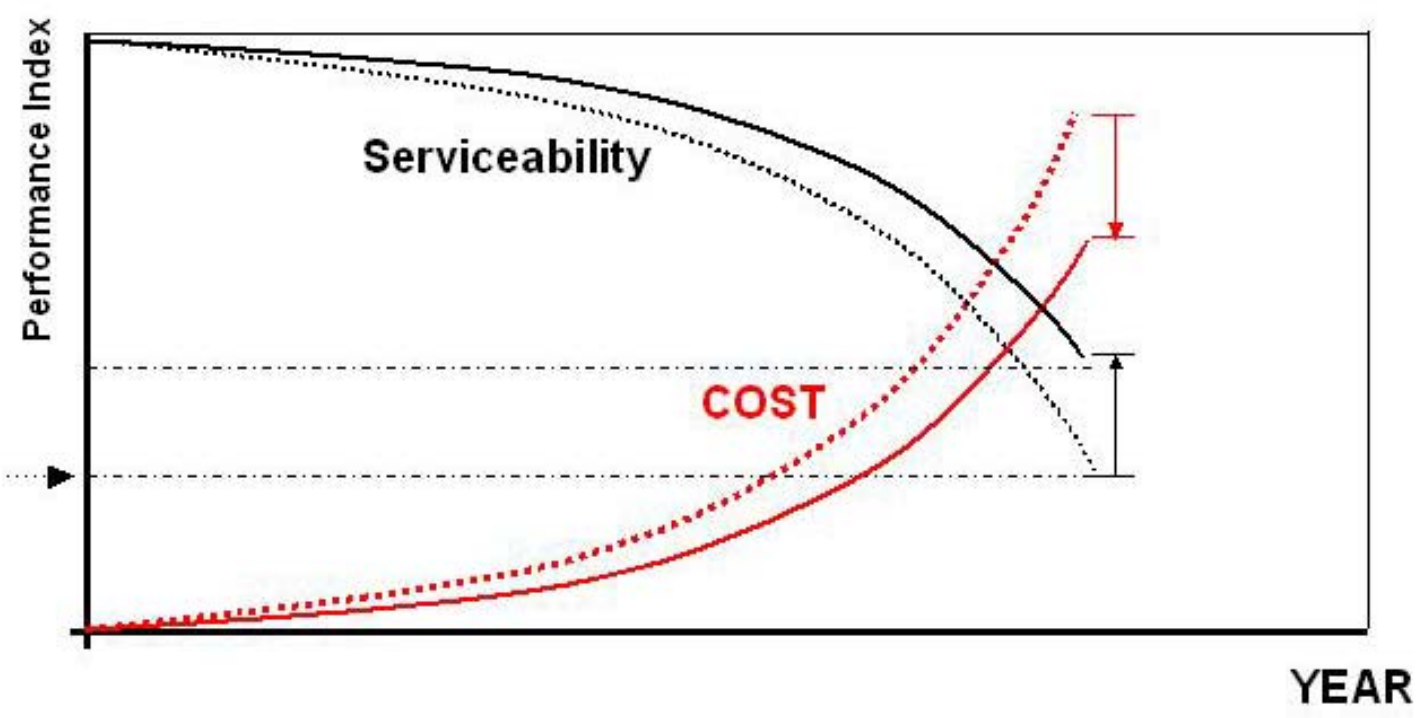

FIGURE 4 Cost-benefit of performance management.

standards and indices (10) for various treatment types need to be established through research and the collection of performance data. To be reliable, these indices must be descriptive of the environment in which the pavement treatments are to be used. This not only includes existing pavement conditions, climatic weather, material properties, and traffic loading, but also agency resources and funding limitations.

The NYSTA's experience has shown that a dedicated fund source with money set aside for pavement preservation activities is highly beneficial.

\section{Work Planning}

A 1995 National Quality Initiative survey found that pavement condition was the number one concern of highway users, and the seemingly ever-present work zones were a close second. This dissatisfaction sometimes can translate into a general perception that highway agencies are not doing a very good job of maintaining the public's roadways. The levels and volumes of traffic on highways today far exceed design expectancy, but timely applied PM strategies can satisfy the general public.

Traffic sensors and toll data provide very real and timely information on what is taking place on the road. This information is used to closely monitor what is taking place along the 641mi system. Also because of the regularity of traffic it is also possible to use this information to identify locations and times when the maintenance and construction crews can safely occupy the pavement with minimum disruption to travelers.

Figure 5 provides a schematic illustration of the resulting work program of projects to be implemented over time to sustain pavement performance. The figure shows how various types of work are scheduled over time over a length of the highway as well as identifying the performance expected in terms of pavement condition levels the mix of work provides. Similar presentations can be made other infrastructure elements such as bridges. The schematic shows that the entire length will receive some form of treatment over the time frame portrayed, in fact some areas might 
receive multiple treatments, based upon what treatment is cost effective, what resources are available, what method its "best" with providing the best lasting, best performing, affordable service within the program's time frame. From a traveler's point of view frequent low-cost treatments if performed and scheduled to minimize traffic disruption can be more favorably received than a colossal project that solves all pavement ills but takes years to complete, because disruption is minimized with the former treatment. By being real time the traffic count stations also provide a view of congestion build up, as well as traffic response to weather conditions, or the snow fighting program's effectiveness, or incidents and breakdowns.

\section{SUMMARY AND CONCLUSIONS}

NYSTA, like most toll-road authorities, receives no appropriations of tax money from the legislature to meet the cost of any of its operations. NYSTA issues bonds for construction. NYSTA also pays all operating and maintenance expenses for both the toll and toll-free sections, including the full cost of the state police patrols. More than 1,400 maintenance personnel use 3,000 different pieces of equipment to take care of the 641-mi Thruway system, including 807 bridges.

Performance-based management incorporates the concept of life-cycle assessment to identify the performance requirements of preserving existing pavement infrastructure. Delaying PM and minor repair until the pavement has gone beyond its effective service life, the work required to renew it will be more extensive and costly than regular maintenance. Any repair or construction work can make a portion of the highway unusable, and the flow of traffic will be disrupted sometimes for an extended period of time.

\section{DIVISION HIGHWAY PROJECT SCHEDULE}

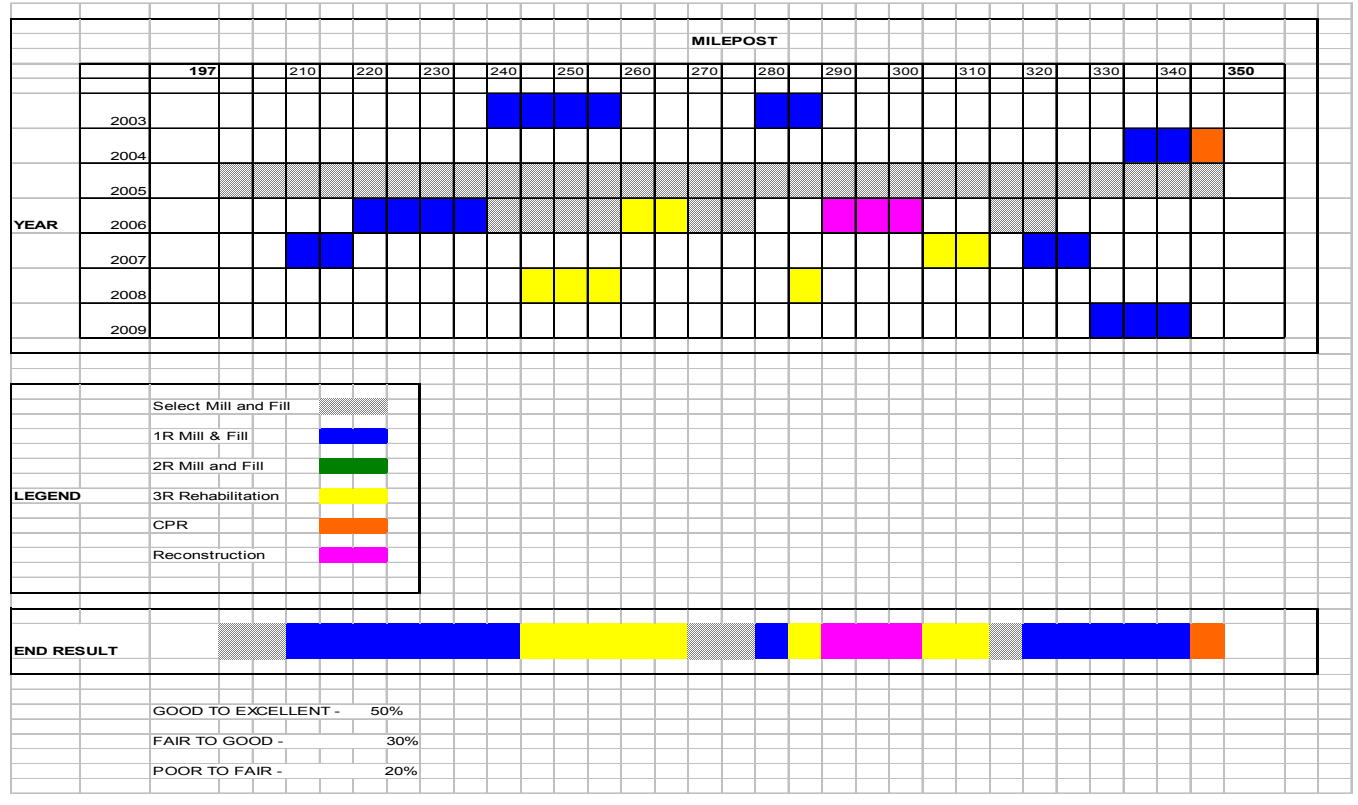

FIGURE 5 Highway project work schedule. 
However, taking a proactive approach in maintaining our existing highway infrastructure can reduce costly, time-consuming rehabilitation and reconstruction and the associated traffic disruptions. Timely preservation treatments can provide the traveling public with improved mobility; reduced congestion; and create safer, smoother, sustainable longer lasting pavements. This is the true goal of pavement preservation - a goal that the FHWA, working in partnership with states, industry organizations, and other interested stakeholders, is committed to achieving.

\section{REFERENCES}

1. NYS Thruway Fact Book. New York State Thruway Authority, Albany, N.Y., 2004. www.thruway.state.ny.us/factbook/index.html.

2. Hoffbeck, S. R. The Pavement Problem: When Road Builders Tried Everything From Iron To Molasses. American Heritage of Invention and Technology, Vol. 7, No. 2, Fall 1991.

3. Pavement Preservation: A Road Map for the Future. Performance Measures to Improve Transportation Systems and Agency Operations. TRB, National Research Council, Washington, D.C., 2001.

4. Performance Measures to Improve Transportation Systems and Agency Operations. Transportation Research Board, National Research Council, Washington, DC. 2001.

5. Shen, Y. C., and L. K. Spainhour. IT: A Potential Solution for Managing the Infrastructure Life Cycle. Journal of Computing in Civil Engineering, ASCE, Vol. 15, No. 1, 2001, pp. 1-2.

6. Galehouse, L. Strategic Planning for Pavement Preventive Maintenance. Pavement Preservation Compendium, FHWA, U. S. Department of Transportation, 2003, pp. 3-8.

7. Shen, Y. C., and D. A. Grivas. Decision-Support System for Infrastructure Preservation. Journal of Computing in Civil Engineering, Vol. 10, No. 1, 1996, pp. 40-50.

8. Shen, Y. C., L. J. Feeser, and G. Tanner. A Decision Support System for Life-Cycle Management of Thruway Bridges. Proc., $8^{\text {th }}$ International Conference on Computing for Civil and Building Engineering, Stanford University, 2000, pp. 1379-1386.

9. Shen, Y. C. Data Warehousing Approach to Assessing Infrastructure Performance. Research Project, Siena Scholars Program, Siena College, Loudonville, N.Y., 2003.

10. Performance-Related Specifications: Next Step in Pavement Quality. In Improved Construction and Maintenance Technologies, FHWA, U.S. Department of Transportation, Oct. 2001. 


\title{
Performance Evaluation of Novachip Surface Treatment in Louisiana
}

\author{
SAMUEL B. COOPER, JR. \\ Louisiana Transportation Research Center \\ Louay N. Mohammad \\ Louisiana Transportation Research Center and Louisiana State University
}

\begin{abstract}
The Novachip ${ }^{\mathrm{TM}}$ is a surface treatment process that was developed in France in 1986. This process increases skid resistance and seals old pavement surfaces, and since 1986 has been used widely in Europe on high-speed, high-volume roadways. This paper documents the 5-year performance of two surface treatment types: the NovachipTM and conventional mill and overlay treatments on routes with similar average daily traffic (ADT) and service life. Three projects located on state route LA-308 in Lafourche Parish were selected for this evaluation. The performance indicators considered included rutting, alligator cracking, random cracking, transverse cracking, and smoothness as determined by international roughness index (IRI). A Life-Cycle Cost analysis (LCCA) was conducted in order to compare the NovachipTM surface treatment process with the conventional surface treatment process of mill and overlay. In general, both surface treatments provided similar performance indicators as measured by rutting, cracking (alligator, random, transverse), and IRI. Based on the LCCA, the NovachipTM surface treatment provided significant cost savings when compared to the conventional surface treatment process of mill and overlay.
\end{abstract}

Tsise he Novachip ${ }^{\mathrm{TM}}$ Surface Treatment Process was developed in France by the construction firm SCREG Routes in $1986(1,2)$. It is a registered trademark of Societe Internationale Routiere, which is a subsidiary of SCREG Routes (2). This process was developed to increase skid resistance and to seal old pavement surfaces (2). Since 1986, the Novachip Surface Treatment has been used widely in Europe as a surfacing on high-speed, high-volume roads $(3,4)$. It is also successfully used in curb and gutter areas in cities.

The Novachip Surface Treatment Process has the capability of placing a thin lift, $1 / 2$ to $3 / 4$ in. of gap-graded hot-mix wearing course over a polymer-modified tack coat using a special type of paver (Figure 1) that can evenly distribute the polymer-modified tack coat immediately in front of the paver augers and apply and level the wearing course concurrently at a rate of 30 to $92 \mathrm{ft}$ per minute (4). The main components of this paver are: a hopper to accept hot-mix from trucks, a storage tank to hold the polymer-modified tack coat, emulsion spray bar, heated vibratory screed, auger system, and electronic controls for surface tolerance (Figure 1).

Figure 2 shows a typical Novachip type of a paver. At the construction site, gap-graded hot-mix asphalt (HMA) is delivered from the hot-mix plant facility and laid at the specified lift thickness within $5 \mathrm{~s}$ of the polymer-modified tack coat application. The typical application range for the polymer-modified tack coat is $0.23 \pm 0.07$ gallons per square yard. It is noted that a thicker emulsion seals the entire surface, including small cracks, and ensures bonding to the existing surface. The heat from the hot-mix causes the emulsion to break quickly and wick 


\section{NOVACHIP MACHINE}

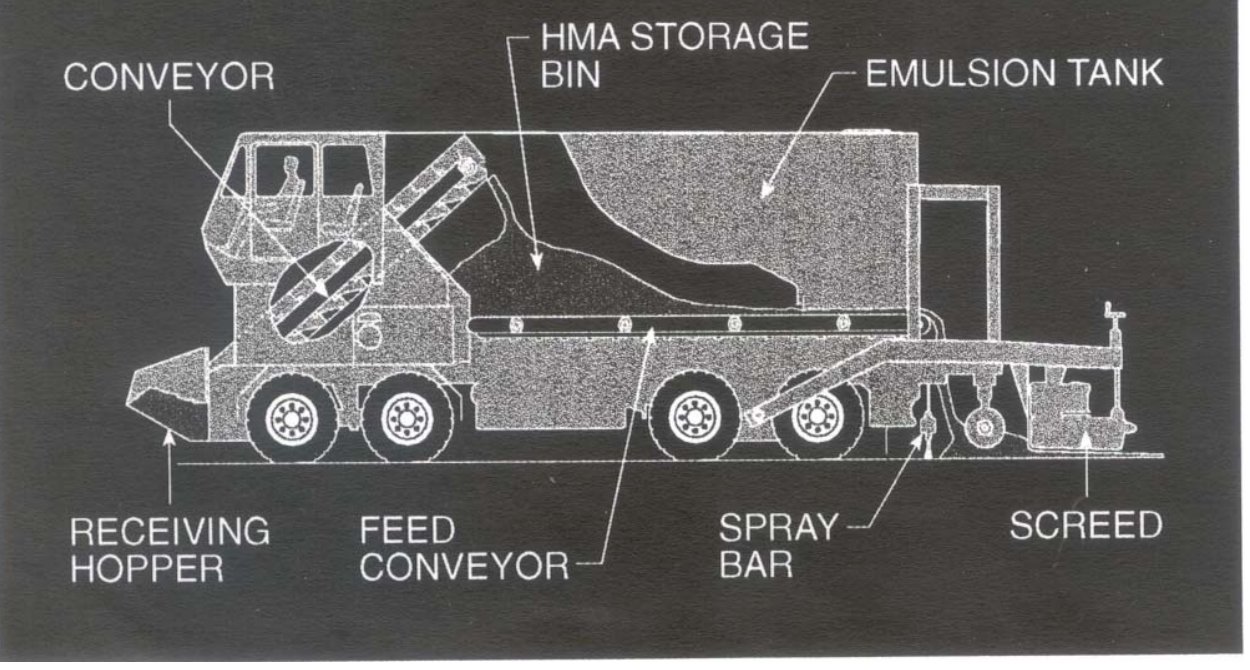

FIGURE 1 Novachip paver schematic.

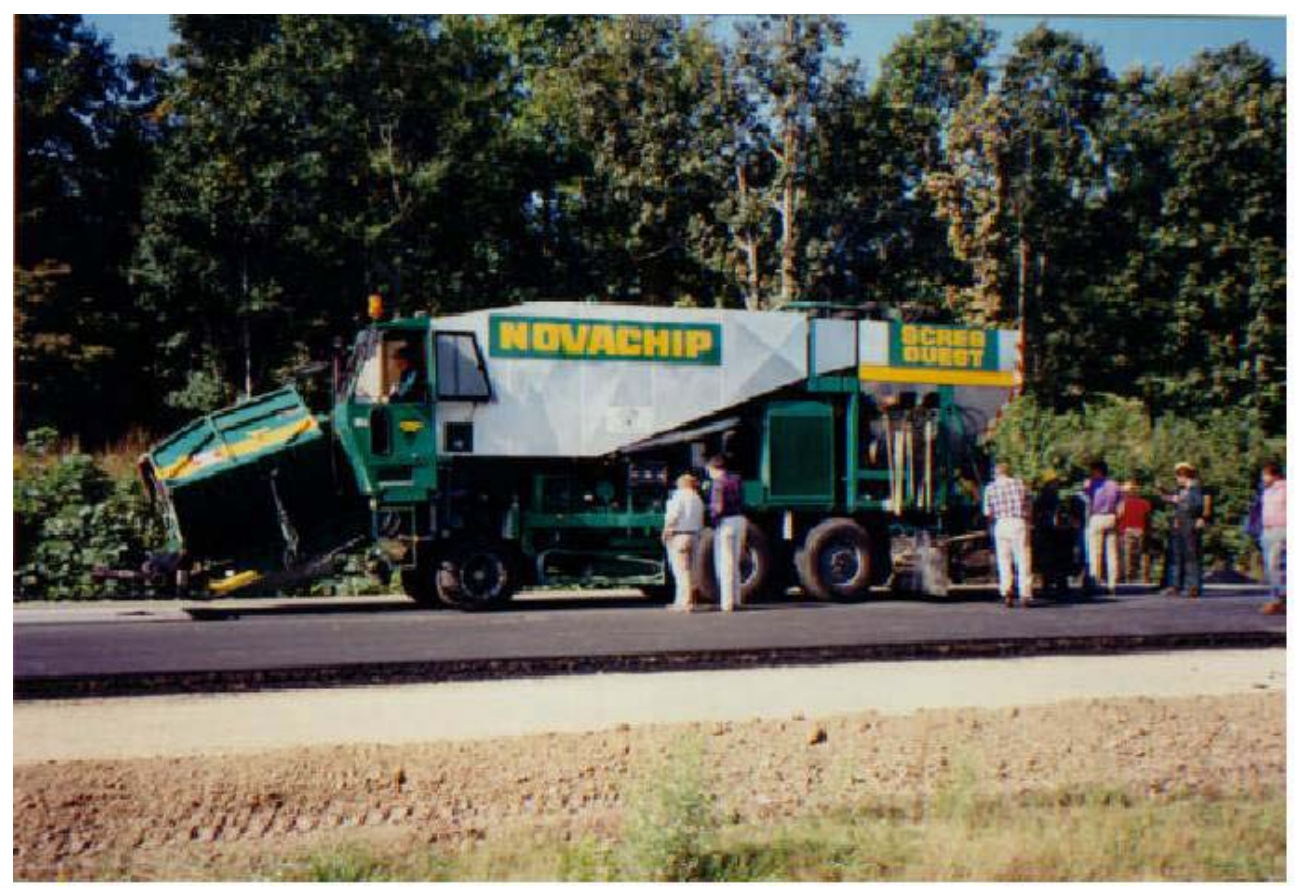

FIGURE 2 Novachip paver. 
upward into the bottom portion of the hot-mix lift. The hot-mix is smoothed over the full lane width in one pass using a heated screed to ensure an even mat. Compaction of the wearing course is carried out using two passes of a double drum roller of sufficient weight to properly seat the aggregate without crushing it. Generally, roadway density is not an issue in the Novachip Surface Treatment process since the aggregate structure used in the gap-graded hot-mix seats quickly. No vibration is allowed during the compaction process except at the transverse joints.

Engineers from the United States were first introduced to the Novachip process through a demonstration given during a European Asphalt Study Tour in 1990 (1). The first Novachip projects in the United States were constructed in Alabama in the fall of 1992 with a machine imported from France ( $(1)$. Test sections were also constructed in Mississippi and Texas during the same time frame using the same machine that was used in the Alabama projects (1).

Louisiana's first Novachip project was completed in September 1997 (4). The initial Novachip paving process used in the United States and Louisiana was proprietary and licensed through KOCH Materials Company, Inc. (2). Louisiana, partnering with KOCH Pavement Solutions, has since developed a non-proprietary special provision specification using this process (5). No longer described as Novachip in Louisiana, it is now named an Ultrathin HMAC (hot-mix asphalt concrete) Wearing Course. This report presents a 5-year evaluation of Louisiana's experience using this process.

\section{OBJECTIVE AND SCOPE}

The objective of this study was to evaluate the field performance of the Novachip surface treatment when compared to conventional mill and overlay systems with similar ADT and service life.

Two mill-and-overlays and one Novachip project were selected for this evaluation. The three projects are located within a 14.89-mi section of roadway on LA-308 in Lafourche Parish. Specifically, Projects 1 and 3 used the mill and overlay treatments with a 2-in. milling and 3.5-in. overlay, while Project 2 employed a $3 / 4$-in. Novachip surfacing treatment. Performance indicators considered in the evaluation included rutting, alligator cracking, random cracking, transverse cracking, and smoothness as measured by IRI. The performance evaluation period considered was from 1997 through 2002. A life-cycle cost analysis was also used to compare the Novachip surface treatment project with the conventional mill and overlay projects used in this evaluation.

\section{MATERIALS AND MIXTURE DESIGN}

\section{Materials}

\section{Asphalt Cement}

An elastomeric type of polymer-modified asphalt cement was specified for this project, meeting the Louisiana Department of Transportation and Development (LADOTD) specification for PAC 40HG (7). It is noted that this asphalt cement binder would classify as a PG 70-22 under the performancegraded system. The optimum asphalt cement content was $4.2 \%, 5.7 \%$ and $4.2 \%$ by weight of total mix for mixtures used in Projects 1,2 and 3, respectively. 


\section{Aggregates}

Siliceous limestone type of aggregates were selected for all mixes used in this study. The siliceous limestone was supplied by Vulcan Materials Company, Gilbertsville, Kentucky.

\section{Antistrip}

The contractor was required to evaluate the HMA mixture's susceptibility to moisture damage by performing the boil test (ASTM D3625). An Ad-Here LA 2 supplied by Arr-Maz Products, Inc. of Winter Haven, Florida, was added to the HMA mixture at a rate of $0.6 \%$ by weight of the mixture. It is noted that LADOTD specifications require an antistrip to be added at a design minimum of $0.6 \%$ by weight of mix in all HMA mixtures $(8,9)$.

\section{Emulsion}

The polymer-modified cationic emulsion used met the recommendations of Novachip and LADOTD specifications (7). The specifications require that the Saybolt Furol viscosity limits for the polymermodified emulsion be between the limits of 20 and 100 at $77^{\circ} \mathrm{F}$ and have a set time between 3 and 7 min at an application temperature of $170^{\circ} \mathrm{F}$. A minimum force ductility ratio of 0.15 was also required by specification on the polymer-modified emulsion residue (7). The force ductility ratio is defined as the ratio of force at $30 \mathrm{~cm}$ elongation to the peak force. The total application rate of the polymer-modified emulsion was 0.15 gallons per square yard (4).

\section{Mixture Design}

Three asphalt concrete mixtures were designed in this study. The Marshall mix design procedure was followed to design all mixtures. Typical high volume LADOTD Type 8F wearing course mixtures (9) were selected for Projects 1 and 3 (mill and overlay projects) while the mixture used for the Novachip project (Project 2) was specially designed based on the specification recommended by SCREG Routes (4). The Marshall mix design method was used for the determination of the optimum asphalt cement content at 75 blows per face and an air voids of $4 \%$ for the mixtures considered. For the mixture used in the Novachip project, the final hot-mix design, asphalt content, and gradation were then adjusted based on the SCREG Routes' recommendations (4). It is noted that the gradation of the Novachip mixture consisted of $70.7 \%-\# 8$ siliceous limestone and $23.6 \%-1 / 4$ X 0 siliceous limestone.

Table 1 presents the job mix formula for the three asphalt mixtures evaluated. The optimum asphalt cement content was $4.2 \%, 5.7 \%$, and $4.2 \%$ by weight of total mix for mixtures used in Projects 1, 2, and 3, respectively. It is noted that for the Novachip project mixture an asphalt draindown test was performed in accordance with ASTM D 6390 with an asphalt cement draindown value of $0.1 \%(4)$. 


\section{FIELD EXPERIMENTAL TEST SECTIONS}

\section{Locations and Description of Test Sections}

Between 1997 and 1998, a 14.89 mi section of LA-308 between Thibodaux and Raceland with the exception of the Theriot Canal Bridge was rehabilitated. There were three projects: Project 1, Project 2, and Project 3, constructed in this section during that time period (Figure 3). The three projects are listed below with their construction type and date, project length, and ADT.

Project 1

Type of construction:

Mill 2 in. with 3.5 in. hot-mix overlay

Project length:

ADT:

$3.10 \mathrm{mi}$

Year constructed:

4,900

1998

Project 2

Type of construction:

Novachip ${ }^{\mathrm{TM}}, 3 / 4$ in. thickness

Project length:

ADT:

$5.26 \mathrm{mi}$

Year constructed:

4,776

1997

Project 3

Type of construction:

Mill 1.5 in. with 3.5 in. hot-mix overlay

Project length:

ADT:

$6.53 \mathrm{mi}$

Year constructed:

5,200

1998

TABLE 1 Job Mix Formula (JMF)

\begin{tabular}{|l|c|c|c|c|c|c|}
\hline & \multicolumn{2}{|c|}{$\begin{array}{c}\text { Project 1 } \\
\text { (Type 8F) }\end{array}$} & \multicolumn{2}{c|}{$\begin{array}{c}\text { Project 2 } \\
\text { (Novachip) }\end{array}$} & \multicolumn{2}{c|}{$\begin{array}{c}\text { Project 3 } \\
\text { (Type 8F) }\end{array}$} \\
\hline \multirow{2}{*}{ Sieve Size (inch) } & JMF & $\begin{array}{c}\text { Field } \\
\text { Data }\end{array}$ & JMF & $\begin{array}{c}\text { Field } \\
\text { Data }\end{array}$ & JMF & $\begin{array}{c}\text { Field } \\
\text { Data }\end{array}$ \\
\hline 1 & \multicolumn{7}{|c|}{ Percent Passing (\%) } \\
\cline { 2 - 7 } & 100 & 100 & 100 & 100 & 100 & 100 \\
\hline $3 / 4$ & 95 & 94 & $/$ & $/$ & 95 & 96 \\
\hline $1 / 2$ & 82 & 83 & 100 & 100 & 83 & 84 \\
\hline $3 / 8$ & 72 & 74 & 97 & 95 & 72 & 71 \\
\hline $1 / 4$ & $/$ & $/$ & 64 & 65 & $/$ & $/$ \\
\hline No.4 & 54 & 52 & 43 & 43 & 51 & 50 \\
\hline No. 10 & 39 & 38 & 20 & 25 & 39 & 39 \\
\hline No. 40 & 26 & 27 & 11 & 12 & 28 & 30 \\
\hline No. 80 & 14 & 14 & 9 & 9 & 22 & 24 \\
\hline No. 200 & 5.2 & 6.0 & 7.3 & 7.5 & 6.0 & 6.8 \\
\hline \multicolumn{7}{|l|}{} \\
\hline \% Asphalt Cement & 4.2 & 4.4 & 5.7 & 5.6 & 4.2 & 4.4 \\
\hline
\end{tabular}




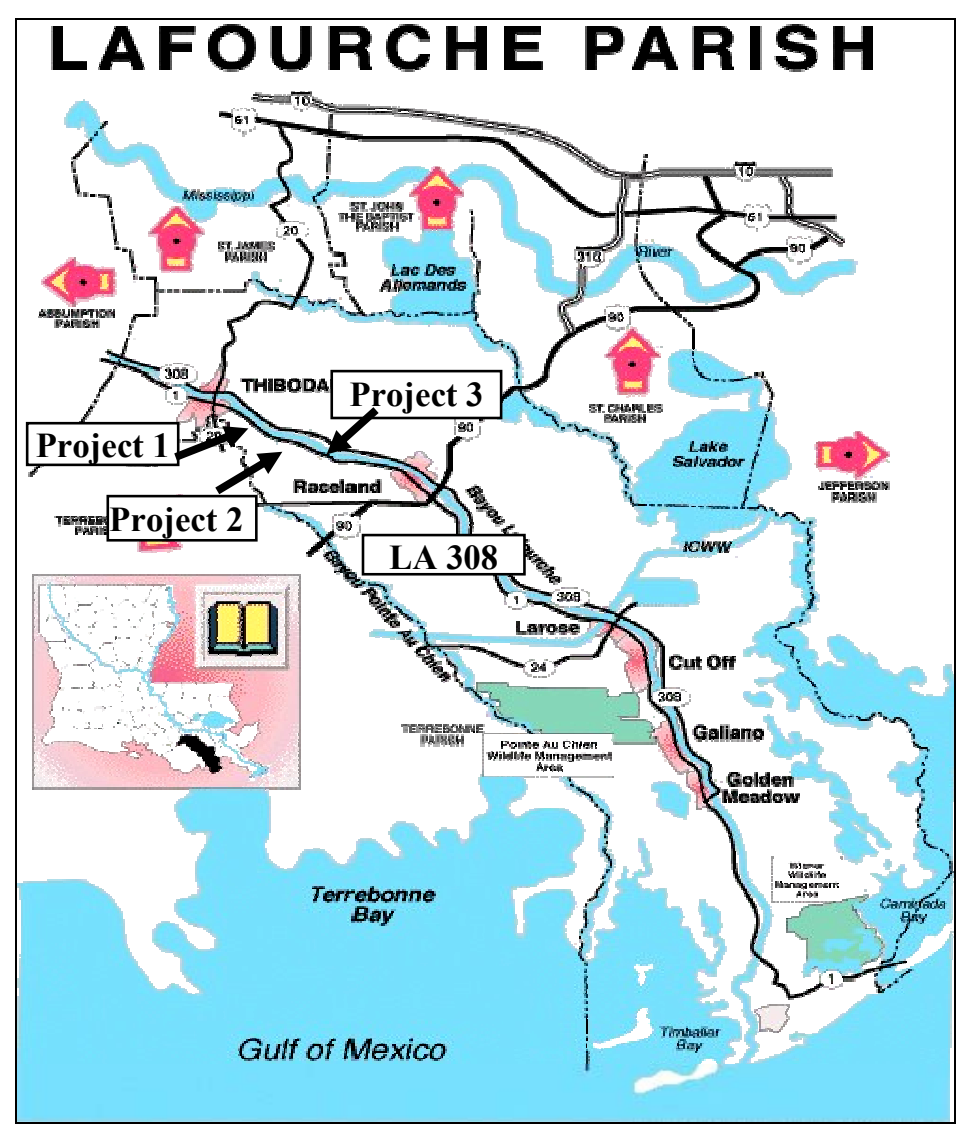

FIGURE 3 Location LA-308 section evaluation.

Prior to the 1997 project, the existing surface was a plant mix seal that was completed in 1978. There were areas along this roadway that had greater than $1 / 4$-in.-wide longitudinal cracks. Under the plant mix seal, there is approximately $7 \mathrm{in}$. of hot mix on top of a sand-shell base (4). The geometrical features of the existing highway are a 22-ft wide pavement with unimproved shoulders. This site has moderate to heavy traffic with an estimated 1996 ADT ranged from 4,776 to 5,200. Heaviest truck traffic is seasonal and runs concurrent with the sugar cane harvest season during the months of October through December.

\section{Project Field Construction}

\section{Projects 1 and 3: Mill-and-Overlay Surface Treatments}

Projects 1 and 3 were rehabilitated using Louisiana's typical rehabilitation techniques, mill and overlay. Typically, 2 in. of the existing surface is removed by milling and then replaced with 2 in. of HMA binder course and $1 \frac{1}{2}$ in. of HMA wearing course mixtures. The type hot mix selected for Projects 1 and 3 were Louisiana's typical Marshall Type 8 Binder Course and Type 8F Wearing Course (9). Conventional milling and paving equipment were used in the rehabilitation process for these projects. 


\section{Project 2: Novachip Surface Treatment}

The 1997 Novachip surface treatment project constructed in Lafourche Parish began at the Theriot Canal Bridge north of Raceland and proceeded west along LA-308 to the St. Charles Bridge for a distance of $5.26 \mathrm{mi}$. The type of construction required was to place a Novachip surface treatment $3 / 4-$ in. thick over the existing roadway structure.

A "small" Novachip paver was used during construction of this project. The capacity of this paver was approximately 100 to 125 tons of mix per hour with a traveling speed of up to $10 \mathrm{mph}$ (4). This paver was capable of distributing the emulsion between the rates of 0.1 and 0.28 gallons per square yard (4). Construction of the Novachip surface treatment was completed in $2 \frac{1}{2}$ days. Approximately $4.5 \mathrm{mi}$ were completed on the first day of production. During construction, hot mix materials could be delivered directly into the paver's hopper from the delivery truck; however, the distance from the tailgate of the truck to the back of the truck's rear tires was too short for the paving machine to accept (4). A materials transfer vehicle (MTV) was used to aide in the delivery of the hot-mix materials into the paver's hopper. The MTV facilitated quicker truck exchanges and may have aided in the improved IRI since the MTV acted like a moving surge bin allowing the paver to travel continuously without stopping (4). There was no smoothness specification required for the construction of this project; however, a 1-mi section of roadway was profiled with the Ames Profilograph before and after construction to demonstrate the ability of a thin lift overlay to improve surface profile. The profile index before construction and after construction was 14 in. per mile and 2.4 in. per mile, respectively. There were 2611.09 tons of hot-mix materials delivered to construct this $67,486.2 \mathrm{yd}^{2}$ project. The average yield for this project was 77.4 lbs per square yard.

\section{FIELD DATA COLLECTION AND PERFORMANCE MONITERING}

Comparisons of the field performance of pavements were achieved using years 1997, 2000, and 2002 visual data acquired from Louisiana's pavement management section in which the IRI, rut-depth measurements, and crack data was evaluated. Also, visual inspection of cracks after 6 years is reported in this study.

\section{Visual Data Collection and Analysis}

Visual data was collected by the Automatic Road Analyzer (ARAN) developed by Roadware Group, Inc., and analyzed for inclusion into Louisiana's pavement management inventory. The data collected by ARAN was analyzed by software developed by Roadware Group, Inc., specifically for ARAN. ARAN is a vehicle that is specially modified to collect accurate and repeatable data for pavement management programs. The ARAN vehicle houses computers and sensors including lasers, inertial measurement units, accelerometers, ultrasonic transducers, digital cameras, and vehicle mounted subsystems. ARAN is capable of measuring and recording up to 36 different characteristics ranging from pavement roughness and rutting to multicamera imagery while traveling at posted speed limits $(10,11)$. 


\section{International Roughness Index}

The IRI is a standard roughness measurement related to those obtained by road meters installed on vehicles or trailers. The IRI is a mathematical model applied to a measured profile. The model simulates a quarter-car system (QCS) traveling at a constant speed of $80 \mathrm{~km} / \mathrm{h}$. The IRI is computed as the cumulative movement of the suspension of the QCS divided by the traveled distance. The calculation of IRI can be found in reference (12).

\section{Crack (Transverse, Random, Alligator) Data Measurement}

Transverse, random, and alligator crack data was obtained by ARAN video imagery technology. The crack data video imagery was analyzed using computer software developed by Roadware Group, Inc. For this study, the reported value of crack measurements for each project is the average crack measurement in linear feet for transverse and random cracks, and square feet for alligator cracks.

\section{Field Rut Depth Measurement}

Field rut depth data collection for this case study was performed by ARAN using two vehiclemounted subsystems. For 1997, data was collected by the ARAN Smart Rutbar which uses ultrasonic transducers to measure the transverse roadway cross section. Ultrasonic transducers are spaced at $100 \mathrm{~mm}$ (4 in.) across the measuring device. Up to 37 transducers are used to cover a 12-ft lane. For 2000 and 2002, data was collected using the ARAN laser transverse profiler, Laser XVP vehicle-mounted subsystem. The laser transverse profiler uses dual synchronized mounted scanning lasers to measure the transverse roadway profile. This technology allows transverse profile measurement up to 13-ft lane widths. In this study, the reported measurement value of rut depth for each project is the average rut depth in inches.

\section{FIVE-YEAR PERFORMANCE EVALUATION}

The 14.89-mi (23.96-km) section of LA-308 between Thibodaux and Raceland was visually inspected in the fall of 2003. In general, visual inspection of Project 2 revealed low severity cracking widths that were less than $1 / 8$ in. In addition, LADOTD Pavement Management's 2002 visual inspection data for this project indicated the presence of approximately $86 \mathrm{ft}$ of longitudinal cracking (low severity). Abadie (4) reported there was up to $250 \mathrm{ft}$ of longitudinal cracking greater than $1 / 4$ in. before the application of the Novachip surface treatment. There were also some areas of corrugation, alligator cracking, and base failures in Project 2. Visual inspection for Projects 1 and 3 also revealed alligator cracking and base failures.

The 5-year performance of Project 2, constructed in 1997, was then evaluated against the 5-year performance of Projects 1 and 3, constructed in 1998. Performance indicators used for this evaluation was IRI, alligator cracking, random cracking, transverse cracking, and rut depth values. Data used for the analysis were obtained through pavement management's visual data for the years of 1997, 2000, and 2002. 


\section{Pavement Smoothness Measured by IRI}

Since no visual data was available for the year 1998, an assumption was made that for Projects 1 and 3, completed in 1998, the IRI value would be no worse than Pavement Management's 2000 IRI visual data value indicated. Therefore, that data was subsequently used for 1998. Also, further assumptions were made that there would be no alligator cracking, no random cracking, no transverse cracking, and no rut depth values reported for Projects 1 and 3 at year 1998.

Figure 4 presents the average IRI for the projects evaluated. Prior to construction of all projects the average IRI values for Project 1, Project 2, and Project 3 were 255, 237, and 219 in. per mile, respectively. As shown in Figure 4, for all projects, a decrease in the overall IRI value of approximately 125 in. per mile or $65 \%$ was experienced after initial construction. Also, in Projects 1 and 3 there is no increase in the IRI values for the time period evaluated. For Project 2 , Figure 4 demonstrates a slight increasing trend in the IRI value for this same time period. The 2002 IRI data indicates that the increase in the IRI value was approximately $20 \%$ above that found in the initial construction year, 1997. Nevertheless, less than 100 in. per mile were considered "good" as defined by the Pavement Management System Guidelines. Projects 1 and 3 are also less than 100 in. per mile and are considered "good."

\section{Alligator Cracking}

Figure 5 shows the average alligator cracking for the projects evaluated. As stated previously, visual observation of these projects indicated existing alligator cracking and base failures. With the exception of the urban areas within this 14.89 mile section of LA 308, the existing shoulders were unimproved. The alligator cracking and base failures began at the outside wheel path and continued to the edge of shoulder. It is suspected that the alligator cracking and base failures were due to moisture intrusion into the untreated sand shell base and/or subgrade (4). Unimproved shoulders in addition to the lack of maintenance of the cross-slope of the existing shoulder may allow moisture to infiltrate the pavement structure. Prior to construction of all

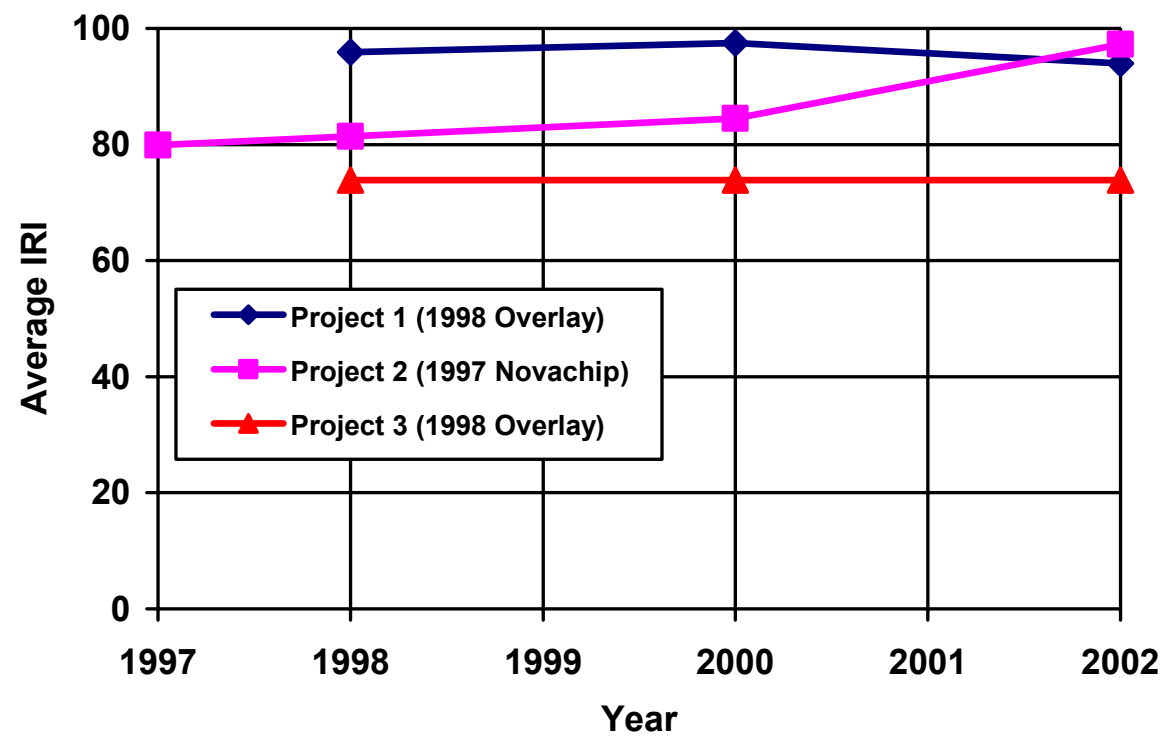

FIGURE 4 Average IRI. 
projects the average square feet of alligator cracking for Project 1, Project 2, and Project 3 were 465, 427, and 390, respectively. As indicated in Figure 5, there was an increasing trend in the square feet of alligator cracking for the time period evaluated. Furthermore, Figure 5 shows that there was a substantial increase in the alligator cracking in 2000 and then a decrease in 2002 for Project 3. The decrease in the alligator cracking was the result of several skin-patched distressed areas in 2002.

\section{Random Cracking}

Figure 6 presents the average random cracking for the projects evaluated. Prior to construction of all projects the average linear feet of random cracking for Project 1, Project 2, and Project 3 were $1,470,1,158$, and 847, respectively. As indicated in Figure 6, there was an increasing trend of random cracking in all projects with Project 2 increasing at a faster rate for the time period evaluated. The data indicated that random cracking for Projects 1 and 3 was increasing at approximately $3.5 \mathrm{ft}$ per year whereas Project 2 was increasing at approximately $14.5 \mathrm{ft}$ per year. The 2002 visual data indicated that Project 1 experienced a low-severity level of cracking. On the other hand, Projects 2 and 3 portrayed low, medium, and high-severity levels of random cracking.

\section{Transverse Cracking}

Figure 7 presents the average transverse cracking for the projects evaluated. Prior to construction of all projects the average linear feet of transverse cracking for Project 1, Project 2, and Project 3 were 865, 711, and 558 respectively. As indicated in Figure 7, there was an increasing trend of transverse cracking in all projects with Project 2 increasing at a faster rate for the time period evaluated. The data indicated transverse cracking for Projects 1 and 3 increased at approximately 2 $\mathrm{ft}$ per year whereas Project 2 increased at approximately $14.5 \mathrm{ft}$ per year. The 2002 visual data indicated that Project 3 experienced low, medium, and high-severity levels of transverse cracking. Visual data for Projects 1 and 2 indicate low-severity levels of transverse cracking.

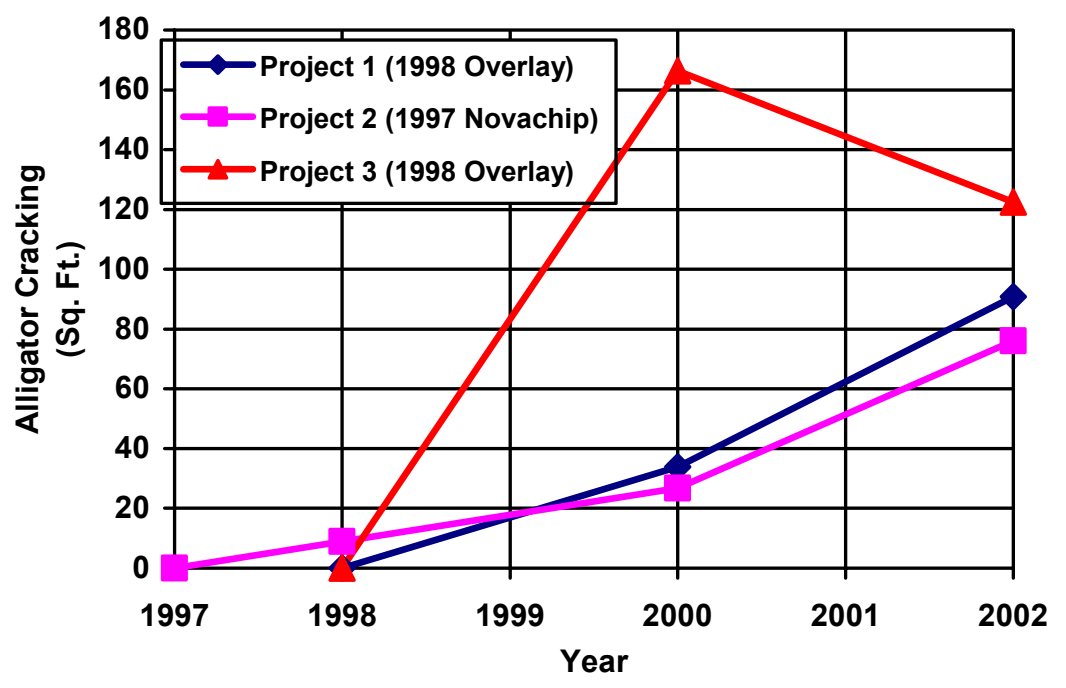

FIGURE 5 Average alligator cracking. 


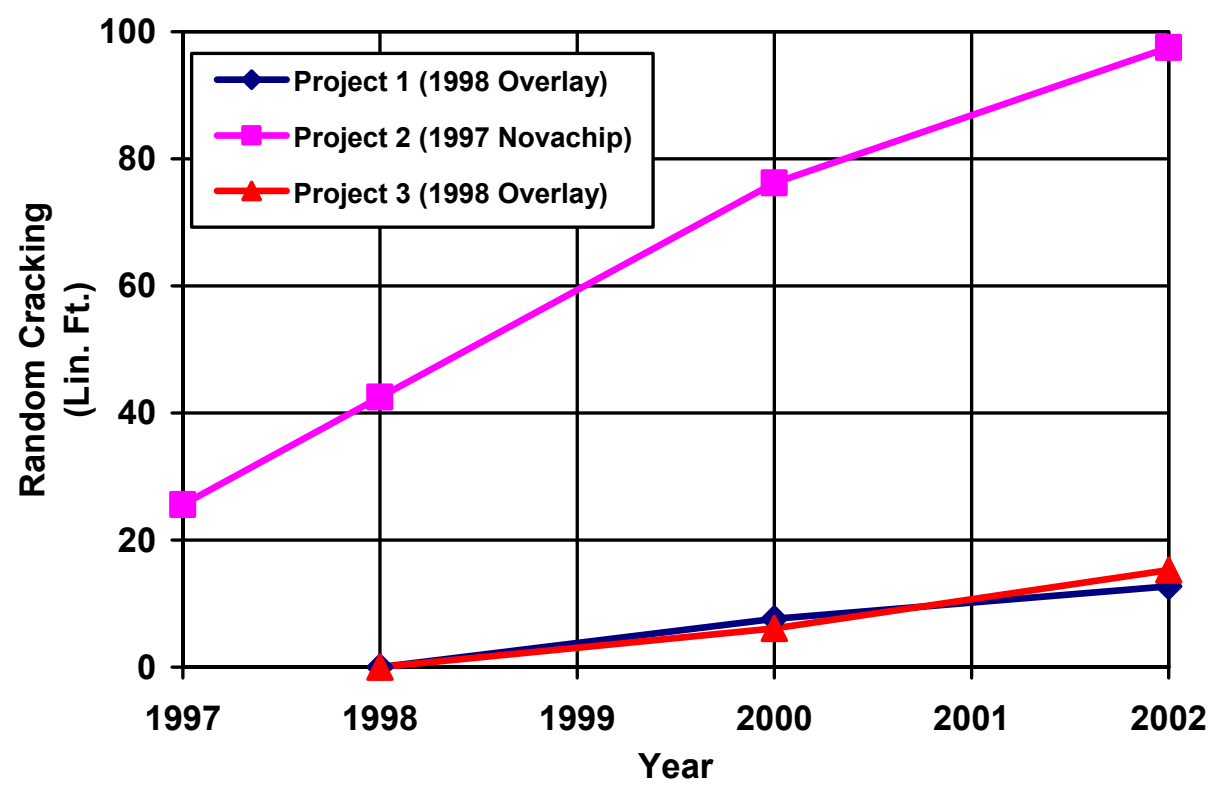

FIGURE 6 Average random cracking.

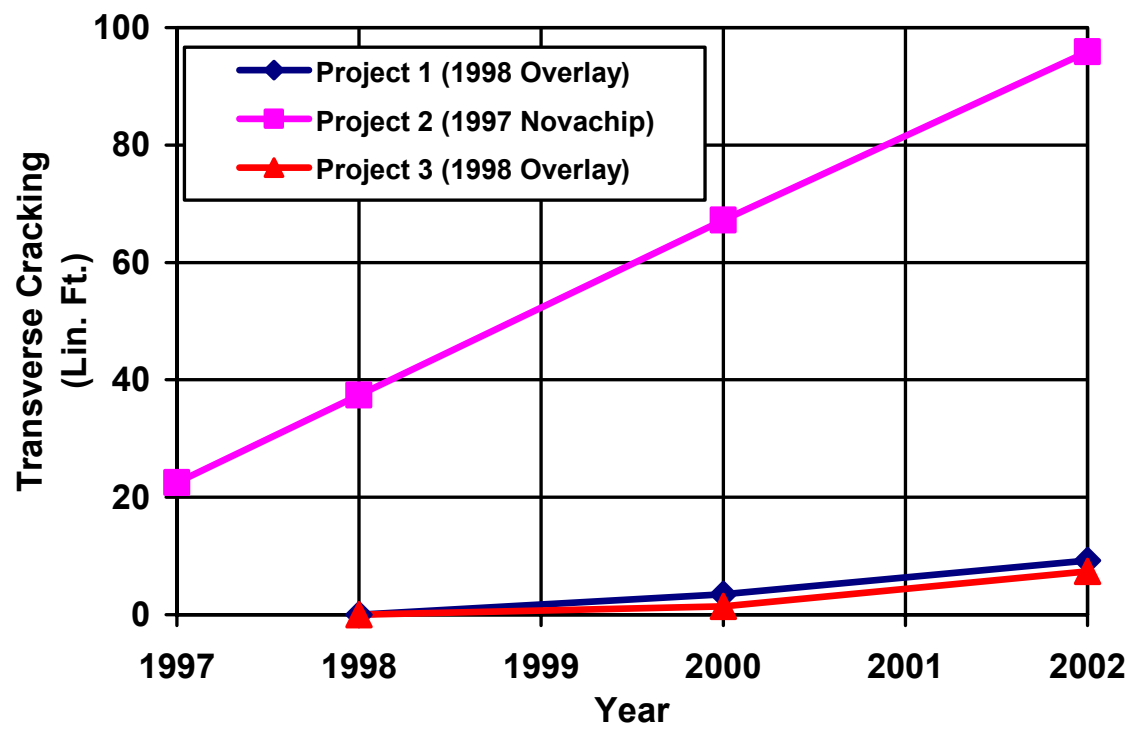

FIGURE 7 Average transverse cracking.

\section{Rut Depth}

Figure 8 shows the average rut depth for the projects evaluated. Prior to construction of all projects the average rut depth in inches for Project 1, Project 2, and Project 3 were $0.5,0.5$, and 0.4 , respectively. As shown in Figure 8, the rut depth for all projects has remained constant since 2000. The visual data for all projects indicate that the rut depth was at 0.1 in. 


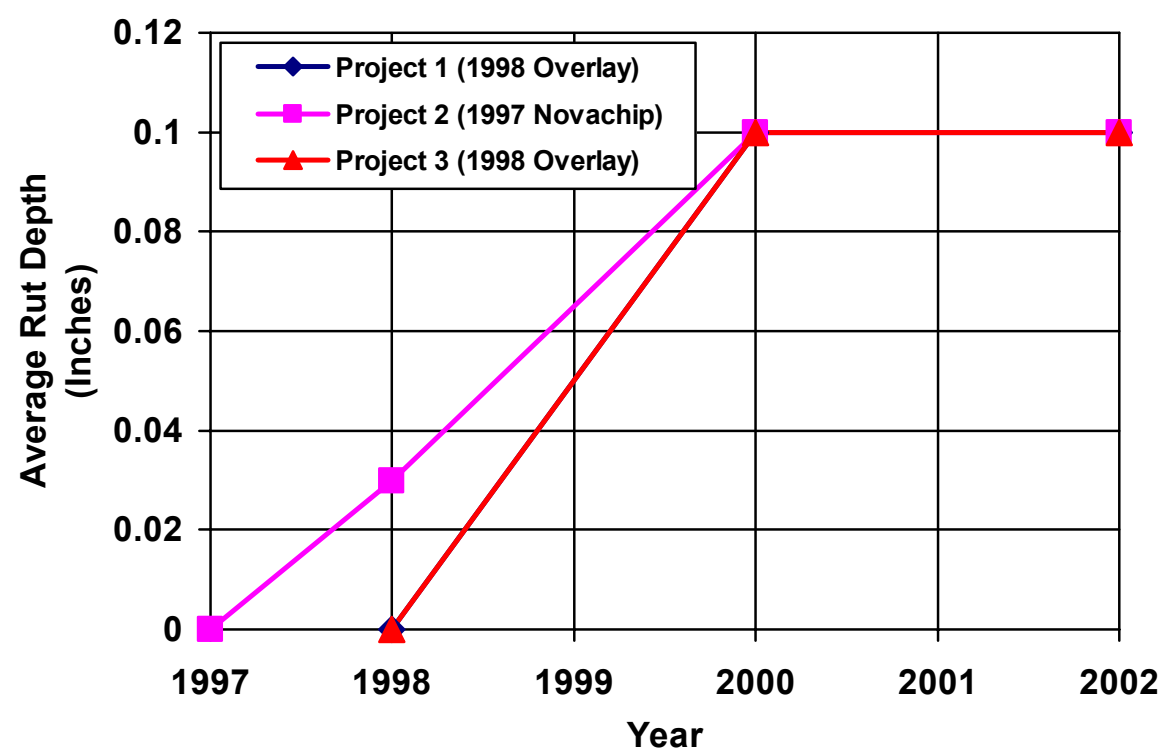

FIGURE 8 Average rut depths.

\section{LIFE-CYCLE COST ANALYSIS}

The final as-built cost for Project 2 was \$337, 866.08 as constructed by T.L. James, Inc., in 1997. There was a total of $67,486.20 \mathrm{yd}^{2}$ of Novachip material placed in this project. The approximate total cost per mile, including all construction items, was $\$ 65,000$ per mile. When computing the total price per square yard of Novachip and hot-mix items only, the calculated as-built price per square yard was $\$ 3.67$.

A life cycle cost comparison of Project 2 versus Projects 1 and 3 was performed. The unit price per square yard for the milling and hot-mix items, excluding any other contract items, for Projects 1 and 3 was calculated using as-built quantities. The computed price per square yard for each of these projects was then averaged. The average as-built unit price was $\$ 10.68 / \mathrm{yd}^{2}$ for Projects 1 and 3.

Before comparing the life-cycle cost of each alternate project some assumptions were made. It was assumed that the interest rates would be constant for the entire 20-year life cycle evaluated. Furthermore, there would be no maintenance costs and no salvage value, and the cost of construction would also be equal during the evaluation period. Also, there is no end-of-service life rehabilitation included in this life-cycle cost evaluation. At the end of the 20-year life cycle, it is assumed that Projects 1 through 3 will undergo the same type rehabilitation. The future cost was calculated using the same interest rate, is equal to 4\%. A 10-year expected life for Project 2 was selected because the expected surface life was estimated at 10 years (3). It was also assumed that Projects 1 and 3 would reach its end-of-service life at 20 years. Project 2 would receive a reapplication of the Novachip surface treatment at 10 years to achieve the 20 -year life cycle needed for evaluation.

Figure 9 presents the life-cycle cost diagram used in the computational analysis for Projects 1 and 3. 
The capitalized cost, or life-cycle cost, was determined as present worth at $t=0$ in Figure 9 as follows:

Life-Cycle Cost $\quad=\$ 10.68 / \mathrm{yd}^{2}$

Figure 10 shows the life-cycle cost diagram used in the computational analysis for Project 2. The capitalized cost, or life cycle cost, was determined as Present Worth at $t=0$ in Figure 10 as follows:

Life-Cycle Cost $\quad=3.67+5.43(\mathrm{P} / \mathrm{F}, 4 \%, 10)$

$$
\begin{aligned}
& =3.67+5.43(0.6756) \\
& =\$ 7.34 / \mathrm{yd}^{2}
\end{aligned}
$$

Although the life-cycle cost analysis is very basic with these assumptions, it indicates that routine maintenance/overlays such as the Novachip surface treatment result in cost savings for LADOTD. In the above calculations, based on the assumptions made, savings of approximately $\$ 3.34 / \mathrm{yd}^{2}$ result.

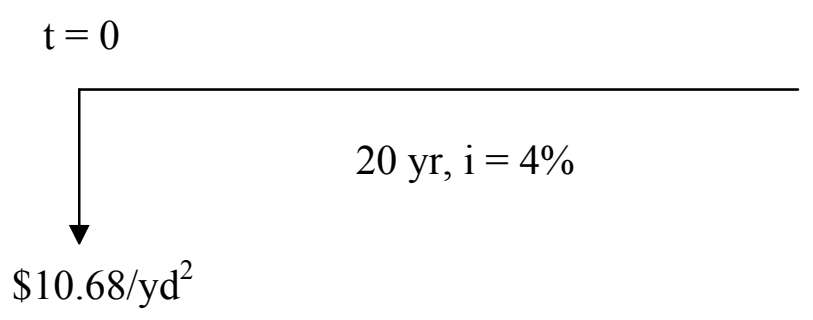

FIGURE 9 Life-cycle cost diagram, Projects 1 and 3.

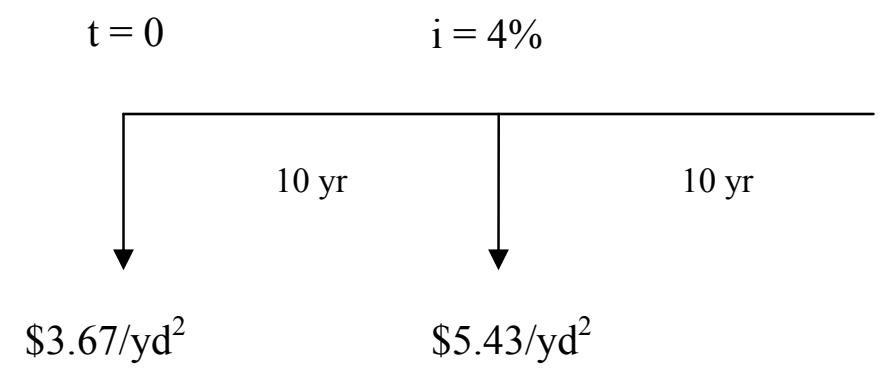

FIGURE 10 Life-cycle cost diagram, Project 2. 


\section{SUMMARY AND CONCLUSIONS}

It was previously stated that the expected surface life of the Novachip process is 10 years. The first projects of this type completed in the United States, if they are still in existence, are just 11 years old. Based on the life-cycle cost analysis of this Novachip project compared to the overlays, the Novachip surface treatment results in a cost savings to LADOTD, provided that the appropriate roadway and rehabilitation technique are selected.

The Novachip project indicates a rut resistance mix for the ADT and truck traffic level selected. The rut resistance may be the result of the composite aggregate gradation selected, which is gap graded.

This Novachip project is performing satisfactorily in regard to IRI, rutting, and alligator, random, and transverse cracking. This can be attributed to the selection of the appropriate roadway for this type application. Alligator cracking was not project specific and cannot be attributed to any type of overlay process selected within the 14.89-mi (23.96-km) section of LA308. It is suspected that the alligator cracking on the three projects constructed on LA-308 is due to moisture intrusion from the top and bottom into the pavement structure, including moisture from the subbase material as this section of LA-308 is in close proximity to Bayou Lafourche.

\section{REFERENCES}

1. Kandhal, P., and L. Lockett. Construction and Performance of Ultrathin Asphalt Friction Course. Report No. 97-5, National Center for Asphalt Technology, 1997.

2. McHattie, R., and J. Elieff. Cost-Effective Rut Repair Methods. Report No. FHWA-AK-RD-01-04, Alaska Department of Transportation, 2001.

3. Bon Jour! NovaChip European Technology Introduced to Minnesota. T2 Minnesota Technology Transfer Program, Center for Transportation Studies, University of Minnesota, 1998. Available at www.cts.umn.edu/T2/archive/novachip.htm.

4. Abadie, C. Novachip ${ }^{\mathrm{TM}}$ Surface Treatment. Technical Assistance Report Number 12, Louisiana Transportation Research Center, 1997.

5. Louisiana Standard Specification for Roads and Bridges. In Special Provision Item S-001, Ultrathin HMAC Wearing Course (3/4” Thick). Louisiana Department of Transportation and Development, Baton Rouge, 2000.

6. Novachip ${ }^{\circledR}$ Ultrathin Bonded Wearing Course. Koch Pavement Solutions, Koch Industries Inc., Wichita, Kansas, 2001. Available at www.kochpavementsolutions.com/ Solutions/novachip.htm.

7. Novachip Surface Treatment (CM), State Project No. 407-04-0034, Theriot Canal Bridge-St. Charles Bridge, Route: LA 308, Lafourche Parish. Louisiana Department of Transportation and Development Construction Contract, 1997.

8. Louisiana Standard Specification for Roads and Bridges. Louisiana Department of Transportation and Development, Baton Rouge, 2000.

9. Louisiana Standard Specification for Roads and Bridges. Louisiana Department of Transportation and Development, Baton Rouge, 1992.

10. About Us - A Brief History. Roadware Group Inc., Paris, Ontario, Canada. Available at www.roadware.com/aboutus.htm.

11. Product Data Sheets. Roadware Group Inc., Paris, Ontario. Available at www.roadware.com/datasheets.htm.

12. Shahin, M. Y. Pavement Management for Air Ports, Roads, and Parking Lots. Chapman and Hall, New York, NY, 1994. 


\title{
Gravel Roads Asset Management
}

\author{
GEORGE HUNTINGTON \\ KHALED KSAIBATI \\ University of Wyoming
}

In the winter of 2004, the Wyoming Technology Transfer Center in cooperation with the Wyoming Department of Transportation and Sheridan, Johnson, and Carbon Counties of Wyoming undertook a 3-year project to institute a geographic information system- (GIS-) based asset management program. It encompasses inventorying, rating, and optimization strategies for improved gravel roads, as well as for the limited mileage of asphalt and unimproved roads in the counties. The roughly $2,000 \mathrm{mi}$ of roads in the three counties were located with a Global Positioning Satellite system and rated using the Wisconsin Transportation Information Center's Pavement Surface Evaluation and Ratings manuals, modified for Wyoming's conditions. In addition, expenditures on each road section are tracked through maintainers' daily reports. Signs, sign supports, cattleguards, approaches, and culverts were rated and located. Bridges were located. Interviews with maintainers were conducted to gather historical and routine maintenance information on each section. This report describes the current status of this asset management program and road surface management system.

The goals of this program are two-fold, similar to those in widespread use for asphalt and concrete roads. First, it is to be used on a network level for financial and management decisions and strategies. Second, at the project level, it is to be used to make specific maintenance and construction recommendations on individual roads, largely through a life-cycle costing approach. Off-the-shelf GIS software is used to enter and manipulate the data collected. Adapting this software to surface management tasks was relatively simple, given the user-friendliness of the newer GIS packages. Recent modifications allow for multiple entries for a single feature. Cost estimates for routine activities, such as mowing, snowplowing, and reshaping gravel roads, allow the counties to make reasonable, detailed estimates of the cost of maintaining gravel roads under different conditions. For these and numerous other applications, the asset management system is streamlining county operations.

T he Wyoming Technology Transfer $\left(\mathrm{T}^{2}\right)$ Center, part of the Local Technical Assistance Program (LTAP), has instituted an asset management program for three Wyoming counties: Carbon, Sheridan, and Johnson. They were chosen because they have had a recent, substantial increase in heavy truck traffic associated with oil and gas drilling. Funding for this study was provided by Wyoming Department of Transportation (WYDOT) through the Local Government Office. Matching fund was obtained from the counties. The goals of this project are two-fold. First, $\mathrm{T}^{2}$ is quantifying the damages caused by the influx of heavy trucks; second, $\mathrm{T}^{2}$ is designing and building a management system that can be taken over by the counties at the conclusion of the 3-year project.

The primary element in the asset management program is the road surface management portion. Many agencies have developed and instituted surface management systems, but most of these are primarily tailored to asphalt and concrete pavement surfaces. Less work has been done for gravel roads. The asset management system that comes out of this project should help fill this need. 
As off-the-shelf geographic information system (GIS) software becomes more user friendly, it becomes easier for small municipalities to develop and maintain their own asset management systems. In spite of these advantages, setting up an asset management system is still beyond the capabilities of many agencies. For small Wyoming counties to reap the benefits of asset management, some other organization needed to step in and develop a management system tailored to their needs. The Wyoming $\mathrm{T}^{2}$ Center has stepped into this role.

\section{BACKGROUND}

\section{Asset Management}

"Asset management is concerned with the entire life cycle of transportation decisions, including planning, programming, construction, maintenance, and operations. It emphasizes integration across these functions, reinforcing the fact that actions taken across this life cycle are interrelated. It also recognizes that investments in transportation assets must be made considering a broad set of objectives, including physical preservation, congestion relief, safety, security, economic productivity, and environmental stewardship" (1).

While state highway agencies, federal agencies, and most larger municipalities have already instituted asset and road surface management systems, such systems are less common among smaller municipalities. With the mandated GASB 34 standards, small municipalities have been compelled to establish the economic value of their road and street networks. However, complying with these functions merely provides the agencies with an inventory and a dollar figure. Generally, there are no technical or analytical capabilities associated with these inventories. Some organizations, including the Utah $\mathrm{T}^{2}$ Center and the Michigan LTAP, have instituted asset management systems for municipalities in their states. Smaller municipalities have smaller infrastructures and correspondingly smaller budgets. Since computers can easily handle large amounts of data, there is a substantial economy of scale for larger agencies and a corresponding diseconomy of scale for smaller agencies.

\section{Drilling Effects on Wyoming County Roads}

A primary objective of this project is to quantify the damage being done to county roads by oil and gas drilling activities. Eastern Johnson and Sheridan Counties and Western Carbon County have seen substantial increases in oil and gas drilling activities over the past few years. Roads that used to have light residential traffic and occasional heavy agricultural trucks now have numerous light and heavy trucks involved in drilling activities in addition to the traffic already present.

\section{Road Rating Systems}

There are a number of systems for evaluating road surface conditions. They range from labor intensive systems such as the pavement condition index (PCI) to less labor intensive systems such as the Pavement Surface Evaluation and Ratings (PASER) system developed by the Wisconsin Transportation Information Center. While the PCI involves detailed measurements of surface defects, the PASER system is a subjective, visual rating system designed for use by local officials (2). 


\section{Gravel Roads Maintenance}

Deterioration of asphalt and concrete roads can be predicted based on initial construction and design, along with environmental effects, particularly traffic. Maintenance and repair of these roads is carried out every few years or so. The case is very different for gravel roads. Whenever moisture conditions are right, Wyoming county road and bridge crews are busy reshaping crowns, removing corrugations (washboards), and otherwise maintaining the gravel road surface. Low initial gravel road construction costs are at least partly offset by more frequent maintenance. Because of this fundamental difference between gravel and more durable pavement surfaces, it is essential that maintenance be considered in any analysis of gravel roads. To this end, the Wyoming $\mathrm{T}^{2}$ Center is incorporating maintenance costs into its asset management system for gravel roads.

\section{ASSET MANAGEMENT SYSTEM}

Fundamentally, the asset management system begins with a Global Positioning System (GPS) receiver connected to a laptop computer. In the future, handheld computers with GPS technology may be used. GIS software puts information gathered by data collectors into the database and associates it with the locations established by the GPS receiver. Digital photographs are taken at each location to complement the measurements and evaluations. Maintenance data is collected by the county road and bridge crews that will allow the combination of maintenance costs and road condition data. In addition, the software allows for the inclusion of traffic data. The combination of these data provides the potential for performing powerful analyses of the county road networks.

\section{Hardware and Software}

Data was collected with a GPS unit and a laptop computer as shown in Figure 1. The ESRI product, ArcPad, was the front end for the graphical user interface (GUI). When the data collectors identified an asset, such as a 1-mi road segment or a sign, the GPS was activated and the geographic data from the GPS was stored. Data entry forms were developed in ArcPad with scroll lists and comment fields, as shown in Figure 2. Such data forms made data entry easier and reduced the likelihood of invalid or erroneous entries.

Data is downloaded daily using VPN Client software to transfer the data to the University of Wyoming's server housing the asset management data. This allows verification that the data is being collected and stored correctly. Since most of the data collectors have easy access to dial-up internet connections only, photographs are not transferred daily. Instead, they are saved on a CD that is sent to the $\mathrm{T}^{2}$ center once a week.

The first year's database did not have a temporal component. Only one rating could be stored for a single road segment or feature. The database was restructured before the second year of data collection with two components, temporal and non-temporal data, functioning as a one-tomany relationship. For all rated segments and features there are multiple records describing what has happened to them. Queries can be written to describe the features as they vary with time.

To maintain the new GIS data set, it was migrated to a Geodatabase which organizes data with the ArcGIS 9.0 software. Data is collected in shapefiles, a format supported by the both ArcGIS and ArcPad software, then imported into the Geodatabase. 
The new database allows additional data to be stored whenever a feature is reevaluated. A feature's location can be updated with the GPS as non-temporal data. When additional evaluations are conducted, a new record is added to the temporal data set. This relationship can exist since a common identifier is present in both the temporal and non-temporal databases. Unique identifiers serve as the link between a feature and its records collected at different times. The times are recorded in the temporal dataset along with the data entered at that time. This will allow for analysis of various features' changes over time individually or collectively.

\section{Hiring and Training}

Teams of two students and retirees from various disciplines were hired. While data collection could be performed by one person, it was decided that in the interests of both safety and data accuracy it was best to have two people collect the data. Data collectors were trained at 2-day training sessions conducted at the $\mathrm{T}^{2}$ Center. They were given a short introduction to the engineering behind gravel and asphalt roads. The various distresses to be rated were described in detail. This was followed by numerous photographs which were rated in the classroom by the data collectors as guided by an experienced engineer.

\section{Surface Condition Data Collection}

Data is collected in two passes. On the first pass, the road surface condition is evaluated in segments roughly $1 \mathrm{mi}$ long. The segments were established during the first year of data collection. These segments will be rated but not remapped in subsequent years. On the second pass, bridges are located and inventoried while the following features are located and

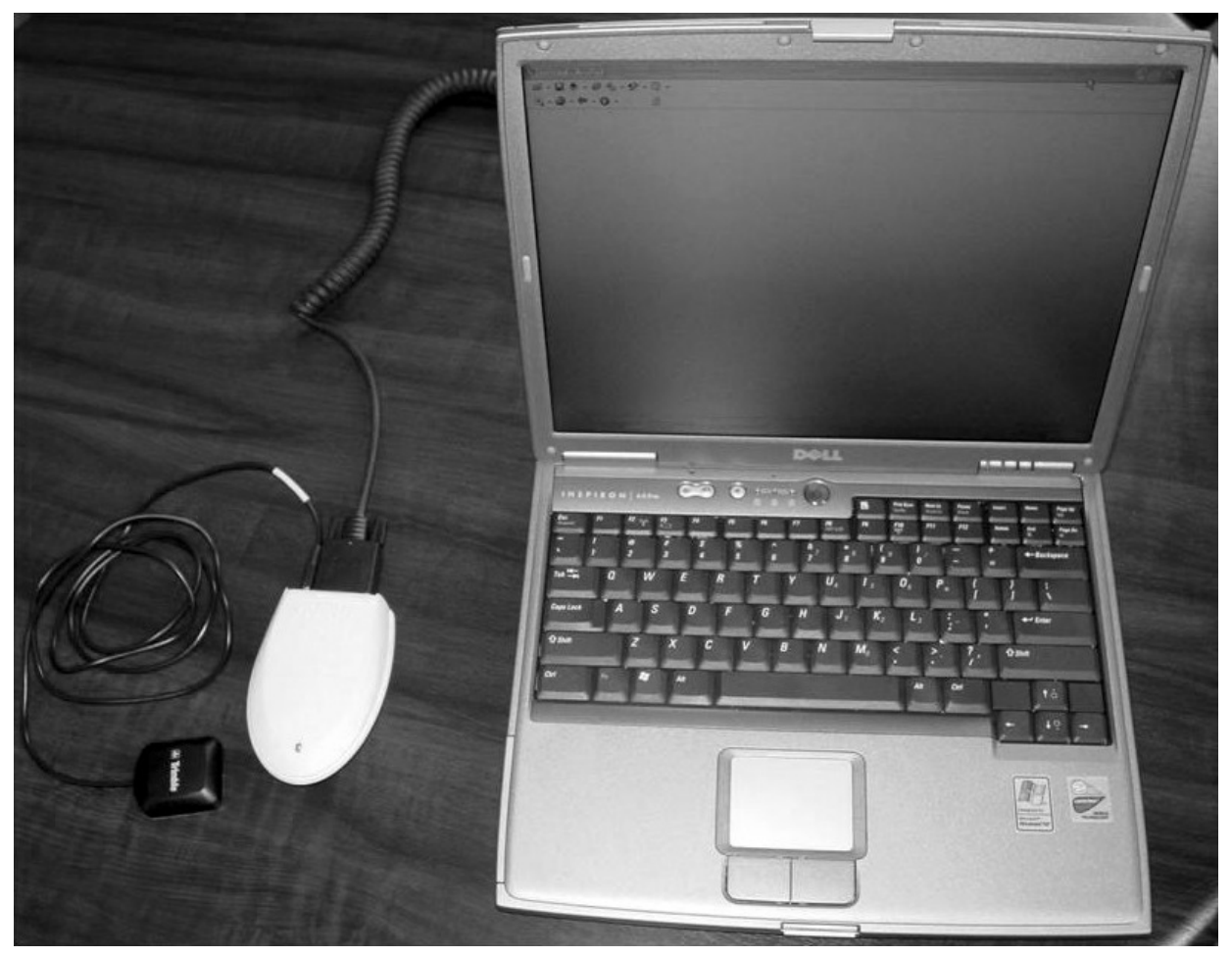

FIGURE 1 Laptop computer with GPS receiver and antenna. 
evaluated: approaches, culverts, cattleguards, signs, and sign supports. This approach was taken for two reasons. First of all, it is easier to get the software to collect only lines or only points at a given time. Second and most important, it would be very difficult to accurately evaluate the surface condition of a 1-mi segment if the data collectors had to stop numerous times within the mile to rate and evaluate other features. It is difficult enough to get consistent surface ratings for a 1-mi segment. If as long as an hour is spent rating other features within that segment, the quality of road surface data would be diminished.

Surface condition ratings are loosely based on the PASER systems with modifications deemed appropriate for conditions in Wyoming. All road surfaces were measured for top width and crown slope. The top width was measured from the edge of the traveled way and the shoulder. Crown slope was measured at a representative location with a four foot level. The particular distresses rated for gravel and asphalt road surfaces are listed in Table 1. Gravel road overall conditions are rated as excellent, good, fair, poor, and failed. Asphalt roads overall conditions were rated as in the PASER rating system with $1=$ failed, $2=$ very poor, $3=$ poor, 4 $=$ fair, $5=$ fair, $6=$ good, $7=$ good, $8=$ very good, $9=$ excellent, and $10=$ excellent. Drainage on asphalt roads was rated on the same scale as that used for gravel roads. All other asphalt distresses were rated as none, low, medium, and high severity. Distresses not rated were assigned a 0 .

One change from the first year, 2004, to the second year, 2005, was the splitting of gravel layer into two separate ratings, gravel quality, and gravel sufficiency. Clearly these are two distinct issues. The question of whether they can be successfully evaluated will be determined after the data collection is completed.

Approaches, cattleguards, culverts, signs, and sign supports were evaluated for the characteristics listed in Table 2. Bridges were located and photographed only since WYDOT evaluates them.

\section{Road Drainage in Wyoming and Wisconsin}

One significant difference between the Wisconsin-developed PASER rating system and the Wyoming system is in how drainage is evaluated. Wyoming's precipitation patterns are different from those in more humid regions such as Wisconsin. During Wyoming winters, the ground is frozen and sometimes snow covered. Spring thaws are relatively brief. Spring and summer rains tend to be brief and intense, followed by extended periods of warm, dry weather. The upshot of this is that bases and subgrades are less vulnerable to moisture since the time interval between frozen ground and sub-saturation moisture contents is relatively brief. However, frequent, intense rainstorms often lead to flash flooding. Wyoming soils don't absorb moisture as quickly as those in other parts of the country. Thus, drainage on Wyoming roads must be able to remove water quickly to prevent washouts, as shown in Figure 3. Though there are many roads in Wyoming that cross low lying, frequently saturated subgrades, the majority are well above the water table most of the time. An additional consideration is that most county roads are on the plains and prairies rather than through the wetter mountainous areas of the state; these are usually maintained by the United States Forest Service. In summary, with lower water tables, drainage on Wyoming county roads is designed as much to handle flash floods as it is to prevent base and subgrade saturation. 


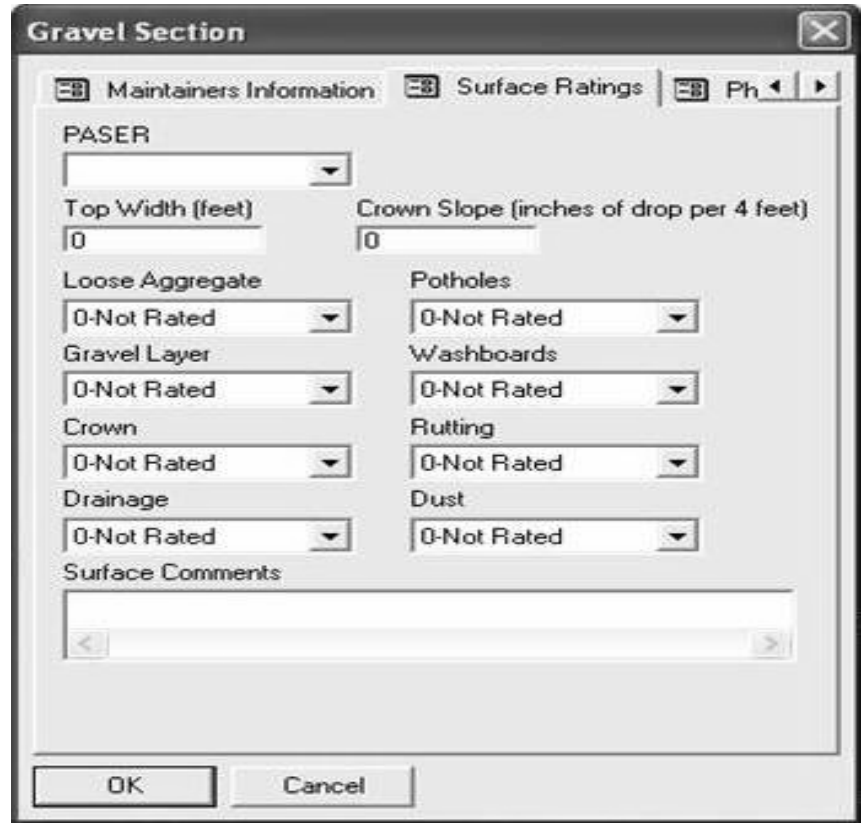

(a)

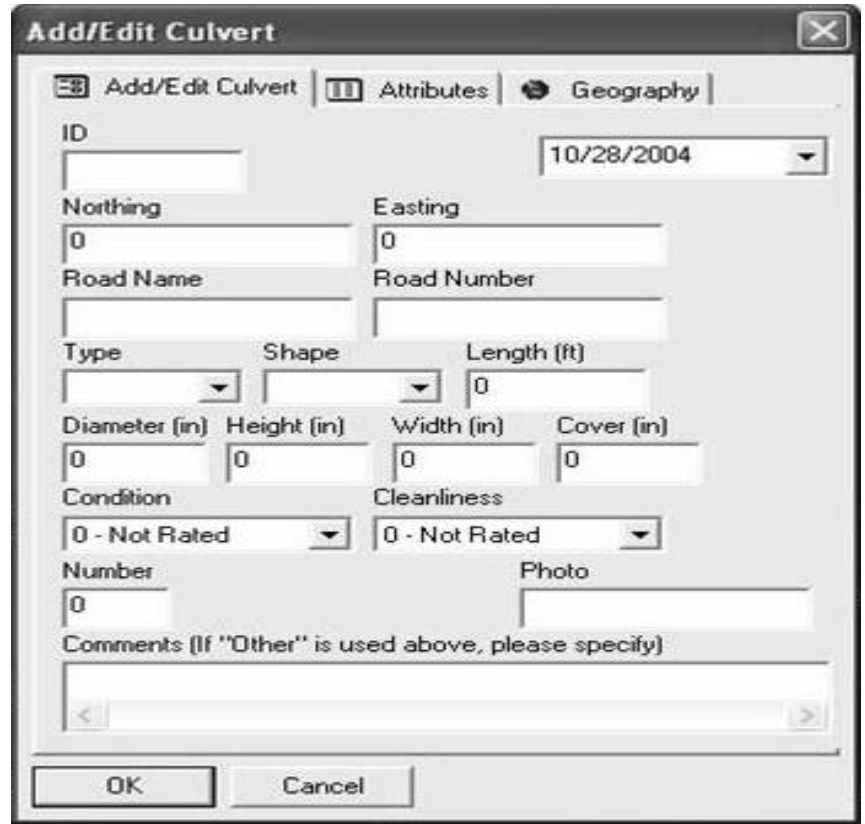

(b)

FIGURE 2 Examples of rating forms: (a) gravel rating form and (b) culvert rating form. 
TABLE 1 Road Surface Distresses Rated

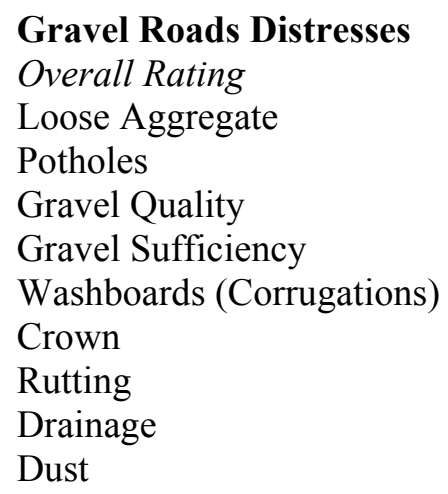

\author{
Asphalt Roads Distresses \\ Overall Rating \\ Drainage \\ Transverse Cracking \\ Reflective Cracking \\ Slippage Cracking \\ Longitudinal Cracking \\ Block Cracking \\ Alligator (Fatigue) Cracking \\ Potholes \\ Patching \\ Distortion \\ Rutting \\ Polishing \\ Flushing (Bleeding) \\ Ravelling
}

\section{Traffic}

The asset management system is set up to accommodate traffic data. As this data becomes available, it will be added to the GIS-based asset management system database. There is also a field that will allow the designation of roads being used to service drilling operations. This will allow analyses to be performed assessing the effects of drilling traffic on these county roads.

\section{Maintainers' Daily Reports}

Data from the county road and bridge crews is being incorporated into the overall asset management program. Currently, each county has their own system for tracking the daily activities of their employees. The $\mathrm{T}^{2}$ Center is developing a system for tracking maintenance expenses that will provide valuable information about the true costs of maintaining county roads. In the meantime, summary reports from the counties are being incorporated into the overall system.

TABLE 2 Features Evaluated for Approaches, Cattleguards, Culverts, Signs, and Supports

\begin{tabular}{|l|l|l|l|l|}
\hline Approaches & Cattleguards & Culverts & Signs & Sign Supports \\
\hline Side of Road & Width & Culvert Type & Side of Road & Number \\
\hline Width & Length & Cover & MUTCD Code & Type \\
\hline Gate Type & Grate Type & Length & Description & Base Type \\
\hline Approach Type & Base Type & Condition & Height & Condition \\
\hline & Grate Condition & Shape & Width & \\
\hline & Base Condition & Height & Condition & \\
\hline & Base Cleanliness & Width & & \\
\hline & Wing Fence Condition & Diameter & & \\
\hline & Approach Condition & Cleanliness & & \\
\hline & WYDOT Standard & Number & & \\
\hline
\end{tabular}




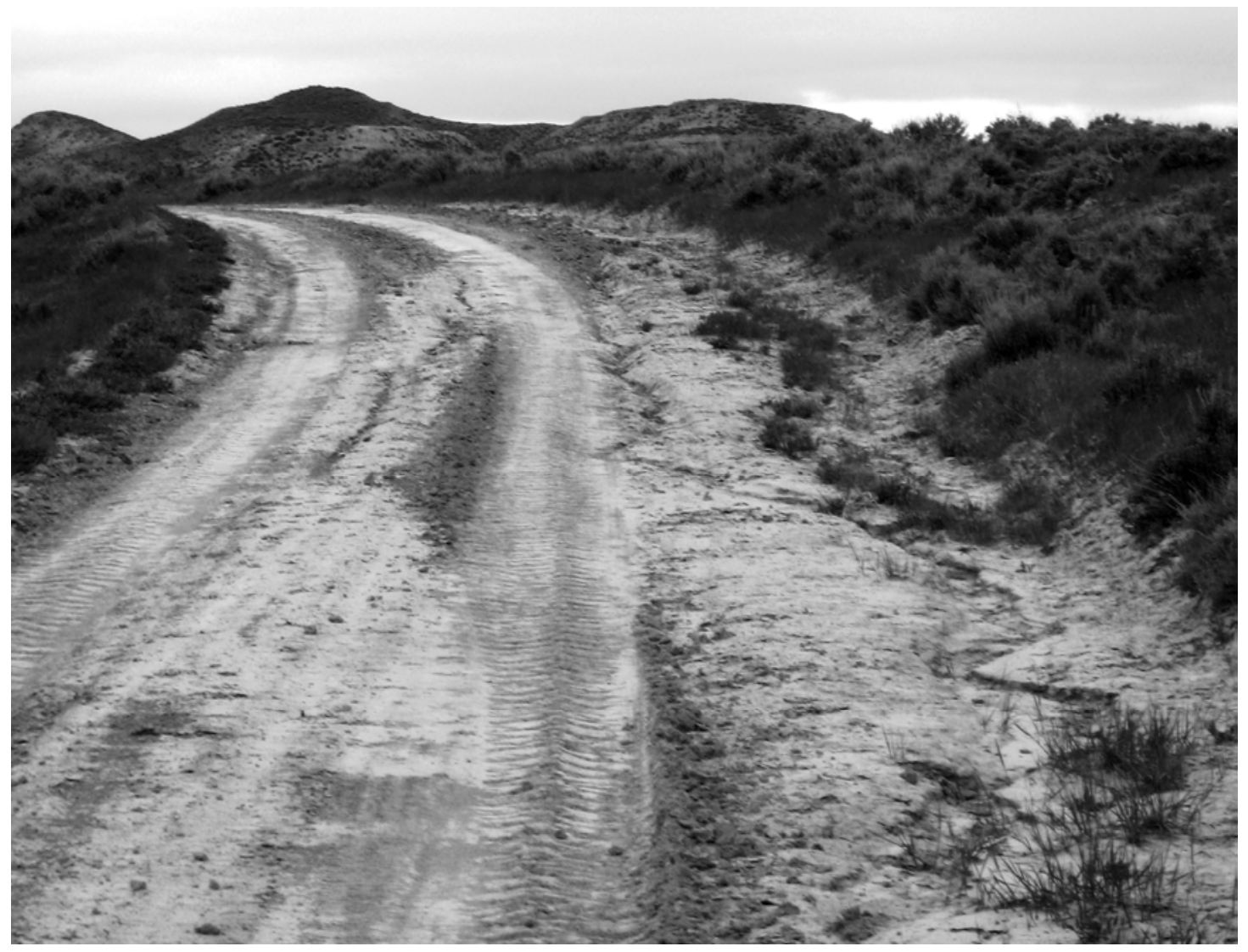

FIGURE 3 County road with small gully in secondary ditch, channeled into main ditch after a recent, heavy rain.

\section{Maintainers' Information}

All three counties handle there road networks similarly. Each motor grader operator is responsible for about $100 \mathrm{mi}$ of gravel roads. The $\mathrm{T}^{2}$ Center attempted to gather information now stored in the maintainers' heads and put it into the database. The maintainers were asked questions such as: How many heavy trucks travel the road? Where was the gravel imported from? How often is the surface reshaped? Their reluctance to provide what might be inaccurate information limited the success of this approach. Alternate methods of getting this information will be tried in the future.

\section{Quality Control}

Quality control during the first year of data collection was performed by having an experienced engineer evaluate segments previously rated by the data collection teams. This evaluation was performed a few days after the initial data collection. The results of these evaluations are presented in Figure 4. Immediately after the quality control ratings were performed, the engineer and the data collectors got together to discuss discrepancies. In a few instances, discrepancies were attributed to washouts caused by recent rains or by recent maintenance. These conditions 
were easily identified in the photographs and were removed from the data used to generate Figure 4.

Figure 4 shows that the engineer generally rated the roads lower than the data collection teams. Though this was in part due to deteriorating road conditions during the time interval between when the data collectors rated the road and when the engineer rated the road, this probably does not account for all the discrepancies. At the post-quality control meetings these issues were addressed and adjustments were made.

For the second year of data collection, a different approach is being used. An engineer and a graduate student who performed data collection on the project last year will be the quality control personnel. After both the quality control personnel and the data collection team rate each segment they will get together and compare ratings. This should help assure that all data collection teams are rating the roads the same way since they will all conform to the views of the quality control personnel.

\section{RESULTS}

In 2004, nearly all the roads in the three counties were evaluated for their road surface conditions. Only a few roads in Sheridan County were not rated since they weren't passable in the data collector's passenger car. In Sheridan and Johnson Counties, about a third of the other features were rated. Very few other than road features were rated in Carbon County because the Carbon County crew interviewed maintainers after they completed their road surface ratings rather than collect data on the other features. Table 3 shows the miles of gravel and asphalt roads rated in each county in 2004 and the number of features rated.

Insights can be gained about the road networks in the various counties. For example,

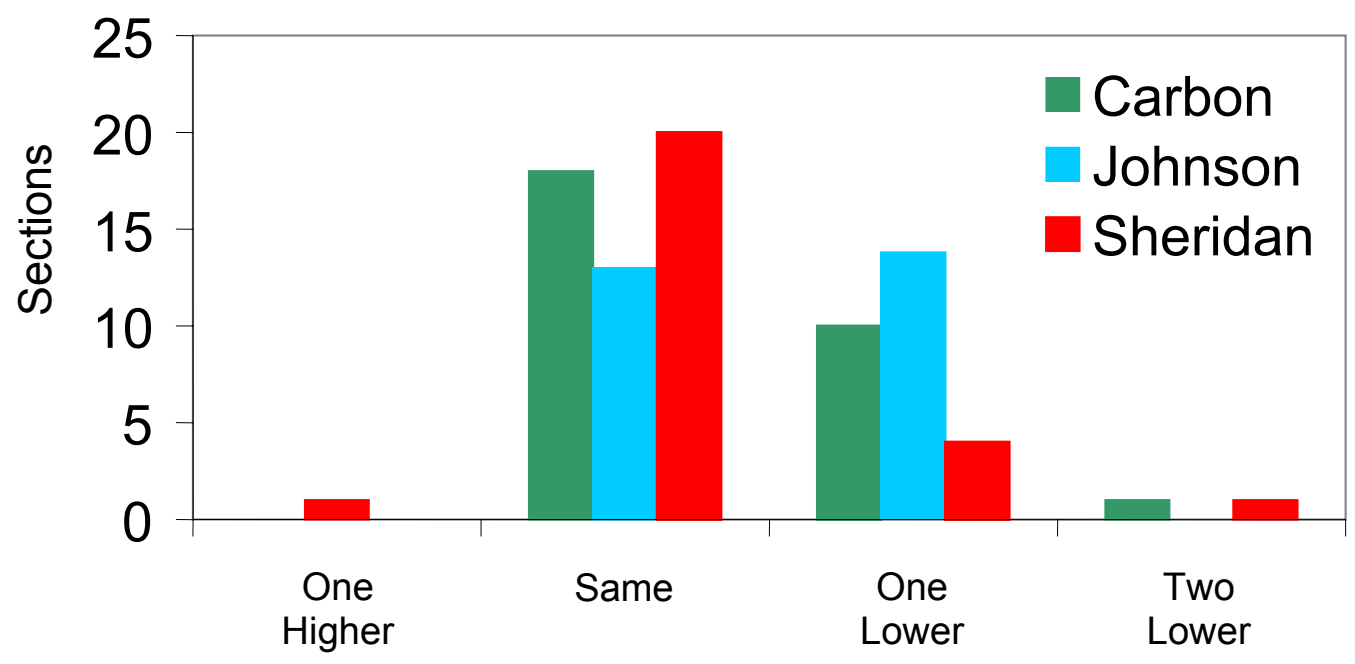

QC Ratings Relative to Original Ratings

FIGURE 4 Quality control ratings relative to those by the data collectors collected during the summer of 2004, the first year of the 3-year study. 
Figure 5 shows the top widths by percentage for each county. While Carbon and Sheridan Counties' gravel roads average $15 \mathrm{ft}$ wide, Johnson County roads average $20 \mathrm{ft}$ wide. Figure 6 shows the overall gravel roads conditions in 2004. In all counties, the majority of roads were rated good overall. In Johnson County, there is a higher percentage of roads rated fair. As improved quality control and training procedures are implemented, the validity of this data will be assessed. Data from 2005 should confirm if these differences are truly due to differing road conditions or to small differences in the rating standards of the data collection teams.

Another example, found in Figure 7, shows the drainage ratings for gravel roads in the three counties. Johnson County's drainage ratings are considerably higher than for the other two counties. This observation, combined with the wider top widths found in Johnson County, as shown in Figure 8, demonstrate that the geometries of Johnson County roads are generally better than in the other two counties. However, this is not reflected in the overall condition ratings. This discrepancy may be due to the use of lower quality gravel in Johnson County, a conclusion that is supported by subjective assessments of the overall condition of gravel roads in the three counties. This year's ratings of gravel quality should bear out this conclusion.

While the output phase of the asset management system is still in its infancy, some products have already been delivered to the counties. Ratings of the overall road conditions, such as the ones in Figure 8 for Carbon County, are in the hands of county commissioners and on the walls of county road and bridge shops. A map of blading costs on Sheridan County roads has been developed, as shown in Figure 9. Figures 10 and 11 show the relative ratings of potholes and washboards for the three counties. Comparisons of the various distresses observed in each county provide insights into the strengths and weaknesses of each county's road system. Queries have been written that answer such basic questions as: Where are the culverts that need to be cleaned? Where are the stop signs that are in poor or failed condition and what size are they? These simple reports are now providing useful information to the counties.

TABLE 3 Number of Features, Segments, and Mileages Rated in 2004 by County

\begin{tabular}{|lllll|}
\hline Feature & Carbon & Johnson & Sheridan & TOTAL \\
\hline Approaches & 33 & 794 & 1890 & 2,717 \\
Bridges & 5 & 37 & 26 & 68 \\
Cattleguards & 9 & 337 & 44 & 390 \\
Culverts & 16 & 1,101 & 887 & 2,004 \\
Maintainers' information & 87 & 0 & 0 & 87 \\
Signs & 11 & 374 & 306 & 691 \\
Gravel segments & 932 & 480 & 519 & 1,931 \\
Gravel miles & 878 & 449 & 479 & 1,806 \\
Asphalt segments & 66 & 120 & 40 & 226 \\
Asphalt miles & 60 & 103 & 29 & 192 \\
Total segments & 998 & 600 & 559 & 2,157 \\
Total miles & 938 & 552 & 508 & 1,998 \\
\hline
\end{tabular}




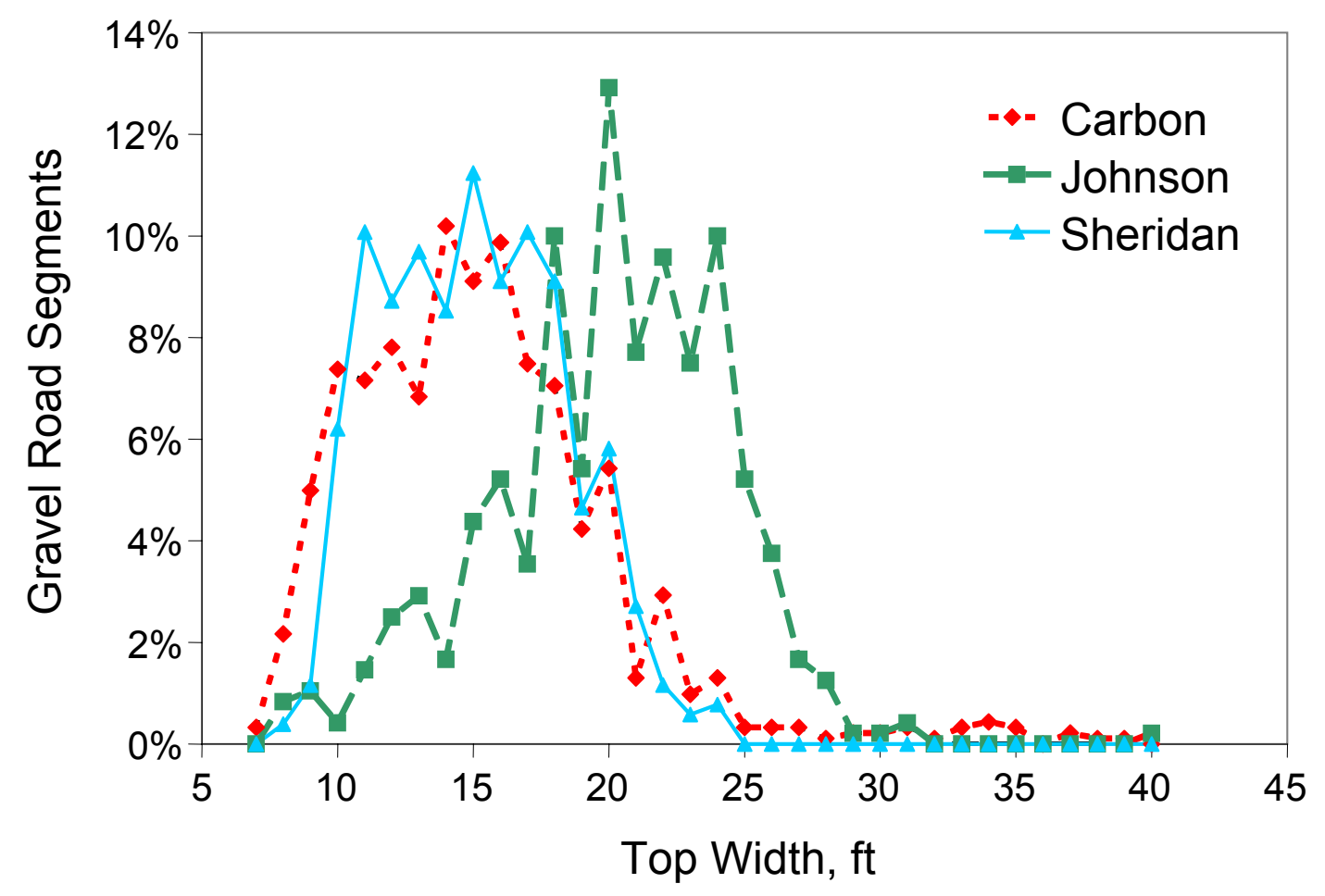

FIGURE 5 Gravel road top width percentage by county.

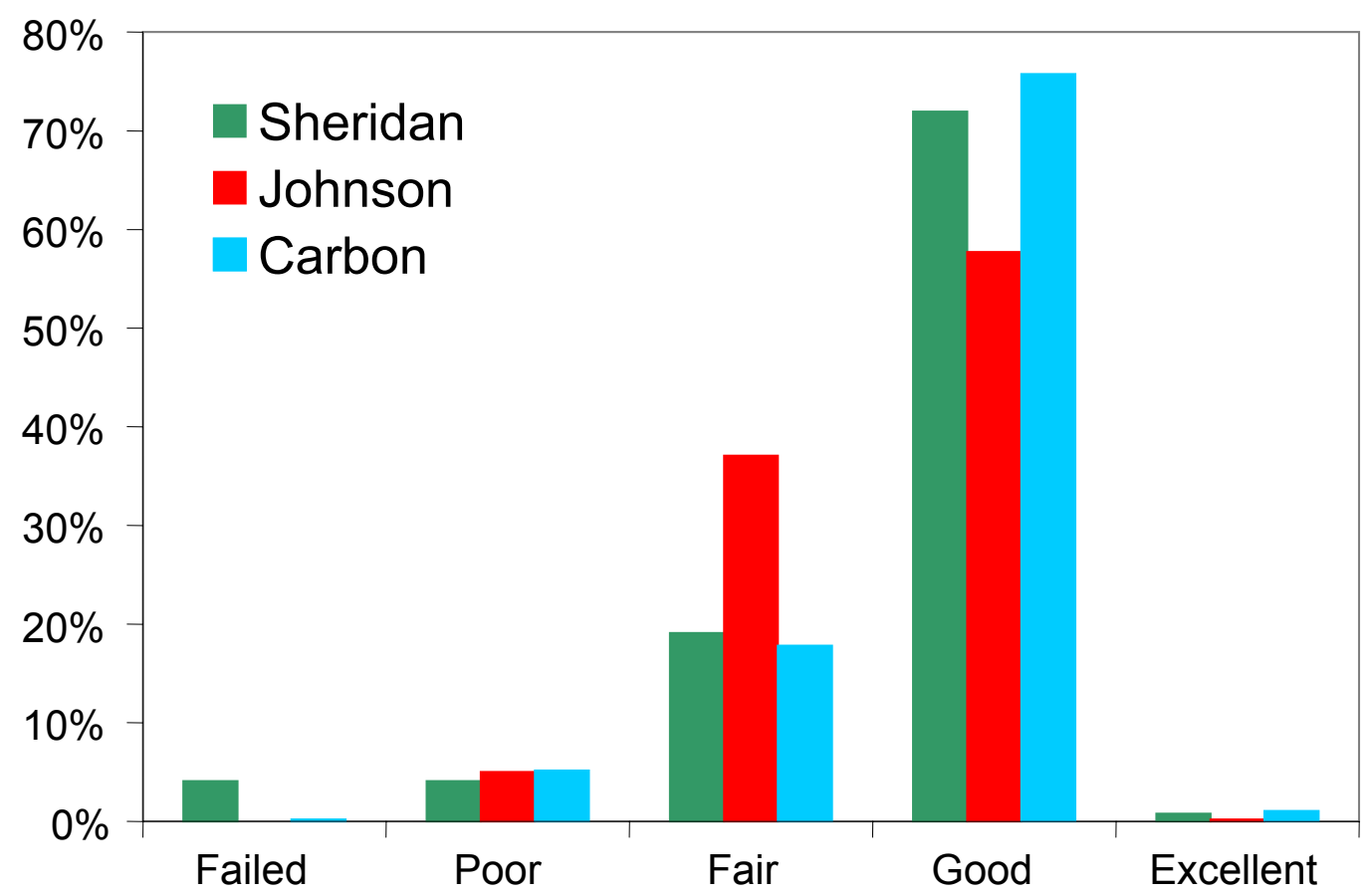

FIGURE 6 Overall gravel roads conditions in 2004. 


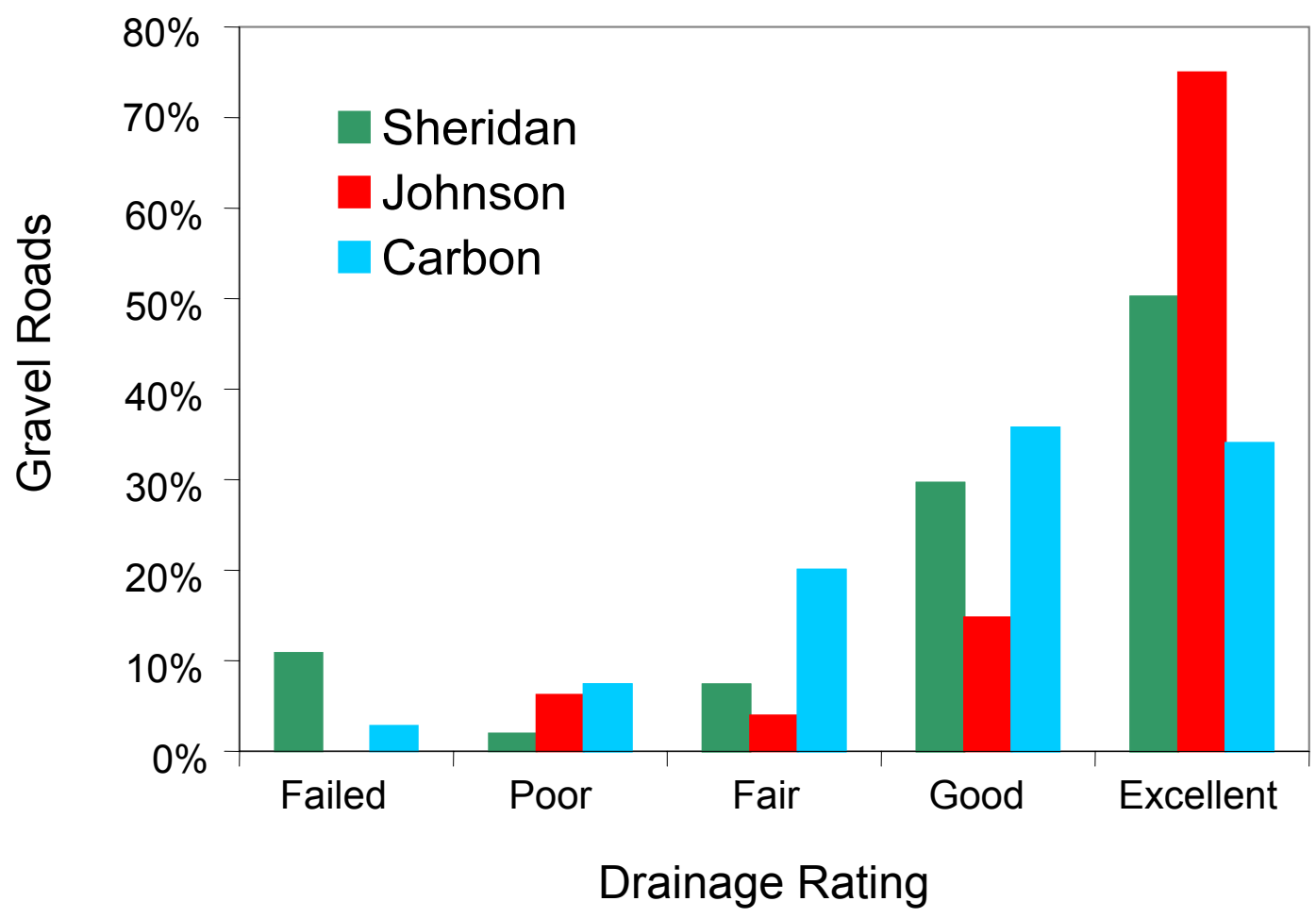

FIGURE 7 Drainage ratings by county for gravel roads in 2004.

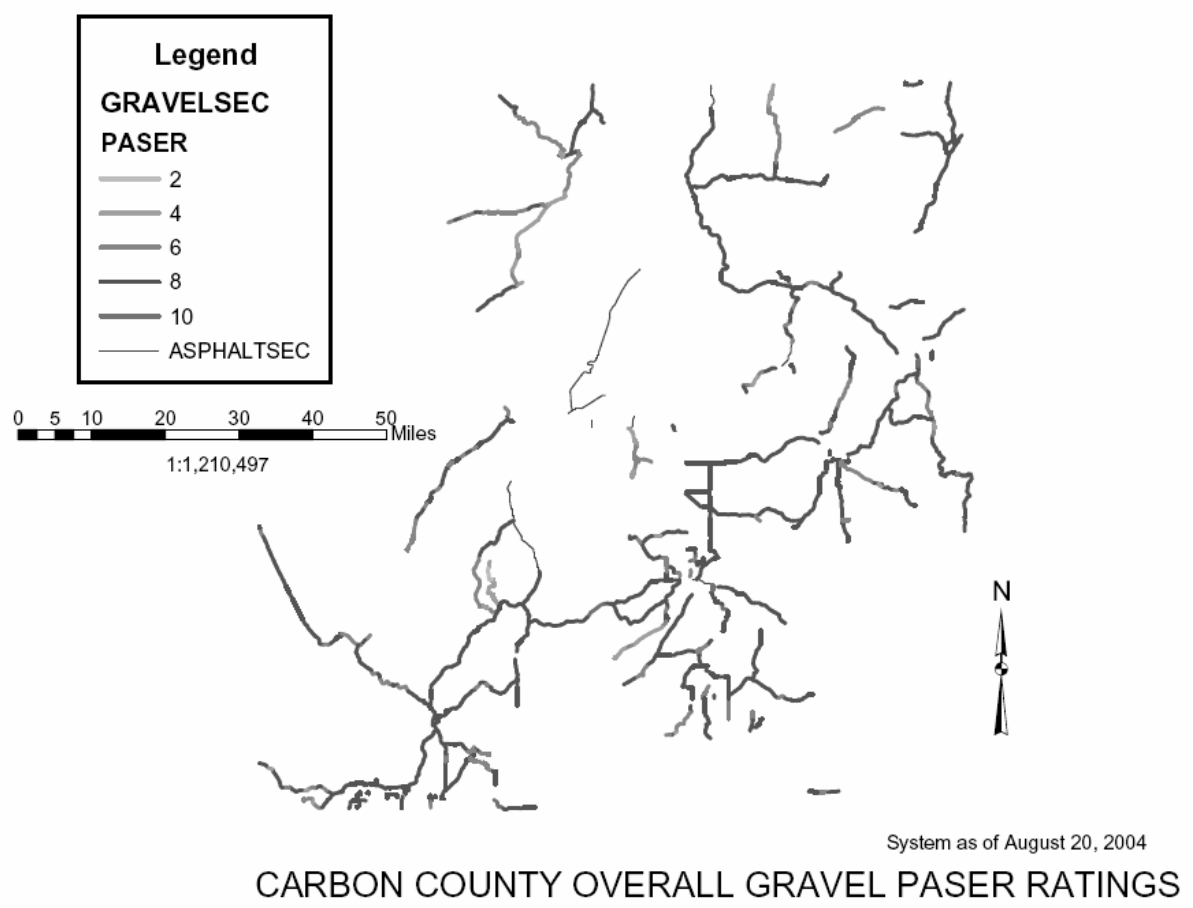

FIGURE 8 Carbon County gravel roads as rated during the summer of 2004. 
Future reports will contain information on more sophisticated analyses as well as more detailed reports of use to the counties. One fundamental question of interest to the counties is how far is it worth hauling high quality gravel? Combining materials and hauling costs of lower and higher quality gravel with the maintenance costs associated with these gravels should allow analyses to be performed that optimize the use of available materials. This issue is particularly well defined in Sheridan and Johnson counties where high quality aggregate is available in the western parts of the counties in the foothills of the Bighorn Mountains. The eastern part of these counties, where much of the drilling activity is taking place, has little high quality aggregate. The question becomes at what point is it cost effective to spend more money up front on good gravel, thereby reducing long-term maintenance costs? The database will be populated with maintenance cost data, road condition data, and traffic data. Answers to questions such as these will be sought.

\section{SUMMARY AND CONCLUSIONS}

Though this project has been ongoing for just over a year, great strides have been made towards developing a functional asset management system that will provide Wyoming counties with vital information on the status of their road networks. In the long term, some crucial decisions need to be made: Who will maintain the database? Who will collect and update condition data? What reports will be generated?

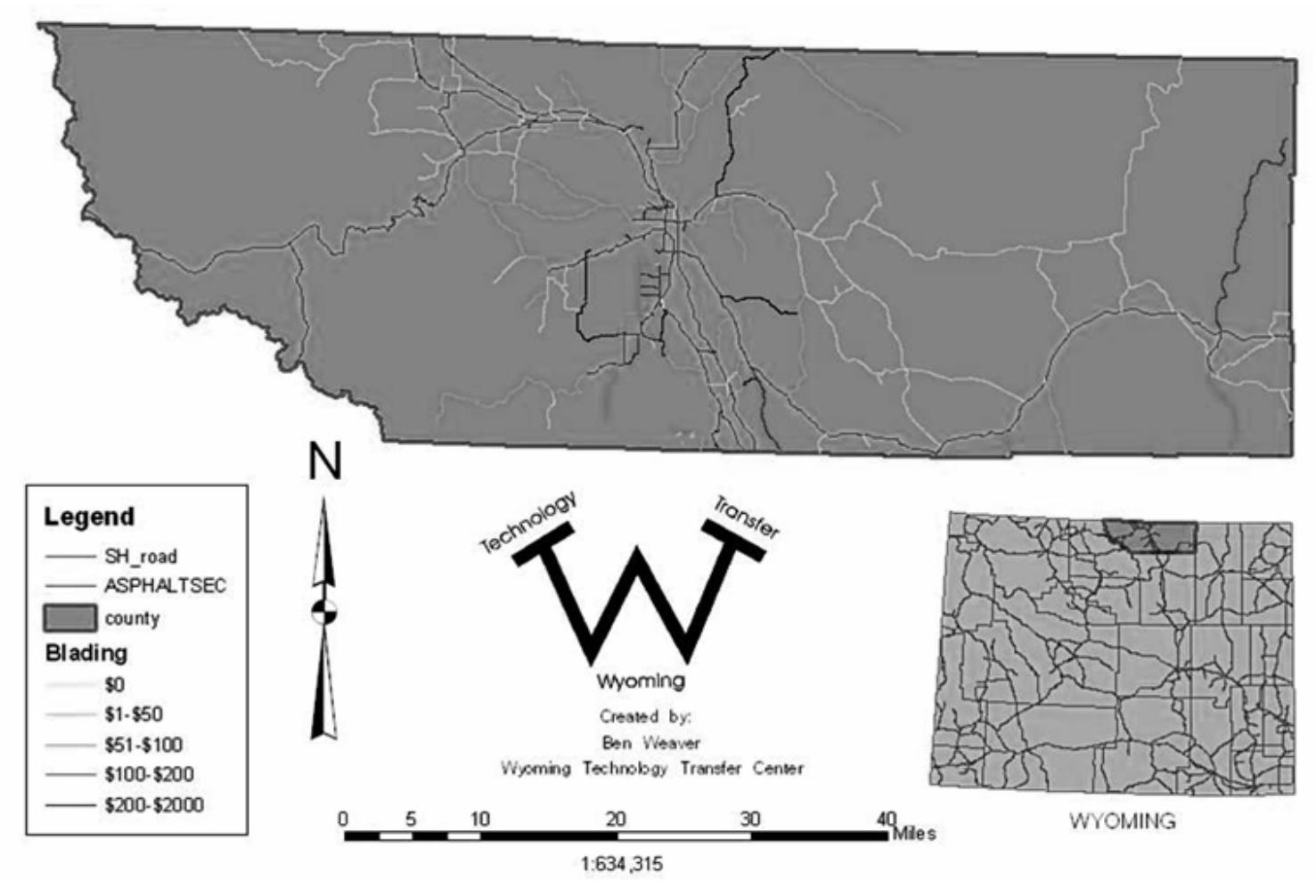

FIGURE 9 Sheridan County blading costs by road. 


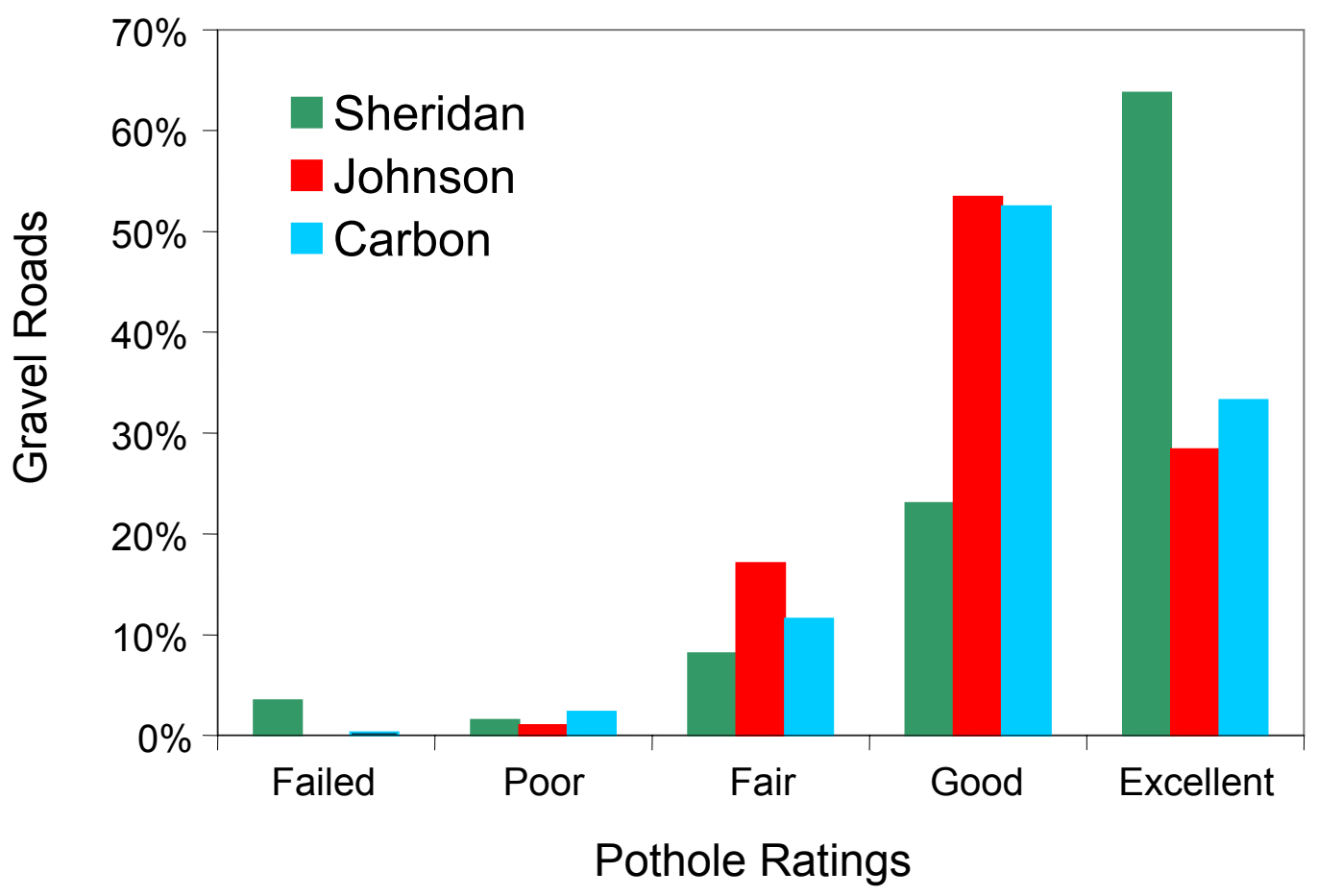

FIGURE 10 Pothole ratings on gravel roads by county in 2004.

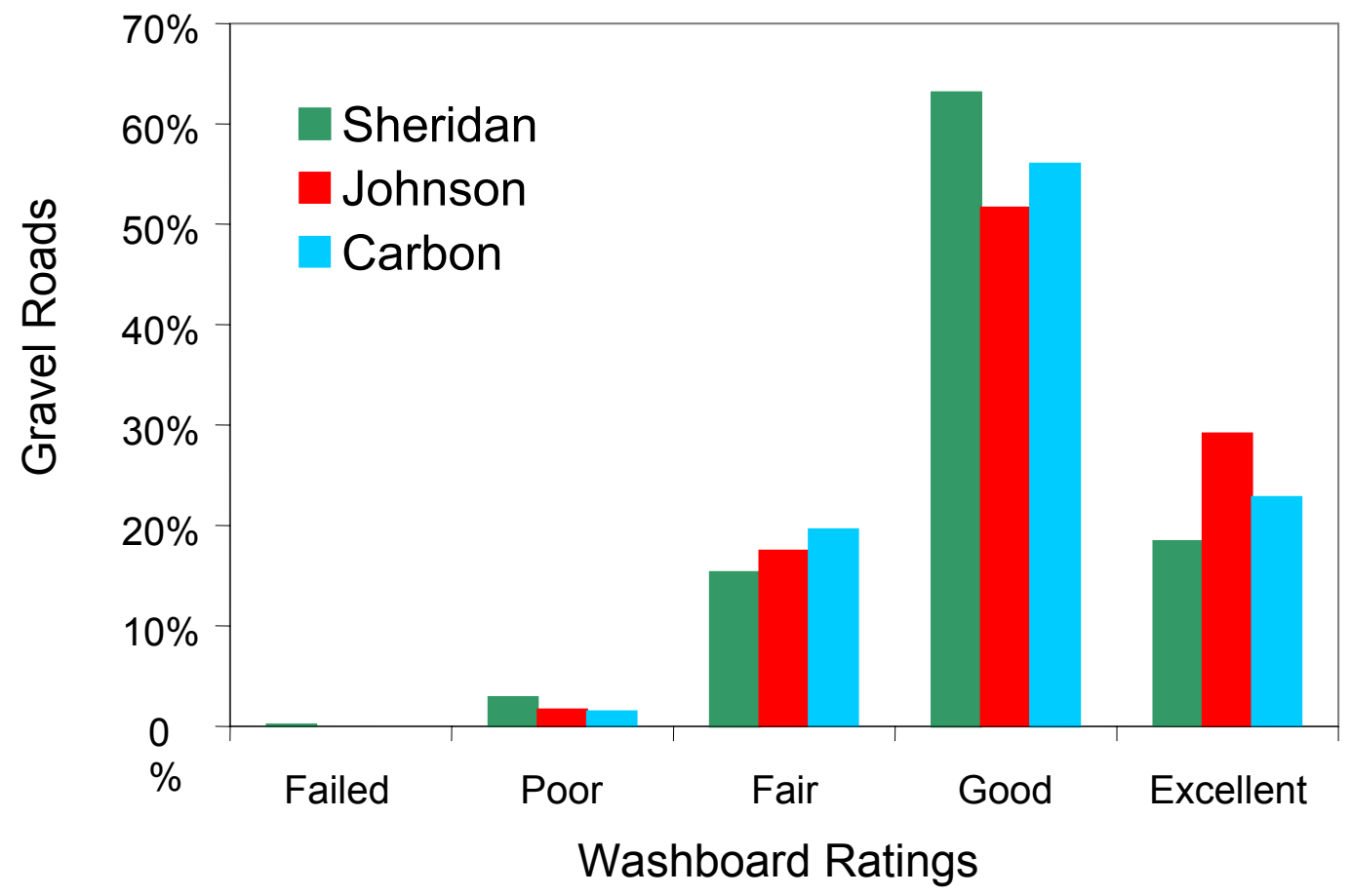

FIGURE 11 Washboard ratings on gravel roads by county in 2004. 
Other issues are being addressed. Splitting the gravel layer rating into two parts, gravel sufficiency and gravel quality, provides more information to the counties about how they might address some of their gravel roads' performance issues. Johnson County is addressing some of their culvert placements problems. Culvert inlets and outlets should be flush with the bottom of the ditch and the foreslope. This is not always the case. Procedures are being developed that will provide the counties with data assessing this issue, perhaps defining critical measurements and taking photographs that portray the existing culvert placement. These and other arising issues can be handled by making relatively simple additions to the database and forms, along with additional training for the data collectors.

By working together with the counties, the $\mathrm{T}^{2}$ Center has developed a system that will provide valuable information to these three counties, as well as a blueprint for other similar agencies. As the needs of the counties become better defined, the flexible nature of the asset management system allows it to adapt to new situations and concerns.

\section{ACKNOWLEDGMENTS}

This is a big project and there are many people to thank, many of whom are not mentioned here, for the list is too long. Without the support of the WYDOT, particularly Rich Douglass, and the County Commissioners of Sheridan, Johnson and Carbon Counties this project would not have gotten off the ground. On the software side, our GIS experts, Anne Marie Powell and Kristen Klaphake, helped keep the rest of us on track by addressing issues and solving problems the rest of us new little about. Doug Lofgren of Sheridan County, Craig Cronk of Johnson County, and Bill Nation of Carbon County and their crews provided support and advice that has been indispensable to the success of this project. In the $\mathrm{T}^{2}$ Center, two people have put in inordinate hours to make this project move forward. Mary Harman and Paul Jacob, we couldn't have done it without you. Thanks to all the data collectors who spent their summers on dusty, remote roads for long hours, day in and day out. And, saving the best for last, thanks to Ben Weaver, a University of Wyoming graduate student who helped with all aspects related to this study.

\section{DISCLAIMER}

The mention of specific commercial products is for informational purposes only and does not constitute an endorsement by the Wyoming $\mathrm{T}^{2}$ Center, WYDOT, the University of Wyoming, or Sheridan, Johnson, or Carbon Counties.

\section{REFERENCES}

1. FHWA White Paper: Right-of-Way and Asset Management. FHWA, U.S. Department of Transportation, May 8, 2005. www.fhwa.dot.gov/infrastructure/asstmgmt/ampprow.htm. Accessed May 9, 2005.

2. Walker, D. Gravel_PASER Manual. Wisconsin Transportation Information Center, 1989. 


\section{APPENDIX}

\section{Author Contact Information}





\section{APPENDIX}

\section{Author Contact Information}

Chistopher Antonucci

Harris \& Sloan Consulting Group

213 E St., Suite B

Davis, CA 95616

Fax: 530-753-5380

CANTONUCCI@hscgi.com

Wael Bekheet

Stantec Consulting

49 Frederick St.

Kitchener, Ontario N2H 6M7 Canada

519-585-7465; fax: 519-579-6733

wbekheet@stantec.com

Peter W. Bolander

USDA Forest Service

Pacific Northwest Region

P.O. Box 3623

Portland, OR 97208

503-808-2503; fax: 503-808-2511

pbolander@fs.fed.us

Dar-Hao Chen

Texas Department of Transportation 4203 Bull Creek Rd.

Austin, TX 78731

512-467-3963

dchen@dot.state.tx.us

Tanveer Chowdhury

Virginia Department of Transportation

1401 E. Broad St.

19th Floor, James Monroe Building

Richmond, VA 23219

804-371-2335; fax: 804-371-2037

Samuel B. Cooper, Jr.

Louisiana Transportation Research Center

4101 Gourrier Ave.

Baton Rouge, LA 70808

225-767-9126; fax: 225-767-9108
Judith Corley-Lay

North Carolina Department of Transportation 1593 Mail Service Center

Raleigh, NC 27699-1593

919-250-4094

jlay@dot.state.nc.us

Jerome Daleiden

Fugro Consultants, LP

8613 Cross Park

Austin, TX 78754

JDaleiden@fugro.com

Deepak Dave

University of North Florida

4567 St. Johns Bluff Rd., South

Jacksonville, FL 32224-2645

Lita Davis

County of San Diego

10366 Rancho Rd.

La Mesa, CA 91941

619-997-9833; fax: 619-670-5668

Ldavis1117@aol.com

Edward J. Denehy

New York State Department of Transportation

50 Wolf Rd., Pod 51

Albany, NY 12232

518-457-6914; fax: 518-457-4203

edenehy@dot.state.ny.us

Douglas C. Gilman

Virginia Department of Transportation

1401 E. Broad St.

Richmond, VA 23219

Douglas.Gilman@VDOT.Virginia.gov

Douglas D. Gransberg

University of Oklahoma

830 Van Vleet Oval, Room 162

Norman, OK 73019-6141

405-325-6092; fax: 405-325-7885

dgransberg@ou.edu 
Khaled Helali

Stantec Consulting

49 Frederick St.

Kitchener, Ontario N2H 6M7 Canada

519-585-7477; fax:519-579-6733

khelali@stantec.com

R. Gary Hicks

MACTEC E\&C

4704 Roseville Rd., Suite 108

North Highlands, CA 95660

916-332-5559

RGHICKS@mactec.com

George Huntington

University of Wyoming

1000 E. University Ave.

Department 3295

Laramie, WY

307-766-6783; fax: 307-766-6784

georgeh@uwyo.edu

N. Mike Jackson

University of North Florida

4567 St. Johns Bluff Rd., South

Jacksonville, FL 32224-2645

352-955-6302; fax: 352-955-6345

njackson@unf.edu

David M. B. James

ICC

Alberta Highway Services Ltd.

23 Bellerose Dr.

St. Albert, Alberta T8N 5E1 Canada

780-419-6503

mjames@ahsl.ca

Tom Kazmierowski

Ministry of Transportation of Ontario

Building C, 1201 Wilson Ave.

Downsview, Ontario M3M 1J8 Canada

416-235-3512; fax: 416-235-3919

tom.kazmierowski@mto.gov.on.ca

Kevin Kennedy

Michigan Department of Transportation

8885 Ricks Rd.

P.O. Box 30049

Lansing, MI 48909

517-322-6043; fax: 517-322-5664

kennedyk@michigan.gov
Khaled Ksaibati

University of Wyoming

1000 E. University Ave.

Department 3295

Laramie, WY

307-766-6230; fax: 307-766-6784

khaled@uwyo.edu

Roger Larson

Applied Pavement Technology, Inc.

3001 Research Rd., Suite C

Champaign, IL 61822

217-398-3977

rlarson@pavementsolutions.com

James W. Mack

Quality Engineering Solutions, Inc.

P.O. Box 3004

405 Water St.

Conneaut Lake, PA 16316

814-382-0373; fax: 814-382-0375

jmack@QESpavements.com

J. Neil Mastin

North Carolina Department of Transportation

1593 Mail Service Center

Raleigh, NC 27699-1593

919-250-4094

jmastin@dot.state.nc.us

Emily O. McGraw

North Carolina Department of Transportation

1567 Mail Service Center

Raleigh, NC 27699-1567

919-733-3725

emcgraw@dot.state.nc.us

Louay N. Mohammad

Louisiana Transportation Research Center

4101 Gourrier Ave.

Baton Rouge, LA 70808

225-767-9126; fax: 225-767-9108

louaym@1su.edu

Dennis A. Morian

Quality Engineering Solutions, Inc.

P.O. Box 3004

405 Water St.

Conneaut Lake, PA 16316

814-382-0373; fax: 814-382-0375

Dmorian@QESpavements.com 
Li Ningyuan

Ministry of Transportation of Ontario

Building C, 1201 Wilson Ave.

Downsview, Ontario M3M 1J8 Canada

416-235-3518; fax: 416-235-3919

li.ningyuan@mto.gov.on.ca

Bryan Pidwerbesky

FIPENZ

Fulton-Hogan Limited

29 Sir William Pickering Dr.

P.O. Box 39185

Christchurch, New Zealand 03-357-0615

bryan.pidwerbesky@fh.co.nz

Gail L. Porritt

Asphalt Systems, Inc.

P.O. Box 25511

Salt Lake City, UT 84125

801-523-1789; fax: 801-523-1791

asi.gail@worldnet.att.net

Peter E. Sebaaly

University of Nevada Reno

1664 N Virginia St.

Reno, NV 89557

775-784-6565; fax: 775-784-1429

sebaaly@unr.nevada.edu

Shakir Shatnawi

California Department of Transportation 5900 Folsom Blvd.

Sacramento, CA 95819

916-227-5706; fax: 916-227-7075

sshatnawi@aol.com
Raja A. Shekharan

Virginia Department of Transportation

1401 E. Broad St.

Richmond, VA 23219

Raja.Shekharan@VDOT.Virginia.gov

Yung-Ching Shen

Siena College

515 Loudon Rd.

Loudonville, NY 12211

518-783-2960; fax: 518-783-2590

yshen@siena.edu

George Tanner

New York State Thruway Authority

200 Southern Blvd,

Albany, NY 12209

518-436-2950; fax: 518-436-3096

George_Tanner@thruway.state.ny.us

Yetkin Yildirim

Superpave and Asphalt Research Program

University of Texas-Austin

3208 Red River, CTR 318

Austin, TX 78705

512-232-3083; fax: 512-232-3070

yetkin@mail.utexas.edu

Kathryn A. Zimmerman

Applied Pavement Technology, Inc.

3001 Research Rd., Suite C

Champaign, IL 61822

217-398-3977

kzimmerman@pavementsolutions.com 



\section{THE NATIONAL ACADEMIES Advisers to the Nation on Science, Engineering, and Medicine}

The National Academy of Sciences is a private, nonprofit, self-perpetuating society of distinguished scholars engaged in scientific and engineering research, dedicated to the furtherance of science and technology and to their use for the general welfare. On the authority of the charter granted to it by the Congress in 1863, the Academy has a mandate that requires it to advise the federal government on scientific and technical matters. Dr. Ralph J. Cicerone is president of the National Academy of Sciences.

The National Academy of Engineering was established in 1964, under the charter of the National Academy of Sciences, as a parallel organization of outstanding engineers. It is autonomous in its administration and in the selection of its members, sharing with the National Academy of Sciences the responsibility for advising the federal government. The National Academy of Engineering also sponsors engineering programs aimed at meeting national needs, encourages education and research, and recognizes the superior achievements of engineers. Dr. William A. Wulf is president of the National Academy of Engineering.

The Institute of Medicine was established in 1970 by the National Academy of Sciences to secure the services of eminent members of appropriate professions in the examination of policy matters pertaining to the health of the public. The Institute acts under the responsibility given to the National Academy of Sciences by its congressional charter to be an adviser to the federal government and, on its own initiative, to identify issues of medical care, research, and education. Dr. Harvey V. Fineberg is president of the Institute of Medicine.

The National Research Council was organized by the National Academy of Sciences in 1916 to associate the broad community of science and technology with the Academy's purposes of furthering knowledge and advising the federal government. Functioning in accordance with general policies determined by the Academy, the Council has become the principal operating agency of both the National Academy of Sciences and the National Academy of Engineering in providing services to the government, the public, and the scientific and engineering communities. The Council is administered jointly by both the Academies and the Institute of Medicine. Dr. Ralph J. Cicerone and Dr. William A. Wulf are chair and vice chair, respectively, of the National Research Council.

The Transportation Research Board is a division of the National Research Council, which serves the National Academy of Sciences and the National Academy of Engineering. The Board's mission is to promote innovation and progress in transportation through research. In an objective and interdisciplinary setting, the Board facilitates the sharing of information on transportation practice and policy by researchers and practitioners; stimulates research and offers research management services that promote technical excellence; provides expert advice on transportation policy and programs; and disseminates research results broadly and encourages their implementation. The Board's varied activities annually engage more than 5,000 engineers, scientists, and other transportation researchers and practitioners from the public and private sectors and academia, all of whom contribute their expertise in the public interest. The program is supported by state transportation departments, federal agencies including the component administrations of the U.S. Department of Transportation, and other organizations and individuals interested in the development of transportation. www.TRB.org 
TRANSPORTATION RESEARCH BOARD

500 Fifth Street, NW

Washington, DC 20001

\section{ADDRESS SERVICE REQUESTED}

\section{THE NATIONAL ACADEMIES}

Advisers to the Nation on Science, Engineering, and Medicine

The nation turns to the National Academies-National Academy of Sciences, National Academy of Engineering, Institute of Medicine, and National Research Councilfor independent, objective advice on issues that affect people's lives worldwide.

www.national-academies.org 